\begin{abstract}
AHMED, TAMER SAMIR. Copolymerization of Vinylidene Fluoride with Hexafluoropropylene in Supercritical Carbon Dioxide. (Under the direction of Prof. George W. Roberts and Prof. Joseph M. DeSimone.)
\end{abstract}

This thesis details research to study the copolymerization of vinylidene fluoride (VF2) with hexafluoropropylene (HFP) in supercritical carbon dioxide $\left(\mathrm{scCO}_{2}\right)$. Another objective of this thesis is to understand the origin of the bimodal molecular weight distribution (MWD) that results under certain conditions during the precipitation polymerization of poly(vinylidene fluoride) (PVDF) in $\mathrm{scCO}_{2}$.

The copolymerization of VF2 with HFP was carried out in $\mathrm{scCO}_{2}$ using a continuous stirred tank reactor (CSTR). The experiments were done at $40{ }^{\circ} \mathrm{C}$ with pressure in the range of 207-400 bar using perfluorobutyryl peroxide as the free radical initiator. Four different copolymer compositions were studied: ca. 10, 23, 26, and 30 mole $\%$ HFP. The $10 \%$-copolymer was collected as a dry free-flowing semicrystalline powder while the other compositions were amorphous elastomeric materials collected continuously using acetone. Most of the polymerizations were heterogeneous, i.e., polymer particles precipitated during the reaction. However, some were homogenous, especially in the higher range of HFP content.

The effects of feed monomer concentration and reaction pressure were both explored at otherwise constant conditions. The rate of polymerization $\left(R_{p}\right)$ and the number-average molecular weight $\left(M_{n}\right)$ increased linearly with the total monomer concentration up to about $6 \mathrm{M}$, the highest concentration investigated. In addition, the $R_{p}$ 
and the $M_{n}$ increased with reaction pressure. The MWDs of the synthesized copolymer showed a long tail that increased to become a broad shoulder with increasing total monomer concentration. This tail decreased with HFP content in the copolymer and increased with reaction pressure.

The experimental results of VF2 homopolymerization and copolymerization with HFP in $\mathrm{scCO}_{2}$ were tested against three kinetic models to determine the main locus of polymerization. The first model, the "solution polymerization" model, is based on the assumption that all the polymerization reactions place in the continuous, $\mathrm{CO}_{2}$-rich phase, with no reaction in the polymer phase. In the second model, the "surface polymerization" model, chain initiation occurs exclusively in the continuous phase, while chain propagation and termination occur in a thin zone on the surface of the polymer particles. The third model, the "interior polymerization" model, is similar to the "surface polymerization" model, except that propagation and termination take place uniformly throughout the polymer particles. Both the surface and the interior polymerization models failed to fit the experimental results. On the other hand, the solution polymerization model was able to describe the experimental results of the polymerizations fairly well over the whole range of polymer compositions. This suggests that the $\mathrm{CO}_{2}$-rich continuous phase is the main locus of polymerization in the precipitation polymerization of VF2 homopolymer and VF2/HFP copolymers $\mathrm{scCO}_{2}$.

Finally, a homogenous model is presented to account for the bimodal MWDs of PVDF. The model takes into account both the change of termination scheme of the polymeric radicals with chain length from chemically-controlled termination to diffusion- 
controlled termination and chain transfer to polymer reaction. The model was successful in accounting for the change of modality with reaction conditions such as monomer concentration, average residence time at low and high monomer concentrations, and the reaction temperature. In addition, the model could capture the occurrence of gelation, which was responsible for an inoperability region that was observed in the polymerization experiments. 


\title{
Copolymerization of Vinylidene Fluoride with Hexafluoropropylene in Supercritical Carbon Dioxide
}

\author{
by \\ Tamer Samir Ahmed
}

\begin{abstract}
A dissertation submitted to the Graduate Faculty of North Carolina State University in partial fulfillment of the requirements for the Degree of

Doctor of Philosophy
\end{abstract}

\section{Chemical Engineering}

\author{
Raleigh, North Carolina
}

2007

\section{APPROVED BY:}

George W. Roberts

(Co-chair of Advisory Committee)
Joseph M. DeSimone

(Co-chair of Advisory Committee) 


\section{DEDICATION}

To my grandparents, who passed away while I was here in the USA.

To my parents, my wife and my kids for their ever lasting help, support, sacrifices, and encouragement. I thank you all for everything. 


\section{BIOGRAPHY}

Tamer Samir Ahmed was born in Giza, Egypt in June 1976. He joined the Faculty of Engineering at Cairo University in 1994 and graduated in 1999 with a major in Chemical Engineering with honor degree. He was ranked the first on the Department of Chemical Engineering. He was nominated to work in the same department as a teaching assistant. Tamer received his MS in Chemical Engineering in 2001 on the Simulation and Optimization of the Propane-Precooled Mixed-Components Refrigerant Process for Liquefaction of Natural Gas. He was promoted in the department as a lecturer assistant in the same year. Tamer got married in September 2001. He was blessed with three kids: Ahmed in 2002, Omar in 2005, and Mariam in 2007. Tamer joined the Department of Chemical and Biomolecular Engineering at North Carolina State University in fall 2002 as a $\mathrm{PhD}$ graduate student. During his graduate studies, he conducted research at the NSF Science and Technology Center on Continuous Polymerization in Supercritical Carbon Dioxide. He was jointly advised by Prof. George W. Roberts and Prof. Joseph M. DeSimone. 


\section{ACKNOWLEDGEMENTS}

First, all thank and praise to Allah for his grace and mercy that has blessed me since and before I was born.

Second, there are many who have contributed in small and large ways to the completion of this dissertation and to whom I give special thanks for what they have given and what I have learned from them.

I would like to express my deep gratitude to my advisors, Prof. George Roberts and Prof. Joseph DeSimone, for their guidance and advice throughout this dissertation. Their extensive knowledge and resources equipped me for success in my research and prepared me for my future as a researcher. Special thanks to my committee members, Prof. Saad Khan and Prof. Alan Tonelli, for their assistance and helpful discussions.

I would like to acknowledge those who helped me through out this research: Tao Liu, Udo Michel, Jennifer Kelly, Ji Guo, ..., and all Roberts and DeSimone research groups.

Special thanks for the members of the Kenan $\mathrm{CO}_{2}$ Center for useful discussions and the interaction we shared on a daily basis. My abilities have grown from working with all of you.

Last, but certainly not least, I am indebted to my friends in Raleigh. There are so many friends that I may forget if I try to list them all. However, special thanks are due to Dr. Ahmed Eissa and Hossam El-Agroudy for their help especially in my first year, and my sincere friend and brother Dr. Yazan Hussain for his continuous help that I will never forget. 


\section{TABLE OF CONTENTS}

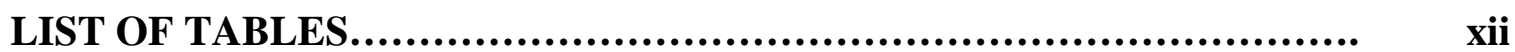

LIST OF FIGURES.................................................... xiv

CHAPTER 1 - INTRODUCTION........................................... 1

1.1 Motivation and Objectives.......................................... 1

1.2 Overview of the Content of the Thesis..................................... 3

1.3 References....................................................... 5

CHAPTER 2 - BACKGROUND.......................................... 9

2.1 Polymer Materials.................................................... 9

2.1.1 Fluoropolymers........................................................ 10

2.2 Polymerization Techniques........................................ 12

2.3 Physical and Chemical Properties of Supercritical Carbon Dioxide............ 14

2.4 Vinylidene Fluoride Homo- and Co-polymers with Hexafluoropropylene...... 16

2.4.1 Microstructure Analysis using NMR Spectroscopy........................... 17

2.4.2 Solubility of PVDF and VF2/HFP copolymers in $\mathrm{scCO}_{2} \ldots \ldots \ldots \ldots \ldots \ldots \ldots . . . \ldots$

2.5 References...................................................... 20

CHAPTER 3 - Copolymerization of Vinylidene Fluoride with Hexafluoropropylene in Supercritical Carbon Dioxide....................... 25

Abstract............................................................ 26

3.1 Introduction...................................................... 27

3.2 Experimental................................................... 28 


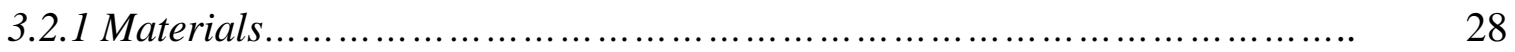

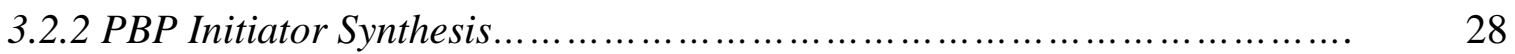

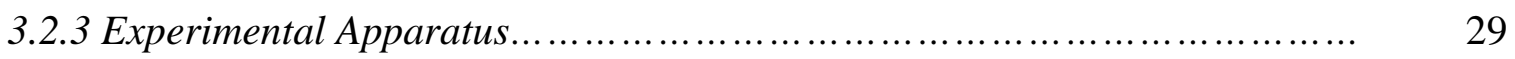

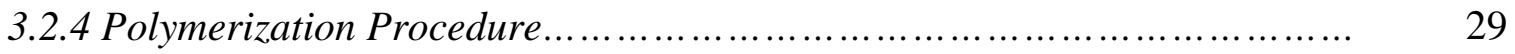

3.2.5 Copolymer Composition...................................................... 29

3.3 Results and Discussion.................................................... 31

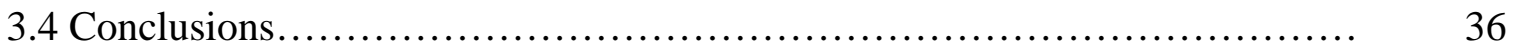

3.5 Acknowledgment..................................................... 36

3.6 Supporting Information Available...................................... 36

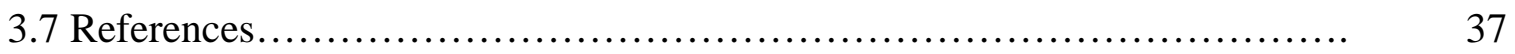

CHAPTER 4 - Continuous Copolymerization of Vinylidene Fluoride with Hexafluoropropylene in Supercritical Carbon Dioxide: Low Hexafluoropropylene-Content Semicrystalline Copolymers...................... 39

Abstract..................................................................... 40

4.1 Introduction........................................................ 41

4.2 Experimental Section................................................... 44

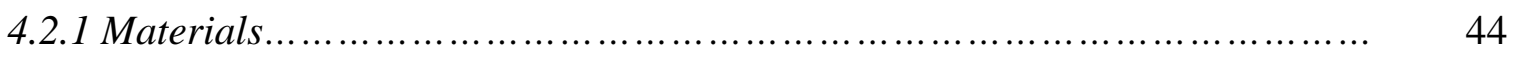

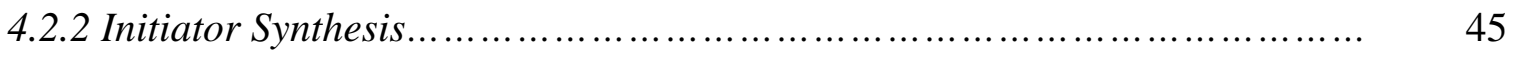

4.2.3 Polymerization Apparatus and Procedure.......................................

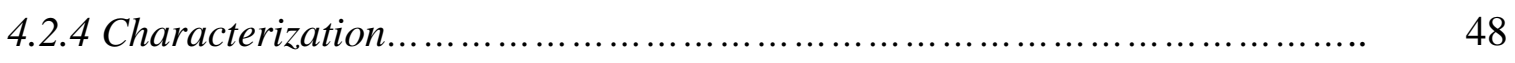

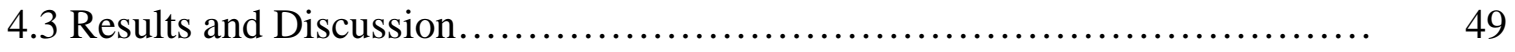

4.3.1 Copolymerization Studies...................................................... 


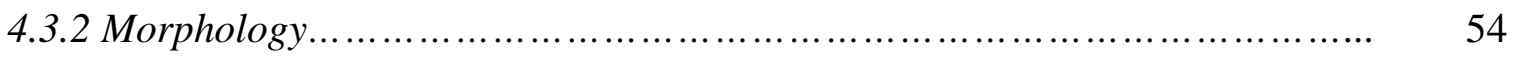

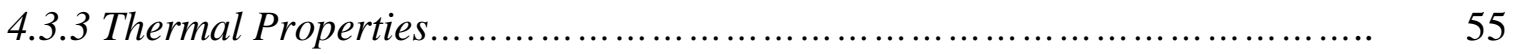

4.3.4 Effect of Total Monomer Concentration...........................................

4.3.5 Effect of Reaction Pressure....................................................... 58

4.3.6 Copolymerization Reaction Constants............................................ 60

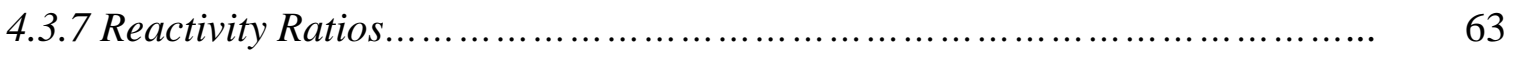

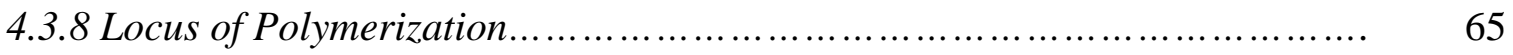

4.4 Conclusions................................................................... 67

4.5 Acknowledgement........................................................... 68

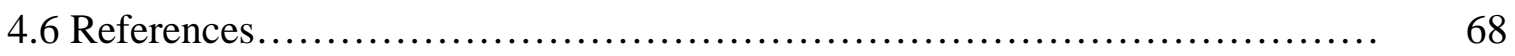

CHAPTER 5 - Continuous Copolymerization of Vinylidene Fluoride with Hexafluoropropylene in Supercritical Carbon Dioxide: High Hexafluoropropylene-Content Amorphous Copolymers........................ 73

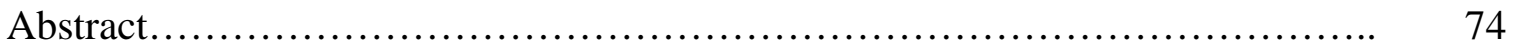

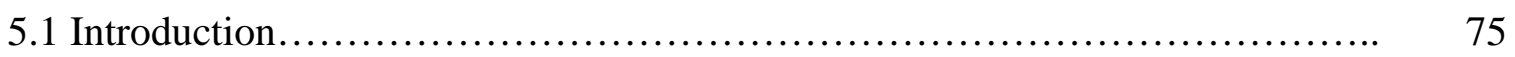

5.2 Experimental Section................................................... 77

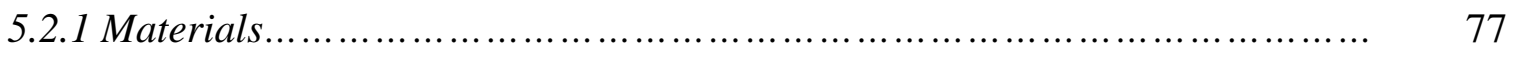

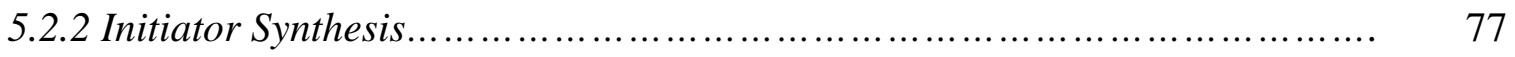

5.2.3 Polymerization Apparatus and Procedure....................................... 77

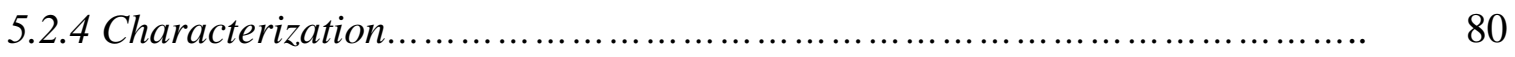

5.3 Results and Discussion................................................... 81

5.3.1 Copolymerization Studies..................................................... 81 


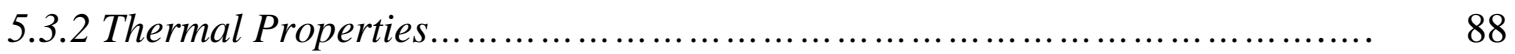

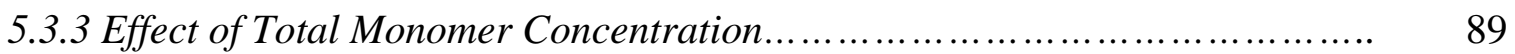

5.3.4 Effect of Reaction Pressure ........................................................ 95

5.3.5 Copolymerization Reaction Constants............................................ 101

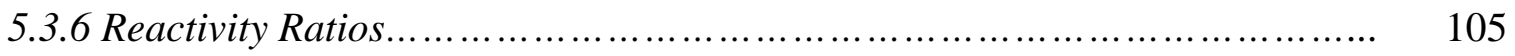

5.4 Conclusions................................................................ 107

5.5 Acknowledgement.................................................... 108

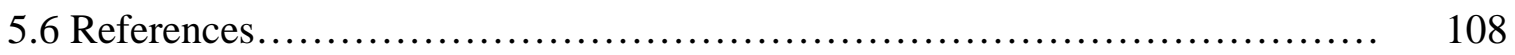

CHAPTER 6 - Kinetics of the Homopolymerization of Vinylidene Fluoride and its Copolymerization with Hexafluoropropylene in Supercritical Carbon $\begin{array}{ll}\text { Dioxide: The Locus of Polymerization } & 113\end{array}$

Abstract............................................................................ 114

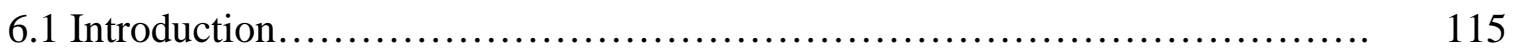

6.2 Experimental Section.................................................. 120

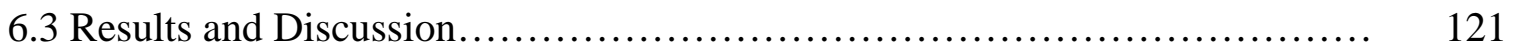

6.3.1 Solution Polymerization Model.................................................... 121

6.3.2 Surface Polymerization Model.................................................... 127

6.3.3 Interior Polymerization Model.................................................... 131

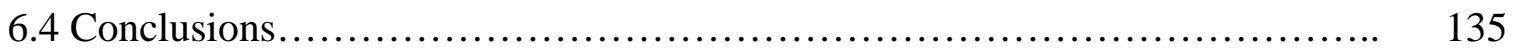

6.5 Acknowledgement...................................................... 136

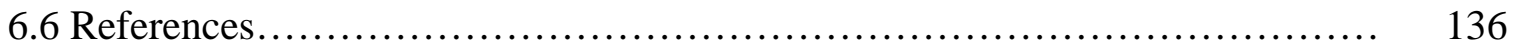


CHAPTER 7 - Continuous Precipitation Polymerization of Vinylidene

Fluoride in Supercritical Carbon Dioxide: Modeling the Molecular Weight

$\begin{array}{ll}\text { Distribution } & 140\end{array}$

Abstract.................................................................... 141

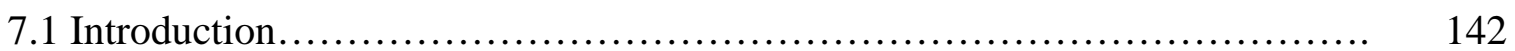

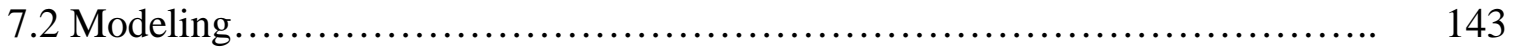

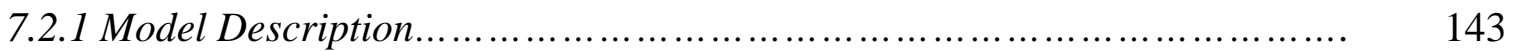

7.2.2 Model Derivation.......................................................... 144

7.2.3 Model Parameters........................................................... 147

7.3 Results and Discussion............................................ 150

7.4 Conclusions....................................................... 152

7.5 Acknowledgement................................................. 152

7.6 References........................................................ 152

CHAPTER 8 - Continuous Precipitation Polymerization of Vinylidene

Fluoride in Supercritical Carbon Dioxide: Modeling the Molecular Weight

Distribution - An Improved Model $\quad 161$

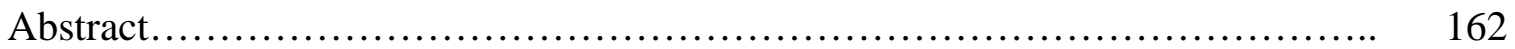

8.1 Introduction........................................................ 163

8.2 Model Development................................................. 172

8.2.1 Model Equations.......................................................... 174

8.2.2 Parameter Evaluation...................................................... 176

8.2.2.1 Termination rate constants....................................... 177 


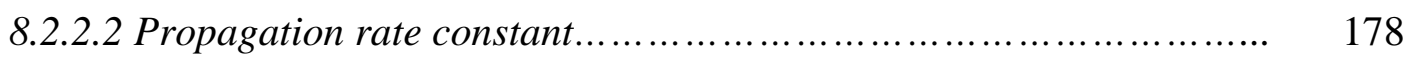

8.2.2.3 Chain transfer to polymer rate constant................................. 178

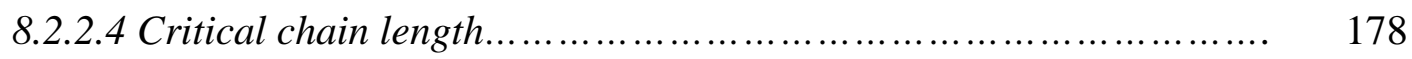

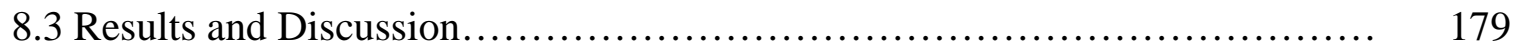

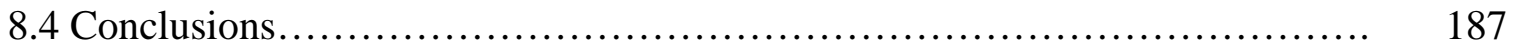

8.5 Acknowledgement..................................................... 188

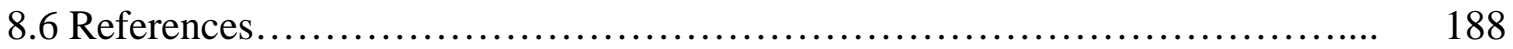

\section{CHAPTER 9 - CONCULSIONS AND RECOMMENDATIONS FOR} FUTURE WORK

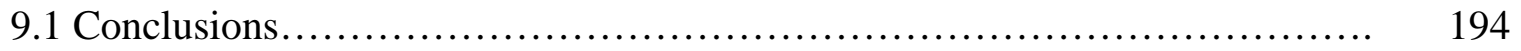

9.1.1 Copolymerization of vinylidene fluoride with hexafluoropropylene in supercritical carbon dioxide. .

9.1.2 Modeling the molecular weight distribution of poly(vinylidene fluoride)

synthesized in $\mathrm{scCO}_{2}$ by precipitation polymerization

9.2 Recommendations for future work

Appendices

A.1 Reaction Scheme.

199

A.2 Raw Materials

A.3 Procedure

199

A.4 Storage. 
A.5 Iodometric Titration................................................ 200

Appendix B - Reduction of Fouling during Polymerization of

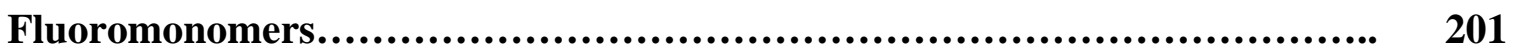

Invention Disclosure: Reduction of Fouling during Polymerization of

Fluoromonomers.............................................................. 202

B.1 Polymerization Apparatus and Procedure................................... 202

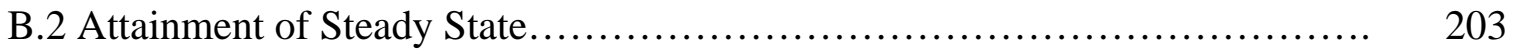

B.3 References........................................................... 205

Appendix C - Matlab Code for the Model in Chapter 8.......................... 207 


\section{LIST OF TABLES}

\section{Chapter 2}

Table 1: Main commercially available fluoroelastomers....................... 12

Table 2: Critical temperatures and pressures of some SCFs................... 15

\section{Chapter 3}

Table 1: Copolymerization of VF2 with HFP at $35{ }^{\circ} \mathrm{C}, 2$ h. reaction time, and 1.52 mole/L total initial monomer concentration

\section{Chapter 4}

Table 1: Effect of inlet total monomer concentration on the continuous copolymerization of VF2 with $\mathrm{HFP}$ in $\mathrm{scCO}_{2}$

Table 2: Effect of reaction pressure on the continuous copolymerization of VF2 with HFP in $\mathrm{scCO}_{2}$

Table 3: Thermal properties of poly(VF2-co-HFP) synthesized in experiment \#5 in Table 1

Table 4: Continuous homopolymerizations of VF2 in $\mathrm{scCO}_{2}$ using PBP initiator..

Table 5: Values for $k_{p} / k_{t}^{0.5}$ for poly(VF2-co-HFP) and PVDF, and $k_{d}$ of the PBP initiator.

Table 6: Reactivity ratio pairs for the copolymerization of VF2 with HFP in the literature.

\section{Chapter 5}

Table 1: Effect of inlet total monomer concentration on the continuous 
Table 2: Effect of reaction pressure on the continuous copolymerization of high HFP-content VF2/HFP copolymers in $\mathrm{scCO}_{2} \ldots \ldots \ldots \ldots \ldots \ldots \ldots \ldots \ldots \ldots \ldots \ldots \ldots \ldots$

Table 3: Average VF2 reverse defects for poly(VF2-co-HFP) polymers

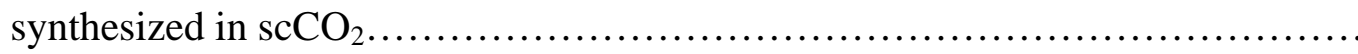

Table 4: Thermal properties of poly(VF2-co-HFP) synthesized in experiment \#5

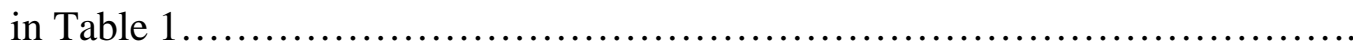

Table 5: Values for $k_{p} / k_{t}^{0.5}$ for poly(VF2-co-HFP) and PVDF, and $k_{d}$ of the PBP initiator

Table 6: Reactivity ratio pairs for the copolymerization of VF2 with HFP in the literature. 


\section{LIST OF FIGURES}

\section{Chapter 2}

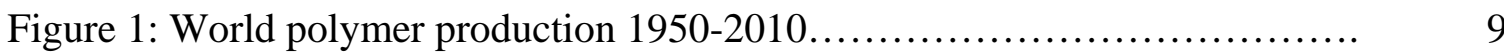

Figure 2: Schematic view of a polymerization process based on $\mathrm{scCO}_{2}$ technology, in which the monomers can be recycled in a closed-loop............. 16

Figure 3: Effect of HFP content on the glass transition temperature of VF2/HFP copolymers..........................................................

\section{Chapter 3}

Figure 1: (a) Qualitative Cloud-point pressure diagram of a polymer-supercritical fluid. (b) Cloudpoint pressure curve of Tecnoflon N215 in $\mathrm{scCO}_{2} \ldots \ldots \ldots \ldots \ldots \ldots$

\section{Chapter 4}

Figure 1: Different copolymers of VF2 with HFP with their main manufacturers and trade names

Figure 2: CSTR polymerization system.

Figure 3: 19F NMR spectrum for 10 mole\% HFP Poly(VF2-co-HFP) collected in experiment \# 3 in Table 1 .

Figure 4: SEM images of VF2-HFP copolymer collected in experiment \#4 in Table 1

Figure 5: Effect of total monomer concentration on: (a) $R_{P}$; (b) $\mathrm{M}_{\mathrm{n}}$ and PDI; (c) MWDs ; (d) $\left[F_{H F P}\right]$

Figure 6: Effect of reaction pressure on: (a) $R_{P}$; (b) $M_{n}$ and PDI; (c) MWDs ; (d) 
$\left[F_{H F P}\right]$

\section{Chapter 5}

Figure 1: CSTR polymerization system..................................... 79

Figure 2: ${ }^{19}$ F NMR spectrum for copolymer collected in experiment \# 6 in Table

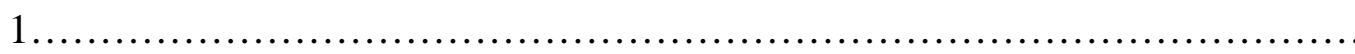

Figure 3: Effect of total monomer concentration for HFP/VF2 feed ratio of 59/41

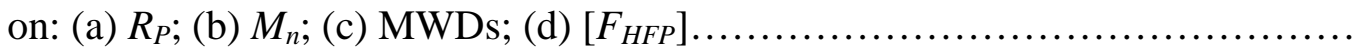

Figure 4: Effect of total monomer concentration for HFP/VF2 feed ratio of 66/34 on: (a) $R_{P}$; (b) $M_{n}$; (c) MWDs; (d) $\left[F_{H F P}\right]$.

Figure 5: Effect of total monomer concentration for HFP/VF2 feed ratio of 73/37

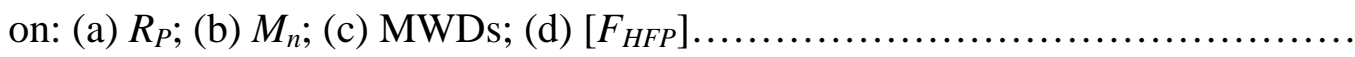

Figure 6: The MWDs of poly(HFP-co-VF2) synthesized in $\mathrm{scCO}_{2}$ for $\left[M_{T}\right]_{i n}=6.5 \mathrm{~mol} / \mathrm{L}, P=400 \mathrm{bar}, T=40^{\circ} \mathrm{C}, T=20 \mathrm{~min},[I]_{\mathrm{in}}=3 \mathrm{mM} \ldots \ldots \ldots \ldots \ldots \ldots$

Figure 7: Effect of reaction pressure for HFP/VF2 feed ratio of 59/41 on: (a) $R_{P}$;

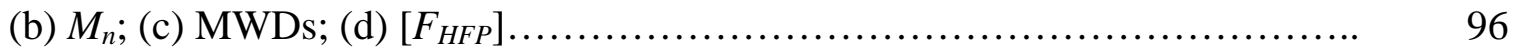
Figure 8: Effect of reaction pressure for HFP/VF2 feed ratio of 66/34 on: (a) $R_{P}$; (b) $M_{n}$; (c) MWDs; (d) $\left[F_{H F P}\right]$.

Figure 9: Effect of reaction pressure for HFP/VF2 feed ratio of 73/27 on: (a) $R_{P}$; (b) $M_{n}$; (c) MWDs; (d) $\left[F_{H F P}\right]$.

Figure 10: Effect of HFP on $k_{p} / k_{t}^{0.5}$ in scCO ${ }_{2}$ at 400 bar and $40{ }^{\circ} \mathrm{C}$. 


\section{Chapter 6}

Figure 1: Test of the solution polymerization model for continuous polymerization of PVDF: (a) Rate of polymerization, (b) Molecular weight.......

Figure 2: Test of the solution polymerization model for the continuous polymerization of low HFP-content poly(VF2-co-9.2mol\% HFP): (a) Rate of

polymerization, (b) Molecular weight...

Figure 3: Test of the solution polymerization model for the continuous polymerization of high-HFP content poly(VF2-co-HFP): (a) Rate of polymerization, (b) Molecular weight

Figure 4: Test of the surface polymerization model for the continuous polymerization of PVDF: (a) Rate of polymerization, (b) Molecular weight........

Figure 5: Test of the surface polymerization model for the continuous polymerization of low-HFP-content poly(VF2-co-9.2mol\% HFP): (a) Rate of polymerization, (b) Molecular weight

Figure 6: Test of the surface polymerization model for the continuous polymerization of high-HFP-content poly(VF2-co-HFP): (a) Rate of polymerization, (b) Molecular weight...................................

Figure 7: Test of the interior polymerization model for the continuous polymerization of PVDF: (a) Rate of polymerization, (b) Molecular weight........

Figure 8: Test of the interior polymerization model for the continuous polymerization of low HFP-content poly(VF2-co-9.2mol\% HFP): (a) Rate of polymerization, (b) Molecular weight. 
Figure 9: Test of the interior polymerization model for the continuous polymerization of high HFP-content poly(VF2-co-HFP):(a) Rate of polymerization, (b) Molecular weight.....................................

\section{Chapter 7}

Figure 1: Experimental MWDs for PVDF. Varying monomer feed concentration at $75{ }^{\circ} \mathrm{C}$ and $27.5 \mathrm{MPa}$ total pressure.

Figure 2: Kinetic scheme to model the bimodal MWD of PVDF synthesized continuously in $\mathrm{scCO}_{2}$

Figure 3: Effect of monomer feed concentration on MWD.

Figure 4: Effect of residence time on the MWD: (a) $\mathrm{M}_{0}=0.78 \mathrm{M}$; (b) $\mathrm{M}_{0}=2.8 \mathrm{M}$.

Figure 5: Effect of temperature on the MWD.

\section{Chapter 8}

Figure 1: Partition coefficients of VF2 between PVDF (Solef® 1010, $\mathrm{Mw}=180,000)$ and $\mathrm{CO}_{2}$ phases as a function of temperature and pressure.

Figure 2: Proposed kinetic scheme for PVDF polymerization in $\mathrm{scCO}_{2}$

Figure 3: Effect of monomer feed concentration on MWD: (a) Experimental; (b) Model.

Figure 4: Effect of monomer feed concentration on PDI

Figure 5: Effect of average residence time on the MWD for low monomer feed concentration with $M_{i n}=0.78 \mathrm{M}$ : (a) Experimental; (b) Model.

Figure 6: Effect of average residence time on the MWD for high monomer feed concentration with $M_{i n}=2.8 \mathrm{M}$ : (a) Experimental; (b) Model. 
Figure 7: Effect of average residence time on PDI. $75{ }^{\circ} \mathrm{C}$ and 276 bar............. 183

\section{Appendix B}

Figure 1: CSTR polymerization system................................. 203

Figure 2: Snapshots of the reactor agitator shaft. (a) 10\% mole HFP poly(VF2-

co-HFP); (b) PVDF; (c) Baked PVDF; (d) 10\% mole HFP poly(VF2-co-HFP)

polymerized after baking PVDF onto interior surfaces......................... 204

Figure 3: Total monomers conversion at different residence times.............. 205 


\section{CHAPTER 1}

\section{INTRODUCTION}

\subsection{Motivation and Objectives}

Supercritical carbon dioxide $\left(\mathrm{scCO}_{2}\right)$ was shown to be a viable medium for polymerization in $1968^{1}$. However, in the 1990s there was an explosion of research in this area ${ }^{2-}$

7. This was motivated by environmental concerns to reduce the use of organic solvents, to completely phase out chlorofluorocarbons, and to reduce the quantity of aqueous waste streams. In addition to the common features of supercritical fluids, such as gas-like diffusivities and liquid-like densities, some unique chemical, environmental, and potential economic advantages make $\mathrm{scCO}_{2}$ a practical and promising alternative to traditional solvents. Carbon dioxide is naturally occurring, abundant, and readily available in high purity from a variety of sources ${ }^{8}$. It has an easily accessible critical point with a $T_{\mathrm{c}}$ of $31.1^{\circ} \mathrm{C}$ and a $P_{\mathrm{c}}$ of $73.8 \mathrm{bar}$. Thus, the tuning of its conditions can be used to eliminate large amounts of hazardous organic or aqueous wastes that require post-treatment and energy-intensive drying steps for product purification. In addition, $\mathrm{CO}_{2}$ is relatively chemically inert, which will allow a wide variety of polymer synthesis mechanisms ${ }^{7}$. Furthermore, the lack of chain transfer to solvent makes $\mathrm{CO}_{2}$ the "most ideal" solvent for free-radical polymerization. Finally, initiators have high efficiencies and acceptable decomposition kinetics in $\mathrm{scCO}_{2}{ }^{9-11}$.

Poly(vinylidene fluoride) (PVDF) is a semicrystalline fluoropolymer widely used for many applications because of its excellent chemical, thermal and mechanical stability combined with its extraordinary piezoelectric and pyroelectric properties ${ }^{12,13}$. Although PVDF has found 
interesting applications, the copolymers of vinylidene fluoride (VF2) with other fluoromonomers have drawn even more interest ${ }^{14}$. One of the most important copolymers of VF2 is that with hexafluoropropylene (HFP). These copolymers have led to various kinds of products differentiated by their contents of HFP. At less than 15 mol\% of HFP, the resulting copolymers show thermoplastic properties and are called "flexible PVDF". For HFP content higher than 1920 mol\%, the copolymers are completely amorphous and are used as elastomers ${ }^{15,16}$.

Poly(vinylidene fluoride) and the low HFP content copolymers are produced commercially by either emulsion or suspension polymerizations in water ${ }^{17,}{ }^{18}$, while the elastomeric VF2/HFP copolymers are produced only by emulsion polymerization ${ }^{15,}{ }^{19-21}$ because of their tacky nature ${ }^{22}$. Both processes generate large quantities of wastewater and require large quantities of energy to isolate the polymer in a dry form. Moreover, the emulsion technique involves the use of relatively expensive fluorinated surfactants such as perfluorooctanoic acid (PFOA) or perfluorooctanyl sulfonates (PFOS) ${ }^{23-25}$. 3M Company discontinued manufacturing these fluorinated surfactants during the period 2000-2002. Currently, DuPont is the only domestic manufacturer. In addition, there are environmental concerns that these fluorinated surfactants are non-biodegradable and with time could bio-accumulate in human fatty tissues. Therefore, the future commercial availability of these surfactants is uncertain ${ }^{23,24}$.

Our research group pioneered the continuous polymerization of vinyl monomers in $\mathrm{scCO}_{2}{ }^{26}$. Both $\mathrm{PVDF}^{10,26-28}$ and poly(acrylic acid) $)^{29-31}$ were synthesized using continuous precipitation polymerization in $\mathrm{scCO}_{2}$ using a continuous stirred tank reactor (CSTR). A challenge identified during the course of continuous polymerization of PVDF was understanding 
the origin of the bimodal molecular weight distribution (MWD) obtained under certain reaction conditions $^{28}$.

The first objective of this research is to study the continuous copolymerization of VF2/HFP copolymers in $\mathrm{scCO}_{2}$ using a CSTR. Poly(vinylidene fluoride) is highly semicrystalline and is not soluble in $\mathrm{scCO}_{2}$ under practical conditions ${ }^{32}$. The incorporation of HFP in the backbone of the copolymer increases the free volume, which in turn promotes facile interactions between solvents and the polymer segments, and hence increases the solubility of the copolymer. Low HFP-content VF2/HFP copolymers are still not soluble in $\mathrm{scCO}_{2}$ under reasonable conditions. On the other hand, depending on the HFP-content in the copolymer, reaction pressure, and the copolymer molecular weight, the amorphous high HFP-content copolymers show much more solubility. Therefore, this study includes the precipitation polymerization of low HFP-content copolymers and precipitation and solution polymerization for the amorphous high HFP content VF2/HFP copolymers. An additional objective of this research is to determine the origin behind the formation of PVDF having a bimodal MWD during the course of precipitation polymerization of $\mathrm{PVDF}$ in $\mathrm{scCO}_{2}$.

\subsection{Overview of the Content of the Thesis}

Chapter 2 presents a general background about fluorinated polymers, polymerization techniques, the general properties of $\mathrm{scCO}_{2}$ and general background about PVDF and VF2/HFP copolymers. More details are included in the introduction sections of the following chapters.

Chapter 3 describes the batch copolymerization of VF2 with HFP in $\mathrm{scCO}_{2}$ using perfluorobutyryl peroxide initiator. 
Chapter 4 describes the experimental study of the continuous precipitation copolymerization of the semicrystalline low HFP-content VF2/HFP copolymers in $\mathrm{scCO}_{2}$. The effects of the operating variables such as monomer concentration and reaction pressure on the polymerization rate, molecular weight, and MWD of the copolymers are evaluated. The experimental data suggest that the carbon-dioxide-rich fluid phase is the primary locus of polymerization.

Chapter 5 describes the experimental study of the continuous precipitation and solution copolymerization of the amorphous high HFP-content VF2/HFP copolymers in $\mathrm{scCO}_{2}$. Similarly, the effect of monomer concentration and reaction pressure on the polymerization rate, molecular weight, and MWD of the copolymers are evaluated. No effect from precipitation of the copolymer during the polymerization is observed on the polymerization kinetics.

Chapter 6 presents the testing of the experimental data of the polymerization of VF2 and VF2/HFP in $\mathrm{scCO}_{2}$ against three kinetic models to determine the main locus of polymerization. The first model is based on the assumption that all the polymerization reactions take place in the continuous $\mathrm{CO}_{2}$-rich phase. The second and third models are based on polymerization on the surface of the polymer particles or inside the polymer particles, respectively. Both the surface and the interior polymerization models fail to fit the experimental results, while the solution polymerization model is able to account for the experimental results of the polymerizations fairly well.

Chapter 7 shows a homogeneous kinetic model that has been proposed to account for the bimodal MWD observed for PVDF polymerization in $\mathrm{scCO}_{2}$. This model takes into account the change in termination mechanisme of the polymeric radicals with chain length, from chemically- 
controlled termination to diffusion-controlled termination. The change of the termination mechanism results in two chain populations that are responsible for the bimodality observed in case of PVDF. The model, although simple, can describe many features of the experimental MWDs, such as the effects of monomer concentration, residence time, and temperature.

Chapter 8 presents an improved version of the above model, where the chain transfer to polymer reaction is included in the reaction scheme. This improved model can capture the abrupt increase in the polydispersity index observed during experiments at high monomer concentrations or high residence times. In addition, the model can capture the occurrence of gelation, which is responsible for an inoperability region that was confirmed in the

polymerization experiments. Moreover, different hypotheses and models claimed to account for the bimodal MWD of PVDF are reviewed in this chapter.

Chapter 9 summarizes the conclusions of all the results and recommends future works.

\subsection{References}

1. Hagiwara, M. Low temperature catalytic polymerization of vinyl monomers in carbon dioxide. FR Patent \#: 1524533 (Sumitomo Chemical Co., Ltd.), 1968.

2. Cooper, A. I. Journal of Materials Chemistry 2000, 10, (2), 207-234.

3. Canelas, D. A.; DeSimone, J. M. Advances in Polymer Science 1997, 133, 103-140.

4. Kendall, J. L.; Canelas, D. A.; Young, J. L.; DeSimone, J. M. Chemical Reviews 1999, 99, (2), 543-563.

5. Ajzenberg, N.; Trabelsi, F.; Recasens, F. Chemical Engineering \& Technology 2000, 23, (10), 829-839. 
6. DeSimone, J. M. Science 2002, 297, (5582), 799-803.

7. Beckman, E. J. Journal of Supercritical Fluids 2004, 28, (2-3), 121-191.

8. Steiner, R. Chemical Engineering 1993, 100, (3), 114-119.

9. $\quad$ Guan, Z.; Combes, J. R.; Menceloglu, Y. Z.; DeSimone, J. M. Macromolecules 1993, 26, (11), 2663-9.

10. Charpentier, P. A.; DeSimone, J. M.; Roberts, G. W. Chemical Engineering Science 2000, 55, (22), 5341-5349.

11. Bunyard, W. C.; Kadla, J. F.; DeSimone, J. M. Journal of the American Chemical Society 2001, 123, (30), 7199-7206.

12. Lovinger, A. J., Poly(vinylidene fluoride). In Developments in crystalline polymers, Basset, D. C., Ed. Applied Science Publishers: London, 1982; Vol. 1, pp 195-273.

13. Dohany, J. E., Poly(vinylidene fluoride). In Kirk-Othmer Encyclopedia of Chemical Technology, Krooschwitz, J. I., Ed. John Wiley \& Sons: New York, 1994; Vol. 11, pp 694-712.

14. Ameduri, B.; Boutevin, B.; Kostov, G. Progress in Polymer Science 2001, 26, (1), 105187.

15. Apostolo, M.; Arcella, V.; Storti, G.; Morbidelli, M. Macromolecules 1999, 32, (4), 9891003.

16. Ajroldi, G.; Pianca, M.; Fumagalli, M.; Moggi, G. Polymer 1989, 30, (12), 2180-2187.

17. Office for Official Publications of the European Communities. Document no.: 302M2690-Solvay/Montedison-Ausimont Merger Procedure. (http://ec.europa.eu/comm/competition/mergers/cases/decisions/m2690_en.pdf), 
18. Abusleme, J. A.; Gavezotti, P. Suspension (co)polymerization with bis(dichlorofluoroacetyl) peroxide for preparation of hydrogen-containing thermoplastic fluoropolymers. US Patent: 5,569,728, 1995.

19. Dixon, S.; Rexford, D. R.; Rugg, J. S. Industrial and Engineering Chemistry 1957, 49, (10), 1687-1690.

20. Arnold, R. G.; Barney, A. L.; Thompson, D. C. Rubber Chemistry and Technology 1973, 46, (3), 619-52.

21. Jagels, S., Materials Engineer in Solvay-Solexis, Thorofare, NJ, USA, Personal Communication. 2003.

22. Stevens, M. P., Polymer Chemistry: An Introduction. 3rd ed.; Oxford University Press: New York, 1999.

23. Tang, P. L. Process for producing fluoroelastomers by emulsion polymerization, US Patent \#: 6,512,063 (DuPont-Dow Elastomers, L.L.C.). 2003.

24. Kaspar, H.; Hintzer, K.; Dewitte, G.; Schwertfeger, W. Emulsifier free aqueous emulsion polymerization process for making fluoropolymers, US Patent \#:6,693,152 (3M Innovative Properties Company). 2004.

25. Wille, R. A.; Burchill, M. T. Copolymers of vinylidene fluoride and hexafluoropropylene having reduced extractable content and improved solution clarity, US Patent \#:6,743,876 (Atofina Chemicals, Inc., USA). 2004.

26. Charpentier, P. A.; Kennedy, K. A.; DeSimone, J. M.; Roberts, G. W. Macromolecules Communications 1999, 32, (18), 5973-5975. 
27. Charpentier, P. A.; DeSimone, J. M.; Roberts, G. W. Industrial \& Engineering Chemistry Research 2000, 39, (12), 4588-4596.

28. Saraf, M. K.; Gerard, S.; Wojcinski, L. M.; Charpentier, P. A.; DeSimone, J. M.; Roberts, G. W. Macromolecules 2002, 35, (21), 7976-7985.

29. Liu, T.; Desimone, J. M.; Roberts, G. W. Journal of Polymer Science, Part A: Polymer Chemistry 2005, 43, (12), 2546-2555.

30. Liu, T.; DeSimone, J. M.; Roberts, G. W. Chemical Engineering Science 2006, 61, (10), 3129-3139.

31. Liu, T.; Garner, P.; DeSimone, J. M.; Roberts, G. W.; Bothun, G. D. Macromolecules 2006, 39, (19), 6489-6494.

32. DiNoia, T. P.; Conway, S. E.; Lim, J. S.; McHugh, M. A. Journal of Polymer Science Part B-Polymer Physics 2000, 38, (21), 2832-2840. 


\section{CHAPTER 2}

\section{BACKGROUND}

\subsection{Polymer Materials}

Synthetic polymers can be denoted as the predominant class of material of the $20^{\text {th }}$ and the $21^{\text {st }}$ centuries. Since World War II, the production volume of polymers has increased tremendously to a current value of about 250 million tonnes in 2006 (Fig. 1) ${ }^{1}$. The enormous growth of synthetic polymers is because they are light in weight, act as insulators for electricity, cover a wide range of properties from soft packaging materials to fibers stronger than steel, and allow for relatively easy processing. In addition, parts with complex shapes can be made easily at low cost and at high speed by shaping polymers or monomers in the liquid state.

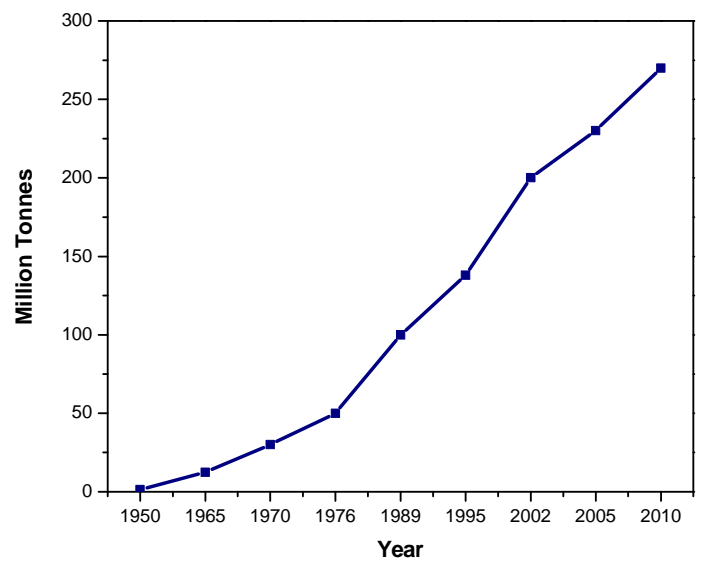

Figure 1: World polymer production $1950-2010^{1}$ 


\subsubsection{Fluoropolymers}

Since the synthesis of low-molecular weight poly(chlorotrifluoroethylene) (PCTFE) in the late $1930 \mathrm{~s}^{2}$ and the high-molecular weight poly(tetrafluoroethylene) (PTFE) by Plunkett in DuPont labs in $1938^{3}$, fluoropolymers have emerged to be the product of choice when metals and other less expensive polymers fail or where long term reliability is required ${ }^{4}$. Fluoropolymers are particularly interesting and attractive compounds because of their versatility and their unique combination of relevant properties. Such properties include high thermal and oxidative stability, low dielectric constant, low moisture absorption, low flammability, low surface energy, excellent biocompatibility, marked gas permeability and excellent resistance to most chemicals ${ }^{5}$. Therefore, these specialty polymers have been used in many applications: building industries (paints and coatings resistant to UV), petrochemical and automotive industries, aerospace and aeronautics, chemical engineering (high-performance membranes), optics (core and cladding of optical fibers), treatment of textiles, and microelectronics. Despite their relatively high cost, fluoropolymers have frequently been used to substantially reduce overall system cost ${ }^{4}$.

Fluoropolymers are collectively divided into fluoroplastics and fluoroelastomers. As a group, fluoroplastics are characterized by chemical inertness, a low coefficient of friction, antistick properties, excellent dielectric properties and outstanding weatherability. These properties are the result of the strong carbon-fluorine valence bonding and the relative sizes of the carbon and fluorine atoms, which enable compact packing of the molecular chains. Most commercial fluoroplastics are homopolymers and copolymers derived from free radical polymerization of a relatively limited number of fluorinated monomers such as tetrafluoroethylene (TFE), vinyl fluoride (VF), vinylidene fluoride (VF2), chlorotrifluoroethylene (CTFE), hexafluoropropylene 
(HFP), and perfluoroalkylvinylether (PAVE). Examples of fluoroplastics include: PTFE, PCTFE, copolymers of TFE and HFP (fluorinated ethylene propylene copolymers (FEP)), copolymers of TFE and PAVE (perfluoroalkoxy polymers (PFA)), copolymers of TFE and ethylene (ETFE), copolymers of TFE and 2,2-Bistrifluoromethyl-4,5-difluoro-1,3-dioxole (Teflon ${ }^{\circledR}$ AF), copolymers of ethylene and CTFE (ECTFE), poly(vinyl fluoride) (PVF), poly(vinylidene fluoride) (PVDF), copolymers of VF2 and HFP with HFP less than 15\% (flexible PVDF), and many others.

On the other hand, fluoroelastomers represent a broad class of high performance elastomers that combine excellent thermal, oxidative, and fluid resistance with very good tensile and compression resistance properties. They are used predominantly in sealing applications in hostile environments requiring extreme resistance to oxidation, high temperatures, aggressive fluids, and chemicals. Although quite expensive relative to other elastomeric materials, their exceptional properties make them the most effective and least costly answer to sealing problems demanding resistance to corrosive high temperature environments ${ }^{6}$.

The dominant building units of the fluoroelastomers world are VF2 and TFE monomers. To create elastomers VF2 or/and TFE must be copolymerized with other monomer(s) bearing a bulky substituent on the vinyl or perfluorovinyl group. Specific properties can be obtained by co- ter-, or tetra-polymerizing VF2 or/and TFE with other monomers such as: HFP, CTFE, 1hydro-pentafluoropropylene (HPFP), propylene (P), or perfluoromethyl vinyl ether (PMVE). Various commercial elastomers with their manufacturers are listed in Table 1. Elastomers of VF2/HFP and VF2/HFP/TFE are produced by most fluoroelastomers manufacturers and represent the most important fluoroelastomers ${ }^{4,6}$. 
Table 1: Main commercially available fluoroelastomers ${ }^{* 4,7}$

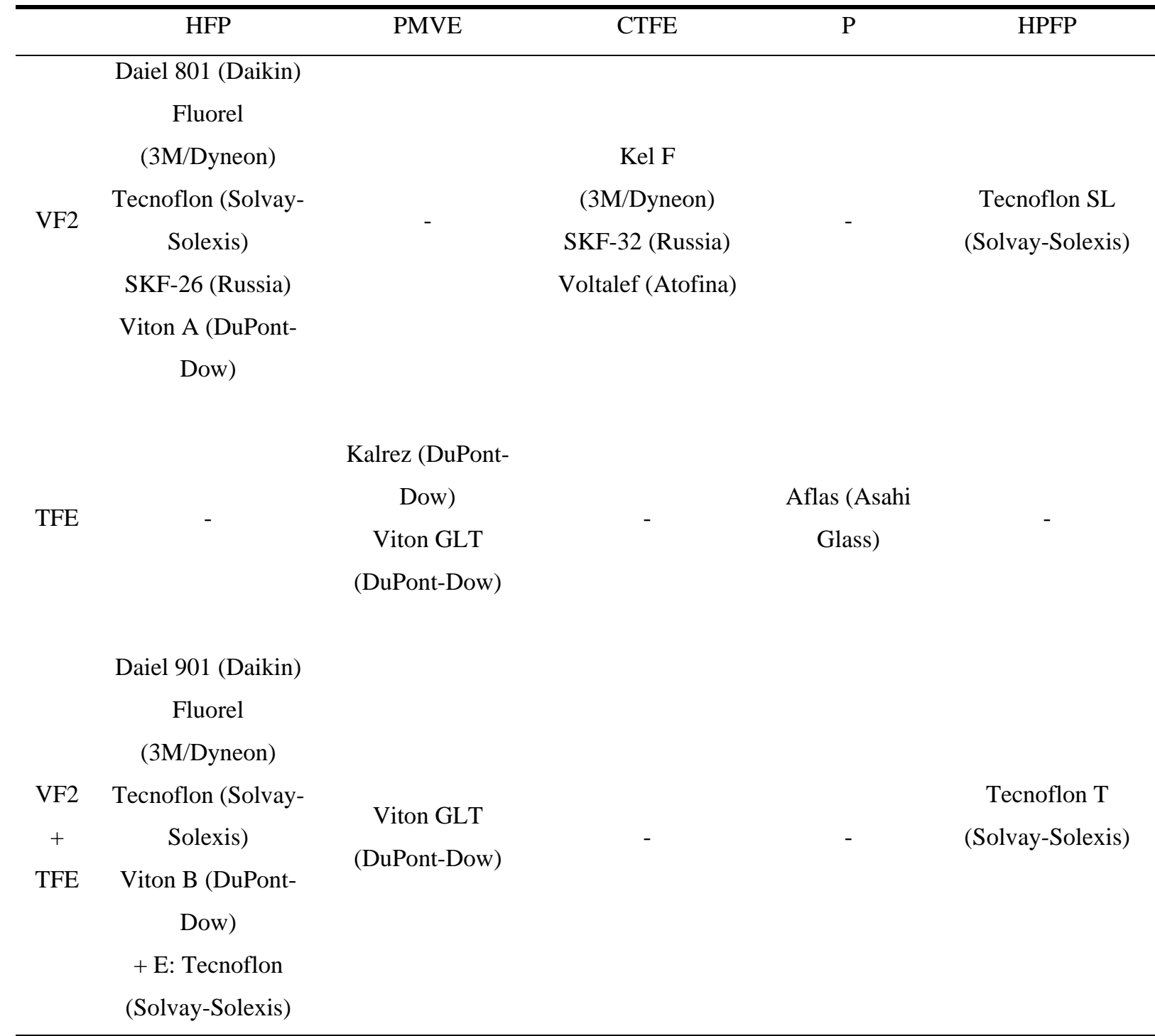

* CTFE: chlorotrifluoroethylene; E: ethylene; HFP: hexafluoropropylene; HPFP: 1-hydro-pentafluoropropylene; P: propylene; PMVE: perfluoromethyl vinyl ether; TFE: tetrafluoroethylene; VF2: vinylidene fluoride.

\subsection{Polymerization Techniques}

Polymerization processes are broadly divided into two groups known as step growth and chain growth polymerizations ${ }^{8}$. In step growth polymerization, polymer is formed by the stepwise reaction between the functional groups of the reactants to produce one larger 
multifunctional molecule, with or without the elimination of a small molecule such as water. Chain growth polymerizations on the other hand involve a chain reaction in which the reactive center may be a free radical, cation, or anion, or a species that is covalently attached to a catalyst such as a transition metal.

Free radical polymerizations are further classified into homogeneous and heterogeneous polymerizations. In a homogeneous polymerization, all components - monomer, polymer, and initiator, form a single phase throughout the reaction. This category includes both bulk and solution (using a solvent) techniques. Bulk techniques do not require separation of the polymer from a solvent. However, bulk polymerization is restricted only to step growth polymers, since the viscosity increases only in the last stages of the polymerization ${ }^{8}$. Chain growth polymers are very difficult to polymerize in bulk, since the reactions are highly exothermic, thus leading to problems associated with heat removal. One of the exceptions is poly(methyl methacrylate) in which the polymer is soluble in its own monomer ${ }^{9}$.

Heterogeneous polymerizations consist of at least two phases at some point during the reaction. They can be classified into four types: suspension, emsulsion, precipitation, and dispersion polymerizations, based on kinetics, initial state of the system and mechanism of particle formation $^{10}$.

In suspension polymerizations, the initiator, monomer and the resulting polymer are insoluble in the polymerization medium, which forms the continuous phase. Frequently, water is used as the polymerization medium. The initiator is usually dissolved in the monomer phase. Therefore, the monomers droplets form batches of bulk polymerizations. The system is 
heterogeneous throughout the polymerization and the continuous phase acts as a dispersant and heat dissipation agent.

In emulsion polymerization, the initiator and the monomer are segregated with the initiator soluble in the continuous phase, which usually is water, and not in the monomer phase. Additionally, the polymer particles formed in emulsion techniques are typically around 10 times smaller than the smallest encountered in suspension polymerizations ${ }^{10}$.

Precipitation polymerization refers to a process in which the initial ingredients monomer, initiator are soluble in the continuous phase, resulting in a homogeneous solution. The polymer chains grow in length and start precipitating once they reach a critical molar mass, beyond which they are not soluble in the continuous phase, thus resulting in the formation of a polymer phase.

Finally, dispersion polymerization is similar to a precipitation polymerization with respect to the solubility of the ingredients and the polymer. The difference is that surfactants are used to prevent coagulation or agglomeration of the polymer particles.

\subsection{Physical and Chemical Properties of Supercritical Carbon Dioxide}

A supercritical fluid (SCF) is defined as a substance for which the temperature and

pressure are above their critical values ${ }^{11-13}$. Above the critical temperature, the vapor-liquid coexistence line no longer exists. Therefore, SCFs can be regarded as "hybrid solvents”, because the properties can be tuned from liquid-like to gas-like without crossing a phase boundary by simply changing the pressure or the temperature. 
Research with supercritical carbon dioxide $\left(\mathrm{scCO}_{2}\right)$ has outpaced research with other SCFs, because $\mathrm{CO}_{2}$ is inexpensive, has a critical point at conditions lower than that of most other SCFs, which increases the range of its tenability (Table 2), and is environmentally benign. In general, $\mathrm{scCO}_{2}$ can be regarded as a viable alternative medium for polymer processing. Besides the obviously environmental benefits, supercritical carbon dioxide also has desirable physical and chemical properties from a process point of view. These include its relatively chemical inertness, readily accessible critical point, excellent wetting characteristics, low viscosity, and highly tunable solvent behavior, facilitating easy separation. The use of such a "volatile" solvent makes the solvent removal step relatively easy. In addition, $\mathrm{scCO}_{2}$ has found particular application as a polymerization medium because of its inertness to free radicals ${ }^{14}$, i.e. no chain transfer to $\mathrm{CO}_{2}$, and high initiator efficiencies ${ }^{14-16}$, as a result of its low viscosity. In principle, using $\mathrm{scCO}_{2}$ as a polymerization medium allows for a closed-loop polymer process, in which the monomers can be recycled as shown in Fig. 2.

Table 2: Critical temperatures and pressures of some SCFs ${ }^{17}$

\begin{tabular}{ccc}
\hline & $\begin{array}{c}\text { Critical Temperature } \\
\left({ }^{\circ} \mathrm{C}\right)\end{array}$ & $\begin{array}{c}\text { Critical pressure } \\
\text { (bar) }\end{array}$ \\
\hline Carbon dioxide $\left(\mathrm{CO}_{2}\right)$ & 31.1 & 73.8 \\
Water $\left(\mathrm{H}_{2} \mathrm{O}\right)$ & 374.4 & 221.2 \\
Ethane $\left(\mathrm{C}_{2} \mathrm{H}_{6}\right)$ & 32.4 & 48.8 \\
Propane $\left(\mathrm{C}_{3} \mathrm{H}_{8}\right)$ & 96.8 & 42.5 \\
Ammonia $\left(\mathrm{NH}_{3}\right)$ & 132.4 & 113.5 \\
Nitrous oxide $\left(\mathrm{N}_{2} \mathrm{O}\right)$ & 36.6 & 72.4 \\
Fluoroform $\left(\mathrm{CHF}_{3}\right)$ & 26.3 & 48.6 \\
\hline
\end{tabular}




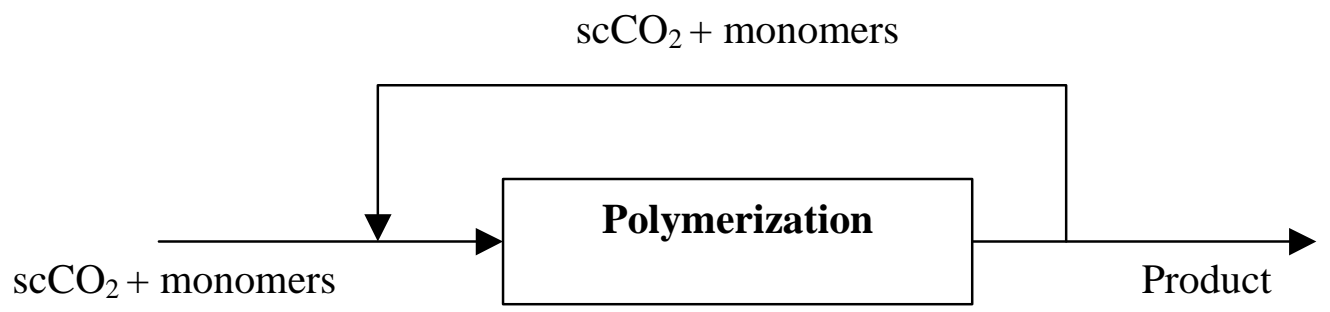

Figure 2: Schematic view of a polymerization process based on $\mathrm{scCO}_{2}$ technology, in which the monomers can be recycled in a closed-loop.

\subsection{Vinylidene Fluoride Homo- and Co-polymers with Hexafluoropropylene}

Polyvinylidene fluoride (PVDF) is produced by the addition polymerization of 1,1difluoroethene $\left(\mathrm{CH}_{2}=\mathrm{CF}_{2}\right)$, also known as vinylidene fluoride (VF2). The homopolymer is characterized by alternating carbon-hydrogen bonds with carbon-fluorine bonds. The structure of PVDF homopolymer is typically regular; however, some variability related to chain branching, head-to-head molecular formation and tail-to-tail molecular formation will exist depending on polymerization method and reactant products $\operatorname{chosen}^{18}$. The polymer contains about $59-60 \%$ fluorine and approximately 3\% hydrogen by weight. PVDF hompolymers are semicrystalline with 35 to $70 \%$ crystallinity, depending on the above variables, and the processing conditions and methods used ${ }^{18,19}$.

Vinylidene fluoride-based copolymers with low HFP content (5-15\%mol HFP ${ }^{4,}{ }^{20}$ ), typically called flexible PVDF, have become the products of choice in many applications that were formerly PVDF homopolymer ${ }^{21}$. These copolymers have also replaced other fluoropolymers or metals in the chemical process industry where PVDF homopolymer had limitations in impact strength and elongation that prevented its use ${ }^{20}$. The main producers of 
PVDF and flexible PVDF are Solvay-Solexis with their Solef ${ }^{\circledR}$ and Hylar ${ }^{\circledR}$ products, Arkema (previously known as Elf Atochem or Atofina) with their Kynar ${ }^{\circledR}$ and KynarFlex ${ }^{\circledR}$ products, and the Japanese company Kureha with its $\mathrm{KF}{ }^{\circledR}$ product.

A second type of VF2/HFP copolymers with HFP content higher than 19-20\% are amorphous and are used as elastomers. DuPont was the first to introduce VF2/HFP elastomers in 1957 under the Viton ${ }^{\circledR}$ trademark $^{22}$. In 1958 , the 3M Company commercialized Fluorel ${ }^{\circledR}$. Later, Ausimont ${ }^{*}$, and Daikin produced their Tecnoflon ${ }^{\circledR}$ and Daiel ${ }^{\circledR}$ products respectively ${ }^{4}$.

There are two distinct manufacturing processes for the production of PVDF and flexible PVDF: the aqueous emulsion polymerization process and the aqueous suspension polymerization process. The suspension process is used by Solvay-Solexis (Solef ${ }^{\circledR}$ product) and by Kureha Company while the emulsion is adopted by Arkema and Solvay-Solexis (Hylar ${ }^{\circledR}$ product) ${ }^{23}$. Usually the suspension process produces larger particles than the emulsion polymerization process. On the other hand, only aqueous emulsion technique is used for the high HFP-content copolymers $^{6,22,24,25}$, because of their tacky nature ${ }^{26}$.

\subsubsection{Microstructural Analysis using NMR Spectroscopy}

Microstructure analysis of PVDF and VF2/HFP copolymers has been the focus of a large number of publications. In fact, the determination of the composition and microstructure of VF2/HFP copolymers was one of the earliest applications of high-resolution F-19 NMR to fluoropolymers $^{27,} 28$. This early work was done at $40 \mathrm{MHz}$, and has been followed by other

\footnotetext{
* In May 2002, Solvay Chemicals International absorbed Ausimont S.A. and the fluoropolymer section of Solvay changed to Solavy-Solexis Fluoropolymers.
} 
studies at higher magnetic fields, which showed a better resolution and revealed additional microstructure details ${ }^{29-34}$.

For VF2/HFP copolymers, the presence of two adjacent HFP units is completely

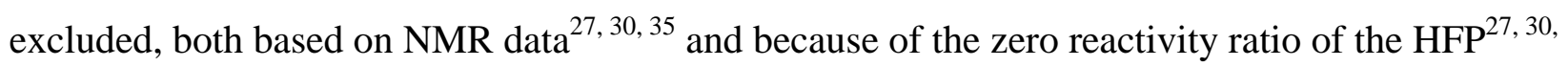
35 . Therefore, the maximum theoretical HFP content in any VF2/HFP copolymer is 50 mol\%. In addition, as mentioned before, the copolymer becomes completely amorphous when the HFP content is higher than $19-20$ mol\%. Therefore, any composition from $19-20$ mol\% to 50 mol\% can be considered theoretically as an elastomer. However, because of the increase of the glass transition temperature of the copolymer with HFP content (Fig. 3), most of the commercial VF2/HFP elastomers contain around 22 mol\% HFP, a composition that represents the best compromise between the requirements of a low glass transition temperature and a fully amorphous polymer. Finally, the above discussion is only applicable to free-radical polymerization at normal polymerization conditions, since poly(hexafluoropropylene) can be produced under “exotic” conditions (high pressure and temperature or special electron beam irradiation $)^{36}$. In addition, telomerization of HFP can be carried out at high temperature in the presence of $\alpha, \omega$-diiodoperfluorobutane by step-growth polymerization ${ }^{37-39}$. 


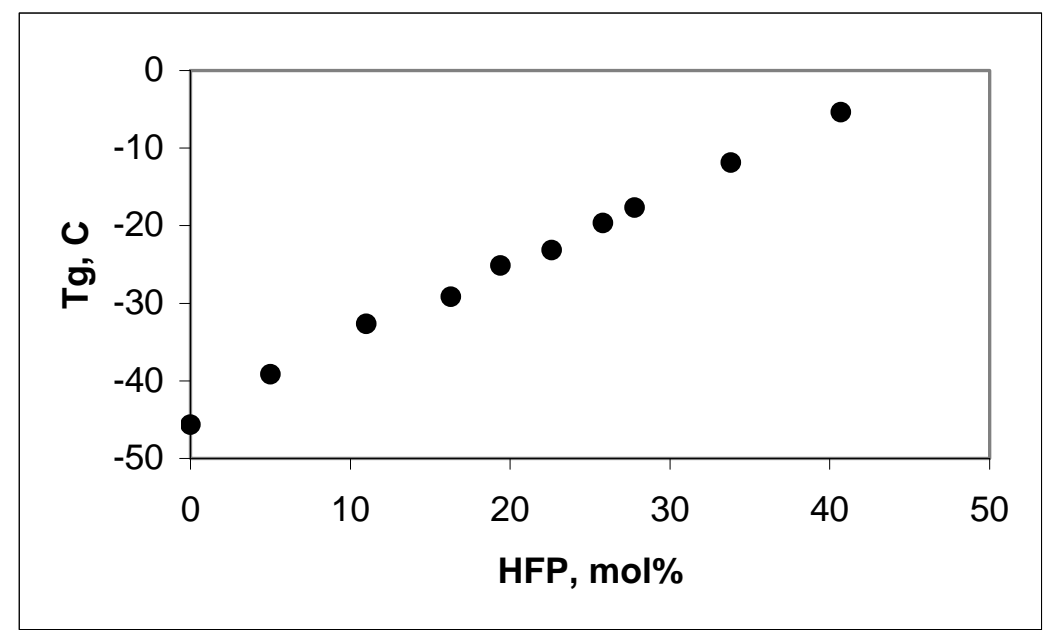

Figure 3: Effect of HFP content on the glass transition temperature of VF2/HFP copolymer ${ }^{40}$

\subsubsection{Solubility of PVDF and VF2/HFP copolymers in $\mathrm{CO}_{2}$}

Poly(vinylidene fluoride) is not soluble in $\mathrm{scCO}_{2}$ under practical conditions. In fact, highmolecular weight PVDF is only soluble in $\mathrm{scCO}_{2}$ at pressure higher than 1500 bar and above 120 ${ }^{\circ} \mathrm{C}^{41}$. However, the incorporation of HFP in the backbone increases the free volume that promotes facile interactions between solvents and the polymer segments, and hence increases the solubility. Fluorel, 3M/Dyneon VF2/HFP elastomer, with a weight-average molecular weight of 85,000 and $22 \mathrm{~mol} \%$ HFP was soluble in $\mathrm{scCO}_{2}$ at cloud-point pressures less than $1000 \mathrm{bar}^{41}$. The cloud-point pressure of Fluorel decreases with temperature and is only 400 bar at $0{ }^{\circ} \mathrm{C}^{41-44}$. The presence of acetone in $\mathrm{CO}_{2}$ greatly reduces the cloud point pressure of Fluorel by more than 300 bars. For only $16 \mathrm{wt} \%$ of acetone in $\mathrm{CO}_{2}$, Fluorel becomes completely soluble at only 40 bar at $25{ }^{\circ} \mathrm{C}^{45}$.

On the contrary, Viton A, DuPont-Dow VF2/HFP elastomer, with the same HFP content as Fluorel, was not soluble in $\mathrm{CO}_{2}$ even at pressures of $2200 \mathrm{bar}^{45}$. This behavior was attributed 
to different chain-end groups or additives in Viton A. In two other experiments, Viton A was first washed with $\mathrm{HCl}$ and water and then was dissolved in acetone and filtered. Even with these two different pre-treatments Viton A still did not dissolve in pure $\mathrm{CO}_{2}$. In addition, Viton A did not dissolve in $\mathrm{CO}_{2}$ with 24.9 wt\% acetone, which was puzzling since Viton A did dissolve in pure acetone at room temperature.

\subsection{References}

1. Association of Plastics Manufacturers, Annual Report; 2006.

2. $\quad$ British Patent \#: 465,520 (Farbenindustrie, I. G.). 1937.

3. Plunkett, R. J. US Patent \#: 2,230,654 (Kinetic Chemicals Inc.). 1941.

4. $\quad$ Ameduri, B.; Boutevin, B.; Kostov, G. Progress in Polymer Science 2001, 26, (1), 105187.

5. Dolbier, W. R. Journal of Fluorine Chemistry 2005, 126, (2), 157-163

6. Logothetis, A. L. Progress in Polymer Science 1989, 14, (2), 251-296.

7. Ameduri, B.; Boutevin, B. Journal of Fluorine Chemistry 2000, 104, (1), 53-62.

8. $\quad$ Odian, G., Principles of Polymerization. 4th ed.; John Wiley \& Sons Inc: 2004.

9. Painter, P. C.; Coleman, M. M., Fundamentals of Polymer Science: An Introductory Text. 2nd ed.; CRC Press: 1998.

10. Billmeyer, F. W. J., Textbook of Polymer Science. John Wiley \& Sons, Inc.: New York, 1962. 
11. S. Angus, B. A., K.M. de Reuck, International Thermodynamic Tables of the Fluid State. Carbon Dioxide. Pergamon Press: Oxford, 1976.

12. R. Span, W. W. Journal of Physical and Chemical Reference Data 1996, 25, (6), 15091596.

13. Darr, J. A.; Poliakoff, M. Chemical Reviews 1999, 99, (2), 495-542.

14. Guan, Z.; Combes, J. R.; Menceloglu, Y. Z.; DeSimone, J. M. Macromolecules 1993, 26, (11), 2663-9.

15. Bunyard, W. C.; Kadla, J. F.; DeSimone, J. M. Journal of the American Chemical Society 2001, 123, (30), 7199-7206.

16. Charpentier, P. A.; DeSimone, J. M.; Roberts, G. W. Chemical Engineering Science 2000, 55, (22), 5341-5349.

17. Manivannan, G.; P.Sawan, S., The supercritical state, in Supercritical Fluid Cleaning: Fundamentals, Technology and Applications. Noyes Publications: Westwood, NJ, 1998; p 1-21.

18. Scheirs, J., Modern Fluoropolymers: High Performance Polymers for Diverse Applications. John Wiley \& Sons, Ltd.: 1997.

19. Drobny, J. G., Technology of Fluoropolymers. CRC Press: 2001.

20. Solef \& Hylar PVDF: Design and Processing Guide (www.Solvaysolexis.com/static/wma/pdf/9/2/2/3/br_Solef_Hylar.pdf). 
21. Robinson, D.; Seiler, D. A., Modifications of PVDF resins leading to new fabrication opportunities with improved service life. In Managing Corrosion with Plastics NACE Proceedings, 1991; Vol. 10 (22), pp 1-14.

22. Dixon, S.; Rexford, D. R.; Rugg, J. S. Industrial and Engineering Chemistry 1957, 49, (10), 1687-1690.

23. Office for Official Publications of the European Communities. Document no.: 302M2690-Solvay/Montedison-Ausimont Merger Procedure. (http://ec.europa.eu/comm/competition/mergers/cases/decisions/m2690_en.pdf),

24. Apostolo, M.; Arcella, V.; Storti, G.; Morbidelli, M. Macromolecules 1999, 32, (4), 9891003.

25. Arnold, R. G.; Barney, A. L.; Thompson, D. C. Rubber Chemistry and Technology 1973, 46, (3), 619-52.

26. Stevens, M. P., Polymer Chemistry: An Introduction. 3rd ed.; Oxford University Press: New York, 1999.

27. Ferguson, R. C. Journal of the American Chemical Society 1960, 82, (10), 2416-2418.

28. Ferguson, R. C. Kautschuk und Gummi 1965, 18, (11), 723-728.

29. Russo, S.; Behari, K.; Chengji, S.; Pianca, M.; Barchiesi, E.; Moggi, G. Polymer 1993, 34, (22), 4777-81.

30. Pianca, M.; Bonardelli, P.; Tato, M.; Cirillo, G.; Moggi, G. Polymer 1987, 28, (2), 224230. 
31. Brame, E. G.; Yeager, F. W. Analytical Chemistry 1976, 48, (4), 709-711.

32. Dec, S. F.; Wind, R. A.; Maciel, G. E. Macromolecules 1987, 20, (11), 2754-2761.

33. Monti, G. A.; Harris, R. K. Magnetic Resonance in Chemistry 1998, 36, (12), 892-900.

34. Isbester, P. K.; Brandt, J. L.; Kestner, T. A.; Munson, E. J. Macromolecules 1998, 31, (23), 8192-8200.

35. Schmiegel, W. W. Angewandte Makromolekulare Chemie 1979, 76-7, (Mar), 39-65.

36. Wall, L. A., Fluoropolymers. Wiley, John \& Sons: New York, 1972.

37. Tortelli, V.; Tonelli, C. Journal of Fluorine Chemistry 1990, 47, (2), 199-217.

38. Baum, K.; Malik, A. A. Journal of Organic Chemistry 1994, 59, (22), 6804-6807.

39. Boulahia, D.; Manseri, A.; Ameduri, B.; Boutevin, B.; Caporiccio, G. Journal of Fluorine Chemistry 1999, 94, (2), 175-182.

40. Bonardelli, P.; Moggi, G.; Turturro, A. Polymer 1986, 27, (6), 905-909.

41. DiNoia, T. P.; Conway, S. E.; Lim, J. S.; McHugh, M. A. Journal of Polymer Science Part B-Polymer Physics 2000, 38, (21), 2832-2840.

42. Rindfleisch, F.; DiNoia, T. P.; McHugh, M. A. Journal of Physical Chemistry 1996, 100, (38), 15581-15587.

43. Mertdogan, C. A.; DiNoia, T. P.; McHugh, M. A. Macromolecules 1997, 30, (24), 75117515.

44. Kirby, C. F.; McHugh, M. A. Chemical Reviews 1999, 99, (2), 565-602. 
45. DiNoia, T. P.; McHugh, M. A.; Cocchiaro, J. E.; Morris, J. B. Waste Management 1998, 17, (2-3), 151-158. 


\section{CHAPTER 3}

\section{Copolymerization of Vinylidene Fluoride with Hexafluoropropylene in Supercritical Carbon Dioxide}

Chapter 5 is a manuscript published in Macromolecules

Ahmed, T. S.; DeSimone, J. M.; Roberts, G. W. Macromolecules 2006, 39, (1), 15-18 


\title{
Copolymerization of Vinylidene Fluoride with Hexafluoropropylene in Supercritical
}

\section{Carbon Dioxide}

\author{
Tamer S. Ahmed ${ }^{1}$, Joseph M. DeSimone ${ }^{1,2}$, and George W. Roberts ${ }^{1, *}$ \\ ${ }^{1}$ Department of Chemical and Biomolecular Engineering, North Carolina State University, Box \\ \#7905, Raleigh, North Carolina 27695-7905 \\ ${ }^{2}$ Department of Chemistry, University of North Carolina-Chapel Hill, Box \# 3290, Chapel Hill, \\ North Carolina 27599-3290
}

\begin{abstract}
Copolymers of vinylidene fluoride with hexafluoropropylene (HFP) have been synthesized in supercritical carbon dioxide using perfluoro butyryl peroxide initiator. The experiments were done at $35{ }^{\circ} \mathrm{C}$ with either 310 or 415 bars total pressure. Three feed compositions were used (30, 50, and 64.5 mole\% HFP), using the same initial total monomer concentration (1.52 mole/L) and two different initial initiator concentrations $\left(1.52 \times 10^{-3}\right.$ and $\left.3.16 \times 10^{-3} \mathrm{~mole} / \mathrm{L}\right)$. Depending on the initial monomer ratio and reaction pressure, the polymerization can proceed heterogeneously, homogenously, or heterogeneously initially, becoming homogenous with increasing reaction time. Reaction pressure impacts both the copolymer molecular weights and effective reactivity ratios.
\end{abstract}

\footnotetext{
* To whom correspondence should be addressed. Tel: +1-919-515-7328; Fax: +1-919-515-3465; E-mail address: groberts@eos.ncsu.edu
} 


\subsection{Introduction}

Supercritical carbon dioxide $\left(\mathrm{scCO}_{2}\right)$ has been used as a medium for a wide range of chain-growth polymerizations. This research is the subject of several reviews ${ }^{1-6}$. The startup of a commercial facility to produce various grades of Teflon ${ }^{\circledR}$ in $\mathrm{scCO}_{2}$ underscores the potential industrial importance of this technology $y^{7,8}$.

The vast majority of the polymerizations that have been studied in $\mathrm{scCO}_{2}$ are heterogeneous ${ }^{1}$. Only a few homogeneous polymerizations have been reported ${ }^{9-11}$. Nevertheless, the behavior of polymerizations in $\mathrm{scCO}_{2}$, and the differences between heterogeneous and homogeneous polymerization, remain poorly understood. In this communication, we report the behavior of a copolymerization that can be tuned to proceed either homogeneously or heterogeneously, depending on total monomer concentration, comonomer ratio, and pressure.

Copolymers of vinylidene fluoride (VF2) with hexafluoropropylene (HFP) are important commercial fluoropolymers ${ }^{12}$. When the HFP content is lower than $19-20$ mol\%, the copolymers are thermoplastic and semicrystalline, while for higher HFP contents, the copolymers are amorphous and elastomeric ${ }^{13,14}$. Most commercial poly(VF2-co-HFP) elastomers contain around 22 mole\% $\mathrm{HFP}^{15}$, a composition that represents the best compromise between a low $\mathrm{T}_{\mathrm{g}}$ and a fully amorphous polymer.

Copolymers of VF2 with HFP are produced commercially by suspension and emulsion polymerization in water ${ }^{16}$. Both processes generate large quantities of wastewater and require large quantities of energy to isolate the polymer in dry form. In addition, some processes may involve the use of ammonium perfluorooctanoate surfactants, which are environmentally 
suspect ${ }^{17}$. Polymerization in supercritical carbon dioxide $\left(\mathrm{scCO}_{2}\right)$ offers a green alternative for these challenges.

The solubility of poly(VF2-co-HFP) copolymers in $\mathrm{scCO}_{2}$ changes with copolymer composition $^{18,19}$. Low HFP-content copolymers are not soluble at reasonable pressures, and must be synthesized in $\mathrm{scCO}_{2}$ via precipitation polymerization. High-HFP-content copolymers are soluble in $\mathrm{CO}_{2}$, and can be synthesized using solution polymerization. For intermediate compositions, the copolymer can be synthesized by either technique. The synthesis of poly(VF2co-HFP) copolymers in $\mathrm{scCO}_{2}$ by both precipitation and solution polymerization is reported herein.

\subsection{Experimental}

Copolymerizations were done in a batch reactor, using perfluoro butyryl peroxide initiator $\left(\left[\mathrm{C}_{3} \mathrm{~F}_{7} \mathrm{COO}\right]_{2}, \mathrm{PBP}\right)$ at $35{ }^{\circ} \mathrm{C}$, pressures of 310-415 bars, and a reaction time of 2 hrs.

3.2.1 Materials. Both VF2 (98\% min) and HFP (99\% min) were obtained from SynQuest Laboratories while SFC grade $\mathrm{CO}_{2}$ (99.998\%) was obtained from National Specialty Gases. All other chemicals were obtained from Fisher Scientific Co. and used as received.

3.2.2 PBP Initiator Synthesis. The PBP initiator was synthesized in Freon ${ }^{\circledR} 113$ as previously reported $^{20}$. All manipulations of the initiator were performed in a $\mathrm{NaCl} /$ ice bath, and the final product was stored under dry ice. The iodine titration technique, ASTM Method E 29891, was utilized to determine the concentration of the initiator in the solution. The half-life decomposition temperature of PBP at $35^{\circ} \mathrm{C}$ in Freon ${ }^{\circledR} 113$ reported to be $1.1 \mathrm{hr}^{20}$. 
3.2.3 Experimental Apparatus. Polymerizations were conducted in an $80-\mathrm{mL}$ cell equipped with a magnetically driven stirrer, thermocouple, rupture disc and a sapphire window that permitted visual observation of the reaction mixture.

3.2.4 Polymerization Procedure. In a typical experiment, the reactor was purged three times with $\mathrm{sCO}_{2}$ to remove oxygen. The monomers were charged in the desired ratio (HFP first, then VF2) using an Isco 260D syringe pump. Enough liquid $\mathrm{CO}_{2}$ to form a homogeneous solution then was added. The reactor was heated to the desired temperature and the initiator solution was transferred to a small tube connected to the $\mathrm{CO}_{2}$ line under argon purge. Finally, the reactor was pressurized to the final pressure with additional $\mathrm{CO}_{2}$, while simultaneously introducing the initiator to the reactor. A 260D Isco dual-cylinder syringe pump was used to maintain the pressure constant by continuously feeding $\mathrm{scCO}_{2}$ to make up for the monomer that was consumed. Temperature control was $\pm 0.2{ }^{\circ} \mathrm{C}$, while pressure control was \pm 1 bar. After the reaction, pressure was released slowly through a glass flask with its mouth covered with double layers of filter paper to retain any copolymer carried in the released stream. Finally, the residual monomers and initiator were extracted three times from the copolymer using $\mathrm{scCO}_{2}$.

3.2.5 Copolymer Characterization. The copolymer composition was determined by both fluorine elemental analysis and by ${ }^{19} \mathrm{~F}$ NMR. The NMR spectra were recorded on a Bruker Avance spectrometer operating at 470.6 $\mathrm{MHz}$ using acetone-d6 (99.9\%) as the solvent and against trichlorofluoroethane $\left(\mathrm{CFCl}_{3}\right)$ as the internal reference. NMR parameters were $5 \mathrm{~s}$ pulse delay, $0.164 \mathrm{~s}$ acquisition time, and 32k data points. The shift assignments used are those reported in the literature ${ }^{21,22}$. The copolymer composition from NMR was calculated using Eq. 1. 


$$
\% \text { mole } \mathrm{HFP}=\frac{I_{\mathrm{CE}_{3}} / 3}{I_{\mathrm{CE}_{2}} / 2}
$$

$I_{C_{3}}$ is the area of the integral corresponding to the fluorine of the $\mathrm{CF}_{3}$ group in the HFP (corresponding to peaks located at ca. $-70.4,-75.0$, and $-75.3 \mathrm{ppm}$ ); $I_{\mathrm{CF}_{2}}$ is the area of the integral corresponding to the fluorine of the $\mathrm{CF}_{2}$ in both HFP and VF2 (corresponding to peaks from ca. -91.4 to $-119 \mathrm{ppm})$.

The molecular weight was determined through both size exclusion chromatography (SEC) and end-group analysis using NMR. The SEC analyses were performed in tetrahydrofuran at $30{ }^{\circ} \mathrm{C}$ against polystyrene standards with a refractive index detector. Number average molecular weight $\left(\mathrm{M}_{\mathrm{n}}\right)$ was calculated via Eq. 2 from the NMR end-group analyses.

$$
M_{n-N M R}=\frac{I_{C \underline{F}_{2}} / 2}{\left(I_{-80 p p m} / 3\right) / 2}\left[150 F_{H F P}+64\left(1-F_{H F P}\right)\right]
$$

Here, $I_{-80 \text { ppm }}$ is the area of the integral corresponding to the fluorine of the $\mathrm{CF}_{3}$ group in the $\mathrm{C}_{3} \mathrm{~F}_{7}$ of the initiator; $F_{H F P}$ is the mole fraction of HFP in the copolymer.

The main assumption in this procedure is that the polymeric radicals terminate by combination. This accounts for the factor of 2 in the denominator of Eq. 2. This assumption is consistent with PDI values around 1.5 observed in this work and previously for the homopolymerization of VF2 in $\mathrm{CO}_{2}{ }^{23}$. Another assumption is that chain transfer reactions are unimportant. The chain transfer reactions that can occur in $\mathrm{CO}_{2}$ are either to monomer, polymer, or initiator. There is no evidence from the literature that chain transfer to monomer can occur to VF2 (chain transfer to HFP is unlikely since it contains only C-F bonds). However, chain transfer to polymer may be important at high monomer concentrations ${ }^{23}$. 


\subsection{Results and Discussion}

Figure 1(a) shows a typical cloud-point pressure curve for a polymer in a supercritical fluid $^{1}$ while Figure 1(b) shows the cloud-point pressure curve for Tecnoflon ${ }^{\circledR}$ N215 copolymer (Solvay-Solexis) in $\mathrm{scCO}_{2}$ (23.1 mole\% HFP by NMR (21.3 \pm 1.28 mole \% HFP by elemental fluorine analysis), $\mathrm{M}_{\mathrm{n}}=54 \mathrm{kDa}$, and PDI= 2.62).
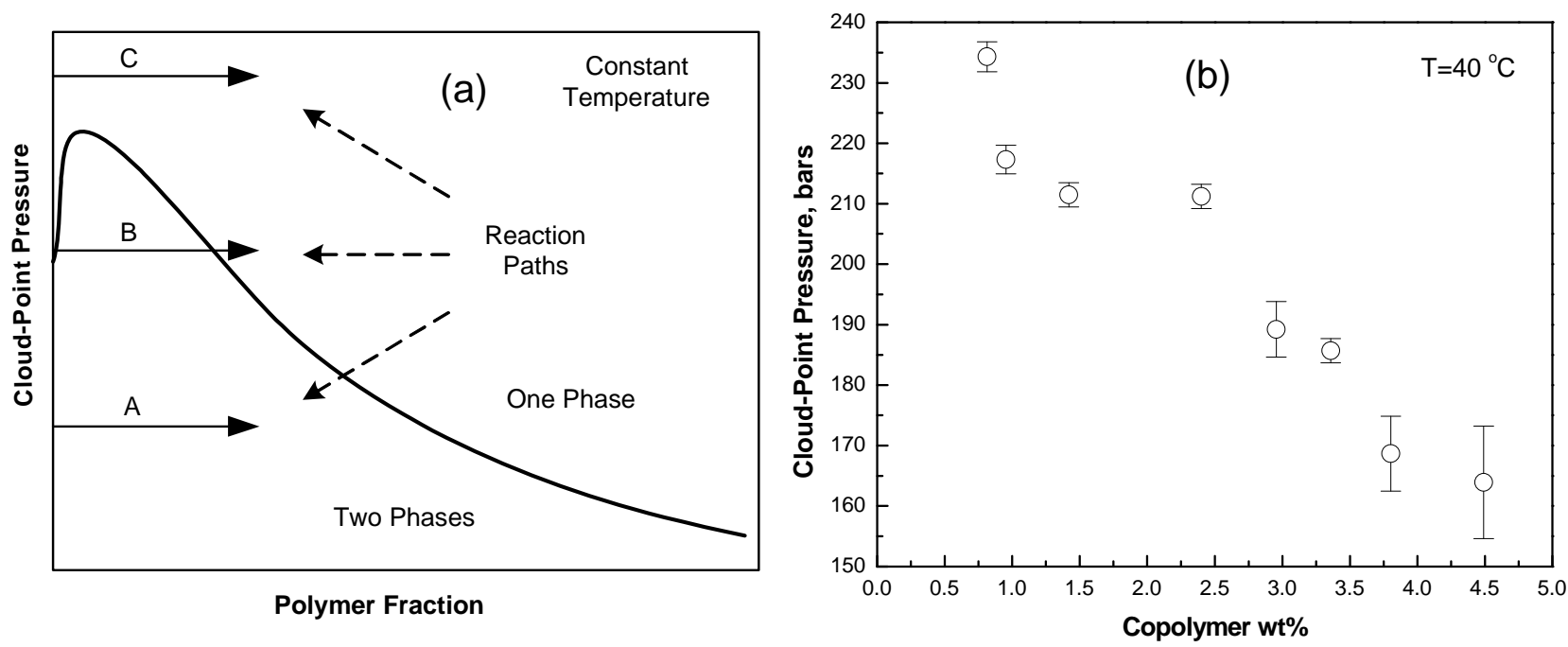

Figure 1: (a) Qualitative Cloud-point pressure diagram of a polymer-supercritical fluid ${ }^{1}$. The horizontal lines represent the reaction paths with respect to the corresponding polymer cloud-point pressure curve. (b) Cloudpoint pressure curve of Tecnoflon N215 in $\mathrm{scCO}_{2}{ }^{19}$.

In a batch polymerization experiment, the pressure and temperature are constant while polymer fraction increases with time. Therefore, a horizontal line on Figure 1(a) represents the reaction path of a typical experiment. A path far below the cloud-point curve will give rise to a completely heterogeneous reaction. Such a path is shown as Line A. If the reaction path is above the highest point in the curve, as shown by Line C, the reaction will be homogenous. Finally, as shown by Line B, a reaction path can begin below the cloud-point pressure curve and cross it as the reaction proceeds. In this case, the copolymer will precipitate from the solution initially but 
will re-dissolve when the cloud-point curve is crossed. The polymerization begins as a precipitation polymerization, but finishes as a homogeneous polymerization.

Table 1 shows the reaction conditions and the results of the copolymerization of VF2 with HFP at $35{ }^{\circ} \mathrm{C}$ with either 310 or 415 bars total pressure. Three comonomer feed compositions were used (30, 50, and 64.5 mole\% HFP), using the same initial total monomer concentration (1.52 mole/L) and two different initial initiator concentrations $\left(1.52 \times 10^{-3}\right.$ and $3.16 \times 10^{-3}$ mole/L). The reaction time was 2 hours. The yield (mass of copolymer produced/total mass of monomers fed) ranged from about 6.5 to $16.1 \%$. This low yield was deliberate, in order to limit copolymer composition drift, and is the result of both the short reaction time and the low temperature. With one exception, the copolymer composition obtained via fluorine elemental analysis is higher than the NMR result. Nevertheless, the two compositions are close enough to lend confidence to the results. The values of $\mathrm{M}_{\mathrm{n}}$ from NMR end-group analysis and SEC agree reasonably well. This may be somewhat fortuitous since the SEC results are relative to polystyrene standards, and in view of the assumptions in the NMR end-group calculation.

For the experiments with 30-mole\% HFP comonomer feed composition, the HFP content of the copolymer was about 8.0-9.4 mole\% by NMR analysis. This copolymer is essentially insoluble in $\mathrm{scCO}_{2}$ at the pressures of these experiments, i.e., the cloud point pressure curve is much higher than the reaction path. The copolymer precipitated at the start of the reaction, and the reaction medium remained visually heterogeneous throughout the reaction. This behavior is consistent with the reaction path shown as Line A in Figure 1(a).

For the 64.5-mole\% HFP comonomer feed composition, the copolymer contained about 23.8-25.4 mole\% HFP by NMR analysis. The cloud point pressure curve for this copolymer 
composition is substantially lower than the curve shown in Figure 1(b), The copolymer remained in solution throughout the reaction, consistent with the reaction path shown as Line C.

Finally, the experiments with 50 mole\% HFP comonomer feed composition produced a copolymer containing about 15.8-18.1 mole\% HFP by NMR analysis. At both pressures, the reaction was heterogeneous initially but became homogeneous as the reaction proceeded, consistent with Line B in Figure 1. 
Table 1: Copolymerization of VF2 with HFP at $35^{\circ} \mathrm{C}, 2$ h. reaction time, and 1.52 mole/L total initial monomer concentration

\begin{tabular}{|c|c|c|c|c|c|c|c|c|c|c|}
\hline$\underset{\#}{\text { Run }}$ & $\begin{array}{c}\mathrm{P} \\
\text { (bars) }\end{array}$ & $\begin{array}{c}\text { Comonomer } \\
\text { feed } \\
\text { composition } \\
\text { (\%mole HFP) }\end{array}$ & $\begin{array}{c}\mathrm{I}_{0}, 10^{-3} \\
\text { (mole/L) }\end{array}$ & $\begin{array}{l}\text { Yield } \\
(\mathrm{wt} \%)\end{array}$ & $\begin{array}{c}\text { Copolymer } \\
\text { Composition } \\
\text { from NMR } \\
\text { (\%mole HFP) }\end{array}$ & $\begin{array}{c}\text { Copolymer } \\
\text { Composition } \\
\text { from Fluorine } \\
\text { analysis } \\
\text { (\%mole HFP) }\end{array}$ & $\begin{array}{l}\mathrm{M}_{\mathrm{n}-\mathrm{SEC}} \\
(\mathrm{kDa})\end{array}$ & $\begin{array}{c}\mathrm{M}_{\mathrm{n}-\mathrm{NMR}} \\
(\mathrm{kDa})\end{array}$ & PDI & Reaction Medium \\
\hline 1 & 310 & 30.0 & 1.52 & 10.0 & 9.2 & $10.48 \pm 1.00$ & 21.1 & 18.2 & 1.56 & Completely heterogeneous \\
\hline 2 & 310 & 30.0 & 3.16 & 14.6 & 9.4 & $10.86 \pm 1.01$ & 16.6 & 14.2 & 1.56 & Completely heterogeneous \\
\hline 3 & 415 & 30.1 & 1.52 & 10.7 & 8.0 & $9.23 \pm 0.97$ & 24.2 & 19.7 & 1.53 & Completely heterogeneous \\
\hline 4 & 415 & 30.1 & 3.16 & 16.1 & 8.5 & $9.60 \pm 0.98$ & 19.3 & 15.8 & 1.50 & Completely heterogeneous \\
\hline 5 & 310 & 50.0 & 1.52 & 9.8 & 17.6 & $20.69 \pm 1.26$ & 20.0 & 20.6 & 1.68 & Completely heterogeneous \\
\hline 6 & 310 & 50.0 & 3.16 & 13.7 & 18.1 & $19.95 \pm 1.24$ & 14.0 & 15.5 & 1.63 & $\begin{array}{l}\text { Heterogeneous initially but became } \\
\text { more homogeneous with time }\end{array}$ \\
\hline 7 & 415 & 50.0 & 1.52 & 11.5 & 17.3 & $19.23 \pm 1.22$ & 27.2 & 26.0 & 1.58 & $\begin{array}{l}\text { Heterogeneous initially but became } \\
\text { more homogeneous with time }\end{array}$ \\
\hline 8 & 415 & 50.0 & 3.16 & 15.6 & 15.8 & $19.21 \pm 1.22$ & 15.8 & 14.7 & 1.61 & $\begin{array}{l}\text { Heterogeneous initially, } \\
\text { homogeneous finally }\end{array}$ \\
\hline 9 & 310 & 64.4 & 1.52 & 6.5 & 25.3 & $24.26 \pm 1.36$ & 15.9 & 16.1 & 1.63 & Completely homogeneous \\
\hline 10 & 310 & 64.6 & 3.16 & 10.5 & 25.1 & $28.86 \pm 1.48$ & 11.1 & 11.1 & 1.45 & Completely homogeneous \\
\hline 11 & 415 & 64.6 & 1.52 & 7.3 & 23.8 & $26.46 \pm 1.42$ & 17.9 & 15.5 & 1.60 & Completely homogeneous \\
\hline 12 & 415 & 64.4 & 3.16 & 9.3 & 25.4 & $28.25 \pm 1.47$ & 12.2 & 10.4 & 1.58 & Completely homogeneous \\
\hline
\end{tabular}


Since the copolymer composition drift was small in these experiments, an estimate of the "effective" reactivity ratios of both comonomers in $\mathrm{scCO}_{2}$ at $35{ }^{\circ} \mathrm{C}$ could be obtained. The values of the effective reactivity ratios with the 95\% confidence limits are:

$r_{H F P}=0 \pm 0.08$ and $r_{V F 2}=3.61 \pm 0.71$ at 310 bars

$r_{H F P}=0.09 \pm 0.09$ and $r_{V F 2}=4.67 \pm 0.77$ at 415 bars

These reactivity ratios were calculated using nonlinear regression of the copolymerization equation $^{24}$ using DataFit ${ }^{\circledR}$ with the Levenberg-Marquardt algorithm ${ }^{25}$. The average comonomer mixture composition during reaction and the final copolymer composition, obtained by averaging the NMR and fluorine elemental analysis results, were used in the calculation. In performing these calculations, it was assumed that the polymerization took place in solution. No attempt was made to account for any polymerization that might have taken place in the polymer particles, as this would have required knowledge of the concentrations of the monomers in the polymer phase. The same approach was used in the literature to calculate the reactivity ratios from emulsion polymerization data ${ }^{26,27}$. In view of this approximation, the reactivity ratios calculated can be considered as "effective" reactivity ratios. The calculated ratios lie within the range of published values: $2.45^{26}$ to $6.7^{27}$ for VF2 and $0^{21,28,29}$ to $0.12^{30}$ for HFP.

The SEC results in Table 1 show that the molecular weight increases with pressure and decreases as the HFP/VF2 feed ratio increases. Since HFP cannot homopolymerize at these reaction conditions, only VF2 units can add to growing chains ending with an HFP. Consequently, as the HFP/VF2 feed ratio increases, the probability of termination relative to propagation increases, which leads to a decrease in the molecular weight. 
Current research involves continuous copolymerization of VF2 with HFP using a stirred tank reactor (CSTR). For certain copolymer compositions, it will be possible to carry out the copolymerization either homogeneously or heterogeneously. This will allow a quantitative evaluation of the effect of precipitation on copolymer properties and reaction kinetics.

\subsection{Conclusions}

The copolymerization of VF2 with HFP in $\mathrm{scCO}_{2}$ was carried out using PBP initiator over a range of pressures and monomer ratios. Depending on the initial monomer ratio and reaction pressure, the reaction can proceed heterogeneously, homogenously, or heterogeneously initially, becoming homogenous with increasing reaction time. Reaction pressure impacts both the copolymer molecular weights and copolymer composition.

\subsection{Acknowledgement}

This material is based upon work supported by the STC Program of the National Science Foundation under Agreement No. CHE-9876674.

\subsection{Supporting Information Available}

A representative ${ }^{19} \mathrm{~F}$ NMR spectrum and the experimental details of the cloud-point measurements are available in the supporting materials. This material is available free of charge via the Internet at http://pubs.acs.org.

\subsection{References}

(1) Beckman, E. J. Journal of Supercritical Fluids 2004, 28, 121-191.

(2) Canelas, D. A.; DeSimone, J. M. Advances in Polymer Science 1997, 133, 103-140.

(3) DeSimone, J. M. Science 2002, 297, 799-803.

(4) Kendall, J. L.; Canelas, D. A.; Young, J. L.; DeSimone, J. M. Chemical Reviews 1999, 99, 543-563. 
(5) Cooper, A. I. Journal of Materials Chemistry 2000, 10, 207-234.

(6) Kennedy, K. A.; Roberts, G. W.; DeSimone, J. M. Advances in Polymer Science 2005, 175, 329-346.

(7) McCoy, M. Chemical \& Engineering News 1999, 77.

(8) DuPont, Wilmington, DE: Press Release: DuPont introduces fluoropolymers made with supercritical $\mathrm{CO}_{2}$ technology, 2002.

(9) Desimone, J. M.; Guan, Z.; Elsbernd, C. S. Science 1992, 257, 945-947.

(10) Michel, U.; Resnick, P.; Kipp, B.; DeSimone, J. M. Macromolecules 2003, 36, 71077113.

(11) Shiho, H.; Desimone, J. M. Journal of Polymer Science, Part A: Polymer Chemistry 2000, 38, 1139-1145.

(12) Scheirs, J. Modern Fluoropolymers: High Performance Polymers for Diverse Applications; John Wiley \& Sons, Ltd., 1997.

(13) Apostolo, M.; Arcella, V.; Storti, G.; Morbidelli, M. Macromolecules 1999, 32, 9891003.

(14) Ajroldi, G.; Pianca, M.; Fumagalli, M.; Moggi, G. Polymer 1989, 30, 2180-2187.

(15) Kaspar, H.; 3M Company: Personal Communication, 2003.

(16) Kaspar, H.; Hintzer, K.; Dewitte, G.; Schwertfeger, W.; (3M Innovative Properties Company): US Patent \#:6,693,152, 2004.

(17) U.S. Environmental Protection Agency, Preliminary Risk Assessment Report, April 2003.

(18) DiNoia, T. P.; Conway, S. E.; Lim, J. S.; McHugh, M. A. Journal of Polymer Science Part B-Polymer Physics 2000, 38, 2832-2840.

(19) Supporting Materials.

(20) Zhao, C. X.; Zhou, R. M.; Pan, H. Q.; Jin, X. S.; Qu, Y. L.; Wu, C. J.; Jiang, X. K. Journal of Organic Chemistry 1982, 47, 2009-2013.

(21) Pianca, M.; Bonardelli, P.; Tato, M.; Cirillo, G.; Moggi, G. Polymer 1987, 28, 224-230.

(22) Isbester, P. K.; Brandt, J. L.; Kestner, T. A.; Munson, E. J. Macromolecules 1998, 31, 8192-8200. 
(23) Saraf, M. K.; Gerard, S.; Wojcinski, L. M.; Charpentier, P. A.; DeSimone, J. M.; Roberts, G. W. Macromolecules 2002, 35, 7976-7985.

(24) Odian, G. Principles of Polymerization, 3rd ed.; John Wiley \& Sons Inc: New York, 1991.

(25) Marquardt, D. W. SLAM Journal of Applied Mathematics 1963, 11, 431-441.

(26) Bonardelli, P.; Moggi, G.; Turturro, A. Polymer 1986, 27, 905-909.

(27) Moggi, G.; Bonardelli, P.; Russo, S. 6th Conv. Ital. Sci. Macromol., [Atti], 1983, 2, 405408.

(28) Schmiegel, W. W. Angewandte Makromolekulare Chemie 1979, 76-7, 39-65.

(29) Ferguson, R. C. Journal of the American Chemical Society 1960, 82, 2416-2418.

(30) Gelin, M.-P.; Ameduri, B. Journal of Fluorine Chemistry 2005, 126, 577-585. 


\section{CHAPTER 4}

Continuous Copolymerization of Vinylidene Fluoride with Hexafluoropropylene in Supercritical Carbon Dioxide: Low Hexafluoropropylene-Content Semicrystalline Copolymers

Chapter 4 is a manuscript accepted for publication in Macromolecules

October 2007 


\title{
Continuous Copolymerization of Vinylidene Fluoride with Hexafluoropropylene in
}

\section{Supercritical Carbon Dioxide: Low Hexafluoropropylene-Content Semicrystalline}

\section{Copolymers}

\author{
Tamer S. Ahmed ${ }^{l}$, Joseph M. DeSimone ${ }^{1,2}$, and George W. Roberts ${ }^{1, *}$ \\ ${ }^{1}$ Department of Chemical and Biomolecular Engineering, North Carolina State University, Box \\ \# 7905, Raleigh, North Carolina 27695-7905 \\ ${ }^{2}$ Department of Chemistry, University of North Carolina at Chapel Hill, Box \# 3290, Chapel \\ Hill, North Carolina 27599-3290
}

\begin{abstract}
The copolymerization of vinylidene fluoride with hexafluoropropylene (HFP) was carried out in supercritical carbon dioxide by precipitation polymerization using a continuous stirred tank reactor. Copolymers with ca. $10 \mathrm{~mol} \%$ HFP were synthesized at $40{ }^{\circ} \mathrm{C}$ and pressures in the range of 207-400 bar using perfluorobutyryl peroxide as the free radical initiator. The effects of feed monomer concentration and reaction pressure were both explored at otherwise constant conditions. The rate of polymerization $\left(R_{p}\right)$ and the number-average molecular weight $\left(M_{n}\right)$ increased linearly with the total monomer concentration up to about $6 \mathrm{M}$, the highest concentration investigated. The $R_{p}$ and the $M_{n}$ were strongly influenced by the reaction pressure. An $80 \%$ increase in both $R_{p}$ and $M_{n}$ was observed when the reaction pressure rose from 207 to 400 bar. The molecular weight distributions of the synthesized copolymer showed a long tail that

\footnotetext{
${ }^{*}$ To whom correspondence should be addressed. Tel: +1-919-515-7328; Fax: +1-919-515-3465; E-mail address: groberts@eos.ncsu.edu
} 
increased to become a broad shoulder with increasing total monomer concentration. This tail increased with increasing reaction pressure. The data suggest that the carbon-dioxide-rich fluid phase is the primary locus of polymerization.

\subsection{Introduction}

Supercritical carbon dioxide $\left(\mathrm{scCO}_{2}\right)$ has emerged as a sustainable alternative to the aqueous and organic media often used in polymer processes ${ }^{1-6}$. Supercritical carbon dioxide has unique properties including being environmentally benign, nontoxic, nonflammable, and inexpensive. Using $\mathrm{scCO}_{2}$ as a polymerization medium allows additional benefits, including inertness to free radicals $^{7}$ which eliminates chain transfer to solvent, and high initiator efficiencies $^{7-9}$ as a result of its low viscosity.

From an industrial perspective, $\mathrm{scCO}_{2}$-based polymerization processes have many advantages over aqueous suspension and emulsion polymerization processes. First, the elimination of water and organic solvents results in the reduction of undesirable effluents from the processes. Second, the production of the polymer directly in a dry form potentially eliminates many separation steps, and reduces the extensive energy consumption associated with drying. Third, it may be possible to polymerize monomers that are difficult or even impossible to be used in an aqueous system, either because of their solubility or because of their reaction with water. Fourth, the polymers produced may have some distinct physical or structural properties, which may facilitate processing or open new applications for such polymers ${ }^{10,11}$. Finally, the use of perfluorooctanoic acid (PFOA), also known as "C8", is eliminated. $\mathrm{C} 8$ is a perfluorinated anionic surfactant used as a dispersing agent in the water-based polymerization and 
copolymerization of many fluoropolymers $^{12}$. In 2003, the United States Environmental Protection Agency (EPA) released a preliminary risk assessment of C8 ${ }^{12}$. In January 2006, the EPA initiated a program to reduce PFOA releases and its presence in products by $95 \%$ by no later than 2010, and to work toward eliminating these sources of exposure no later than $2015^{13}$. To date, no viable, alternative dispersing agent has been publicly identified. Polymerization in $\mathrm{scCO}_{2}$ is the only known alternative that can eliminate the need for $\mathrm{C} 8$ in the manufacturing process $^{6}$.

A continuous process is essential to harness the advantages of using $\mathrm{scCO}_{2}$ as a polymerization medium for high-volume polymers. Relative to batch polymerization, continuous processing requires smaller equipment per unit of throughput, and therefore is less capital intensive. This is a particular advantage for processes involving $\mathrm{scCO}_{2}$ because relatively high pressures are intrinsic. In addition, continuous polymerization leads to a more uniform product because of the time-invariant reaction conditions, and to easier recycle of unreacted monomer and $\mathrm{CO}_{2}$. Moreover, continuous operation offers the potential to couple polymerization with continuous downstream processing. Finally, the startup of a commercial facility to produce various grades of Teflon ${ }^{\circledR}$ in $\mathrm{scCO}_{2}$ by continuous polymerization underscores the potential industrial importance of the $\mathrm{CO}_{2}$-based continuous polymerization technology ${ }^{14,15}$.

Vinylidene fluoride-based copolymers, typically called PVDF copolymers, have become the products of choice in many applications ${ }^{16}$. Copolymers of vinylidene fluoride (VF2) with hexafluoropropylene (HFP) are one of the most important PVDF copolymers ${ }^{17}$. Low HFPcontent copolymers, also known as "Flexible PVDF", are thermoplastic and semicrystalline copolymers containing about 5-15 mole $\% \mathrm{HFP}^{18,}{ }^{19}$. They are used in many applications 
including tubing, valves and fittings, cable and wire jacketing, lithium-ion batteries, and membranes. When the HFP content is higher than 19-20 mol\%, the copolymers are amorphous and elastomeric ${ }^{20,21}$. The maximum theoretical incorporation of HFP in the copolymer is restricted only to $50 \mathrm{~mole} \%$ because of the reactivity ratio of $\mathrm{HFP}^{22-24}$. Most commercial poly(VF2-co-HFP) elastomers contain around $22 \mathrm{~mole} \% \mathrm{HFP}^{25}$, a composition that represents the best compromise between a low glass transition temperature $\left(T_{g}\right)$ and a fully amorphous polymer. The high HFP-content copolymers are used mainly as polymer processing aids to improve extrusion, blow molding, and rotomolding, and in sealing such as in gaskets, and Orings. Figure 1 shows different poly(VF2-co-HFP) copolymers with their main manufacturers and trade names.

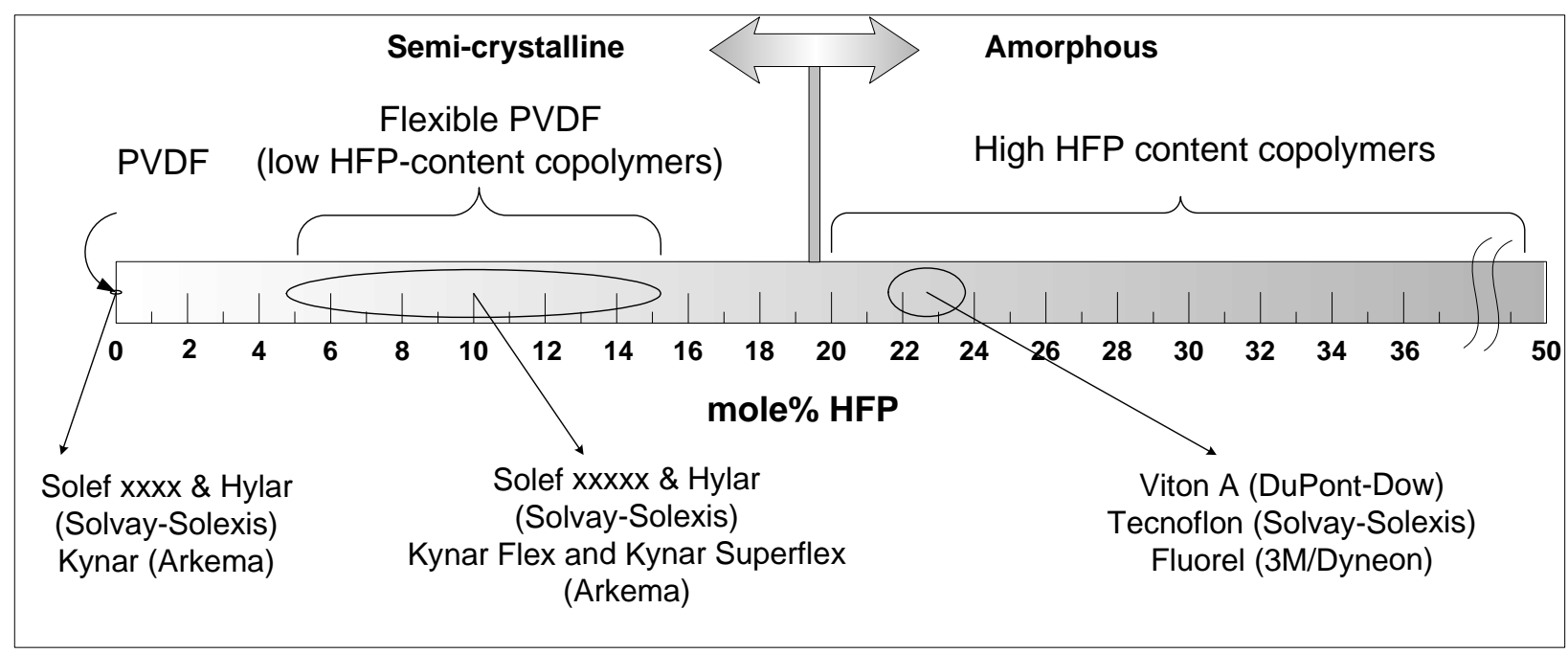

Figure 1: Different copolymers of VF2 with HFP with their main manufacturers and trade names

Low HFP-content copolymers are typically manufactured commercially by aqueous emulsion or suspension polymerization ${ }^{26,27}$. Only aqueous emulsion techniques are used for the 
high HFP-content copolymers ${ }^{20,28-30}$ because of their tacky nature ${ }^{31}$. Both processes generate a large quantity of wastewater, and require a substantial quantity of energy for drying the polymer product, if drying is required ${ }^{32}$. As a result of the ionic end groups from the initiator (ammonium or potassium persulfate or the redox persulfate/sodium sulfite system ${ }^{30}$ ), PVDF copolymers tend to be self emulsified for low solids-content polymerizations ${ }^{33}$. However, for high solids-content processes, PFOA salts are used ${ }^{34}$. Polymerization in $\mathrm{scCO}_{2}$ offers a "green" solution to the above problems and challenges.

Our research group has reported a process for the continuous precipitation polymerization of chain-growth polymers in $\mathrm{scCO}_{2}$ using a continuous stirred-tank reactor (CSTR) ${ }^{35}$. This process has been applied for the continuous precipitation polymerization of both poly(vinylidene fluoride) $(\mathrm{PVDF})^{9,35-37}$ and poly(acrylic acid) $(\mathrm{PAA})^{10,38,39}$. Here, we report the continuous precipitation copolymerization of low HFP-content copolymers in $\mathrm{scCO}_{2}$ using a modified version of the above-mentioned continuous process. To date, copolymerization of VF2 with HFP in $\mathrm{scCO}_{2}$ has been reported only in batch reactors ${ }^{40-42}$. This paper will underline the advantages of $\mathrm{scCO}_{2}$ as a polymerization medium. In addition, it is the first report of any continuous copolymerization in $\mathrm{scCO}_{2}$.

\subsection{Experimental Section}

4.2.1 Materials. Carbon dioxide ( $\mathrm{SFC}$ grade, $99.998 \%, \max \mathrm{O}_{2}=2 \mathrm{ppm}$ ), nitrogen ( 99.999\%), and argon (99.9999\%) were obtained from National Specialty Gases. To completely remove $\mathrm{O}_{2}$ from the $\mathrm{CO}_{2}$, three Alltech High Pressure Oxy-Trap traps were installed in parallel between the $\mathrm{CO}_{2}$ tanks and $\mathrm{CO}_{2}$ pump. Both VF2 ( $99 \%$ min, balance $\left.\mathrm{N}_{2}\right)$ and $\mathrm{HFP}(99 \%$ min, 
4.2.2 Initiator Synthesis. Perfluorobutyryl peroxide $\left(\left[\mathrm{C}_{3} \mathrm{~F}_{7} \mathrm{COO}\right]_{2}, \mathrm{PBP}\right)$ was the initiator used in the copolymerization. The initiator was synthesized in 1,1,2-trichloro-1,2,2trifluoroethane (HPLC-grade, 99.8\%, Freon 113) as previously reported ${ }^{43}$. All manipulations of the initiator were performed in a $\mathrm{NaCl} /$ ice bath, and the final product was stored under dry ice. The iodine titration technique, ASTM Method E 298-91, was utilized to determine the concentration of the initiator in the solution. The initiator concentration was reduced to $0.03 \mathrm{M}$ by dilution with additional Freon 113 before use. After a second titration, the initiator solution was introduced to the initiator pump under an argon blanket. The half-life of PBP in Freon 113 is about 35 min at $40{ }^{\circ} \mathrm{C}^{43}$.

4.2.3 Polymerization Apparatus and Procedure. Figure 2 shows a schematic of the continuous polymerization system. There are some differences between the current system and the one reported previously by us for the continuous polymerization of $\mathrm{PVDF}^{9,35-37}$ and $\mathrm{PAA}^{10}$, 38, 39. The reactor (C) is a $100 \mathrm{~mL}$ high-pressure autoclave (Autoclave Engineers) with a magnetically-driven agitator (Autoclave Engineers). Three downward-pumping impellers were mounted on the shaft of the agitator. The current autoclave has the same length to diameter ratio as our previously reported $800 \mathrm{~mL}$ reactor used for $\mathrm{PVDF}^{9,35-37}$ and $\mathrm{PAA}^{10,38,39}$. The smaller reactor allowed more flexibility in the range of reaction parameters that could be reached. In addition, a continuous syringe pump (A2, 260D Isco dual-cylinder syringe pump) was used to inject nitrogen into the effluent from the reactor $(\mathrm{C})$. The nitrogen was cooled in a dry 
ice/acetone bath before it was injected. The role of nitrogen was: 1) to increase the flow rate after the reactor to prevent settling of the effluent copolymer particles in the lines; 2) to minimize the solubility of low-molecular-weight or high-HFP polymeric chains in the effluent mixture, thereby ensuring that all the synthesized copolymer was collected in the high pressure filters (F1, F2, F3); and 3) to quench the reaction, dilute the effluent mixture, and decrease the residence time in the filters to minimize post polymerization. This was especially important since PBP is a very active initiator ${ }^{43}$. In addition, two heat exchangers were used: one at the reactor exit (E1) and one after the filters (E2). A cold refrigerant $\left(-10^{\circ} \mathrm{C}\right)$ was used in these heat exchangers to stop the initiator decomposition and minimize post polymerization.

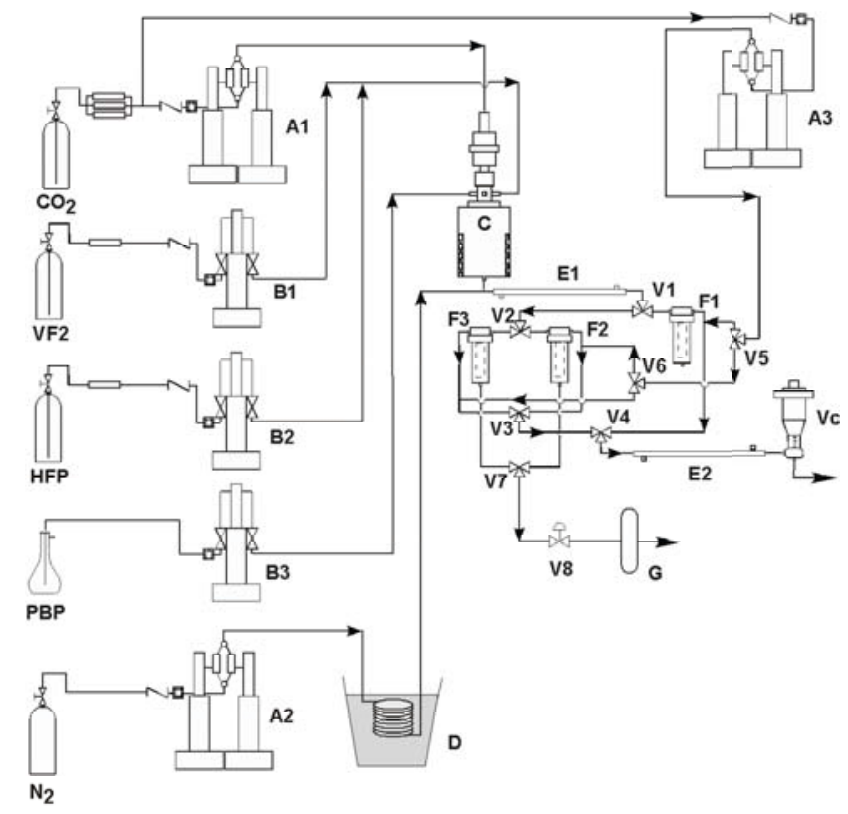

Figure 2: CSTR polymerization system: A1,A2,A3- Continuous syringe pumps; B1,B2,B3- Syringe pumps; CAutoclave with stirrer; D- Dry ice/Acetone bath; E1,E2- Heat exchangers; F1- Steady state filter; F2,F3- Non steady state filters; G- Bag filter; V1,V2,V3,V4,V5,V6,V7- 3-Way valves; V8- 2-Way valve; Vc- Control valve 
In a typical experiment for copolymerization of VF2 and HFP, the reactor (C) and the high pressure filters $(\mathrm{F} 1, \mathrm{~F} 2, \& \mathrm{~F} 3)$ were purged three times with $\mathrm{CO}_{2}$ at 1500 psig to remove oxygen. Syringe pumps A1, A2, B1 (cooled by $15{ }^{\circ} \mathrm{C}$ refrigerant), B2 (cooled by $15{ }^{\circ} \mathrm{C}$ refrigerant), and $\mathrm{B} 3$ (cooled by $-7.5{ }^{\circ} \mathrm{C}$ refrigerant) were used to feed $\mathrm{CO}_{2}, \mathrm{~N}_{2}, \mathrm{VF} 2$, $\mathrm{HFP}$, and PBP solution in Freon 113, respectively. The speed of the reactor agitator was fixed to $2000 \mathrm{rpm}$ in all the runs. The outlet stream from the reactor, consisting of the copolymer particles, $\mathrm{CO}_{2}$, and unreacted VF2, HFP, and PBP, plus the nitrogen that was injected into the effluent from the reactor, was directed by a three-way ball valve (V1) into either the steady-state filter housing (F1) or to another three-way ball valve (V2) to direct the stream to the unsteady-state filters (F2 and F3). All filters contained $1 \mu \mathrm{m}$ stainless steel mesh filter media. During startup of the reactor, before steady state was attained, the copolymer was collected in one of the unsteady state filters (e.g. F2) until it was filled (indicated by the pressure drop across the filter). Valves V2 and V3 then were switched, so that the copolymer was being collected in the other unsteady state filter (F3). The particles then were discharged from filter $\mathrm{F} 2$ by back-flushing with a $\mathrm{CO}_{2}$ stream from a continuous syringe pump (A3). Valves V7 and V8 then were actuated sequentially, with V7 being closed before V8 was opened, allowing the copolymer particles to flow from the highpressure filter housing into the bag filter, which was at ambient pressure. When filter F3 was nearly full, the stream leaving the reactor was switched back to filter F2, and filter F3 was emptied using the same technique. This procedure was repeated until the reactor had reached steady state after five average residence times. The stream leaving the reactor then was switched to the steady state filter (F1) using valves V1 and V4. The copolymer particles were collected for at least one residence time. The system was then shut down and the residual monomers and 
initiator were extracted three times from the copolymer using $\mathrm{CO}_{2}$ from the continuous syringe pump A3. Finally, the filter F1 was opened and the copolymer was collected and weighed. In all the experiments, a homopolymerization of VF2 was first carried out in the reactor, followed by flushing the reactor with $\mathrm{CO}_{2}$. This was followed by baking the PVDF layer at $100{ }^{\circ} \mathrm{C}$ for $30 \mathrm{~min}$ before starting the copolymerization of VF2 and HFP. Finally, the monomer densities that were used to calculate the flow rates out of the pump were corrected for pressure using the HakinsonBrobst-Thomson method ${ }^{44,45}$.

4.2.4 Characterization. Gel permeation chromatography (GPC) was performed at $40{ }^{\circ} \mathrm{C}$ using a Waters 150-CV GPC equipped with Waters Styragel HR 5, 4, 2, and 0.5 columns and a refractive index detector. Tetrahydrofuran was used as the mobile phase, and polystyrene standards were used for the calibration.

Hydrogen, carbon, and fluorine elemental analysis were performed by Atlantic Microlab, Inc. Hydrogen and carbon analyses were performed by combustion using automatic analyzers while fluorine analyses was performed by flask combustion followed by ion chromatography.

Fluorine-19 Nuclear Magnetic Resonance $\left({ }^{19} \mathrm{~F}\right.$ NMR) spectra were recorded on a Bruker Avance spectrometer operating at $470.6 \mathrm{MHz}$ using acetone-d6 (99.9\%) as the solvent and trichlorofluoroethane $\left(\mathrm{CFCl}_{3}\right)$ as the internal reference. Pulse delay was $5 \mathrm{~s}$ and 256-1024 scans were used.

Differential scanning calorimetry (DSC) measurements were conducted using a TAInstruments DSC-Q100. The instrument was calibrated using indium. Samples were heated to $200{ }^{\circ} \mathrm{C}$ at a heating rate of $10{ }^{\circ} \mathrm{C} / \mathrm{min}$. The glass transition temperature, the melting temperature, and the heat of melting were determined from the second heating curve. 
Finally, a thermal gravimetric analyzer (TA Instruments TGA-Q500) was used for determining the decomposition temperature $\left(T_{d}\right)$ of the synthesized copolymers. Samples were heated to $850{ }^{\circ} \mathrm{C}$ at a heating rate of $10{ }^{\circ} \mathrm{C} / \mathrm{min}$ in nitrogen atmosphere. The $T_{d}$ was determined for $1 \mathrm{wt} \%$ polymer loss.

\subsection{Results and Discussion}

4.3.1 Copolymerization Studies. Experiments were carried out to study the effect of total inlet monomer concentration $\left(\left[M_{T}\right]_{i n}\right)$ and reaction pressure $(P)$ on the copolymerization of VF2 with HFP at $40{ }^{\circ} \mathrm{C}$ in the CSTR using PBP initiator. The results of these experiments are shown in Tables 1 and 2, respectively. The copolymers were characterized for their composition, average molecular weight, and molecular weight distribution (MWD). The molar rate of polymerization $\left(R_{P}\right)$ and the total monomer concentration in the reactor and in the outlet stream $\left(\left[M_{T}\right]_{\text {out }}\right)$ were calculated from the amount of polymer collected $\left(m_{p}\right)$ during the time of steady state collection ( $\left.\Delta t_{s s}\right)$ using Eqs. (1) and (2) respectively. Equations (1) and (2) are based on the assumption that the reactor behaved as an ideal CSTR.

$$
\begin{gathered}
R_{P}=\frac{m_{p}}{V_{R} \Delta t_{s s}\left(\left[F_{H F P}\right] M_{H F P}+\left(1-\left[F_{H F P}\right]\right) M_{V F 2}\right)} \\
{\left[M_{T}\right]_{\text {out }}=\left[M_{T}\right]_{\text {in }}-R_{P} \tau}
\end{gathered}
$$

where: $V_{R}$ is the reactor volume $(100 \mathrm{~mL}) ;\left[F_{H F P}\right]$ is the mole fraction of HFP in the copolymer; $M_{H F P}$ and $M_{V F 2}$ are the molecular weights of HFP and VF2 respectively; $\tau$ is the average residence time in the reactor. 
Table 1: Effect of inlet total monomer concentration on the continuous copolymerization of VF2 with HFP in $\mathrm{scCO}_{2}{ }^{(a)}$

\begin{tabular}{cccccccccc}
\hline & {$\left[M_{T}\right]_{\text {in }}$} & {$\left[F_{H F P}\right]_{F^{-} E A}$} & {$\left[F_{H F P}\right]_{N M R}$} & $\left(R_{P}\right)_{a v}$ & {$\left[M_{T}\right]_{\text {out }-a v}$} & $X$ & $\left(M_{n}\right)_{\mathrm{NMR}}$ & $\left(M_{n}\right)_{\mathrm{GPC}}$ & \\
& $(\mathrm{mol} / \mathrm{L})$ & $(\mathrm{mol} \%)^{(b)}$ & $(\mathrm{mol} \%)^{(c)}$ & $\left(10^{-2} \mathrm{~mol} / \mathrm{L} \cdot \mathrm{min}\right)^{(d)}$ & $\begin{array}{c}\text { PDI } \\
(\mathrm{mol} / \mathrm{L})^{(e)}\end{array}$ & $\%^{(f)}$ & $(\mathrm{kDa})^{(g)}$ & $(\mathrm{kDa})$ & \\
\hline 1 & 1.96 & 10.74 & 8.75 & 0.83 & 1.80 & 8.16 & 19.0 & 19.7 & 1.5 \\
2 & 2.61 & 10.65 & 8.60 & 1.34 & 2.34 & 10.34 & 29.8 & 31.1 & 1.7 \\
3 & 3.92 & 9.97 & 8.42 & 1.94 & 3.53 & 9.95 & 43.4 & 43.8 & 3.2 \\
4 & 5.23 & 9.77 & 8.13 & 2.38 & 4.76 & 8.99 & 60.2 & 56.8 & 3.6 \\
5 & 6.53 & 9.55 & 7.73 & 3.04 & 5.92 & 9.34 & 87.0 & 79.2 & 3.9 \\
\hline
\end{tabular}

${ }^{a}$ Reaction conditions: $P=400$ bar; $T=40{ }^{\circ} \mathrm{C} ; \tau=20 \mathrm{~min} ;[]_{\text {in }}=0.003 \mathrm{M}$; HFP/VF2 molar feed ratio $=26.5 / 73.5 .{ }^{b}$ HFP incorporation in the copolymer from fluorine elemental analysis (Eq. 3). ${ }^{c}$ HFP incorporation in the copolymer from NMR (Eq. 4). ${ }^{d}$ Average molar rate of polymerization based on the average of $\left[F_{H F P}\right]_{F-E A}$ and $\left[F_{H F P}\right]_{N M R}$ (Eq. 1). ${ }^{e}$ Average total monomer concentration inside the reactor and in the effluent based on the average of $\left[F_{H F P}\right]_{F-E A}$ and $\left[F_{H F P}\right]_{N M R}$ (Eq. 2). ${ }^{f}$ Total conversion. ${ }^{g}$ Number-average molecular weight calculated from initiator end-group analysis by NMR (Eq. 5)

Table 2: Effect of reaction pressure on the continuous copolymerization of VF2 with $\mathrm{HFP}$ in $\mathrm{scCO}_{2}{ }^{(a)}$

\begin{tabular}{cccccccccc}
\hline & $P$ & {$\left[F_{H F P}\right]_{F^{-E A}}$} & {$\left[F_{H F P}\right]_{N M R}$} & $\left(R_{P}\right)_{a v}$ & {$\left[M_{T}\right]_{o u t-a v}$} & $X$ & $\left(M_{n}\right)_{N M R}$ & $\left(M_{n}\right)_{G P C}$ & \\
& $($ bar $)$ & $(\mathrm{mol} \%)$ & $(\mathrm{mol} \%)$ & $\left(10^{-2} \mathrm{~mol} / \mathrm{L} \cdot \mathrm{min}\right)$ & $(\mathrm{mol} / \mathrm{L})$ & $\%$ & $(\mathrm{kDa})$ & $(\mathrm{kDa})$ & \\
\hline 4 & 400 & 9.77 & 8.13 & 2.38 & 4.76 & 8.99 & 60.2 & 56.8 & 3.6 \\
6 & 310 & 9.76 & 8.50 & 1.94 & 4.84 & 7.46 & 37.8 & 43.1 & 2.5 \\
7 & 207 & 10.6 & 8.71 & 1.34 & 4.96 & 5.16 & 28.5 & 31.8 & 1.7 \\
\hline
\end{tabular}

${ }^{a} \overline{\text { Reaction conditions: }\left[M_{T}\right]_{i n}=5.23 \mathrm{~mol} / \mathrm{L} ; T=40{ }^{\circ} \mathrm{C} ; \tau=20 \mathrm{~min} ;[\mathrm{I}]_{\mathrm{in}}=0.003 \mathrm{M} ; \mathrm{HFP} / \mathrm{VF} 2 \text { molar feed ratio }}=$ 26.5/73.5.

The copolymer composition was determined by both fluorine elemental analysis and by

${ }^{19}$ F NMR. All elemental analyses were determined on a weight basis with accuracy and precision 
error limits of $\pm 0.3 \mathrm{wt} \%$. The error of the elemental analyses on a mole basis depends on the molecular weight of the analyzed element. Since fluorine has the highest molecular weight of the three elements forming the copolymer (hydrogen, carbon, and fluorine), only fluorine elemental analysis (F-EA) was considered. For $10 \mathrm{~mole} \%$ HFP poly(VF2-co-HFP), the $\pm 0.3 \mathrm{wt} \%$ error limit corresponds to about \pm 1 mole $\%$ HFP. Equation 3 was used to calculate $\left[F_{H F P}\right]_{F-E A}$ (mole fraction HFP in the copolymer from F-EA) from the average of two measurements $\left(W_{F}\right)_{a v}$ (average weight fraction of fluorine in the copolymer).

$$
\left[F_{H F P}\right]_{F-E A}=\frac{19-32\left(W_{F}\right)_{a v}}{43\left(W_{F}\right)_{a v}-38}
$$

A representative ${ }^{19} \mathrm{~F}$ NMR spectrum for poly(VF2-co-HFP) is given in Figure 3. The detailed chemical shifts are available in the literature ${ }^{23,}{ }^{46}$. The ${ }^{19} \mathrm{~F}$ NMR spectrum exhibits various groups of signals; those assigned to VF2 units are centered at -91.4 to $-96.2 \mathrm{ppm}$ for head-to-tail normal additions $\left(-\mathrm{CH}_{2} \mathrm{CF}_{2} \mathrm{CH}_{2} \mathrm{CF}_{2}\right.$-), at -108.6 to -112.3 ppm for $\mathrm{CF}_{2}$ groups adjacent to a HFP unit (- $\left.\mathrm{CH}_{2} \mathrm{CF}_{2} \mathrm{CF}_{2} \mathrm{CF}\left(\mathrm{CF}_{3}\right)-\right)$, and at -113.6 and $-115.9 \mathrm{ppm}$ for the head-tohead reversed addition (- $\mathrm{CH}_{2} \mathrm{CF}_{2} \mathrm{CF}_{2} \mathrm{CH}_{2}$-). Those assigned to HFP units are centered at -70.3 and $-75 \mathrm{ppm}$ for the pendant $\mathrm{CF}_{3}$ group $\left(-\mathrm{CF}_{2} \mathrm{CF}\left(\mathrm{CF}_{3}\right)-\right)$, at -115.3 and -117 to $-119.2 \mathrm{ppm}$ for $\mathrm{CF}_{2}\left(-\mathrm{CF}_{2} \mathrm{CF}\left(\mathrm{CF}_{3}\right)-\right)$ group, and at -181.4 and-184.1 ppm for the $\mathrm{CF}\left(-\mathrm{CF}_{2} \mathrm{CF}\left(\mathrm{CF}_{3}\right)-\right)$ group. Finally, the peaks at ca. $-80 \mathrm{ppm}$ and -126 to $-127 \mathrm{ppm}$ are assigned to the $-\mathrm{CF}_{3}$ and $-\mathrm{CF}_{2}$ fluorine in the initiator respectively. 


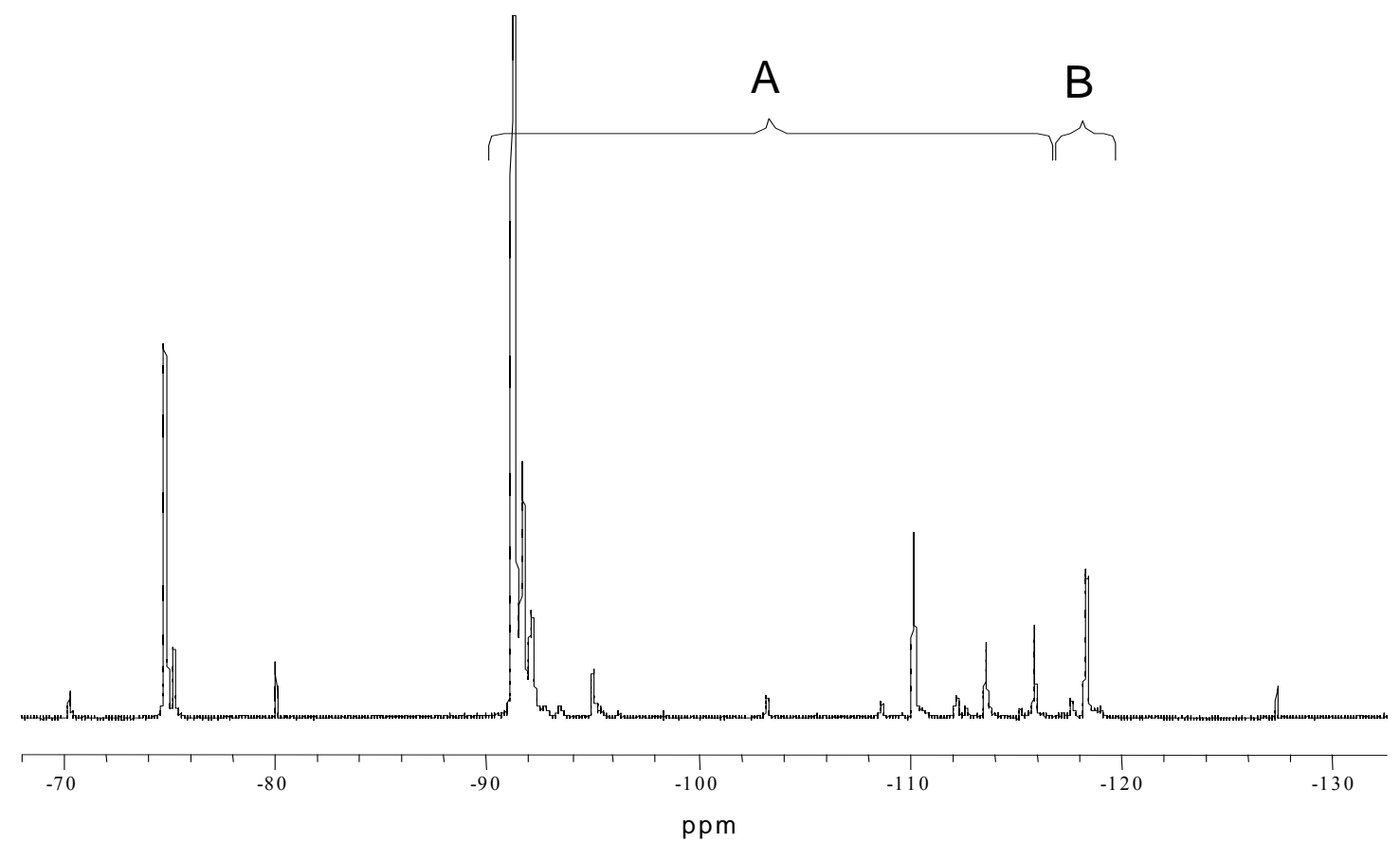

Figure 3: ${ }^{19} \mathrm{~F}$ NMR spectrum for 10 mole\% HFP Poly(VF2-co-HFP) collected in experiment \# 3 in Table 1. The resonances due to the CF fluorine in HFP at ca. $-181 \mathrm{ppm}$ to $-184 \mathrm{ppm}$ are not shown. Copolymer compositions were determined by the integrals of the peaks in the A \& B regions.

The mole fraction of HFP monomer in the copolymer $\left(\left[F_{H F P}\right]_{N M R}\right)$ was calculated from Eq. 4, where $A$ corresponds to the sum of the areas of the NMR signals from -91.4 to -115.9 ppm and $B$ corresponds to the sum of the areas of the NMR signals from -117 to $-119.2 \mathrm{ppm}$ (Fig. 3). The copolymer composition obtained via fluorine elemental analysis was always higher than that from NMR. Nevertheless, the two compositions are close enough to lend confidence to the results.

$$
\left[F_{H F P}\right]_{N M R}=\frac{B}{A+B}
$$

In addition, NMR was used to determine the number-average molecular weight $\left(M_{n}\right)$ from end-group analysis of the initiator. Usually, end-group analysis is accurate only for $M_{n}$ 
below $20-30 \mathrm{kDa}^{47}$. However, this rule of thumb is primarily applied to hydrocarbon polymers. For fluorinated polymers, since fluorine has a much higher molecular weight than hydrogen, the average molecular weight of the repeating unit in the polymer is higher than for hydrocarbon polymers. Consequently, for the same degree of polymerization, end-group analysis can be used to determine $M_{n}$ to higher values for fluorinated polymers than for hydrocarbon polymers. The number-average molecular weight using the end-group analysis of the PBP initiator by NMR $\left(\left(M_{n}\right)_{N M R}\right)$ was calculated via Eq. 5.

$$
\left(M_{n}\right)_{N M R}=\frac{\left(I_{C F 2}\right) / 2}{\left(I_{-80 p p m} / 3\right) / 2}\left[150\left[F_{H F P}\right]_{N M R}+64\left(1-\left[F_{H F P}\right]_{N M R}\right)\right]
$$

Here, $I_{-80 p p m}$ is the integral of the signal corresponding to the fluorine of the $\mathrm{CF}_{3}$ group in the $\mathrm{C}_{3} \mathrm{~F}_{7}$ of the PBP initiator located at ca. $-80 \mathrm{ppm} ; I_{C F 2}$ is the sum of the integrals for the signals corresponding to the fluorine in $\mathrm{CF}_{2}$ groups in the copolymer from -91.4 to $-119.2 \mathrm{ppm}(A+B$ in Figure 3).

The main assumption in Eq. 5 is that termination is by combination. This accounts for the factor of $1 / 2$ that multiplies $\left(I_{-80} \mathrm{ppm} / 3\right)$ in the denominator. This assumption is consistent with PDI values around 1.5 observed previously for the homopolymerization of VF2 in $\mathrm{CO}_{2}{ }^{37}$, for the batch copolymerization of VF2 and $\mathrm{HFP}^{40}$, and in this work for low feed monomer concentrations (e.g., experiments 1 and 2 in Table 1). Another assumption is that chain transfer reactions to monomer and initiator are unimportant. There is no evidence from the literature that chain transfer to VF2 can occur, while chain transfer to HFP, PBP, or Freon 113 are unlikely since they do not contain hydrogen. 
Molecular weights were assessed using both GPC and NMR end-group analysis. Both agree reasonably well for low molecular weights. For the high molecular weights, small deviations appear between the molecular weights from GPC and NMR end-group analysis (Table 1). The agreement between the two techniques may be somewhat fortuitous since the GPC results are relative to polystyrene standards, and in view of the assumptions in the NMR endgroup calculation.

4.3.2 Morphology. Figure 4 shows scanning electron micrographs (SEM) for VF2-HFP copolymer collected in experiment $\# 4$ at $40{ }^{\circ} \mathrm{C}$. The particles generally show spherulitic structures with diameters approximately $10-50 \mu \mathrm{m}$. In addition, they show a relatively porous structure that would offer little resistance to transport of small molecules such as monomers or initiator.

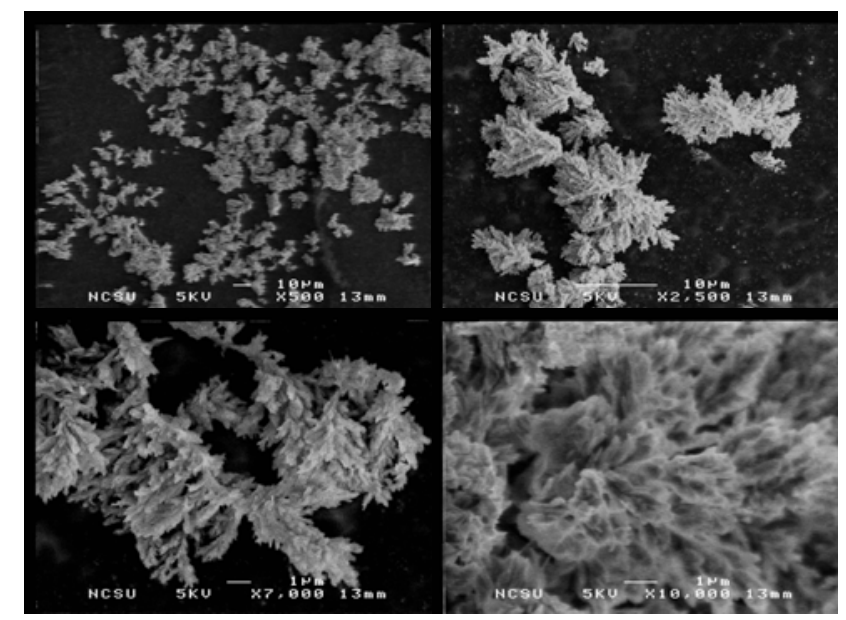

Figure 4: SEM images of VF2-HFP copolymer collected in experiment \#4 in Table 1. Images are with increasing magnification 
4.3.3 Thermal Properties. Table 3 shows the thermal properties for the highest molecular weight copolymer synthesized in this work (Experiment \#5, Table 1). As expected, the introduction of the $-\mathrm{CF}_{3}$ side group arising from $\mathrm{HFP}$ into the backbone of the copolymer raised the glass transition temperature $\left(T_{g}\right)$ compared to PVDF homopolymer (Typical $T_{g}$ for PVDF= $\left.-40{ }^{\circ} \mathrm{C}^{48}\right)$

Table 3: Thermal properties of poly(VF2-co-HFP) synthesized in experiment \#5 in Table 1

\begin{tabular}{ccccc}
\hline & $T_{g}^{(a)}$ & $T_{m}{ }^{(b)}$ & $\Delta H_{m}{ }^{(c)}$ & $T_{d}^{(d)}$ \\
& $\left({ }^{\circ} \mathrm{C}\right)$ & $\left({ }^{\circ} \mathrm{C}\right)$ & $\mathrm{J} / \mathrm{g}$ & $\left({ }^{\circ} \mathrm{C}\right)$ \\
\hline Experiment \# 5 & -31.4 & 120.7 & 16.5 & 418.1
\end{tabular}

(a) Glass transition temperature; ${ }^{\left({ }^{b}\right)}$ Melt peak temperature; ${ }^{(c)}$ Heat of melting; ${ }^{(d)} 1 \mathrm{w} t \%$ decomposition temperature in nitrogen

4.3.4 Effect of Total Monomer Concentration. Five experiments were carried out with $\left[M_{T}\right]_{\text {in }}$ varying from 1.96 to $6.53 \mathrm{~mol} / \mathrm{L}$ at otherwise identical conditions. The results are given in Table 1 and Fig. 5(a-d). In a CSTR, the concentration that affects the polymerization is the concentration inside the reactor, which is the same as the effluent concentration $\left(\left[M_{T}\right]_{\text {out }}\right)$. Consequently, the results in Fig 5 are plotted versus the average $\left[M_{T}\right]_{\text {out }}$ from F-EA and NMR. All experiments were run with the same temperature, average residence time $(\tau)$ and feed initiator concentration $\left(\left[I_{\text {in }}\right)\right.$. Therefore, the initiator concentration in CSTR and in the effluent ([I $\left.]_{\text {out }}\right)$ should be the same for each of these experiments (Eq. 6).

$$
[I]_{\text {out }}=\frac{[I]_{\text {in }}}{1+k_{d} \tau}
$$

where: $k_{d}$ is decomposition rate constant of the initiator. 


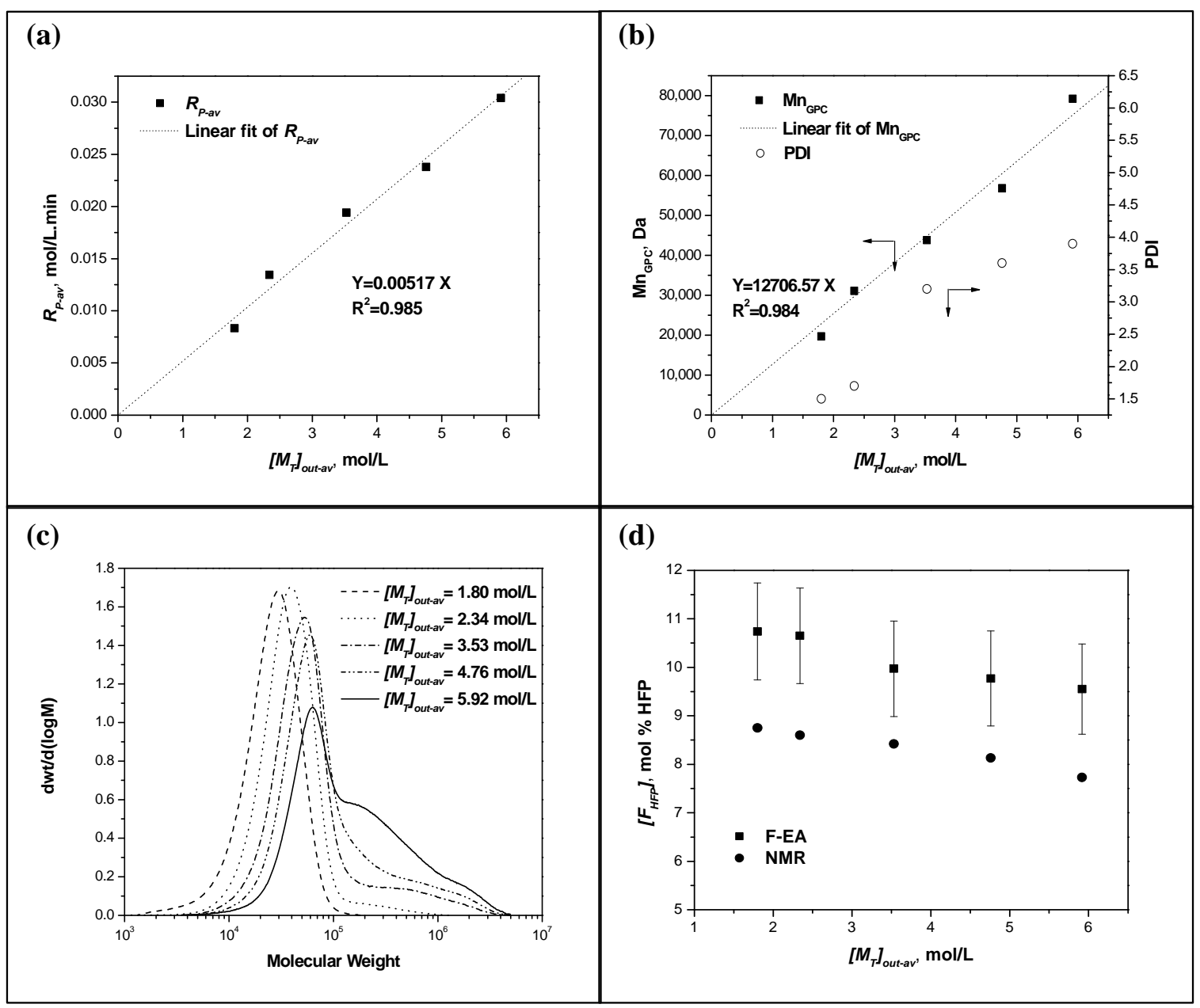

Figure 5: Effect of total monomer concentration on: (a) $R_{P}$; (b) $M_{n}$ and PDI; (c) MWDs ; (d) $\left[F_{H F P}\right]$. Reaction conditions are in Table 1

Figures 5(a) and 5(b) show the effect of $\left[M_{T}\right]_{\text {out }}$ on $R_{P}$ and $\left(M_{n}\right)_{G P C}$ respectively. In both figures, the increase in $\left[M_{T}\right]_{\text {out }}$ results in a linear increase in both $R_{P}$ and $\left(M_{n}\right)_{G P C}$. The dotted lines in Figs. 5(a) and 5(b) represent the best fit of the experimental data by a straight line passing through the origin. The coefficient of determination $\left(\mathrm{R}^{2}\right)$ of the fit is near unity in both figures. The first-order dependence of $R_{P}$ and $M_{n}$ on the monomer concentration is characteristic of a conventional solution polymerization. This behavior is different from what was reported in 
case of the precipitation polymerization of PAA in $\mathrm{scCO}_{2}$, where the order of the polymerization with respect to $\left[M_{T}\right]_{\text {out }}$ was significantly greater than unity for both $R_{P}$ and the viscosity-average molecular weight ${ }^{38}$.

Figures 5(b) (right y-axis) and 5(c) show the polydispersity indices (PDI) and the corresponding molecular weight distributions (MWDs) of the synthesized copolymers, respectively. The increase in $\left[M_{T}\right]_{\text {out }}$ resulted in major changes in the shape of the MWDs. For low $\left[M_{T}\right]_{o u t}$, the distribution is perfectly unimodal with a PDI of 1.5. As $\left[M_{T}\right]_{o u t}$ increases, a long tail develops and increases into a broad shoulder for the highest monomer concentration. This behavior is similar to what was observed in the precipitation polymerization of VF2 in $\mathrm{scCO}_{2}{ }^{37}$. However, the MWDs of PVDF homopolymer showed distinct bimodal MWDs and higher PDIs at lower monomer concentrations.

Finally, Fig. 5(d) shows the effect of total monomer concentration on HFP incorporation into the copolymer. Both fluorine elemental analysis and NMR show a slight decrease in HFP incorporation with increasing total monomer concentration. Since the rate of polymerization increases with total monomer concentration (Fig 5a), the copolymer volume fraction in the CSTR also increases. The decrease in HFP may be connected to this increase in the copolymer solid-content in the CSTR. 


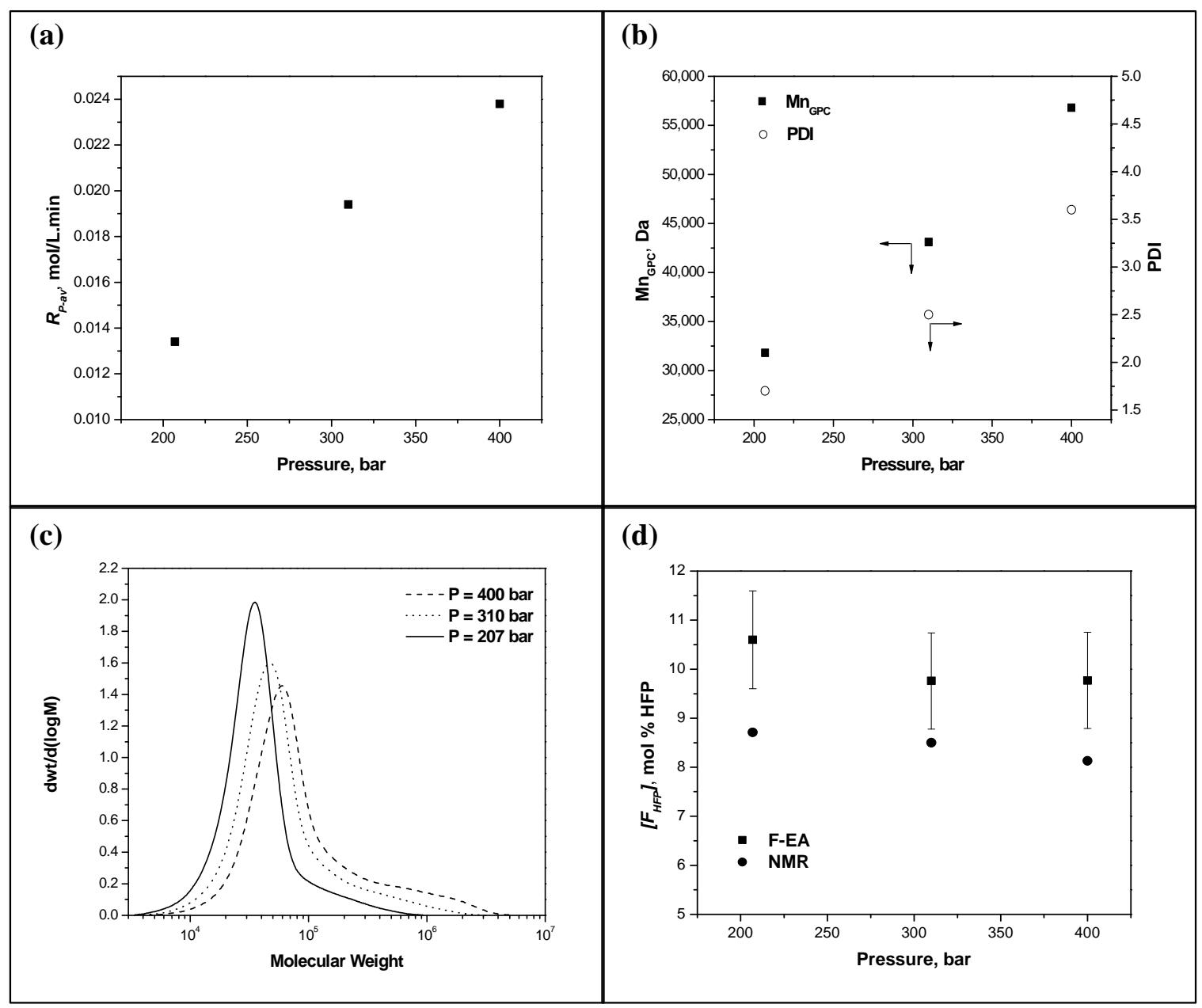

Figure 6: Effect of reaction pressure on: (a) $R_{P}$; (b) $M_{n}$ and PDI; (c) MWDs ; (d) $\left[F_{H F P}\right]$. Reaction conditions are in Table 2

4.3.5 Effect of Reaction Pressure. The effect of pressure was evaluated from 207 to 400 bars at otherwise identical conditions. The results are given in Table 2 and Fig. 6(a-d). The effect of pressure on the monomer densities was taken into account, ensuring that only pressure was affecting the polymerization.

Figures 6(a) and 6(b) show that the reaction pressure has a significant effect on both $R_{P}$ and $\left(M_{n}\right)_{G P C}$. Doubling the pressure results in about an $80 \%$ increase in both $R_{P}$ and $\left(M_{n}\right)_{G P C}$. 
From transition state theory, the effect of pressure on a rate constant can be assessed from Eq. 7. Assuming that the activation volume is constant over the pressure range under consideration, Eq. 7 can be integrated to give Eq. 8 .

$$
\begin{gathered}
\frac{d \ln k}{d P}=-\frac{\Delta V^{*}}{R T} \\
k_{2}=k_{1} \times \exp \left(-\frac{\Delta V^{*}}{R T}\left(P_{2}-P_{1}\right)\right)
\end{gathered}
$$

where: $\Delta V^{*}$ is the activation volume; $R$ is the universal gas constant; $T$ is the temperature; $k_{1}$ and $k_{2}$ are the rate constants at pressures $P_{1}$ and $P_{2}$ respectively.

For typical values of the overall activation volume of polymerization (-0.01 to -0.03 $\mathrm{L} / \mathrm{mol})^{49}$, the maximum increase in the apparent rate constant of polymerization for the pressure range $207-400$ bars is calculated to be only about $25 \%$. Therefore, the observed effect of pressure cannot be explained completely only by the effect of pressure on the reaction rate constants. This issue of pressure dependence is revisited in the final portion of this section.

Figures 6(b) (right y-axis) and 6(c) show the effect of pressure on the PDI and the corresponding MWDs of the synthesized copolymers, respectively. Pressure impacts both the PDI and the MWD significantly. The increase of pressure from 207 to 400 bar results in an increase in the PDI from 1.7 to 3.6, caused by the increase in the tail of the MWD with pressure.

Finally, Fig. 6(d) shows the effect of the pressure on HFP incorporation into the copolymer. Similar to the effect of total monomer concentration, HFP in the copolymer decreases slightly with the increase of pressure and with the increase in the amount of copolymer in the reactor. However, this decrease is within the error of the analysis. 
4.3.6 Copolymerization Reaction Constants. Equations 9 and 10 describe the rate of polymerization and the number-average molecular weight, respectively, for a classical solution polymerization. For a copolymerization at constant temperature and pressure, the copolymerization propagation rate constant $\left(k_{p}\right)$ is a function of the mole fractions of the monomers, and their reactivity ratios. Equation 11 shows the expression for $k_{p}$ in the case of the terminal model ${ }^{47}$. The termination rate is usually diffusion-controlled ${ }^{47,}{ }^{50}$. For a copolymerization, the simplest "ideal diffusion" model for the copolymerization rate constant $\left(k_{t}\right)$ is given by a linear combination of the termination rate constants for the two homopolymerizations (Eq. 12) ${ }^{51}$.

$$
\begin{gathered}
R_{P}=k_{p}\left(\frac{2 f k_{d}}{k_{t}}\right)^{0.5}[M][I]^{0.5} \\
M_{n}=\alpha M_{o} k_{p}\left(2 f k_{d} k_{t}\right)^{-0.5}[M][I]^{-0.5} \\
\bar{k}_{p}=\frac{r_{1} f_{1}^{2}+2 f_{1} f_{2}+r_{2} f_{2}^{2}}{\left(r_{1} f_{1} / k_{11}\right)+\left(r_{2} f_{2} / k_{22}\right)} \\
k_{t}=F_{1} k_{t 1}+F_{2} k_{t 2}
\end{gathered}
$$

where: $f$ is the initiator decomposition efficiency; $[M]$ and $[I]$ are the concentrations of monomer(s) and initiator in the reactor; $f_{i}, F_{i}, r_{i}, k_{i i}$, and $k_{t i}$ are the mole fraction in the feed, mole fraction in the copolymer, reactivity ratio, self propagation (homopropagation) rate constant, and self termination (homotermination) rate constant for monomer $i$ respectively; $\alpha$ equals 1 or 2 for termination by disproportionation or combination respectively; $M_{o}$ is the average molecular weight of a monomer unit in the polymer. 
Setting $[M]=\left[M_{T}\right]_{\text {out }}$ and $[I]=[I]_{\text {out }}$ in Eq. 9 and 10, and combining them with Eq. 6, shows that $R_{p}$ and $M_{n}$ should be linear functions of $\left[M_{T}\right]_{\text {out }}$. This is the behavior shown by the experimental data presented in Figs. 5(a) and 5(b). By fitting the data to Eqs. 9 and 10, values of $k_{p} / k_{t}^{0.5}$ for the copolymerization of VF2 with HFP and $k_{d}$ for PBP decomposition in $\mathrm{scCO}_{2}$ at 40 ${ }^{\circ} \mathrm{C}$ and 400 bar can be estimated. Since there is no evidence in the literature for termination by disproportionation $^{37}$, termination by combination was assumed and a value of $\alpha=2$ was used. A value of $f=0.6$ was assumed, similar to that observed for diethyl peroxydicarbonate decomposition in $\mathrm{scCO}_{2}{ }^{9}$. A value of $M_{o}=71.94$ was calculated from the average of the values of the copolymer compositions from F-EA and NMR (Table 1). Only molecular weight data from GPC were used, although they are against polystyrene standards. However, as shown in Tables 1 and 2, the differences between molecular weights from GPC and NMR end-group analysis are small.

It is interesting to compare the values of $k_{p} / k_{t}^{0.5}$ for the copolymerization of VF2 with HFP with those of the homopolymerization of VF2 in $\mathrm{scCO}_{2}$. Unfortunately, the values of $k_{p} / k_{t}^{0.5}$ for VF2 homopolymerization that are available in the literature were obtained at completely different conditions with a different initiator ${ }^{36}$. To obtain an approximate value for comparison at the same conditions, two homopolymerizations of VF2 were carried out at 276 bar and $40{ }^{\circ} \mathrm{C}$ using PBP initiator. The results are shown in Table 4. Since there is not much effect of pressure on the rate of initiator decomposition in $\mathrm{CO}_{2}{ }^{8,9}$, the value of $k_{d}$ calculated from the copolymer data was used in Eq. 9. For the homopolymer, Eq. 8 was used to adjust the value of $k_{p} / k_{t}^{0.5}$ to 400 bar. The activation volume for $k_{p} / k_{t}^{0.5}\left(\Delta V_{p}^{*}-1 / 2 \Delta V_{t}^{*}\right)$ was estimated from Eq. 13 using an overall polymerization activation volume $\left(\Delta V_{\text {poly }}^{*}\right)$ of $-0.025 \mathrm{~L} / \mathrm{mol}^{49}$. Since solvent cage effects 
are minimal in the case of $\mathrm{CO}_{2}{ }^{8}$, the activation volume for the initiator decomposition $\left(\Delta V_{d}^{*}\right)$ was taken to be $+0.0045 \mathrm{~L} / \mathrm{mol}^{47}$. A calculation based on Eq. 8 then shows that $k_{p} / k_{t}^{0.5}$ of PVDF homopolymer increases by about $14 \%$ from 276 to 400 bar.

$$
\begin{aligned}
& \Delta V_{p o l y}^{*}=\Delta V_{p}^{*}-\frac{1}{2} \Delta V_{t}^{*}+\frac{1}{2} \Delta V_{d}^{*} \\
& \left(\Delta V_{p}^{*}-\frac{1}{2} \Delta V_{t}^{*}\right)=\Delta V_{p o l y}^{*}-\frac{1}{2} \Delta V_{d}^{*}
\end{aligned}
$$

Table 4: Continuous homopolymerizations of VF2 in $\mathrm{scCO}_{2}$ using PBP initiator ${ }^{(a)}$.

\begin{tabular}{ccc}
\hline $\begin{array}{c}{\left[M_{T}\right]_{\text {in }}} \\
(\mathrm{mol} / \mathrm{L})\end{array}$ & $\begin{array}{c}\left(R_{P}\right) \\
\left(10^{-2} \mathrm{~mol} / \mathrm{L} \cdot \mathrm{min}\right)\end{array}$ & $\begin{array}{c}{\left[M_{T}\right]_{\text {out }}} \\
(\mathrm{mol} / \mathrm{L})\end{array}$ \\
\hline 1.97 & 1.52 & 1.66 \\
2.62 & 1.95 & 2.23 \\
\hline
\end{tabular}

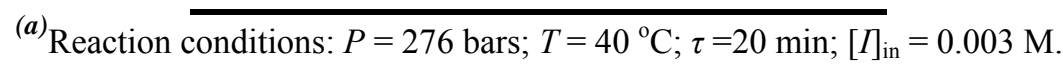

Table 5: Values for $k_{p} / k_{t}^{0.5}$ for poly(VF2-co-HFP) and PVDF, and $k_{\mathrm{d}}$ of the PBP initiator. $P=400$ bar and $T=40{ }^{\circ} \mathrm{C}$

\begin{tabular}{ccc}
\hline & $k_{p} / k_{t}^{0.5}$ & $k_{d}$ \\
& $\left(\mathrm{~L}^{0.5} / \mathrm{mol}^{0.5} \cdot \mathrm{s}^{0.5}\right)$ & $\left(10^{-4} \mathrm{~s}^{-1}\right)$ \\
\hline Poly(VF2-co-9.2 mol\% HFP) & 0.68 & 4.01 \\
PVDF & 1.3 & - \\
\hline
\end{tabular}

Table 5 shows the values obtained for $k_{p} / k_{t}^{0.5}$ and $k_{d}$ from the experimental data for copolymerization of VF2 with HFP, and $k_{p} / k_{t}^{0.5}$ for PVDF homopolymerization. There is a good agreement between the estimated $k_{d}$ for $\mathrm{PBP}$ in $\mathrm{scCO}_{2}$ and the one reported for PBP decomposition in Freon $113\left(3.26 \times 10^{-4} \mathrm{~s}^{-1}\right)^{43}$. The value of $k_{p} / k_{t}^{0.5}$ for the copolymer is about half of that for PVDF. A low value of $k_{p}$ is consistent with the much lower reactivity of the polymeric radicals with terminal HFP units compared to the radicals with terminal VF2 units. In 
fact, the reactivity ratio for HFP is essentially zero ${ }^{22-24,40}$. Consequently, HFP monomer units cannot add to growing chains with a terminal HFP unit. For the same reasons, the chemical kinetic termination rate constant is expected to be lower for the copolymerization than for the homopolymerization.. However, since termination is diffusion-controlled, at least for the highmolecular-weight chains, the effect is weaker in the observed termination rate constant. In addition, $k_{p} / k_{t}^{0.5}$ is more sensitive to changes in $k_{p}$ than in $k_{t}$.

4.3.7 Reactivity ratios. Previously reported reactivity ratios for the copolymerization of VF2 with HFP are shown in Table 6. Although various investigators agree that the reactivity ratio of HFP is essentially zero, there are substantial differences in the value for VF2. This is probably due to differences from study to study in: the mode of polymerization (emulsion, precipitation, solution, etc); reaction conditions, and/or; monomer composition drift for batch reactors. Additional differences can arise from the different analytical methods used for determining the copolymer composition. Most of the reported values are for copolymer compositions determined from NMR and only few are from F-EA. Moreover, due to the heterogeneity of the polymerization systems, most of the reported values contain a "concentration factor" that changes with reaction conditions. Therefore, the reported values should be considered as "effective" reactivity ratios. The only exception is the reactivity ratios reported for solution polymerization in acetonitrile by Gelin et al. at $120{ }^{\circ} \mathrm{C}^{52}$. 
Table 6: Reactivity ratio pairs for the copolymerization of VF2 with HFP in the literature

\begin{tabular}{cccc}
\hline Set \# & $r_{H F P}$ & $r_{V F 2}$ & Reference \\
\hline $\mathrm{A}^{*},(a)$ & 0 & 6.7 & Moggi et $\mathrm{al}^{53}$ \\
$\mathrm{~B}^{*,(a)}$ & 0 & 5 & Logothetis et $\mathrm{al}^{30}$ \\
$\mathrm{C}^{*,(b)}$ & 0 & 2.45 & Bonardelli et $\mathrm{al}^{54}$ \\
$\mathrm{D}^{*,(c)}$ & $0.12 \pm 0.05$ & $2.9 \pm 0.6$ & Gelin et $\mathrm{al}^{52}$ \\
$\mathrm{E}^{*,(d)}$ & 0 & $5.13 \pm 0.44$ & Tai et $\mathrm{al}^{42}$ \\
& $0^{(*)}$ & $3.6^{(*)}$ & \\
$\mathrm{F}^{(e)}$ & $0^{(* *)}$ & $8.2^{(* *)}$ & Beginn et $\mathrm{al}^{41}$ \\
& $0^{(* * *)}$ & $4.8^{(* *)}$ & \\
$\mathrm{G}^{(f)}$ & $0 \pm 0.08^{(* * *)}$ & $3.61 \pm 0.71^{(* *)}$ & \\
& $0.09 \pm 0.09^{(* * *)}$ & $4.67 \pm 0.77^{(* * *)}$ & Ahmed et $\mathrm{al}^{40}$ \\
\hline
\end{tabular}

(*) Based on copolymer composition obtained from NMR; ${ }^{(* *)}$ Based on copolymer composition obtained from F-EA; ${ }^{(* * *)}$ Based on copolymer composition obtained from the average of both NMR and F-EA. ${ }^{(a)}$ Batch emulsion polymerization at $70-130{ }^{\circ} \mathrm{C}$ and $20-70$ bar (exact conditions not known); ${ }^{(b)}$ Batch emulsion polymerization at $85{ }^{\circ} \mathrm{C}$ and 13.2 bar, values from NMR; ${ }^{(c)}$ Batch solution polymerization in acetonitrile at $120{ }^{\circ} \mathrm{C}$; ${ }^{(d)}$ Batch precipitation polymerization in $\mathrm{scCO}_{2}$ at $55{ }^{\circ} \mathrm{C}$ and initial pressure of 276 bar; ${ }^{(e)}$ Batch polymerization in $\mathrm{scCO}_{2}$ at $50{ }^{\circ} \mathrm{C}$ and initial pressure of 280 bar; ${ }^{(f)}$ Batch polymerization in $\mathrm{scCO}_{2}$ at $35^{\circ} \mathrm{C}$ and initial pressure of 310 and 415 bar

For a CSTR, there is no composition drift. Consequently, the reactivity ratios calculated should be more accurate than those obtained from batch reactor experiments. Equation 14 is the differential form of the Mayo-Lewis equation ${ }^{55}$. Based on the data in Table $6, r_{H F P}$ was set equal to zero. For this case, Eq. 14 simplifies to Eq. 15, so that $r_{V F 2}$ can be calculated from the values of $F_{H F P}$ and $f_{H F P}$ (mole fraction of HFP in the effluent monomers, Eq. 16).

$$
F_{H F P}=\frac{r_{H F P} f_{H F P}^{2}+f_{H F P}\left(1-f_{H F P}\right)}{r_{H F P} f_{H F P}^{2}+2 f_{H F P}\left(1-f_{H F P}\right)+r_{V F 2}\left(1-f_{H F P}\right)^{2}}
$$




$$
\begin{gathered}
r_{V F 2}=\frac{\left(2-\frac{1}{F_{H F P}}\right)}{\left(1-\frac{1}{f_{H F P}}\right)} \\
f_{H F P}=\frac{\left(f_{H F P}\right)_{\text {in }}\left[M_{T}\right]_{i n}-\tau F_{H F P}\left(R_{p}\right)_{a v}}{\left[M_{T}\right]_{o u t-a v}}
\end{gathered}
$$

where: $\left(f_{H F P}\right)_{\text {in }}$ is the mole fraction of HFP in the feed monomers to the reactor and $F_{H F P}$ is the mole fraction of HFP in the copolymer, based on the average from NMR and F-EA.

Using the values of experiment \#1 from Table 1, the "effective" reactivity ratio for VF2 for the copolymerization of VF2 with $\mathrm{HFP}$ in $\mathrm{scCO}_{2}$ is:

$$
r_{V F 2}=3.2 \text { at } 40{ }^{\circ} \mathrm{C} \text { and } 400 \text { bar }
$$

This value is very close to the value of 2.9 obtained from solution polymerization in acetonitrile by Gelin et al. ${ }^{52}$. However, Gelin et al.'s experiments were at much higher temperature $\left(120^{\circ} \mathrm{C}\right)$ and in a batch reactor with about $10-12 \%$ VF2 conversion ${ }^{52}$.

4.3.8 Locus of polymerization. The question of where the polymerization takes place is of both theoretical interest and practical importance. When polymer precipitates during the polymerization reaction, the reaction can take place either in the supercritical fluid phase, in the precipitated polymer particles, or simultaneously in both phases. For the precipitation copolymerization of VF2 with HFP, many features of the current results suggest that the copolymerization takes place mainly in the $\mathrm{CO}_{2}$-rich fluid phase. First, the first-order dependence of both $R_{p}$ and $M_{n}$ on total monomer concentration, as shown in Figs $5 \mathrm{a}$ and $5 \mathrm{~b}$, is characteristic of a conventional solution polymerization. If the polymer phase was a significant polymerization locus, a higher order of dependence of both $R_{p}$ and $M_{n}$ on total monomer 
concentration should have been observed ${ }^{38}$. Second, the significant increase of both $R_{p}$ and $M_{n}$ with increasing pressure is consistent with the hypothesis that polymerization occurs primarily in the fluid phase. Besides the effect of pressure on the reaction rate constants discussed before, the increase in the pressure increases the solubility of the copolymer in $\mathrm{scCO}_{2}$ and causes the growing chains to precipitate at higher molecular weights, leading to an increase in the concentration of polymer radicals in the fluid phase. This leads directly to an increase in $R_{p}$ and $M_{n}$. Finally, the increased concentration of high molecular weight polymer radicals leads to the increase of the MWD tail with increasing pressure, since the effective termination rate constant decreases with increasing radical chain length ${ }^{50,56}$.

The bimodal MWD observed experimentally for the homopolymerization of VF2 in $\mathrm{scCO}_{2}{ }^{37,57}$ is the subject of some controversy. The bimodality has been attributed either to a simultaneous polymerization in both the fluid and the polymer phases, taking into account the transport of polymeric radicals between the two phases $^{57}$, or to a homogeneous polymerization, recognizing the transition of the termination reaction from a kinetically-controlled regime to a diffusion-controlled regime with increasing macroradical molecular weight ${ }^{56}$. For VF2/HFP copolymerization, the heterogeneous model cannot account for the increase of the tail with increasing pressure since transport of the polymeric radicals from the fluid phase to the polymer phase should decrease with increasing pressure as their diffusion coefficients decrease with pressure. On the other hand, according to the homogeneous model, the decrease of the diffusion coefficient of the polymeric radicals with pressure leads to a lower effective termination rate constant leading to the increase of the tail. 
Finally, the slight decrease in HFP incorporation in the copolymer with increasing copolymer volume fraction may be the result of preferential partitioning of HFP into the precipitated copolymer particles. This could lead to a decrease of the HFP/VF2 ratio in the fluid phase, giving rise to lower HFP-content copolymers. This explanation rationalizes the use of experiment \#1 for calculating the reactivity ratio for VF2.

\subsection{Conclusions}

The continuous precipitation copolymerization of VF2 with HFP in $\mathrm{scCO}_{2}$ was successfully carried out using PBP initiator in a CSTR. The copolymer was collected continuously as a dry, free-flowing powder. The effects of total monomer concentration and reaction pressure were both explored at otherwise constant conditions.

Both $R_{p}$ and $M_{n}$ increased linearly with total monomer concentration, and both increased with pressure by about $80 \%$ from 207 to 400 bar. This increase cannot be accounted for only by the effect of pressure on the reaction rate constants. The MWDs of the synthesized copolymer showed a long tail that became a broad shoulder with increasing total monomer concentration. This tail increased with increasing reaction pressure.

The $k_{p} / k_{t}^{0.5}$ ratio for the copolymerization is less than that for the homopolymerization of VF2 in $\mathrm{scCO}_{2}$ at identical conditions. This was attributed to the low reactivity of HFP-terminated polymer radicals. The reactivity ratio of VF2 calculated from the experimental data is similar to the value reported for the solution polymerization of VF2 with HFP in acetonitrile.

Finally, the experimental data suggests that the $\mathrm{CO}_{2}$-rich fluid phase is the primary locus of polymerization. Homogenous polymerization in the $\mathrm{CO}_{2}$-rich fluid phase can account for the 
first-order dependence of $R_{p}$ and $M_{n}$ on the total monomer concentration, the increase of $R_{p}$ and $M_{n}$ with pressure, and the increase of the MWD tail with pressure.

\subsection{Acknowledgement}

This material is based upon work supported by the STC Program of the National Science Foundation under Agreement No. CHE-9876674.

\subsection{References}

1. Beckman, E. J. Journal of Supercritical Fluids 2004, 28, (2-3), 121-191.

2. Canelas, D. A.; DeSimone, J. M. Advances in Polymer Science 1997, 133, 103-140.

3. DeSimone, J. M. Science 2002, 297, (5582), 799-803.

4. Kendall, J. L.; Canelas, D. A.; Young, J. L.; DeSimone, J. M. Chemical Reviews 1999, 99, (2), 543-563.

5. Cooper, A. I. Journal of Materials Chemistry 2000, 10, (2), 207-234.

6. Kennedy, K. A.; Roberts, G. W.; DeSimone, J. M. Advances in Polymer Science 2005, $175,329-346$.

7. Guan, Z.; Combes, J. R.; Menceloglu, Y. Z.; DeSimone, J. M. Macromolecules 1993, 26, (11), 2663-9.

8. Bunyard, W. C.; Kadla, J. F.; DeSimone, J. M. Journal of the American Chemical Society 2001, 123, (30), 7199-7206.

9. Charpentier, P. A.; DeSimone, J. M.; Roberts, G. W. Chemical Engineering Science 2000, 55, (22), 5341-5349. 
10. Liu, T.; Garner, P.; DeSimone, J. M.; Roberts, G. W.; Bothun, G. D. Macromolecules 2006, 39, (19), 6489-6494.

11. Saraf, M. K.; Wojcinski, L. M., II; Kennedy, K. A.; Gerard, S.; Charpentier, P. A.; DeSimone, J. M.; Roberts, G. W. Macromolecular Symposia 2002, 182, 119-129.

12. Preliminary Risk Assessment: Perfluorooctanic Acid (PFOA) and Fluorinated Telomers; US Environmental Protection Agency: April, 2003.

13. 2010/15 PFOA Stewardship Program; U.S. Environmental Protection Agency: January, 2006.

14. McCoy, M. Chemical \& Engineering News 1999, 77, (10).

15. Press Release: DuPont introduces fluoropolymers made with supercritical $\mathrm{CO}_{2}$ technology. DuPont, Wilmington, DE 2002.

16. Robinson, D.; Seiler, D. A., Modifications of PVDF resins leading to new fabrication opportunities with improved service life. In Managing Corrosion with Plastics NACE Proceedings, 1991; Vol. 10 (22), pp 1-14.

17. Scheirs, J., Modern Fluoropolymers: High Performance Polymers for Diverse Applications. John Wiley \& Sons, Ltd.: 1997.

18. Ameduri, B.; Boutevin, B.; Kostov, G. Progress in Polymer Science 2001, 26, (1), 105187.

19. Solvay-Solexis, Solef \& Hylar PVDF: Design and Processing Guide In www.Solvaysolexis.com/static/wma/pdf/9/2/2/3/br_Solef_Hylar.pdf.

20. Apostolo, M.; Arcella, V.; Storti, G.; Morbidelli, M. Macromolecules 1999, 32, (4), 9891003. 
21. Ajroldi, G.; Pianca, M.; Fumagalli, M.; Moggi, G. Polymer 1989, 30, (12), 2180-2187.

22. Ferguson, R. C. Journal of the American Chemical Society 1960, 82, (10), 2416-2418.

23. Pianca, M.; Bonardelli, P.; Tato, M.; Cirillo, G.; Moggi, G. Polymer 1987, 28, (2), 224230.

24. Schmiegel, W. W. Angewandte Makromolekulare Chemie 1979, 76-7, (Mar), 39-65.

25. Kaspar, H. 3M Company, Personal Communication 2003.

26. Office for Official Publications of the European Communities. Document no.: 302M2690-Solvay/Montedison-Ausimont Merger Procedure. (302M2690),

27. Abusleme, J. A.; Gavezotti, P. Suspension (co)polymerization with bis(dichlorofluoroacetyl) peroxide for preparation of hydrogen-containing thermoplastic fluoropolymers. US Patent: 5,569,728, 1995.

28. Arnold, R. G.; Barney, A. L.; Thompson, D. C. Rubber Chemistry and Technology 1973, $46,(3), 619-52$.

29. Dixon, S.; Rexford, D. R.; Rugg, J. S. Industrial and Engineering Chemistry 1957, 49, (10), 1687-1690.

30. Logothetis, A. L. Progress in Polymer Science 1989, 14, (2), 251-296.

31. Stevens, M. P., Polymer Chemistry: An Introduction. 3rd ed.; Oxford University Press: New York, 1999.

32. Howe-Grant, M., Fluorine Chemistry: A Comprehensive Treatment. Wiley: New York, 1995.

33. Bonardelli, P.; Moggi, G.; Russo, S. Makromolekulare Chemie, Supplement 1985, 10-11, $11-23$. 
34. Humphrey, J. S.; Amin-Sanayei, R., Vinylidene Fluoride Polymers. In Encyclopedia of Polymer Science and Technology, 3rd ed.; Mark, H. F., Ed. Wiley: 2004; Vol. 4, pp 510533.

35. Charpentier, P. A.; Kennedy, K. A.; DeSimone, J. M.; Roberts, G. W. Macromolecules Communications 1999, 32, (18), 5973-5975.

36. Charpentier, P. A.; DeSimone, J. M.; Roberts, G. W. Industrial \& Engineering Chemistry Research 2000, 39, (12), 4588-4596.

37. Saraf, M. K.; Gerard, S.; Wojcinski, L. M.; Charpentier, P. A.; DeSimone, J. M.; Roberts, G. W. Macromolecules 2002, 35, (21), 7976-7985.

38. Liu, T.; Desimone, J. M.; Roberts, G. W. Journal of Polymer Science, Part A: Polymer Chemistry 2005, 43, (12), 2546-2555.

39. Liu, T.; DeSimone, J. M.; Roberts, G. W. Chemical Engineering Science 2006, 61, (10), 3129-3139.

40. Ahmed, T. S.; DeSimone, J. M.; Roberts, G. W. Macromolecules 2006, 39, (1), 15-18.

41. Beginn, U.; Najjar, R.; Ellmann, J.; Vinokur, R.; Martin, R.; Moeller, M. Journal of Polymer Science, Part A: Polymer Chemistry 2006, 44, (3), 1299-1316.

42. Tai, H.; Wang, W.; Howdle, S. M. Macromolecules 2005, 38, (22), 9135-9142.

43. Zhao, C. X.; Zhou, R. M.; Pan, H. Q.; Jin, X. S.; Qu, Y. L.; Wu, C. J.; Jiang, X. K. Journal of Organic Chemistry 1982, 47, (11), 2009-2013.

44. Reid, R. C.; Prausnitz, J. M.; Poling, B. E., The Properties of Gases and Liquids. 4th ed.; McGraw Hill: 1987.

45. Thomson, G. H.; Brobst, K. R.; Hankinson, R. W. AIChE Journal 1982, 28, (4), 671-676. 
46. Isbester, P. K.; Brandt, J. L.; Kestner, T. A.; Munson, E. J. Macromolecules 1998, 31, (23), 8192-8200.

47. Odian, G., Principles of Polymerization. 4th ed.; John Wiley \& Sons Inc: 2004.

48. Dohany, J. E., Poly(Vinylidene Fluoride). In Kirk-Othmer Encyclopedia of Chemical Technology, 4th ed.; Kirk-Othmer, Ed. John Wiley \& Sons: 1998.

49. Luft, G.; Ogo, Y., Activation Volumes of Polymerization Reactions. In Polymer Handbook, 4th ed.; Brandrup, J.; Immergut, E. H.; Grulke, E. A., Eds. John Wiley \& Sons: New York, 1999; pp II-429.

50. Matyjaszewski, K.; Davis, T. P., Handbook of Radical Polymerization. WileyInterscience 2002.

51. Ito, K.; O'Driscoll, K. F. Journal of Polymer Science, Polymer Chemistry Edition 1979, 17, (12), 3913-3921.

52. Gelin, M.-P.; Ameduri, B. Journal of Fluorine Chemistry 2005, 126, (4), 577-585.

53. Moggi, G.; Bonardelli, P.; Russo, S. 6th Conv. Ital. Sci. Macromol., [Atti], 1983, 2, 405408.

54. Bonardelli, P.; Moggi, G.; Turturro, A. Polymer 1986, 27, (6), 905-909.

55. Mayo, F. R.; Lewis, F. M. Journal of the American Chemical Society 1944, 66, (9), 1594 $-1601$.

56. Ahmed, T. S.; DeSimone, J. M.; Roberts, G. W. Chemical Engineering Science 2004, 59, (22-23), 5139-5144.

57. Mueller, P. A.; Storti, G.; Apostolo, M.; Martin, R.; Morbidelli, M. Macromolecules 2005, 38, (16), 7150-7163. 


\section{CHAPTER 5}

\section{Continuous Copolymerization of Vinylidene Fluoride with Hexafluoropropylene in Supercritical Carbon Dioxide: High Hexafluoropropylene-Content Amorphous Copolymers}

Chapter 5 is a manuscript that has been submitted for publication in Macromolecules 


\title{
Continuous Copolymerization of Vinylidene Fluoride with Hexafluoropropylene in Supercritical Carbon Dioxide: High Hexafluoropropylene-Content Amorphous \\ Copolymers
}

\author{
Tamer S. Ahmed ${ }^{l}$, Joseph M. DeSimone ${ }^{1,2}$, and George W. Roberts ${ }^{1, *}$ \\ ${ }^{1}$ Department of Chemical and Biomolecular Engineering, North Carolina State \\ University, Box \#7905, Raleigh, North Carolina 27695-7905 \\ ${ }^{2}$ Department of Chemistry, University of North Carolina at Chapel Hill, Box \# 3290, \\ Chapel Hill, North Carolina 27599-3290
}

\begin{abstract}
Copolymerization of vinylidene fluoride (VF2) and hexafluoropropylene (HFP) was carried out in supercritical carbon dioxide using a continuous stirred tank reactor. Three different HFP/VF2 molar feed ratios were studied: 59/41, 66/34, and 73/27, giving rise to amorphous copolymers containing about 23,26 , and $30 \mathrm{~mol} \%$ HFP, respectively. The experiments were carried out at $40{ }^{\circ} \mathrm{C}$ with pressures in the range of $207-400$ bar using perfluorobutyryl peroxide as the free radical initiator. Depending on the copolymer composition, the molecular weight, and the reaction pressure, either a homogeneous or a precipitation polymerization was observed. The effects of feed monomer concentration and reaction pressure were explored at otherwise constant conditions. The rate of polymerization $\left(R_{p}\right)$ and the number-average molecular weight $\left(M_{n}\right)$ increased linearly
\end{abstract}

\footnotetext{
${ }^{*}$ To whom correspondence should be addressed. Tel: +1-919-515-7328; Fax: +1-919-515-3465; E-mail address: groberts@eos.ncsu.edu
} 
with the total monomer concentration, independent of the mode of polymerization. Both $R_{p}$ and $M_{n}$ increased by about $20-30 \%$ when the reaction pressure was increased from 207 to 400 bar. This increase could be accounted for by the effect of pressure on the reaction rate constants. The molecular weight distributions were perfectly unimodal except for the lowest HFP content copolymers at the highest monomer concentrations. The data suggest that the carbon-dioxide-rich fluid phase is the main locus of polymerization, even when the polymer precipitates during the reaction.

\subsection{Introduction}

Since their discovery in 1957 by DuPont de Nemours company ${ }^{1}$, copolymers of vinyidene fluoride (VF2) with hexafluoropropylene (HFP) have found use in many applications. When the HFP content of the copolymer is in the range of $5-15 \mathrm{~mol} \%$, the copolymers show thermoplastic properties and are called "flexible PVDF". For HFP contents higher than about $20 \mathrm{~mol} \%$, the copolymers are amorphous and elastomeric ${ }^{2,3}$. The maximum theoretical incorporation of HFP in the copolymer is restricted to $50 \mathrm{~mol} \%$ since HFP has a zero reactivity ratio ${ }^{4-6}$.

Flexible PVDF copolymers are produced commercially by either emulsion or suspension polymerizations in water $^{7,8}$, while the elastomeric VF2-HFP copolymers are produced only by aqueous emulsion polymerization ${ }^{1,2,9,10}$ because of their tacky nature $^{11}$. Both processes generate large quantities of wastewater and require large quantities of energy to isolate the polymer in a dry form. Moreover, the emulsion

technique involves the use of perfluorooctanoic acid (PFOA)-based surfactants ${ }^{12}$ especially for high solid-content loadings ${ }^{12}$. These fluorinated surfactants are of 
environmental concern since they are non-biodegradable and bio-accumulate in human fatty tissues ${ }^{13}$. In addition, their future availability is uncertain ${ }^{14}$. Polymerization in supercritical carbon dioxide $\left(\mathrm{scCO}_{2}\right)$ is the only known alternative that can eliminate the need for PFOA-based surfactants in the manufacturing process ${ }^{15}$.

In a recent publication ${ }^{16}$, we described the use of continuous precipitation polymerization to synthesize low-HFP-content poly(VF2-co-HFP) containing about 10 mol\% HFP. The Introduction Section of that publication described in details the properties of $\mathrm{scCO}_{2}$, the incentives for using it as a polymerization medium, the rationale for continuous operation, and the uses and manufacturing processes for commercial poly(VF2-co-HFP) products.

This publication describes the synthesis of amorphous copolymers of VF2 and HFP containing from 23 to $30 \mathrm{~mol} \% \mathrm{HFP}$, via continuous polymerization in $\mathrm{scCO}_{2}$. The behavior of these polymerizations differs from those of the low-HFP-content copolymers $^{16}$ and from VF2 homopolymers (PVDF) ${ }^{17-20}$. In particular, some of the polymerizations are heterogeneous, i.e. polymer precipitates during the reaction, whereas some are homogeneous. These differences required modification of the experimental equipments. Nevertheless, the differences helped in illuminate the polymerization mechanism over a broader range of conditions. Moreover, the data for the high-HFPcontent polymerizations shed additional light on the important issue of where the polymerization actually takes places ${ }^{16}$. 


\subsection{Experimental Section}

5.2.1 Materials. Carbon dioxide (SFC grade, $99.998 \%, \max \mathrm{O}_{2}=2 \mathrm{ppm}$ ) and argon (99.9999\%) were obtained from National Specialty Gases. To completely remove $\mathrm{O}_{2}$ from the $\mathrm{CO}_{2}$, three-in-parallel Alltech High Pressure Oxy-Trap traps were installed between the $\mathrm{CO}_{2}$ tanks and $\mathrm{CO}_{2}$ pump. Both VF2 ( $99 \%$ min, balance $\left.\mathrm{N}_{2}\right)$ and HFP $(99 \%$ min, balance $\mathrm{N}_{2}$ ) were obtained from SynQuest Laboratories. An Alltech High Pressure Oxy-Trap trap was installed between each monomer cylinder and its corresponding pump. All other chemicals were obtained from Fisher Scientific and used as received.

5.2.2 Initiator Synthesis. Perfluorobutyryl peroxide $\left(\left[\mathrm{C}_{3} \mathrm{~F}_{7} \mathrm{COO}\right]_{2}, \mathrm{PBP}\right)$ was synthesized in 1,1,2-trichloro-1,2,2-trifluoroethane (HPLC-grade, 99.8\%, Freon 113) as previously reported ${ }^{21}$. All manipulations of the initiator were performed in a $\mathrm{NaCl} /$ ice bath, and the final product was stored under dry ice. The iodine titration technique, ASTM Method E 298-91, was utilized to determine the concentration of the initiator in the solution. The initiator concentration was reduced to $0.03 \mathrm{M}$ by dilution with additional Freon 113 before use. After a second titration, the initiator solution was introduced to the initiator pump under an argon blanket. The half-life of PBP in Freon 113 is about $35 \mathrm{~min}$ at $40^{\circ} \mathrm{C}^{21}$.

5.2.3 Polymerization Apparatus and Procedure. Figure 1 shows a schematic of the continuous polymerization system. The reactor (E) is a $100 \mathrm{~mL}$ high-pressure autoclave (Autoclave Engineers) with a magnetically driven agitator (Autoclave Engineers). Three downward-pumping impellers were mounted on the shaft of the agitator. The current autoclave has the same length to diameter ratio as the $800 \mathrm{~mL}$ 
reactor used for $\mathrm{PVDF}^{17-20}$ and poly(acrylic acid) ${ }^{22-24}$, and is the same one used for low HFP-content poly(VF2-co-HFP) ${ }^{16}$. An HPLC pump (C, Alltech 301 HPLC pump) was used to inject acetone continuously into the effluent from the reactor $(\mathrm{E})$. The acetone was cooled in a dry ice/acetone bath before it was injected. McHugh et al. ${ }^{25}$ reported that acetone acted as a cosolvent with $\mathrm{CO}_{2}$ to reduce the cloud-point curve of poly(VF2co-HFP) containing about $22 \mathrm{~mol} \%$ HFP to near atmospheric pressure for temperatures below $10{ }^{\circ} \mathrm{C}$. The purpose of cold acetone injection in these experiments was to increase the solubility of the copolymer in the effluent mixture to facilitate passing the effluent stream through the control valve $(\mathrm{Vc})$. Thus, a continuous stream of acetone with the copolymer dissolved in it was collected into one of two flasks (H1, H2). The precooling of the acetone stream helped to prevent chain transfer to acetone, and to minimize post polymerization. This was especially important since PBP is a very active initiator ${ }^{21}$. In addition, a heat exchanger $(\mathrm{G})$ with a cold refrigerant $\left(-10{ }^{\circ} \mathrm{C}\right)$ was used to reduce initiator decomposition and post polymerization. 


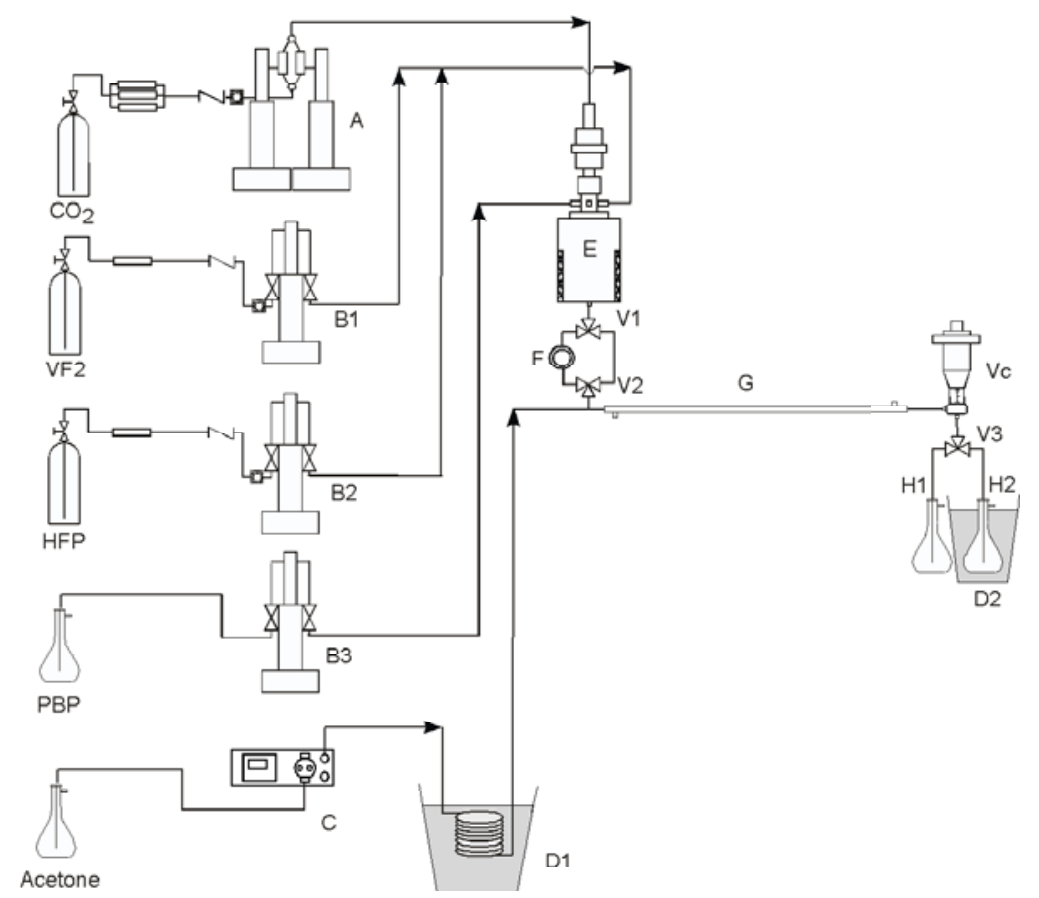

Figure 1: CSTR polymerization system: A- Continuous syringe pump; B1,B2,B3- Syringe pumps; CHPLC pump; D1, D2- Dry ice/Acetone baths; E- Autoclave with stirrer; F- View cell; G- Heat exchanger; H1, H2- Glass flasks; V1,V2,V3- 3-Way valves; Vc- Control valve

In a typical experiment, the reactor $(\mathrm{E})$ and the lines were purged three times with $\mathrm{CO}_{2}$ at 1500 psig to remove oxygen. Syringe pumps A, B1 (cooled by $15{ }^{\circ} \mathrm{C}$ refrigerant), B2 (cooled by $15{ }^{\circ} \mathrm{C}$ refrigerant), $\mathrm{B} 3$ (cooled by $-7.5^{\circ} \mathrm{C}$ refrigerant), and $\mathrm{C}$ were used to feed $\mathrm{CO}_{2}$, VF2, HFP, PBP solution, and acetone respectively. The effect of pressure on the monomer densities that were used to calculate the flow rates out of the pumps was taken into account using the Hakinson-Brobst-Thomson method ${ }^{26,27}$. The speed of the reactor agitator was fixed at $2000 \mathrm{rpm}$ in all the runs. Two three-way ball valves (V1 and V2) were used to direct the effluent from the reactor either to a high-pressure view cell (F) or to normal tubing. The view cell was used to monitor the phase of the effluent from the reactor to determine if the polymer had precipitated in the reactor. The view cell was also used to determine the cloud-point pressure of the reaction mixture. The temperature 
of the view cell and all tubing connecting it to the reactor was maintained at reactor temperature. The effluent stream containing the injected acetone was directed by another three-way valve (V3) to either the unsteady-state (H1) or the steady-state (H2) collection flasks. The unreacted monomers and $\mathrm{CO}_{2}$ were purged through an opening in each flask while acetone/copolymer solution was collected. The acetone/copolymer solution was collected for at least one average residence time after steady state was attained. In addition, the steady-state flask $(\mathrm{H} 2)$ was maintained in a dry ice/acetone bath to prevent post polymerization. After the steady-state collection, valve V3 was switched back to the unsteady-state flask (H1) and the view cell (F) was connected to the system using valves $\mathrm{V} 1$ and V2 to monitor the phase of the reaction mixture. If the reaction mixture was homogeneous, the pressure was decreased slowly to determine the cloud-point pressure (CPP), defined as the pressure at which the solution becomes so opaque that the magnetic stirrer in the view cell can no longer be seen. Cloud points obtained in this manner are generally very close to those defined as the point where there is a $90 \%$ drop in transmitted light through the solution ${ }^{28}$. The system was then shut down and the residual monomers were purged from the acetone solution by bubbling argon into the solution for at least $30 \mathrm{~min}$. Acetone was then evaporated and the collected copolymer was kept at 50 ${ }^{\circ} \mathrm{C}$ in a vacuum oven for at least $12 \mathrm{~h}$.

5.2.4 Characterization. Gel permeation chromatography (GPC) was performed at $40{ }^{\circ} \mathrm{C}$ using a Waters 150-CV GPC equipped with Waters Styragel HR 5, 4, 2, and 0.5 columns and a refractive index detector. Tetrahydrofuran was used as the mobile phase, and polystyrene standards were used for the calibration. 
Hydrogen, carbon, and fluorine elemental analysis were performed by Atlantic Microlab, Inc. Hydrogen and carbon analyses were performed by combustion using automatic analyzers while fluorine analyses were performed by flask combustion followed by ion chromatography.

Fluorine-19 Nuclear Magnetic Resonance $\left({ }^{19} \mathrm{~F}\right.$ NMR) spectra were recorded on a Bruker Avance spectrometer operating at $470.6 \mathrm{MHz}$ using acetone-d6 (99.9\%) as the solvent and trichlorofluoroethane $\left(\mathrm{CFCl}_{3}\right)$ as the internal reference. Pulse delay was $5 \mathrm{~s}$ and 256-1024 scans were used.

Differential scanning calorimetry (DSC) measurements were conducted using a TA-Instruments DSC-Q100. The instrument was calibrated using indium. Samples were heated to $150{ }^{\circ} \mathrm{C}$ at a heating rate of $10{ }^{\circ} \mathrm{C} / \mathrm{min}$. The glass transition temperature was determined from the second heating curve.

Finally, a thermal gravimetric analyzer (TA Instruments TGA-Q500) was used for determining the decomposition temperature $\left(T_{d}\right)$ of the synthesized copolymers. Samples were heated to $800{ }^{\circ} \mathrm{C}$ at a heating rate of $10{ }^{\circ} \mathrm{C} / \mathrm{min}$ in nitrogen atmosphere. The $T_{d}$ was determined for $1 \mathrm{wt} \%$ polymer loss.

\subsection{Results and Discussion}

5.3.1 Copolymerization Studies. The effect of total inlet monomer concentration $\left(\left[M_{T}\right]_{i n}\right)$ and reaction pressure $(P)$ on the continuous copolymerization of VF2 and HFP was studied. Experiments were carried out at $40{ }^{\circ} \mathrm{C}$ in the CSTR using PBP initiator. Three different HFP/VF2 feed ratios were investigated: 59/41, 66/34, and 73/27, giving rise to copolymers containing about $23.3,26.3$, and 30.3 mole $\%$ HFP, respectively. The 
results of these experiments are shown in Tables 1 and 2. The composition, average molecular weight, and molecular weight distribution (MWD) of the copolymers were measured. The molar rate of polymerization $\left(R_{P}\right)$ and the total monomer concentration in the reactor and in the outlet stream $\left(\left[M_{T}\right]_{\text {out }}\right)$ were calculated from the amount of polymer collected $\left(m_{p}\right)$ during the time of steady state collection $\left(\Delta t_{s s}\right)$, using Eqs. (1) and (2) respectively. Equations (1) and (2) are based on the assumption that the reactor behaved as an ideal CSTR.

$$
\begin{gathered}
R_{P}=\frac{m_{p}}{V_{R} \Delta t_{s s}\left(\left[F_{H F P}\right] M_{H F P}+\left(1-\left[F_{H F P}\right]\right) M_{V F 2}\right)} \\
{\left[M_{T}\right]_{\text {out }}=\left[M_{T}\right]_{\text {in }}-R_{P} \tau}
\end{gathered}
$$

Here: $V_{R}$ is the reactor volume $(100 \mathrm{~mL}) ;\left[F_{H F P}\right]$ is the mole fraction of HFP in the copolymer; $M_{H F P}$ and $M_{V F 2}$ are the molecular weights of HFP and VF2 respectively; and $\tau$ is the average residence time in the reactor.

Both fluorine elemental analysis (F-EA) and ${ }^{19} \mathrm{~F}$ NMR were used to determine the copolymer composition. All elemental analyses were on a weight basis with accuracy and precision error limits of $\pm 0.3 \mathrm{wt} \%$. On a mole basis, the error of the elemental analyses depends on the molecular weight of the analyzed element. Since fluorine has the highest molecular weight among the three elements forming the copolymer, only fluorine elemental analysis was considered. Equation 3 was used to calculate $\left[F_{H F P}\right]_{F-E A}$ (mole fraction HFP in the copolymer from F-EA) from the average of two measurements $\left(W_{F}\right)_{a v}$ (average weight fraction of fluorine in the copolymer).

$$
\left[F_{H F P}\right]_{F-E A}=\frac{19-32\left(W_{F}\right)_{a v}}{43\left(W_{F}\right)_{a v}-38}
$$


A representative ${ }^{19} \mathrm{~F}$ NMR spectrum for poly(VF2-co-HFP) with high HFPcontent is shown in Figure 3 (experiment \# 6). The detailed chemical shifts are available in the literature ${ }^{5,29}$. The ${ }^{19} \mathrm{~F}$ NMR spectrum exhibits various groups of signals; those assigned to VF2 units are centered at -91.4 to $-96.2 \mathrm{ppm}$ for head-to-tail normal additions (- $\mathrm{CH}_{2} \mathrm{CF}_{2} \mathrm{CH}_{2} \mathrm{CF}_{2}-$ ), at -108.6 to -112.3 ppm for $\mathrm{CF}_{2}$ groups adjacent to a HFP unit ($\left.\mathrm{CH}_{2} \mathrm{CF}_{2} \mathrm{CF}_{2} \mathrm{CF}\left(\mathrm{CF}_{3}\right)-\right)$, and at -113.6 and $-115.9 \mathrm{ppm}$ for the head-to-head reversed addition $\left(-\mathrm{CH}_{2} \mathrm{CF}_{2} \mathrm{CF}_{2} \mathrm{CH}_{2}-\right)$. Those assigned to HFP units are centered at -70.3 and -75 ppm for the pendant $\mathrm{CF}_{3}$ group $\left(-\mathrm{CF}_{2} \mathrm{CF}\left(\mathrm{CF}_{3}\right)-\right)$, at -115.3 and -117 to $-119.2 \mathrm{ppm}$ for $\mathrm{CF}_{2}\left(-\mathrm{CF}_{2} \mathrm{CF}\left(\mathrm{CF}_{3}\right)-\right)$ group, and at -181.4 and-184.1 ppm for the $\mathrm{CF}\left(-\mathrm{CF}_{2} \mathrm{CF}\left(\mathrm{CF}_{3}\right)-\right)$ group. Finally, the peaks at ca. $-80 \mathrm{ppm}$ and -126 to $-127 \mathrm{ppm}$ are assigned to the $-\mathrm{CF}_{3}$ and $-\mathrm{CF}_{2}$ fluorine in the initiator respectively. 
Table 1: Effect of inlet total monomer concentration on the continuous copolymerization of high $\mathrm{HFP}$-content VF2/HFP copolymers in scCO ${ }_{2}{ }^{(a)}$

\begin{tabular}{|c|c|c|c|c|c|c|c|c|c|c|}
\hline \# & $\begin{array}{l}\text { HFP/VF2 } \\
\text { molar feed } \\
\text { ratio }\end{array}$ & $\begin{array}{c}{\left[M_{T}\right]_{i n}} \\
(\mathrm{~mol} / \mathrm{L})\end{array}$ & $\begin{array}{l}{\left[F_{H F P}\right]_{F-E A}} \\
(\operatorname{mol} \%)^{(b)}\end{array}$ & $\begin{array}{l}{\left[F_{H F P}\right]_{N M R}} \\
(\mathrm{~mol} \%)^{(c)}\end{array}$ & $\begin{array}{c}\left(R_{P}\right)_{a v} \\
\left(10^{-2} \mathrm{~mol} / \mathrm{L} \cdot \mathrm{min}\right)^{(d)}\end{array}$ & $\begin{array}{l}{\left[M_{T}\right]_{\text {out-av }}} \\
(\mathrm{mol} / \mathrm{L})^{(e)}\end{array}$ & $\begin{array}{l}\left(M_{n}\right)_{\mathrm{NMR}} \\
(\mathrm{kDa})^{(f)}\end{array}$ & $\begin{array}{c}\left(M_{n}\right)_{\mathrm{GPC}} \\
(\mathrm{kDa})\end{array}$ & PDI & Reaction Medium and CPP ${ }^{(g)}$ \\
\hline 1 & $59 / 41$ & 1.5 & $23.7 \pm 1.35$ & 22.4 & 0.72 & 1.36 & 14.4 & 14.7 & 1.5 & Homogenous (CPP $=303$ bar $)$ \\
\hline 2 & $59 / 41$ & 3.6 & $24.2 \pm 1.36$ & 22.6 & 1.58 & 3.28 & 32.2 & 29.5 & 1.5 & Heterogeneous \\
\hline 3 & $59 / 41$ & 5.2 & $23.7 \pm 1.35$ & 22.8 & 2.16 & 4.80 & 48.8 & 45.6 & 1.5 & Heterogeneous \\
\hline 4 & $59 / 41$ & 6.5 & $24.4 \pm 1.36$ & 22.8 & 3.07 & 5.89 & 67.4 & 59.8 & 1.6 & Heterogeneous \\
\hline 5 & $66 / 34$ & 1.5 & $27.0 \pm 1.43$ & 25.9 & 0.64 & 1.37 & 13.3 & 13.7 & 1.5 & Homogenous $(\mathrm{CPP}=271$ bar $)$ \\
\hline 6 & $66 / 34$ & 3.6 & $26.4 \pm 1.42$ & 26.1 & 1.43 & 3.31 & 30.6 & 29.2 & 1.5 & Homogenous ( $\mathrm{CPP}=352$ bar $)$ \\
\hline 7 & $66 / 34$ & 5.2 & $26.4 \pm 1.44$ & 26.3 & 2.20 & 4.79 & 44.7 & 44.3 & 1.5 & Heterogeneous \\
\hline 8 & $66 / 34$ & 6.5 & $26.2 \pm 1.44$ & 26.4 & 2.59 & 5.98 & 60.9 & 52.7 & 1.5 & Heterogeneous \\
\hline 9 & $73 / 27$ & 1.5 & $30.3 \pm 1.53$ & 28.9 & 0.55 & 1.39 & 12.0 & 12.3 & 1.5 & Homogenous ( $\mathrm{CPP}=231$ bar $)$ \\
\hline 10 & $73 / 27$ & 3.6 & $31.8 \pm 1.58$ & 29.2 & 1.41 & 3.32 & 31.9 & 29.0 & 1.5 & Homogenous $(\mathrm{CPP}=291$ bar $)$ \\
\hline 11 & $73 / 27$ & 5.2 & $31.8 \pm 1.57$ & 29.3 & 2.20 & 4.79 & 49.9 & 46.5 & 1.5 & Homogenous $(\mathrm{CPP}=331$ bar $)$ \\
\hline 12 & $73 / 27$ & 6.5 & $30.8 \pm 1.57$ & 30.1 & 2.71 & 5.96 & 63.2 & 57.1 & 1.5 & Homogenous $(\mathrm{CPP}=372$ bar $)$ \\
\hline
\end{tabular}

${ }^{a}$ Reaction conditions: $P=400$ bars; $T=40{ }^{\circ} \mathrm{C} ; \tau=20 \mathrm{~min} ;[]_{i n}=0.003 \mathrm{M} ;{ }^{b}$ HFP incorporation in the copolymer from fluorine elemental analysis (Eq. 3 ); The error limit in $\left[F_{H F P}\right]_{F-E A}$ corresponds to the $\pm 0.3 \mathrm{wt} \%$ accuracy and precision error. ${ }^{c}$ HFP incorporation in the copolymer from NMR (Eq. 4). ${ }^{d}$ Average molar rate of polymerization based on the average of $\left[F_{H F P}\right]_{F-E A}$ and $\left[F_{H F P}\right]_{N M R}($ Eq. 1$){ }^{e}$ Average total monomer concentration inside the reactor and in the effluent based on the average of $\left[F_{H F P}\right]_{F-E A}$ and $\left[F_{H F P}\right]_{N M R}$ (Eq. 2). ${ }^{f}$ Number-average molecular weight calculated from initiator endgroup analysis by NMR (Eq. 5); ${ }^{(g)} \mathrm{CPP}=$ Cloud-point pressure 
Table 2: Effect of reaction pressure on the continuous copolymerization of high $\mathrm{HFP}_{-c o n t e n t} \mathrm{VF} 2 / \mathrm{HFP}$ copolymers in $\mathrm{scCO}_{2}{ }^{(a)}$

\begin{tabular}{|c|c|c|c|c|c|c|c|c|c|c|}
\hline$\#$ & $\begin{array}{c}\text { HFP/VF2 } \\
\text { mole-feed- } \\
\text { ratio }\end{array}$ & $\begin{array}{c}P \\
\text { (bar) }\end{array}$ & $\begin{array}{l}{\left[F_{H F P}\right]_{F-E A}} \\
(\mathrm{~mol} \%)^{(b)}\end{array}$ & $\begin{array}{c}{\left[F_{H F P}\right]_{N M R}} \\
(\mathrm{~mol} \%)\end{array}$ & $\begin{array}{c}\left(R_{P}\right)_{a v} \\
\left(10^{-2} \mathrm{~mol} / \mathrm{L} . \mathrm{min}\right)\end{array}$ & $\begin{array}{l}{\left[M_{T}\right]_{\text {out-av }}} \\
(\mathrm{mol} / \mathrm{L})\end{array}$ & $\begin{array}{c}\left(M_{n}\right)_{\mathrm{NMR}} \\
(\mathrm{kDa})\end{array}$ & $\begin{array}{c}\left(M_{n}\right)_{\mathrm{GPC}} \\
(\mathrm{kDa})\end{array}$ & PDI & Reaction Medium \\
\hline 2 & $59 / 41$ & 400 & $24.2 \pm 1.36$ & 22.6 & 1.58 & 3.28 & 32.2 & 29.5 & 1.5 & Heterogeneous \\
\hline 13 & $59 / 41$ & 310 & $24.0 \pm 1.35$ & 22.5 & 1.50 & 3.30 & 28.9 & 26.7 & 1.5 & Heterogeneous \\
\hline 14 & $59 / 41$ & 207 & $23.5 \pm 1.33$ & 22.5 & 1.18 & 3.36 & 24.7 & 23.7 & 1.5 & Heterogeneous \\
\hline 6 & $66 / 34$ & 400 & $26.4 \pm 1.42$ & 26.1 & 1.43 & 3.31 & 30.6 & 29.2 & 1.5 & Homogenous ( $\mathrm{CPP}=352$ bar) \\
\hline 15 & $66 / 34$ & 310 & $27.2 \pm 1.44$ & 25.4 & 1.18 & 3.36 & 26.2 & 25.2 & 1.5 & Heterogeneous \\
\hline 16 & $66 / 34$ & 207 & $27.2 \pm 1.44$ & 25.7 & 1.14 & 3.37 & 25.0 & 22.7 & 1.5 & Heterogeneous \\
\hline 10 & $73 / 27$ & 400 & $31.8 \pm 1.58$ & 29.2 & 1.41 & 3.32 & 31.9 & 29.0 & 1.5 & Homogenous ( $\mathrm{CPP}=291$ bar $)$ \\
\hline 17 & $73 / 27$ & 310 & $31.0 \pm 1.55$ & 29.1 & 1.27 & 3.35 & 28.5 & 24.5 & 1.5 & Homogenous ( $\mathrm{CPP}=283$ bar $)$ \\
\hline 18 & $73 / 27$ & 207 & $30.8 \pm 1.54$ & 29.0 & 1.02 & 3.40 & 24.6 & 21.5 & 1.5 & Heterogeneous \\
\hline
\end{tabular}

${ }^{a}$ Reaction conditions: $\left[M_{T}\right]_{i n}=3.6 \mathrm{~mol} / \mathrm{L} ; T=40^{\circ} \mathrm{C} ; \tau=20 \mathrm{~min} ;[]_{i n}=0.003 \mathrm{M} .{ }^{(b)}$ The error limit in $\left[F_{H F P}\right]_{F-E A}$ corresponds to $\pm 0.3 \mathrm{wt} \%$ accuracy and precision error. 


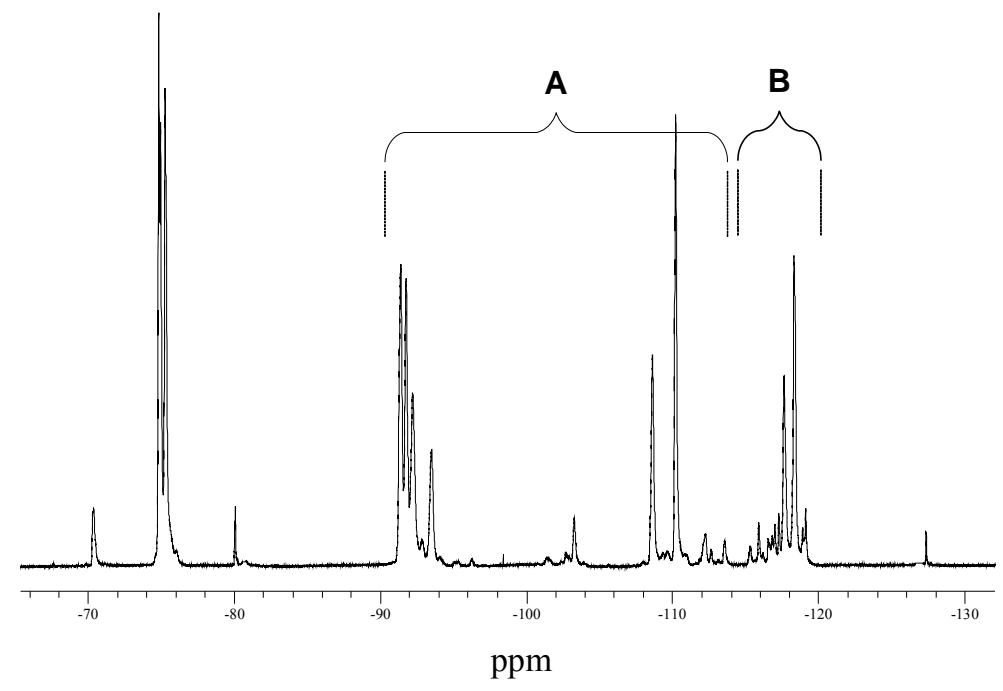

Figure 2: ${ }^{19} \mathrm{~F}$ NMR spectrum for copolymer collected in experiment \# 6 in Table $1(26.4 \pm 1.42 \mathrm{~mol} \% \mathrm{HFP}$ by F-EA, $26.1 \mathrm{~mol} \% \mathrm{HFP}$ by NMR). The resonances due to the CF fluorine in HFP at ca. $-181 \mathrm{ppm}$ to $184 \mathrm{ppm}$ are not shown. Copolymer compositions were determined from the integrals of the peaks in the A \& B regions.

The mole fraction of HFP monomer in the copolymer $\left(\left[F_{H F P}\right]_{N M R}\right)$ was calculated from Eq. 4, where $A$ corresponds to the sum of the areas of the NMR signals from -91.4 to $-115.9 \mathrm{ppm}$ and $B$ corresponds to the sum of the areas of the NMR signals from -117 to -119.2 ppm (Fig. 3). With the exception of experiment \# 8, the copolymer composition obtained via fluorine elemental analysis was higher than that from NMR. Nevertheless, the two compositions are close enough to lend confidence to the results.

$$
\left[F_{H F P}\right]_{N M R}=\frac{B}{A+B}
$$

In addition, NMR was used to determine the VF2 reverse defects of chaining (head-to-head VF2 units). Table 3 shows the average VF2 reverse defects (Eq. 5) for the three current copolymer compositions along with the defects for the $9.2 \mathrm{~mol} \% \mathrm{HFP}$ copolymer previously reported ${ }^{16}$. 
Table 3: Average VF2 reverse defects for poly(VF2-co-HFP) polymers synthesized in $\mathrm{scCO}_{2}$. Reaction conditions: $T=40^{\circ} \mathrm{C} ; P=400$ bars.

\begin{tabular}{cc}
\hline Copolymer & Average VF2 reverse defects, \% \\
\hline Poly(VF2-co-9.2 mol\% HFP) ${ }^{16}$ & 6.1 \\
Poly(VF2-co-23.3 mol\% HFP) & 3.1 \\
Poly(VF2-co-26.3 mol\% HFP) & 2.6 \\
Poly(VF2-co-30.3 mol\% HFP) & 2.4 \\
\hline
\end{tabular}

$$
\text { VF2 reverese defects }=\frac{I_{-113.6}+I_{-115.9}}{A}
$$

where, $I_{-113.6}$ and $I_{-115.9}$ are the integral of the signals corresponding to the fluorine of the $\mathrm{CF}_{2}$ groups at -113.6 and $-115.9 \mathrm{ppm}$, respectively.

Finally, NMR was used to determine the number-average molecular weight $\left(M_{n}\right)$ from end-group analysis of the initiator. End-group analysis can be used to determine $M_{n}$ to higher values for fluorinated polymers than for hydrocarbon polymers ${ }^{16}$. The numberaverage molecular weight using the end-group analysis of the PBP initiator by NMR $\left(\left(M_{n}\right)_{N M R}\right)$ was calculated via Eq. 6.

$$
\left(M_{n}\right)_{N M R}=\frac{\left(I_{C F 2}\right) / 2}{\left(I_{-80 p p m} / 3\right) / 2}\left[150\left[F_{H F P}\right]_{N M R}+64\left(1-\left[F_{H F P}\right]_{N M R}\right)\right]
$$

Here, $I_{-80 p p m}$ is the integral of the signal corresponding to the fluorine of the $\mathrm{CF}_{3}$ group in the $\mathrm{C}_{3} \mathrm{~F}_{7}$ of the PBP initiator located at ca. $-80 \mathrm{ppm} ; I_{C F 2}$ is the sum of the integrals for the signals corresponding to the fluorine in $\mathrm{CF}_{2}$ groups in the copolymer from -91.4 to $119.2 \mathrm{ppm}(A+B$ in Figure 3$)$. 
The main assumption in Eq. 6 is that termination is by combination, which is consistent with the measured PDI values of around 1.5 , accounts for the factor of $1 / 2$ that multiplies $\left(I_{-80} \mathrm{ppm} / 3\right)$ in the denominator. Another assumption is that chain transfer to both monomer and initiator is unimportant. There is no evidence from the literature that chain transfer to VF2 can occur, while chain transfer to HFP, PBP, or Freon 113 are unlikely since these compounds do not contain hydrogen.

Molecular weights determined using both GPC and NMR end-group analysis agree reasonably well. However, the agreement may be somewhat fortuitous since the GPC results are relative to polystyrene standards, and in view of the assumptions in the NMR end-group calculation.

5.3.2 Thermal Properties. Table 4 shows the thermal properties of the highest molecular weight copolymer for each of the three copolymer compositions synthesized in this work (Experiments \# 4, 8, and 12 in Table 1). No crystallization or melting was observed for these copolymers. This is consistent with the fact that VF2/HFP copolymers become completely amorphous for an HFP content higher than $19-20 \mathrm{~mol} \%^{2,3}$. From Table 4, the increase of the $-\mathrm{CF}_{3}$ side group with increasing HFP content in the copolymer raised the glass transition temperature $\left(T_{g}\right)$. This increase of $T_{g}$ with increasing HFP-content is consistent with the $T_{g}$ of PVDF homopolymer (Typical $T_{g}$ for PVDF= -40 $\left.{ }^{\circ} \mathrm{C}^{30}\right)$ and that of ca. $10 \%$ HFP poly(VF2-co-HFP) $\left(-31.4{ }^{\circ} \mathrm{C}^{16}\right)$. 
Table 4: Thermal properties of poly(VF2-co-HFP) synthesized in experiment \#5 in Table 1

\begin{tabular}{ccccc}
\hline Experiment & $\# 4$ & $\# 8$ & $\# 12$ \\
$\%$ mol HFP in copolymer ${ }^{(c)}$ & 24.4 & 26.2 & 30.8 \\
\hline$T_{g}^{(a)}\left({ }^{\circ} \mathrm{C}\right)$ & -20.8 & -18.4 & -15.6 \\
$T_{d}^{(b)}\left({ }^{\circ} \mathrm{C}\right)$ & 347 & 377 & 374 \\
${ }^{(a)}$ Glass transition temperature; ${ }^{(b)} 1 \mathrm{wt} \%$ decomposition temperature in nitrogen; \\
analysis
\end{tabular}

5.3.3 Effect of Total Monomer Concentration. For each HFP/VF2 feed ratio, four experiments were carried out with $\left[M_{T}\right]_{\text {in }}$ varying from 1.5 to $6.5 \mathrm{~mol} / \mathrm{L}$, at otherwise identical conditions. The results are given in Table 1 and Figs. 3(a-d), 4(a-d), and 5(a-d) for the 59/41, 66/34, and 73/27 HFP/VF2 feed ratios respectively. In a CSTR, the concentration that affects the polymerization is the concentration inside the reactor, which is the same as the effluent concentration $\left(\left[M_{T}\right]_{\text {out }}\right)$. Consequently, the results in these figures are plotted versus the average $\left[M_{T}\right]_{\text {out }}$ from F-EA and NMR $\left(\left[M_{T}\right]_{\text {out-av }}\right)$. All experiments were run at the same temperature, average residence time $(\tau)$ and feed initiator concentration $\left(\left[I_{\text {in }}\right)\right.$. Therefore, the initiator concentration in the CSTR and in the effluent $\left([]_{\text {out }}\right)$ should be the same for each of these experiments (Eq. 7).

$$
[I]_{\text {out }}=\frac{[I]_{\text {in }}}{1+k_{d} \tau}
$$

where: $k_{d}$ is decomposition rate constant of the initiator.

The (a) and (b) plots in Figs. 3, 4, and 5 show the effect of $\left[M_{T}\right]_{\text {out }}$ on $R_{P}$ and $\left(M_{n}\right)_{G P C}$ respectively. For all the three monomer feed ratios, both $R_{P}$ and $M_{n}$ increase with 
$\left[M_{T}\right]_{\text {out }}$ in a linear manner. The dotted lines in the (a) and (b) plots represent the best fit of the experimental data by a straight line passing through the origin. The fit is excellent, with a coefficient of determination $\left(\mathrm{R}^{2}\right)$ near unity for all three feed ratios. The first-order dependence of $R_{P}$ and $M_{n}$ on the monomer concentration is characteristic of a conventional solution polymerization. This is expected for the $73 / 27 \mathrm{HFP} / \mathrm{VF} 2$ feed ratio since all of these polymerizations were homogeneous. However, for the $66 / 34$ and 59/41 feed ratios, some of the polymerizations were homogenous, while others were heterogeneous, i.e., the polymer precipitated during the reaction. In particular, the lowmolecular weight copolymers, formed at low inlet monomer concentrations, were soluble while the high molecular weight polymers precipitated during the polymerization. Nevertheless, for these two feed ratios, all of the data points fell on the same straight line, suggesting that precipitation does not influence the $R_{P}$ and $M_{n}$. The same linear dependence was reported previously for the copolymerization of a semicrystalline compositions of poly(VF2-co-HFP) (with ca. $10 \mathrm{~mol} \% \mathrm{HFP}$ ) in $\mathrm{scCO}_{2}{ }^{16}$. The copolymerization of these fluoropolymers appears to occur mainly in the $\mathrm{CO}_{2}$-rich fluid phase. If there had been a significant amount of polymerization in the precipitated polymer phase, a higher order of dependence of both $R_{p}$ and $M_{n}$ on total monomer concentration would have been observed ${ }^{22,23}$ especially for higher molecular weights. For example, in the polymerization of poly(acrylic acid) in $\mathrm{scCO}_{2}$ where the polymer phase was believed to be the main locus of polymerization ${ }^{23}$, the order with respect to $\left[M_{T}\right]_{o u t}$ was significantly greater than unity for both $R_{P}$ and the viscosity-average molecular weight $\mathrm{t}^{22}$. 


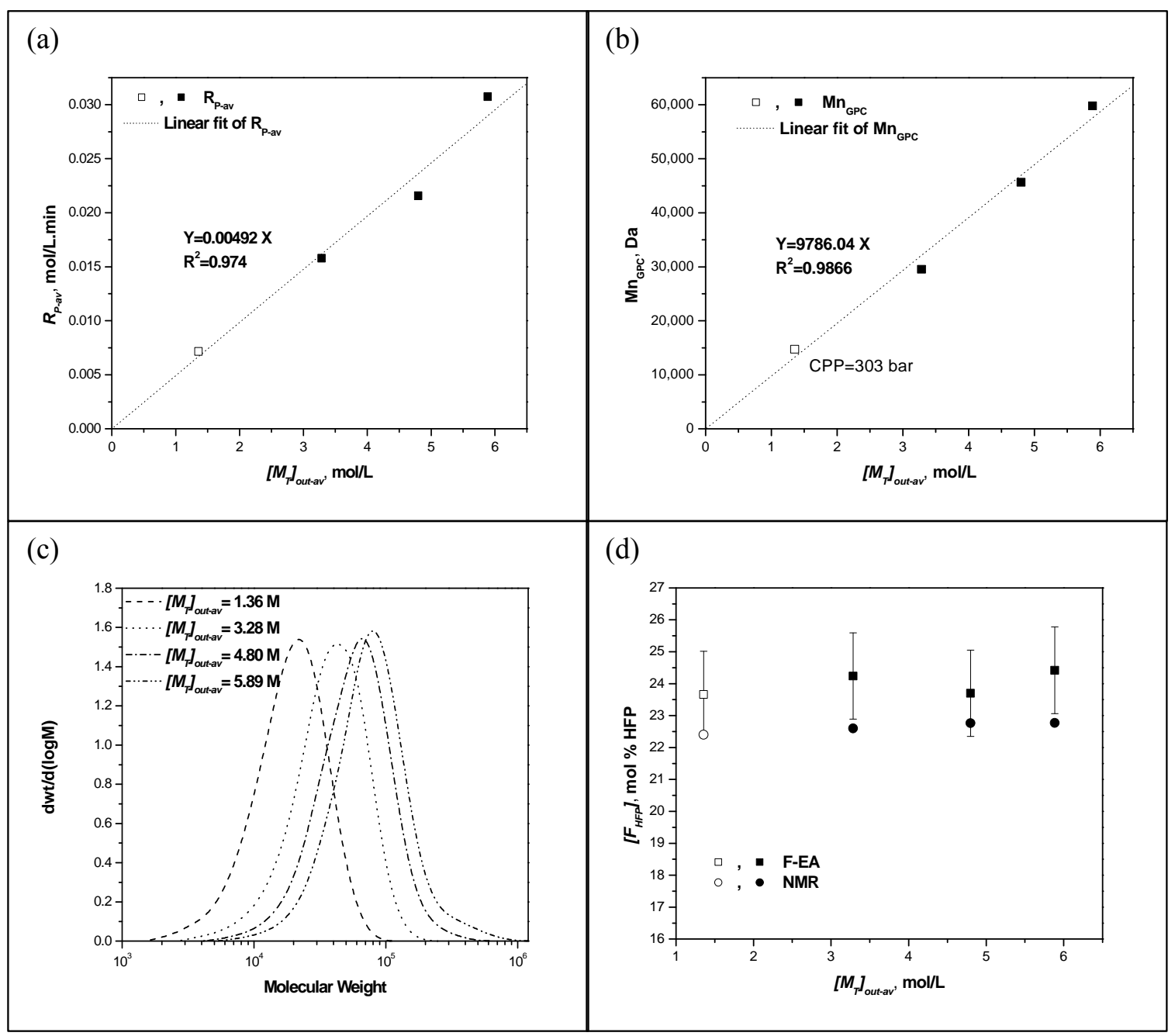

Figure 3: Effect of total monomer concentration for HFP/VF2 feed ratio of 59/41 on: (a) $R_{P}$; (b) $\mathrm{Mn}$; (c) MWDs ; (d) $\left[F_{H F P}\right]$. In (a), (b), and (d), the filled symbols are for heterogeneous polymerizations while the open ones are for homogeneous polymerizations. In (b), CPP is the cloud-point pressure. Reaction conditions are as in Table 1 


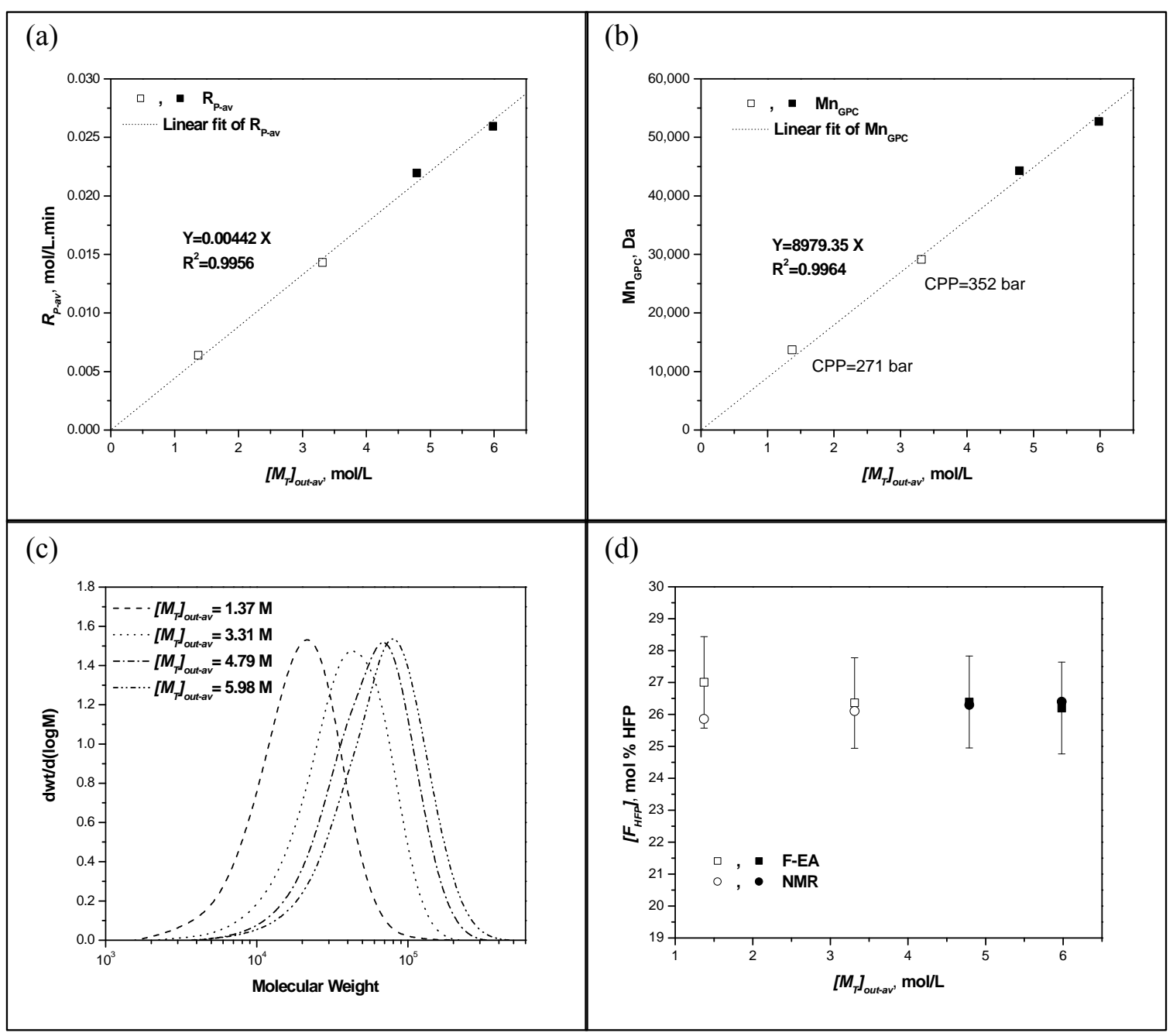

Figure 4: Effect of total monomer concentration for HFP/VF2 feed ratio of 66/34 on: (a) $R_{P}$; (b) $\mathrm{Mn}$; (c) MWDs ; (d) $\left[F_{H F P}\right]$. In (a), (b), and (d), the filled symbols are for heterogeneous polymerizations while the open ones are for homogeneous polymerizations. In (b), CPP is the cloud-point pressure. Reaction conditions are as in Table 1 


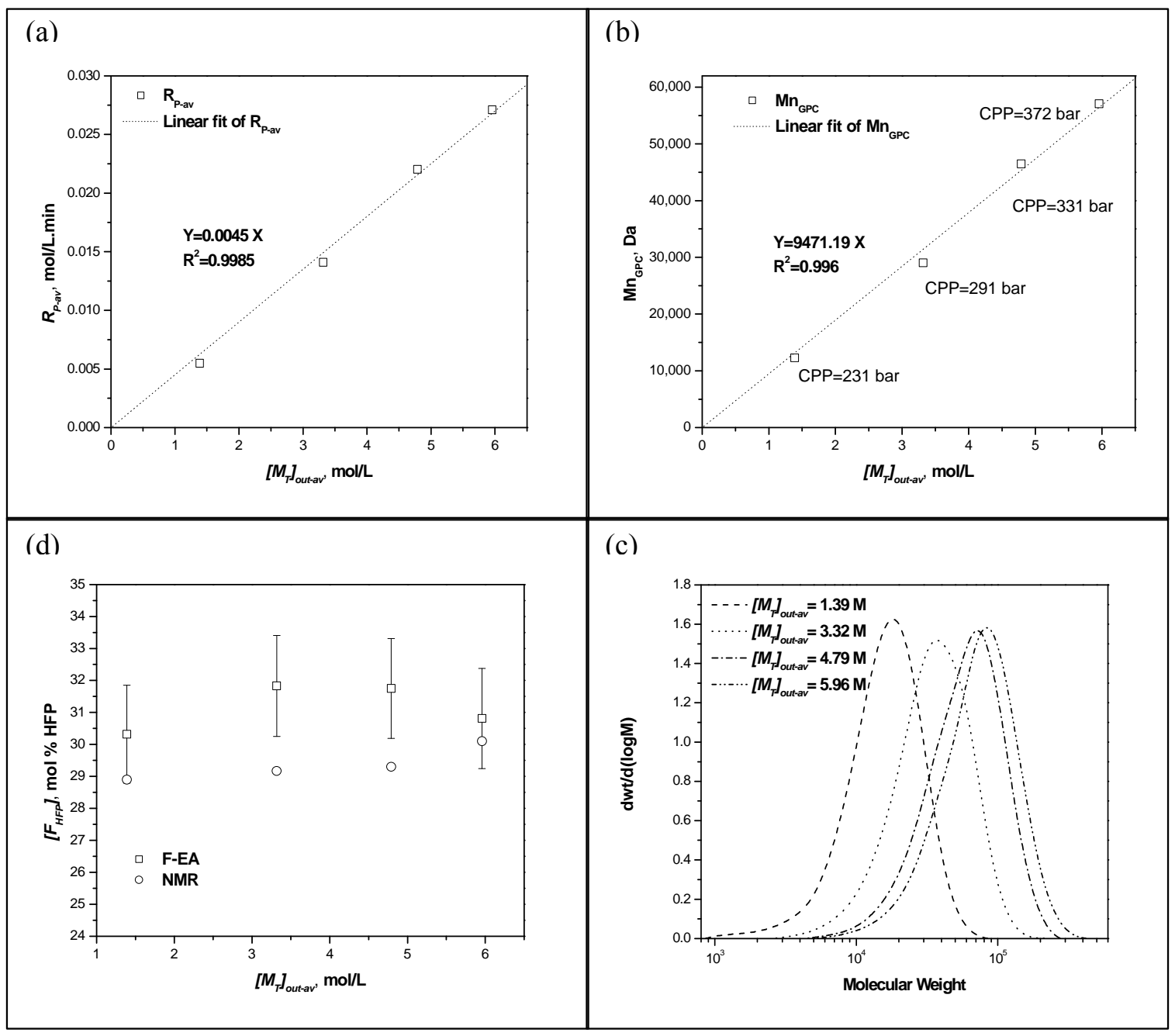

Figure 5: Effect of total monomer concentration for HFP/VF2 feed ratio of 73/37 on: (a) $R_{P}$; (b) $\mathrm{Mn}$; (c) MWDs ; (d) $\left[F_{H F P}\right]$. In (b), CPP is the cloud-point pressure. Reaction conditions are as in Table 1

The (c) plot in Figs. 3, 4, and 5 shows the molecular weight distributions (MWDs) of the synthesized copolymers for the three feed ratios. With one exception, the MWDs are unimodal with a polydispersity index (PDI) of 1.5 . The exception is for the 59/41 feed ratio, where a tail developed for the highest monomer concentration $(6.5 \mathrm{~mol} / \mathrm{L}$, experiment \# 4 in Table 1). Figure 6 shows the MWDs of the three current copolymers compared with the MWD of the copolymer produced with a 26.5/73.5 HFP/VF2 feed ratio $\left(9.2 \mathrm{~mol} \% \mathrm{HFP}\right.$ in the copolymer) recently reported ${ }^{16}$, for $\left[M_{T}\right]_{i n}=6.5 \mathrm{~mol} / \mathrm{L}$. The 
MWD of the 26.5/73.5 feed ratio copolymer has a long tail and a broad shoulder. Increasing the HFP/VF2 feed ratio to $59 / 41$ (23.3 mol\% HFP in the copolymer) diminished the tail, while further increase of the HFP content of the copolymer eliminated the tail completely for the $66 / 34$ and $73 / 27$ feed ratios (26.3 and $30.3 \mathrm{~mol} \%$ HFP in the copolymer, respectively). For comparison, the MWDs of PVDF homopolymer synthesized in $\mathrm{scCO}_{2}$ showed bimodal MWDs and much higher PDIs at lower monomer concentrations $^{20}$. Clearly, the bimodality/tail decreases with HFP content in the copolymer.

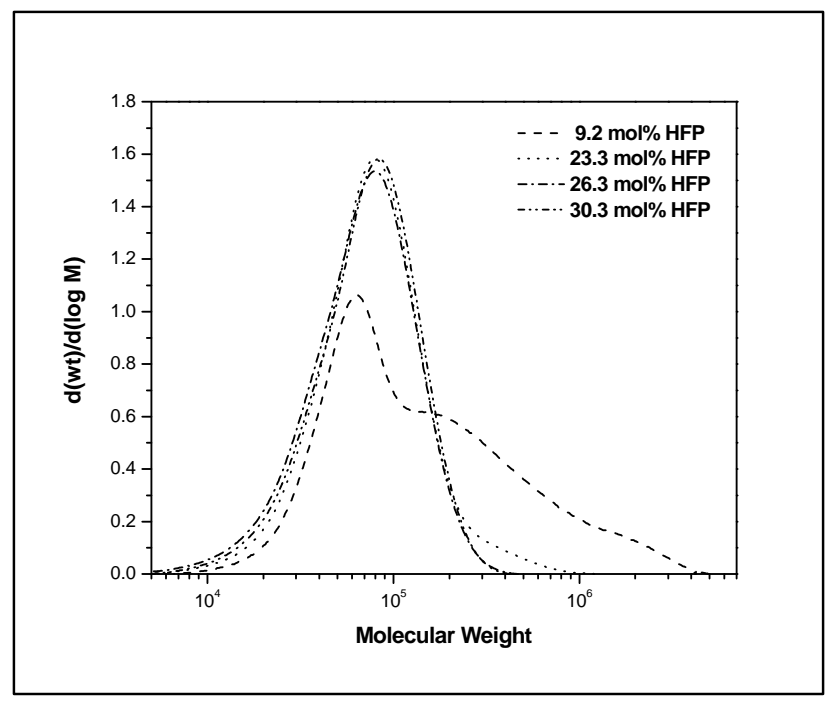

Figure 6: The MWDs of poly(HFP-co-VF2) synthesized in $\mathrm{scCO}_{2}$ for $\left[M_{T}\right]_{i n}=6.5 \mathrm{~mol} / \mathrm{L}, P=400$ bar, $T=40$ ${ }^{\circ} \mathrm{C}, \tau=20 \mathrm{~min},[I]_{\mathrm{in}}=3 \mathrm{mM}$.

Finally, the (d) plots in Figs. 3, 4, and 5 show the effect of total monomer concentration on HFP incorporation into the copolymer. For each feed ratio, the copolymer composition does not vary significantly with monomer concentration. Even though the copolymer precipitated during the experiments with high monomer concentrations for the 59/41 and 66/34 feed ratios, the precipitation did not affect the 
copolymer composition. In comparison, at a much lower feed ratio of 27/73 (ca. $10 \mathrm{~mol} \%$ HFP in copolymer) ${ }^{16}$, HFP incorporation into the copolymer decreased slightly with increasing total monomer concentration. This was attributed to preferential partitioning of HFP into the precipitated copolymer particles ${ }^{16}$. For the high HFP-content amorphous copolymers, no apparent partitioning is observed. This can be explained in two ways. First, solubility of the copolymer in $\mathrm{scCO}_{2}$ increases with HFP content ${ }^{31}$, causing the fraction of precipitated chains to decrease. This makes any partitioning less observable. The second possibility is the expected change in the partitioning itself as a result of the expanding of the polymer chains with the increase in their HFP-content in the copolymer. The expanding is itself a result of the increase of the solubility in the reaction mixture with the increase of HFP-content in the copolymer ${ }^{31}$.

5.3.4 Effect of Reaction Pressure. The effect of pressure was evaluated from 207 to 400 bars at otherwise identical conditions. The results are given in Table 2 and Figs. 7(a-d), 8(a-d), and 9(a-d) for the 59/41, 66/34, and 73/27 HFP/VF2 feed ratios, respectively. 


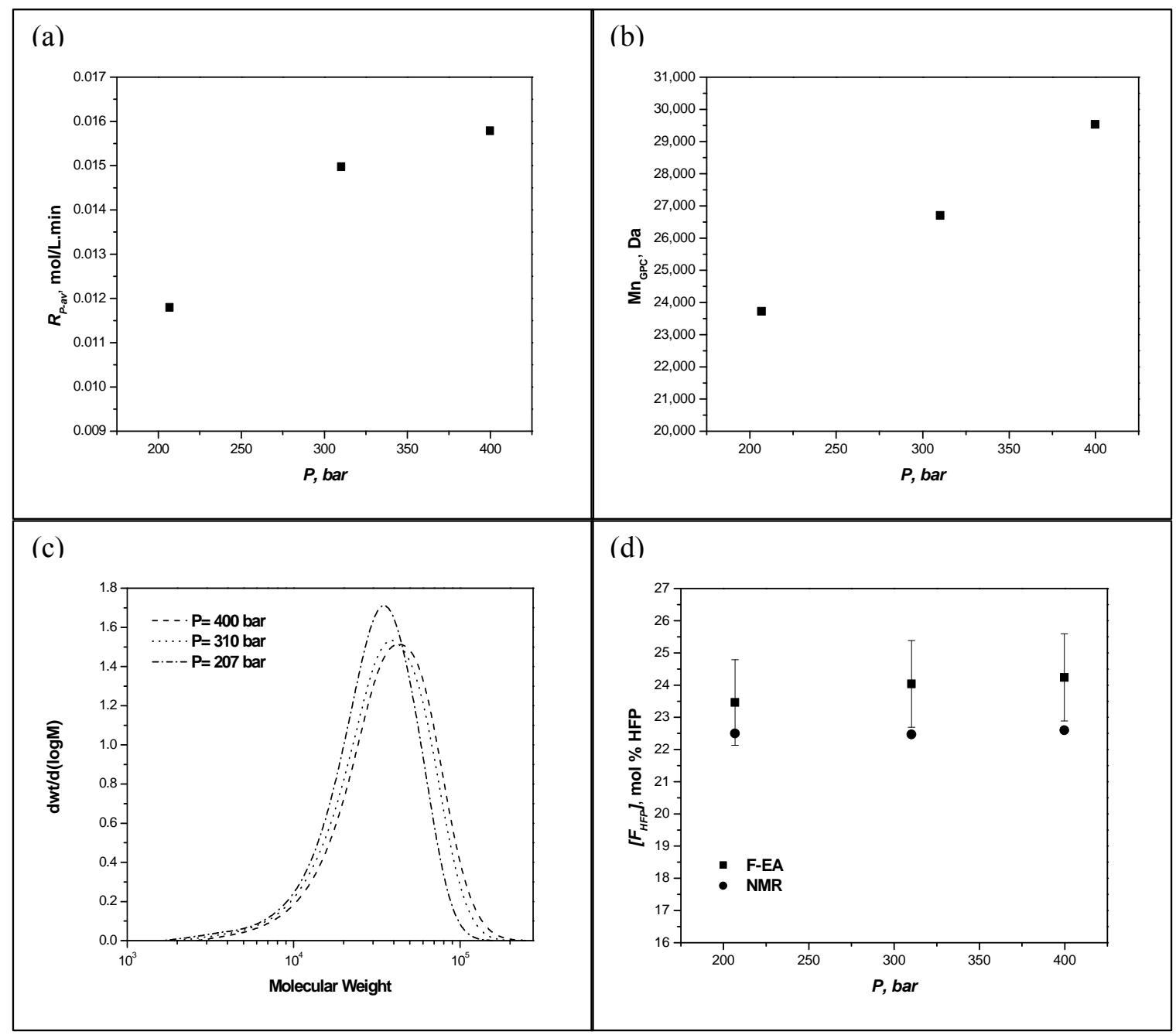

Figure 7: Effect of reaction pressure for HFP/VF2 feed ratio of 59/41 on: (a) $R_{P}$; (b) Mn; (c) MWDs ; (d) $\left[F_{H F P}\right]$. Reaction conditions are in Table 2. 


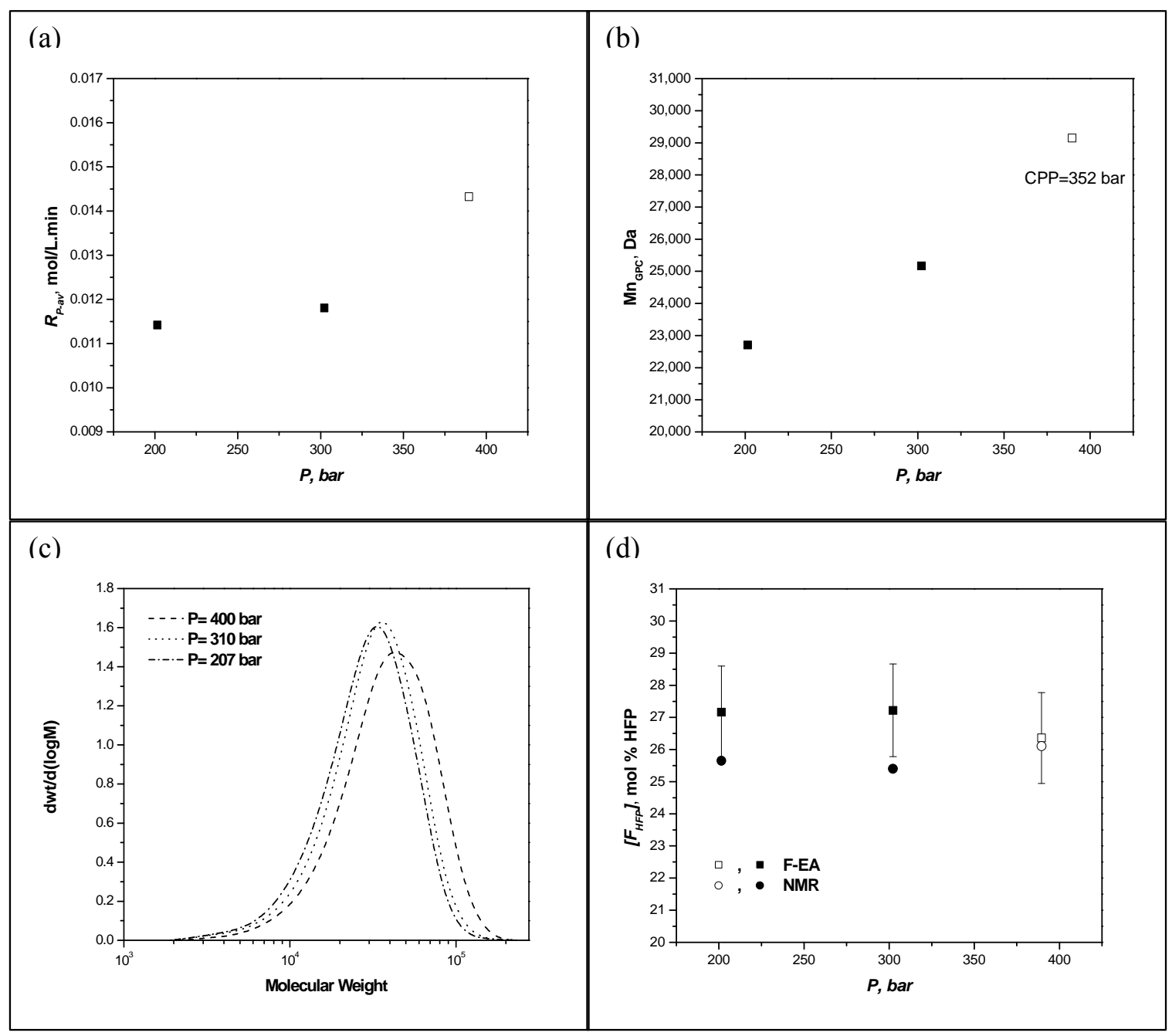

Figure 8: Effect of reaction pressure for HFP/VF2 feed ratio of 66/34 on: (a) $R_{P}$; (b) Mn; (c) MWDs ; (d) $\left[F_{H F P}\right]$. In (a), (b), and (d), the filled symbols are for heterogeneous polymerizations while the open ones are for homogeneous polymerizations. In (b), CPP is the cloud-point pressure. Reaction conditions are in Table 2 


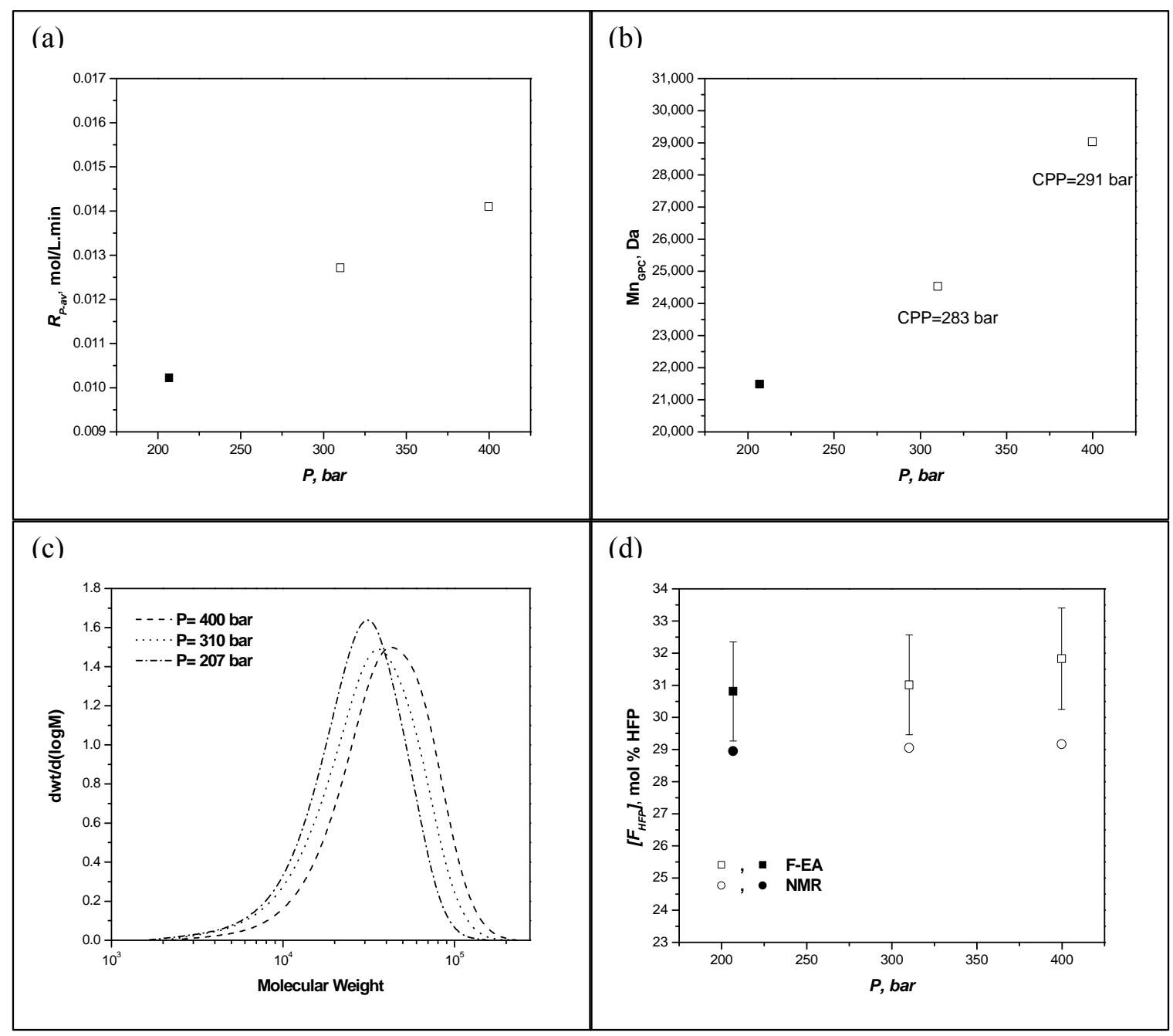

Figure 9: Effect of reaction pressure for HFP/VF2 feed ratio of 73/27 on: (a) $R_{P}$; (b) Mn; (c) MWDs ; (d) $\left[F_{H F P}\right]$. In (a), (b), and (d), the filled symbols are for heterogeneous polymerizations while the open ones are for homogeneous polymerizations. In (b), CPP is the cloud-point pressure. Reaction conditions are in Table 2

Plots (a) and (b) in Figs. 7, 8, and 9 show the effect of pressure on the $R_{P}$ and $M_{n}$ for the three feed ratios. The increase of pressure from 207 to 400 bar resulted in a 20$30 \%$ increase in both $R_{P}$ and $M_{n}$. For comparison, in case of the semicrystalline low-HFP copolymers, the effect was more pronounced with about an $80 \%$ increase for the same range of pressure ${ }^{16}$. 
For classical solution polymerization, Eqs. 8 and 9 describe the rate of polymerization and the number-average molecular weight respectively. For a copolymerization at constant temperature and pressure, the copolymerization propagation rate constant $\left(k_{p}\right)$ is a function of the mole fractions of the monomers, and their reactivity ratios. Equation 10 shows the expression for $k_{p}$ in the case of the terminal model ${ }^{32}$. The termination rate is usually diffusion-controlled ${ }^{32,33}$. For a copolymerization, the simplest "ideal diffusion" model for the copolymerization rate constant $\left(k_{t}\right)$ can be given by a linear combination of the termination rate constants for the two homopolymerizations (Eq. 11)

$$
\begin{gathered}
R_{P}=k_{p}\left(\frac{2 f k_{d}}{k_{t}}\right)^{0.5}[M][I]^{0.5} \\
M_{n}=\alpha M_{o} k_{p}\left(2 f k_{d} k_{t}\right)^{-0.5}[M][I]^{-0.5} \\
k_{p}=\frac{r_{1} f_{1}^{2}+2 f_{1} f_{2}+r_{2} f_{2}^{2}}{\left(r_{1} f_{1} / k_{11}\right)+\left(r_{2} f_{2} / k_{22}\right)} \\
k_{t}=F_{1} k_{t 1}+F_{2} k_{t 2}
\end{gathered}
$$

In these equations, $f$ is the initiator decomposition efficiency; $[M]$ and $[I]$ are the concentrations of monomer(s) and initiator in the reactor; $f_{i}, F_{i}, r_{i}, k_{i i}$, and $k_{t i}$ are the mole fraction in the feed, mole fraction in the copolymer, reactivity ratio, self propagation rate constant, and self termination rate constant for monomer $i$ respectively. The value of $\alpha$ is 1 for termination by disproportionation and 2 for termination by combination; $M_{o}$ is the average molecular weight of a monomer unit in the polymer. 
From transition state theory, the effect of pressure on a rate constant can be assessed from Eq. 12. If the activation volume is constant over the pressure range under consideration, Eq. 12 can be integrated to give Eq. 13.

$$
\begin{gathered}
\frac{d \ln k}{d P}=-\frac{\Delta V^{*}}{R T} \\
k_{2}=k_{1} \times \exp \left(-\frac{\Delta V^{*}}{R T}\left(P_{2}-P_{1}\right)\right)
\end{gathered}
$$

where: $\Delta V^{*}$ is the activation volume; $R$ is the universal gas constant; $T$ is the temperature; and $k_{1}$ and $k_{2}$ are the rate constants at pressures $P_{1}$ and $P_{2}$ respectively.

From the 73/27 feed ratio results, experiments \#17 and \#18 (Table 2) are for homogeneous solution polymerizations at 400 and 310 bar respectively. Hence, these two values can be used to estimate a value for the overall activation volume of polymerization. Using Eq. 8 and neglecting the effect of pressure on $f$ and $k_{d}$ for $\mathrm{PBP}^{18}$, $K_{\text {poly-400-bar }} / K_{\text {poly-310-bar }}=1.12$ is obtained, where $K_{\text {poly }}=k_{p} k_{d}^{0.5} / k_{t}^{0.5}$. By substituting in Eq. 13 , the overall activation volume of polymerization is estimated to be $-0.033 \mathrm{~L} / \mathrm{mol}$. This value agrees reasonably well with the reported values in the literature ${ }^{35}$. This activation volume accounts for about a $28 \%$ increase in $K_{\text {poly }}$ over the pressure range from 207 to 400 bar. Using the same procedure, Eq. 9 results in a value of $-0.035 \mathrm{~L} / \mathrm{mol}$ for the activation volume of $k_{p} /\left(k_{d} k_{t}\right)^{0.5}$, which predicts about $30 \%$ increase in $M_{n}$ for the same pressure range. Therefore, the observed increases in $R_{P}$ and $M_{n}$ with pressure for the high HFP-content copolymers can be accounted for by the effect of pressure on the reaction rate constants. This contrasts with the low HFP-content copolymers, where this effect was not sufficient ${ }^{16}$. 
Finally, plots (c) and (d) in Figs. 7, 8, and 9 show the effect of pressure on the MWDs and HFP incorporation in the copolymer. All the MWDs are perfectly unimodal. For each of there feed ratios, the copolymer composition is essentially constant. Similar to the effect of monomer concentration, no selective partitioning is observed with increasing pressure, i.e., with increasing copolymer fraction in the reactor. Again, this is different from the case of the low HFP-content copolymers ${ }^{16}$.

5.3.5 Copolymerization Reaction Constants. Whether the copolymer precipitated or not, $R_{P}$ and $M_{n}$ were linear with $\left[M_{T}\right]_{o u t}$ for all the three feed compositions. Consequently, Eqs. 8 and 9 can be used to estimate the copolymerization reaction constants. By fitting the experimental results to Eqs. 8 and 9 after setting $[M]=\left[M_{T}\right]_{\text {out }}$ and $[I]=[I]_{\text {out }}$, and combining them with Eq. 7 , values of $k_{p} / k_{t}^{0.5}$ for the copolymerization of VF2 with HFP and $k_{d}$ for PBP decomposition in $\mathrm{scCO}_{2}$ can be estimated as shown in Eqs. 14 and 15 respectively.

$$
\begin{gathered}
\frac{k_{p}}{k_{t}^{0.5}}=\left(\frac{S_{R p} \times S_{M n}}{\alpha M_{o}}\right)^{0.5} \\
k_{d}=\frac{\alpha M_{o}}{2 f\left[I_{i n}\right]\left(\frac{S_{M n}}{S_{R p}}\right)-\tau \alpha M_{o}}
\end{gathered}
$$

Here, $S_{R p}$ and $S_{M n}$ are slopes of the best fit passing through the origin for the experimental data of $R_{p}$ and $M_{n}$ versus $\left[M_{T}\right]_{\text {out }}$ respectively

Since there is no evidence in the literature for termination by disproportionation ${ }^{20}$, termination by combination was assumed and a value of $\alpha=2$ was used. A value of $f=0.6$ was assumed, similar to that observed for diethyl peroxydicarbonate decomposition in 
$\mathrm{ScCO}_{2}{ }^{18}$. Values of $M_{o}$ of $84.06,86.65$, and 90.08 were used for the $59 / 41,66 / 34$, and $73 / 27$ feed ratios, respectively. These $M_{o}$ values were calculated from the average of the copolymer compositions from F-EA and NMR (Table 1), for each feed ratio. Only the molecular weight data from GPC were used to obtain $S_{M n}$. However, as shown in Tables 1 and 2, the differences between molecular weights from GPC and NMR end-group analysis are small.

The results of this analysis are presented in Table 5 and in Fig. 10. For comparison, the values reported recently ${ }^{16}$ for PVDF and the low HFP-content copolymer made by continuous copolymerization (HFP/VF2 feed ratio of $26.5 / 73.5$; average copolymer composition of $9.2 \mathrm{~mol} \% \mathrm{HFP}$ ) are included. The values of $k_{p} / k_{t}^{0.5}$ in Fig. 10 are plotted versus HFP mol\% in the effluent monomer (Eq. 16) since this is the actual concentration inside the CSTR.

$$
\left(f_{H F P}\right)_{\text {out }}=\frac{\left(f_{H F P}\right)_{\text {in }}\left[M_{T}\right]_{\text {in }}-\tau F_{H F P}\left(R_{p}\right)_{a v}}{\left[M_{T}\right]_{\text {out }-a v}}
$$

where: $\left(f_{H F P}\right)_{\text {in }}$ and $\left(f_{H F P}\right)_{\text {out }}$ are the mole fraction of HFP in the feed and effluent monomers repectively; $F_{H F P}$ is the mole fraction of HFP in the copolymer, based on the average from NMR and F-EA. 
Table 5: Values for $k_{p} / k_{t}^{0.5}$ for poly(VF2-co-HFP) and PVDF, and $k_{\mathrm{d}}$ of the PBP initiator. $P=400$ bar and $T=40{ }^{\circ} \mathrm{C}$

\begin{tabular}{ccccc}
\hline & HFP/VF2 & Average & \\
& feed-ratio & HFP/VF2 & $k_{p} / k_{t}^{0.5}$ & $k_{d}$ \\
& & effluent-ratio & $\left(\mathrm{L}^{0.5} / \mathrm{mol}^{0.5} . \mathrm{s}^{0.5}\right)$ & $\left(10^{-4} \mathrm{~s}^{-1}\right)$ \\
\hline PVDF $^{16}$ & 0 & 0 & 1.3 & - \\
\hline Poly(VF2-co-9.2 mol\% HFP $)^{16}$ & $26.5 / 73.5$ & $28.2 / 71.8$ & 0.68 & 4.01 \\
Poly(VF2-co-23.3 mol\% HFP) & $59 / 41$ & $62.5 / 37.5$ & 0.54 & 7.38 \\
Poly(VF2-co-26.3 mol\% HFP) & $66 / 34$ & $69.6 / 30.4$ & 0.48 & 7.51 \\
Poly(VF2-co-30.3 mol\% HFP) & $73 / 27$ & $76.7 / 23.3$ & 0.49 & 7.55 \\
\hline
\end{tabular}

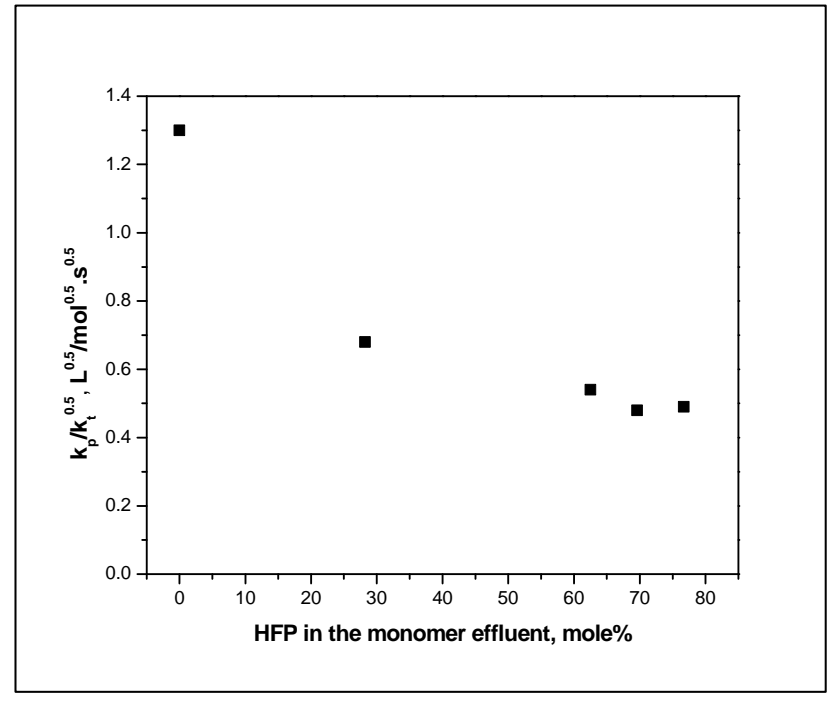

Figure 10: Effect of HFP on $k_{p} / k_{t}^{0.5}$ in $\mathrm{scCO}_{2}$ at 400 bar and $40{ }^{\circ} \mathrm{C}$

For low HFP/VF2 ratios, $k_{p} / k_{t}^{0.5}$ decreases significantly with increasing HFP mole fraction, while the decrease is much less for higher ratios. Since HFP has an essentially zero reactivity ratio ${ }^{4-6,31}$, HFP monomer units cannot add to growing chains with a 
terminal HFP unit. Therefore, $k_{p}$ is expected to decrease with increasing HFP/VF2 ratio since the polymeric radicals with terminal HFP units are much less reactive than radicals with terminal VF2 units. For the same reason, the intrinsic termination rate constant should also increase with increasing HFP mole fraction. However, since termination is diffusion-controlled ${ }^{32,33}$, at least for the high-molecular-weight chains, the effect of HFP concentration on the observed termination rate constant is weaker. In addition, $k_{p} / k_{t}^{0.5}$ is more sensitive to changes in $k_{p}$ than in $k_{t}$. Thus, the large observed decrease of $k_{p} / k_{t}^{0.5}$, especially at low HFP concentrations, is reasonable. Moreover, the increase of HFP content in the polymeric chains increases their solubility in $\mathrm{scCO}_{2}{ }^{31}$. This results in an increase of the viscosity of the reaction mixture, which decreases the observed termination rate constant. Hence, the rate of decrease of the $k_{p} / k_{t}^{0.5}$ ratio decreases with increasing HFP content.

Equation 15 was used to estimate the decomposition rate constant of PBP $\left(k_{d}\right)$ in the reaction mixture for each of the three feed ratios covered in this work (Table 5). In addition, the value of $k_{d}$ that we reported recently for the continuous polymerization of semicrystalline, low HFP copolymer is included for comparison. The difference in $k_{d}$ estimated from the low and high HFP copolymerization data may be the result of neglecting the possibility of initiator partitioning between the fluid phase and the polymer phase in case of the low HFP-content copolymer. This assumption is implicit when the feed initiator concentration $\left[I_{i n}\right]$ is used to calculate the concentration of the initiator in the CSTR $\left[I_{\text {out }}\right]$ from Eq. 7. Since all the experiments for the $73 / 27 \mathrm{HFP} / \mathrm{VF} 2$ feed ratio were homogeneous, the value of $k_{d}=7.55 \times 10^{-4} \mathrm{~s}^{-1}$ is free of this assumption and represents the actual decomposition constant of PBP in the reaction medium at 400 bar and $40{ }^{\circ} \mathrm{C}$. 
This value of $k_{d}$ was used in Eq. 15 to calculate a value of $\left[I_{i n}\right]$ for each feed composition. The resulting values were $2.99,2.97$, and $2.05 \mathrm{mmol} / \mathrm{L}$ for the $66 / 34,59 / 41$, and 26.5/73.5 monomer feed ratios, respectively. Compared to the actual initiator feed concentration of $3 \mathrm{mmol} / \mathrm{L}$, these values suggest that the partitioning of the initiator into the polymer phase is near nil for the high HFP-content amorphous copolymers, while appreciable for the low HFP semicrystalline ones. This can be rationalized by a decrease in the fraction of precipitated chains due to the increase of polymer solubility with HFP content, which in turn makes any partitioning less observable. In addition, the partitioning itself should decrease since the precipitated chains become more expanded with increasing the HFP-content.

5.3.6 Reactivity ratios. Table 6 shows the reactivity ratios reported in the literature for VF2/HFP free-radical copolymerizations. Most of the reported values of the reactivity ratio of $\operatorname{HFP}\left(r_{H F P}\right)$ are zero or very close to zero. However, there is a substantial difference in the reported values for the reactivity ratio of VF2 $\left(r_{V F 2}\right)$. This is probably due to differences from study to study in: a) the mode of polymerization (emulsion, precipitation, solution, etc); b) reaction conditions, and/or c) monomer composition drift for batch reactors. Additional differences can arise from the different analytical methods used for determining the copolymer composition. Most of the reported values are for copolymer compositions determined from NMR; and only a few are from F-EA. Moreover, due to the heterogeneity of the polymerization systems, most of the reported values contain a "concentration factor" that changes with reaction conditions. Therefore, the reported values should be considered as "effective" reactivity ratios. The 
only exception is the reactivity ratios for VF2/HFP solution copolymerization in acetonitrile reported by Gelin et al. at $120^{\circ} \mathrm{C}^{36}$.

Table 6: Reactivity ratio pairs for the copolymerization of VF2 with HFP in the literature

\begin{tabular}{cccc}
\hline Set \# & $r_{H F P}$ & $r_{V F 2}$ & Reference \\
\hline $\mathrm{A}^{*},(a)$ & 0 & 6.7 & Moggi et $\mathrm{al}^{37}$ \\
$\mathrm{~B}^{*},(a)$ & 0 & 5 & Logothetis et $\mathrm{al}^{38}$ \\
$\mathrm{C}^{*},(b)$ & 0 & 2.45 & Bonardelli et $\mathrm{al}^{39}$ \\
$\mathrm{D}^{*,(c)}$ & $0.12 \pm 0.05$ & $2.9 \pm 0.6$ & Gelin et $\mathrm{al}^{36}$ \\
$\mathrm{E}^{*,(d)}$ & 0 & $5.13 \pm 0.44$ & Tai et $\mathrm{al}^{40}$ \\
& $0^{(*)}$ & $3.6^{(*)}$ & \\
$\mathrm{F}^{(e)}$ & $0^{(* *)}$ & $8.2^{(* *)}$ & Beginn et $\mathrm{al}^{41}$ \\
& $0^{(* * *)}$ & $4.8^{(* * *)}$ & \\
$\mathrm{G}^{(f)}$ & $0 \pm 0.08^{(* * *)}$ & $3.61 \pm 0.71^{(* * *)}$ & \\
& $0.09 \pm 0.09^{(* * *)}$ & $4.67 \pm 0.77^{(* * *)}$ & Ahmed et $\mathrm{al}^{31}$ \\
$\mathrm{H}^{(g)}$ & 0 & $3.2^{(* * *)}$ & Ahmed et $\mathrm{al}^{16}$
\end{tabular}

(*) Based on copolymer composition obtained from NMR; ${ }^{(* *)}$ Based on copolymer composition obtained from F-EA; ${ }^{(* *)}$ Based on copolymer composition obtained from the average of both NMR and F-EA. ${ }^{(a)}$ Batch emulsion polymerization at $70-130{ }^{\circ} \mathrm{C}$ and $20-70$ bar (exact conditions not known); (b) Batch emulsion polymerization at $85{ }^{\circ} \mathrm{C}$ and 13.2 bar, values from NMR; ${ }^{(c)}$ Batch solution polymerization in acetonitrile at $120{ }^{\circ} \mathrm{C} ;{ }^{(d)}$ Batch precipitation polymerization in $\mathrm{scCO}_{2}$ at $55{ }^{\circ} \mathrm{C}$ and initial pressure of 276 bar; ${ }^{(e)}$ Batch polymerization in $\mathrm{scCO}_{2}$ at $50{ }^{\circ} \mathrm{C}$ and initial pressure of $280 \mathrm{bar}$; ${ }^{(f)}$ Batch polymerization in $\mathrm{scCO}_{2}$ at $35^{\circ} \mathrm{C}$ and initial pressure of 310 and $415 \mathrm{bar}$; ${ }^{(g)}$ Continuous precipitation polymerization of low HFP content in $\mathrm{scCO}_{2}$ at $40{ }^{\circ} \mathrm{C}$ and reaction pressure of 400 bar.

The Mayo-Lewis equation ${ }^{42}$ (Eq. 17) was used to calculate the reactivity ratios of HFP and VF2 from the present results. These ratios were estimated by fitting Eq. 17 to the experimental data using nonlinear regression (DataFit® with the LevenbergMarquardt algorithm ${ }^{43}$ ). The HFP mole fraction in the effluent monomer was calculated from Eq. 16; the HFP mole fraction in the copolymer was the average values from F-EA 
and NMR. The calculation was based on the three compositions covered in this work plus the fourth composition from our recent report of low HFP-content copolymerization ${ }^{16}$. Only the data for three homogeneous experiments for the three feed ratios in the current work (experiments \# 1, 5, and 9 from Table 1) plus the data for experiment \#1 in Table 1 from our recent report ${ }^{16}$ were used. This last experiment was chosen since it is expected to produce the least partitioning of the monomers ${ }^{16}$. The values of the reactivity ratios obtained with the $95 \%$ confidence limits are: $r_{H F P}=0 \pm 0.05$ and $r_{V F 2}=3.3 \pm 0.74$ at 40 ${ }^{\circ} \mathrm{C}$ and 400 bar.

$$
F_{H F P}=\frac{r_{H F P}\left(f_{H F P}\right)_{\text {out }}{ }^{2}+\left(f_{H F P}\right)_{\text {out }}\left(1-\left(f_{H F P}\right)_{\text {out }}\right)}{r_{H F P}\left(f_{H F P}\right)_{\text {out }}{ }^{2}+2\left(f_{H F P}\right)_{\text {out }}\left(1-\left(f_{H F P}\right)_{\text {out }}\right)+r_{\text {VF } 2}\left(1-\left(f_{H F P}\right)_{\text {out }}\right)^{2}}
$$

where: $\left(f_{H F P}\right)_{\text {in }}$ is the mole fraction of HFP in the feed monomers to the reactor and $F_{H F P}$ is the mole fraction of HFP in the copolymer, based on the average from NMR and F-EA.

\subsection{Conclusions}

The continuous copolymerization of VF2 with $\mathrm{HFP}$ in $\mathrm{scCO}_{2}$ was successfully carried out in a CSTR for three HFP/VF2 molar feed ratios: 59/41, 66/34, and 73/27. The effects of total monomer concentration and reaction pressure were both explored at otherwise constant conditions.

Both $R_{p}$ and $M_{n}$ increased linearly with total monomer concentration, and both increased with pressure by about 20-30\% from 207 to 400 bar at all three HFP/VF2 feed ratios. This latter increase was accounted for by the effect of pressure on the reaction rate constants. All of the MWDs were perfectly unimodal with a PDI of 1.5 except for the highest monomer concentration at the 59/41 feed ratio, in which a small tail appeared. A 
comparison with PVDF and the low HFP-content poly(VF2-co-HFP) previously reported, suggests that the bimodality/tail/PDI decreases with HFP content in the copolymer.

The $k_{p} / k_{t}^{0.5}$ ratio for the copolymerization decreased with increasing HFP content in the copolymer. However, its rate of change also decreased with increasing HFP content. The decrease of $k_{p} / k_{t}^{0.5}$ with increasing HFP was attributed to the low reactivity of HFP-terminated polymer radicals, while the increase of the viscosity of the reaction medium with increasing solubility of the high HFP-content copolymers could account for the decreased rate of change of $k_{p} / k_{t}^{0.5}$ with HFP content.

The value of $k_{d}$ of PBP at $40{ }^{\circ} \mathrm{C}$ in the reaction mixture was calculated from the homogeneous copolymerizations of the $73 / 27$ feed-ratio. A comparison with the values obtained from the copolymerizations at the other feed ratios suggests that PBP has an appreciable partitioning in the semicrystalline, low HFP-content polymer phase, but negligible partitioning in the high HFP-content amorphous copolymers.

\subsection{Acknowledgement}

This material is based upon work supported by the STC Program of the National Science Foundation under Agreement No. CHE-9876674.

\subsection{References}

1. Dixon, S.; Rexford, D. R.; Rugg, J. S. Industrial and Engineering Chemistry 1957, 49, (10), 1687-1690.

2. Apostolo, M.; Arcella, V.; Storti, G.; Morbidelli, M. Macromolecules 1999, 32, (4), 989-1003. 
3. Ajroldi, G.; Pianca, M.; Fumagalli, M.; Moggi, G. Polymer 1989, 30, (12), 21802187.

4. Ferguson, R. C. Journal of the American Chemical Society 1960, 82, (10), 24162418.

5. Pianca, M.; Bonardelli, P.; Tato, M.; Cirillo, G.; Moggi, G. Polymer 1987, 28, (2), 224-230.

6. Schmiegel, W. W. Angewandte Makromolekulare Chemie 1979, 76-7, (Mar), 3965.

7. Office for Official Publications of the European Communities. Document no.: 302M2690-Solvay/Montedison-Ausimont Merger Procedure. (http://ec.europa.eu/comm/competition/mergers/cases/decisions/m2690_en.pdf),

8. Abusleme, J. A.; Gavezotti, P. Suspension (co)polymerization with bis(dichlorofluoroacetyl) peroxide for preparation of hydrogen-containing thermoplastic fluoropolymers. US Patent: 5,569,728, 1995.

9. Arnold, R. G.; Barney, A. L.; Thompson, D. C. Rubber Chemistry and Technology 1973, 46, (3), 619-52.

10. Jagels, S., Materials Engineer in Solvay-Solexis, Thorofare, NJ, USA, Personal Communication. 2003.

11. Stevens, M. P., Polymer Chemistry: An Introduction. 3rd ed.; Oxford University Press: New York, 1999.

12. Humphrey, J. S.; Amin-Sanayei, R., Vinylidene Fluoride Polymers. In Encyclopedia of Polymer Science and Technology, 3rd ed.; Mark, H. F., Ed. Wiley: 2004; Vol. 4, pp 510-533. 
13. Preliminary Risk Assessment: Perfluorooctanic Acid (PFOA) and Fluorinated Telomers; US Environmental Protection Agency: April, 2003.

14. 2010/15 PFOA Stewardship Program; U.S. Environmental Protection Agency: January, 2006.

15. Kennedy, K. A.; Roberts, G. W.; DeSimone, J. M. Advances in Polymer Science 2005, 175, 329-346.

16. Ahmed, T. S.; DeSimone, J. M.; Roberts, G. W. Continuous Copolymerization of Vinylidene Fluoride with Hexafluoropropylene in Supercritical Carbon Dioxide: Low Hexafluoropropylene-Content Copolymers, Accepted for publication in Macromolecules 2007.

17. Charpentier, P. A.; DeSimone, J. M.; Roberts, G. W. Industrial \& Engineering Chemistry Research 2000, 39, (12), 4588-4596.

18. Charpentier, P. A.; DeSimone, J. M.; Roberts, G. W. Chemical Engineering Science 2000, 55, (22), 5341-5349.

19. Charpentier, P. A.; Kennedy, K. A.; DeSimone, J. M.; Roberts, G. W. Macromolecules Communications 1999, 32, (18), 5973-5975.

20. Saraf, M. K.; Gerard, S.; Wojcinski, L. M.; Charpentier, P. A.; DeSimone, J. M.; Roberts, G. W. Macromolecules 2002, 35, (21), 7976-7985.

21. Zhao, C. X.; Zhou, R. M.; Pan, H. Q.; Jin, X. S.; Qu, Y. L.; Wu, C. J.; Jiang, X. K. Journal of Organic Chemistry 1982, 47, (11), 2009-2013.

22. Liu, T.; Desimone, J. M.; Roberts, G. W. Journal of Polymer Science, Part A: Polymer Chemistry 2005, 43, (12), 2546-2555. 
23. Liu, T.; DeSimone, J. M.; Roberts, G. W. Chemical Engineering Science 2006, 61, (10), 3129-3139.

24. Liu, T.; Garner, P.; DeSimone, J. M.; Roberts, G. W.; Bothun, G. D. Macromolecules 2006, 39, (19), 6489-6494.

25. DiNoia, T. P.; McHugh, M. A.; Cocchiaro, J. E.; Morris, J. B. Waste Management 1998, 17, (2-3), 151-158.

26. Reid, R. C.; Prausnitz, J. M.; Poling, B. E., The Properties of Gases and Liquids. 4th ed.; McGraw Hill: 1987.

27. Thomson, G. H.; Brobst, K. R.; Hankinson, R. W. AIChE Journal 1982, 28, (4), 671-676.

28. Rindfleisch, F.; DiNoia, T. P.; McHugh, M. A. Journal of Physical Chemistry 1996, 100, (38), 15581-15587.

29. Isbester, P. K.; Brandt, J. L.; Kestner, T. A.; Munson, E. J. Macromolecules 1998, $31,(23), 8192-8200$.

30. Dohany, J. E., Poly(Vinylidene Fluoride). In Kirk-Othmer Encyclopedia of Chemical Technology, 4th ed.; Kirk-Othmer, Ed. John Wiley \& Sons: 1998.

31. Ahmed, T. S.; DeSimone, J. M.; Roberts, G. W. Macromolecules 2006, 39, (1), $15-18$.

32. Odian, G., Principles of Polymerization. 4th ed.; John Wiley \& Sons Inc: 2004.

33. Matyjaszewski, K.; Davis, T. P., Handbook of Radical Polymerization. WileyInterscience 2002.

34. Ito, K.; O'Driscoll, K. F. Journal of Polymer Science, Polymer Chemistry Edition 1979, 17, (12), 3913-3921. 
35. Luft, G.; Ogo, Y., Activation Volumes of Polymerization Reactions. In Polymer Handbook, 4th ed.; Brandrup, J.; Immergut, E. H.; Grulke, E. A., Eds. John Wiley \& Sons: New York, 1999; pp II-429.

36. Gelin, M.-P.; Ameduri, B. Journal of Fluorine Chemistry 2005, 126, (4), 577-585.

37. Moggi, G.; Bonardelli, P.; Russo, S. 6th Conv. Ital. Sci. Macromol., [Atti], 1983, 2, 405-408.

38. Logothetis, A. L. Progress in Polymer Science 1989, 14, (2), 251-296.

39. Bonardelli, P.; Moggi, G.; Turturro, A. Polymer 1986, 27, (6), 905-909.

40. Tai, H.; Wang, W.; Howdle, S. M. Macromolecules 2005, 38, (22), 9135-9142.

41. Beginn, U.; Najjar, R.; Ellmann, J.; Vinokur, R.; Martin, R.; Moeller, M. Journal of Polymer Science, Part A: Polymer Chemistry 2006, 44, (3), 1299-1316.

42. Mayo, F. R.; Lewis, F. M. Journal of the American Chemical Society 1944, 66, (9), $1594-1601$.

43. Marquardt, D. W. SIAM Journal of Applied Mathematics 1963, 11, (2), 431-441. 


\section{CHAPTER 6}

Kinetics of the Homopolymerization of Vinylidene Fluoride and its

Copolymerization with Hexafluoropropylene in Supercritical

Carbon Dioxide: The Locus of Polymerization

Chapter 6 is a manuscript that will be submitted for publication in Macromolecules 


\title{
Kinetics of the Homopolymerization of Vinylidene Fluoride and its Copolymerization with Hexafluoropropylene in Supercritical Carbon Dioxide: The Locus of Polymerization
}

\author{
Tamer S. Ahmed ${ }^{l}$, Joseph M. DeSimone ${ }^{1,2}$, and George W. Roberts ${ }^{1, *}$ \\ ${ }^{1}$ Department of Chemical and Biomolecular Engineering, North Carolina State University, Box \\ \# 7905, Raleigh, North Carolina 27695-7905 \\ ${ }^{2}$ Department of Chemistry, University of North Carolina at Chapel Hill, Box \# 3290, Chapel \\ Hill, North Carolina 27599-3290
}

\begin{abstract}
The continuous polymerization of vinylidene fluoride (VF2) and mixtures of VF2 with hexafluoropropylene (HFP) was carried out in supercritical carbon dioxide $\left(\mathrm{scCO}_{2}\right)$ using a continuous stirred-tank reactor (CSTR). Most of the polymerizations were heterogeneous, i.e., polymer particles precipitated during the reaction. However, some were homogenous, especially in the higher range of HFP content. The data were tested against three kinetic models to determine the main locus of polymerization. The first model, the "solution polymerization" model, is based on the assumption that all the polymerization reactions take place in the continuous, $\mathrm{CO}_{2}$-rich phase, with no reaction in the polymer phase. In the second model, the "surface polymerization" model, chain initiation occurs exclusively in the continuous phase, while chain propagation and termination occur in a thin zone on the surface of the polymer particles. The third model, the "interior polymerization" model, is similar to the "surface polymerization" model, except that propagation and termination take place uniformly throughout

\footnotetext{
${ }^{*}$ To whom correspondence should be addressed. Tel: +1-919-515-7328; Fax: +1-919-515-3465; E-mail address: groberts@eos.ncsu.edu
} 
the polymer particles. Both the surface and the interior polymerization models fail to fit the experimental results. On the other hand, the solution polymerization model is able to describe the experimental results of the polymerizations fairly well over the whole range of polymer compositions. This suggests that the $\mathrm{CO}_{2}$-rich continuous phase is the main locus of polymerization in the precipitation polymerization of VF2 homopolymer and VF2/HFP copolymers $\mathrm{scCO}_{2}$.

\subsection{Introduction}

Considerable effort has been devoted since the early 1990’s to find environmentally benign solvents and processes for fluoropolymers synthesis, particularly as a result of increased environmental regulations $^{1,2}$. Fluoropolymers are typically manufactured commercially in aqueous suspension or/and emulsion polymerization systems ${ }^{3}$. Such processes require the use of large quantities of water and fluorinated surfactants for emulsion polymerization. Many of the fluorinated surfactants typically employed in aqueous emulsion polymerizations and sometimes in suspension polymerizations are currently under scrutiny due to bioaccumulation and environmental persistence ${ }^{4,5}$. These issues have resulted in an increasingly urgent impetus for transition from the conventional fluoropolymer synthesis processes to alternatives that meet the requirements of emerging public and regulatory demands ${ }^{6}$.

Supercritical carbon dioxide $\left(\mathrm{scCO}_{2}\right)$ has been demonstrated to be a promising alternative

reaction medium for polymerizations ${ }^{2,7-13}$. Advantages of $\mathrm{CO}_{2}$ are associated particularly with its environmental compatibility, low viscosity, ease of separation from the polymeric product, inertness to chain transfer reactions, and the ease of tuning of its properties because of its 
accessible critical point. In addition, monomers that are difficult or even impossible to polymerize in an aqueous system, either because of their solubility or because of their reaction with water, can be polymerized in $\mathrm{scCO}_{2}$. Moreover, polymers produced in $\mathrm{CO}_{2}$ show some unique physical or structural properties, which may facilitate processing or open new applications for such polymers ${ }^{14,15}$. Since only amorphous or low-melting fluoropolymers and silicones show appreciable solubility at relatively mild temperatures and pressures $\left(\mathrm{T}<100{ }^{\circ} \mathrm{C}\right.$, $\mathrm{P}<400$ bar) ${ }^{1,16}$, only these two classes of polymers can be synthesized by a homogeneous polymerization in $\mathrm{scCO}_{2}$. All other types of polymers must be made by heterogeneous methods, such as precipitation, dispersion, emulsion, and suspension polymerizations, since the polymers are insoluble in $\mathrm{scCO}_{2}$ at reasonable conditions. The majority of the polymerizations in $\mathrm{scCO}_{2}$ reported in the literature are precipitation polymerizations, and to a lesser extent, dispersion polymerizations $^{11}$.

During precipitation polymerization, polymer particles precipitate from the continuous phase. Depending on the characteristic time for polymerization compared to those for precipitation and transport of the radicals to the polymer particles, the growing radicals can either terminate in the continuous phase or enter the polymer phase without termination. In the latter case, propagation can continue in the polymer particles if there is appreciable monomer(s) partitioning into the polymer phase. In addition, the partitioning of the monomer(s) itself depends on many factors including the solubility of the monomers in the polymer, hydrodynamic conditions in the reactor, and the size of the polymer particles. Since diffusion of the macroradicals is hindered in the polymer phase, and the radical ends become less accessible to each other, bimolecular radical termination in the particles is very slow. The macroradicals can 
terminate mainly either by the diffusion of oligomers from the continuous phase or by primary termination if there is appreciable initiator partitioning in the polymer phase. This discussion shows the complexity of precipitation polymerization

Accordingly, three limiting scenarios can be distinguished. First, initiation, propagation, and termination occur mainly in the continuous phase. This scenario occurs if the kinetics of termination is much faster than the kinetics of precipitation/transport. A similar situation occurs if the solubility of the monomer is negligible in the polymer phase so that propagation in the polymer phase is negligible. The second scenario is when the radicals grow until precipitation/transport takes place, and the precipitated radicals continue growing in the polymer phase. In this case, both phases can be important loci of polymerization. The third scenario occurs when the growing radicals precipitate at very low chain lengths and polymerization continues in the polymer phase. In that case, the polymer phase is the main locus of polymerization.

The question of where polymerization occurs is of both theoretical interest and practical importance. An improperly controlled reaction can give rise to operational difficulty and safety problems, and can lead to out-of-specification product. In addition, knowledge of the locus of polymerization can help in tailoring the polymer properties. For example, the precipitation polymerization of poly(acrylic acid) (PAA) in $\mathrm{scCO}_{2}$ is believed to occur predominantly in the polymer phase ${ }^{17}$. Consequently, it was possible to synthesize cross-linked PAA particles in a single reactor process simply by adding a multi-functional monomer (cross-linker) to the monomer that was fed to the reactor ${ }^{18}$. By varying the cross-linker concentration, the polymer product could be made soluble, partially soluble, or insoluble in water. 
Recently, Mueller et al. developed a mathematical model for the precipitation polymerization process, and provided a methodology for understanding and predicting the relative contributions of the two different loci to the overall polymerization process. This model and methodology were applied for the dispersion polymerization of poly(methyl methacrylate) in $\mathrm{scCO}_{2}{ }^{19,} 20$ and the precipitation polymerization poly(vinylidene fluoride) (PVDF) in $\mathrm{scCO}_{2}{ }^{21}$. A large number of parameters are required to use this approach, and the results are very sensitive to the accuracy of these parameters, which are generally difficult to be estimated experimentally.

A much simpler methodology to determine the main locus of polymerization was reported by Liu et al. ${ }^{17}$. This approach was developed for use with a continuous stirred-tank reactor (CSTR). Briefly, a simple set of experiments is carried out where the amount of polymer in the reactor at steady state is varied at constant temperature and reaction pressure. This can be accomplished by running experiments where the inlet monomer concentration, and/or the inlet initiator concentration, and/or the average residence time are changed at constant temperature and pressure. The variation of the rate of polymerization $\left(R_{p}\right)$ and number-average molecular weight $\left(M_{n}\right)$ with the polymer volume fraction in the CSTR, permits one to distinguish between polymerization in the continuous phase, on the surface of the precipitated polymer, or inside the precipitated polymer. This methodology was applied to the precipitation polymerization in $\mathrm{scCO}_{2}$ of PAA and suggested that the main locus of polymerization was the polymer phase ${ }^{17}$.

Vinylidene fluoride (VF2) homopolymer and copolymers with hexafluoropropylene (HFP) are important commercial fluoropolymers ${ }^{3}$. The homopolymer (PVDF) is used generally in applications requiring the highest purity, strength, and resistance to solvents, acids, bases, and heat, in addition to low smoke generation during a fire event. It is widely used for fabricating 
pipe, tubing in plastic heat exchangers, column packing, valves, pumps, and membranes ${ }^{22}$. Vinylidene fluoride copolymers with HFP are divided into two main categories: a) the low-HFPcontent, semicrystalline copolymers with HFP about 5-15 mol\%, and; b) the high-HFP-content, amorphous copolymers with HFP higher than $19-20$ mol $\%^{23-26}$. The low-HFP-content copolymers are used in tubing, valves and fittings, cable and wire jacketing, lithium-ion batteries, and membranes while the high-HFP-content copolymers are used mainly as polymer processing aids to improve extrusion, blow molding, and rotomolding, and in sealing such as in gaskets and O-rings. Telomers of VF2 are soluble in $\mathrm{scCO}_{2}$ under $300 \mathrm{bars}^{27}$ while the highmolecular- weight polymer is only soluble above 1700 bar and $130{ }^{\circ} \mathrm{C}^{28}$. On the other hand, poly(VF2-co-HFP) is soluble in $\mathrm{scCO}_{2}$ at much lower conditions ${ }^{24,28,29}$.

The continuous precipitation polymerization of $\mathrm{PVDF}$ in $\mathrm{scCO}_{2}$ was reported by our research group ${ }^{15,30-32}$. This was followed by the continuous precipitation polymerization of lowHFP-content, semicrystalline Poly(VF2-co-HFP $)^{23}$, and the continuous precipitation and solution polymerizations of the high-HFP-content, amorphous Poly(VF2-co-HFP) ${ }^{24}$ in $\mathrm{scCO}_{2}$.

Bimodal molecular weight distributions (MWDs) were observed during the homopolymerization of VF2 in $\mathrm{scCO}_{2}{ }^{21,32}$, especially at high monomer concentrations. There was only a long tail/shoulder for low HFP-content copolymers depending on the monomer concentration $^{23}$. For high-HFP-content copolymers, a tail was observed only for very high monomer concentrations, for a copolymer composition of about 23 mol\% $\mathrm{HFP}^{24}$. When the HFP-content was about 26 mol\% HFP and higher, there was no tail and MWDs were perfectly unimodal with a polydespersity index (PDI) of $1.5^{24}$. The bimodality and broad MED of PVDF is the subject of some controversy. The bimodality has been attributed either to a simultaneous 
polymerization in both the fluid and the polymer phases, taking into account the transport of polymeric radicals between the two phases ${ }^{21}$, or to a homogeneous polymerization, recognizing the transition of the termination reaction from a kinetically-controlled regime to a diffusioncontrolled regime with increasing macroradical molecular weight ${ }^{33}$.

The objective of this publication is to apply the methodology reported by Liu et al. ${ }^{17}$ to the precipitation homopolymerization of VF2 and to the precipitation and homogeneous copolymerization of VF2 with HFP in $\mathrm{scCO}_{2}$. This will help to resolve the controversy concerning the locus of polymerization, helps to understand how the polymerization of these fluoropolymers proceeds in $\mathrm{scCO}_{2}$, and help to identify the source of bimodality in case of PVDF and the tail/shoulder in case of VF2/HFP copolymers.

\subsection{Experimental Section}

The equipment used for continuous precipitation polymerization in $\mathrm{scCO}_{2}$ was reported originally by our research group ${ }^{31}$. It consisted of an $800-\mathrm{mL}$ CSTR and a system of highpressure filters for the continuous collection of the polymer particles. This system was used for the continuous polymerization of $\mathrm{PVDF}$ in $\mathrm{scCO}_{2}$ at 276 bar and $75{ }^{\circ} \mathrm{C}$ with diethylperoxydicarbonate as the free radical initiator ${ }^{30-32,34}$. The apparatus and polymerization procedure used for PVDF polymerization are described in detail elsewhere ${ }^{30,32}$. For the lowHFP-content poly(VF2-co-HFP) (ca. 9.2 mol\% HFP), the copolymerization was done using a similar continuous system, but with a smaller CSTR $(100 \mathrm{~mL})^{23}$. The copolymerization experiments were done at 400 bar and $40{ }^{\circ} \mathrm{C}$ using perfluorobutyryl peroxide (PBP) as the free radical initiator. As a result of the high reactivity of PBP, the polymerization procedure was 
modified to minimize post polymerization ${ }^{23}$. Finally, the high HFP-content poly(VF2-co-HFP) copolymerization was reported recently ${ }^{24}$. Three different copolymer compositions (ca. 23.3, 26.3, and 30.3 mol\% HFP) were synthesized at 400 bar and $40{ }^{\circ} \mathrm{C}$ using PBP initiator. Some reactions were heterogeneous (i.e. precipitation polymerization) and some were homogeneous, depending on the copolymer composition, reaction pressure, and molecular weight. The postpolymerization collection system for the high poly(VF2-co-HFP) copolymerization was changed to allow the continuous collection of these amorphous copolymers ${ }^{24}$. The experimental results for the continuous polymerization of PVDF, low-HFP-content poly(VF2-co-HFP), and highHFP-content poly(VF2-co-HFP) that are analyzed below were reported by Saraf et al. ${ }^{32}$, and by $\mathrm{us}^{23,24}$.

\subsection{Results and Discussion}

Ideally, precipitation polymerization may occur at three different loci: the continuous solution phase, the surface of the precipitated polymer particles, or the interior of the precipitated polymer particles. The relative importance of these loci may depend on the reaction conditions. To understand the physical mechanism and kinetics of PVDF and poly(VF2-co-HFP) precipitation polymerization, three mathematical models that correspond to the three polymerization loci are compared with the experimental results.

6.3.1 Solution polymerization model. The main characteristic of the solution polymerization model is that all the reactions occur in the continuous phase, with no reaction in the polymer phase. This implies that the characteristic time of termination/transport of radicals is much less than that for precipitation, so that the polymeric radicals terminate before 
precipitation. This scenario is one limiting case of the reaction behavior. Liu et al. ${ }^{17}$ derived Eqs. 1 and 2 for the overall rate of polymerization $\left(R_{P}\right)$ and the number-average molecular weight $\left(M_{n}\right)$ for polymerization in a CSTR at steady state. For this model, the original expressions were for homopolymerization. However, with some changes, they can be applied for copolymerization. For example, at constant temperature and pressure, the copolymerization propagation rate constant $\left(k_{p}\right)$ is a function of the mole fractions of the monomers and their reactivity ratios. Equation 3 shows the expression for $k_{p}$ in the case of the terminal model ${ }^{35}$. In addition, the copolymerization termination rate constant is a combination of the termination rate constants for the two homopolymerizations. The termination rate is usually diffusioncontrolled $^{35,36}$. The simplest “ideal diffusion" model for $k_{t}$ is given by a linear combination of the termination rate constants for the two homopolymerizations (Eq. 4) ${ }^{37}$. Finally, for copolymerization, $[M]_{\text {out }}$ is replaced by the total monomer concentration in the effluent $\left(\left[M_{T}\right]_{\text {out }}\right)^{35}$. As the volume fraction of the polymer in the CSTR $\left(v_{p}\right)$ approaches zero, the expressions for $R_{P}$ and $M_{n}$ (Eqs. 1 and 2) reduce to the classical expressions for solution polymerization $^{35}$.

$$
\begin{gathered}
R_{P}=k_{p}\left(\frac{2 f k_{d}}{\left(2 k_{t}\right)}\right)^{0.5} \frac{\left[M_{T}\right]_{\text {out }}[I]_{\text {out }}^{0.5}\left(1-v_{p}\right)}{\left[1+(\alpha-1) v_{p}\right]\left[1+(\beta-1) v_{p}\right]^{0.5}} \\
\frac{M_{n}}{M_{o}}=\frac{\psi k_{p}}{\left(2 f k_{d}\left(2 k_{t}\right)\right)^{0.5}} \frac{\left[M_{T}\right]_{\text {out }}[I]_{\text {out }}^{-0.5}\left[1+(\beta-1) v_{p}\right]^{0.5}}{\left[1+(\alpha-1) v_{p}\right]} \\
k_{p}=\frac{r_{1} f_{1}^{2}+2 f_{1} f_{2}+r_{2} f_{2}^{2}}{\left(r_{1} f_{1} / k_{11}\right)+\left(r_{2} f_{2} / k_{22}\right)} \\
k_{t}=F_{1} k_{t 1}+F_{2} k_{t 2}
\end{gathered}
$$


In these equations, $k_{p}$ and $2 k_{t}$ are the average propagation and termination rate constants for the copolymerization; $k_{d}$ and $f$ are the initiator decomposition rate constant and decomposition efficiency; $\left[M_{T}\right]_{o u t}$ and $\left[I_{\text {out }}\right.$ are the concentrations of total monomer and initiator in the reactor and the effluent from the reactor; $v_{p}$ is polymer/copolymer volume fraction in the CSTR; $\alpha$ and $\beta$ are the partition coefficients of the total monomer and initiator between the polymer phase and the continuous phase (i.e., the ratio of the concentration in polymer phase to that in the continuous phase); $\psi$ equals 1 or 2 for termination by disproportionation or combination, respectively; $M_{o}$ is the average molecular weight of a monomer unit in the polymer; $f_{i}, F_{i}, r_{i}, k_{i i}$, and $k_{t i}$ are the mole fraction in the feed, mole fraction in the copolymer, reactivity ratio, self propagation rate constant, and self termination rate constant for monomer $i$, respectively.

Equation 1 can be rewritten as Eq. 5. If $\alpha$ and $\beta$ equal zero, the right-hand side of Eq. 5 will be a constant that depends only on the temperature and pressure of the reaction, but is independent of $v_{p}$. In this case, all of the monomer(s) and initiator are in the continuous phase, i.e., there is no partitioning of these components into the polymer particles. If $\alpha$ and/or $\beta$ are greater than zero, the right-hand side of Eq. 5 decreases with increasing $v_{p}$ since some of the monomer(s) and/or initiator are "stored" in the polymer particles, where they do not participate in the polymerization according to the assumption of the solution polymerization model. Consequently, a significant increase in $R_{P}\left(1-v_{p}\right)^{0.5} /\left(\left[M_{T}\right]_{\text {out }}\left[I_{\text {out }}{ }^{0.5}\right)\right.$ is a clear indication that the solution polymerization model is not obeyed since Eq. 5 is either independent of $v_{p}$ if there is no monomer(s) or initiator partitioning or shows a decrease in $R_{P}\left(1-v_{p}\right)^{0.5} /\left(\left[M_{T}\right]_{\text {out }}\left[I_{\text {out }}{ }^{0.5}\right)\right.$ with $v_{p}$ if there is partitioning. 


$$
\begin{aligned}
& \frac{R_{P}\left(1-v_{p}\right)^{0.5}}{\left[M_{T}\right]_{\text {out }}[I]_{\text {out }}^{0.5}}=k_{p}\left(\frac{2 f k_{d}}{\left(2 k_{t}\right)}\right)^{0.5} \frac{\left(1-v_{p}\right)^{1.5}}{\left[1+(\alpha-1) v_{p}\right]\left[1+(\beta-1) v_{p}\right]^{0.5}} \\
& \frac{M_{n}[I]_{\text {out }}^{0.5}\left(1-v_{p}\right)^{0.5}}{M_{o}\left[M_{T}\right]_{\text {out }}}=\frac{\psi k_{p}}{\left(2 f k_{d}\left(2 k_{t}\right)\right)^{0.5}} \frac{\left[1+(\beta-1) v_{p}\right]^{0.5}\left(1-v_{p}\right)^{0.5}}{\left[1+(\alpha-1) v_{p}\right]}
\end{aligned}
$$

Similarly, Eq. 2 can be rewritten as Eq. 6. The effect of monomer(s) and initiator partitioning on $M_{n}$ is more complex than in case of $R_{P}$. If $\alpha$ and $\beta$ equal zero, the right hand side of Eq. 6 will be independent of $v_{p}$ but will depend on the temperature and pressure of the reaction. For any other values for $\alpha$ and $\beta$, the right hand side of Eq. 6 will decrease with $v_{p}$ unless $\beta$ is high enough to outweigh the effect of $\alpha$. In this case, the decrease of the initiator concentration in the continuous phase outweighs the decrease of the monomer(s) concentration(s), resulting in higher molecular weight polymers and causing the right-hand side to increase.

Tests of the experimental data against the solution polymerization model are shown in Figs. 1, 2, and 3 for PVDF, low-HFP-content poly(VF2-co-HFP), and high-HFP-content poly(VF2-co-HFP), respectively. The experimental data for PVDF were generated by varying the inlet monomer concentration and the residence time at $75{ }^{\circ} \mathrm{C}$ and $276 \mathrm{bar}^{32}$. The experimental data for the low- and high-HFP-content poly(VF2-co-HFP) were generated by changing the inlet total monomer concentration only at $40{ }^{\circ} \mathrm{C}$ and $400 \mathrm{bar}^{23,24}$.

Figures 1 (a) and (b) shows plots of $R_{P}\left(1-v_{p}\right)^{0.5} /\left(\left[M_{T}\right]_{\text {out }}\left[I_{\text {out }}{ }^{0.5}\right)\right.$ and $M_{n}[I]_{\text {out }}{ }^{0.5}\left(1-v_{p}\right)^{0.5} /\left(\mathrm{M}_{\mathrm{o}}\right.$ $\left[M_{T}\right]_{o u t}$ ) versus $v_{p}$, respectively, for PVDF. In general, the data in both figures are showing an essentially constant trend. However, both $R_{P}\left(1-v_{p}\right)^{0.5} /\left(\left[M_{T}\right]_{\text {out }}\left[I_{\text {out }}{ }^{0.5}\right)\right.$ and $M_{n}\left[I_{\text {out }}{ }^{0.5}\left(1-v_{p}\right)^{0.5} /\left(\mathrm{M}_{\mathrm{o}}\right.\right.$ 
$\left[M_{T}\right]_{\text {out }}$ ) show a slight decrease trend for low polymer volume fractions. This decrease can be accounted for by VF2 and/or DEPDC initiator partitioning into the polymer phase. However, the decreases in $R_{P}\left(1-v_{p}\right)^{0.5} /\left(\left[M_{T}\right]_{\text {out }}\left[I_{\text {out }}{ }^{0.5}\right)\right.$ and $M_{n}\left[I_{\text {out }}^{0.5}\left(1-v_{p}\right)^{0.5} /\left(\mathrm{M}_{\mathrm{o}}\left[M_{T}\right]_{\text {out }}\right)\right.$ do not continue for the high polymer volume fractions. Since gelled fractions of the polymer are expected for these polymer fractions as a result of termination by combination coupled with chain transfer to polymer reaction ${ }^{38}$, the change of the partitioning is not surprising at high polymer volume fractions. As noted before, the only trend that confirms that the solution polymerization is not obeyed is the significant increase of $R_{P}\left(1-v_{p}\right)^{0.5} /\left(\left[M_{T}\right]_{\text {out }}\left[I_{\text {out }}{ }^{0.5}\right)\right.$ with $v_{p}$. Therefore, the trends of the data in Figs. 1(a) and (b) can be accounted for by the solution polymerization model and indicates that the continuous phase is the primary locus of polymerization for PVDF.

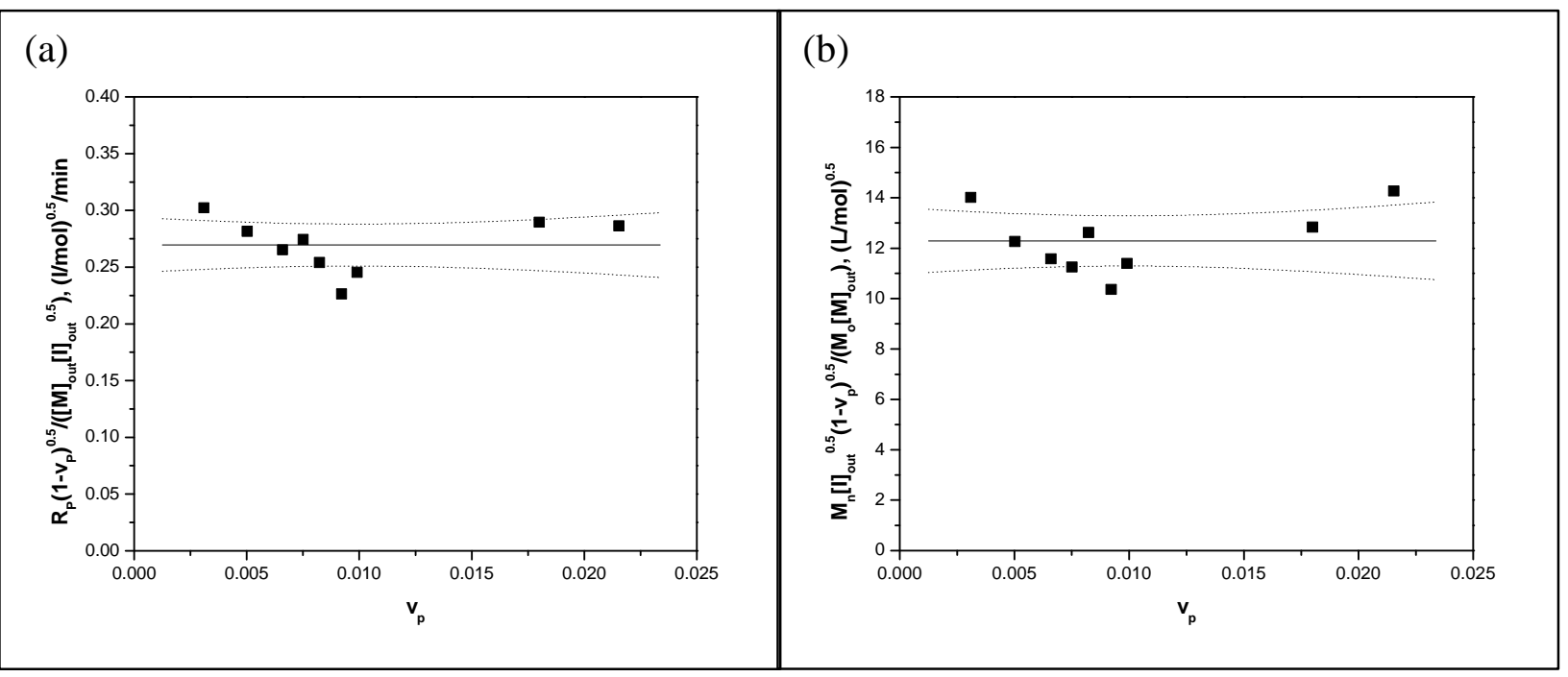

Figure 1: Test of the solution polymerization model for continuous polymerization of PVDF: (a) Rate of polymerization, (b) Molecular weight; $P=276$ bar, $T=75{ }^{\circ} \mathrm{C}$, varying inlet monomer concentration and average residence time ${ }^{32}$; The line is the best horizontal linear fit for the data; The dotted points are the $95 \%$ confidence bands for the linear fit. 
Figures 2 (a) and (b) shows plots of $R_{P}\left(1-v_{p}\right)^{0.5} /\left(\left[M_{T}\right]_{\text {out }}\left[I_{\text {out }}{ }^{0.5}\right)\right.$ and $M_{n}\left[I_{\text {out }} 0.5\left(1-v_{p}\right)^{0.5} /\left(\mathrm{M}_{\mathrm{o}}\right.\right.$ $\left.\left[M_{T}\right]_{o u t}\right)$ versus $v_{p}$, respectively, for low-HFP-content poly(VF2-co-HFP). The values of $R_{P}(1-$ $\left.v_{p}\right)^{0.5} /\left(\left[M_{T}\right]_{\text {out }}[]_{\text {out }}{ }^{0.5}\right)$ and $M_{n}\left[I_{\text {out }}{ }^{0.5}\left(1-v_{p}\right)^{0.5} /\left(\mathrm{M}_{\mathrm{o}}\left[M_{T}\right]_{\text {out }}\right)\right.$ in Fig. 2 are essentially constant. This behavior is consistent with the solution polymerization model, for conditions where the partitioning of the monomers and initiator is relatively small.

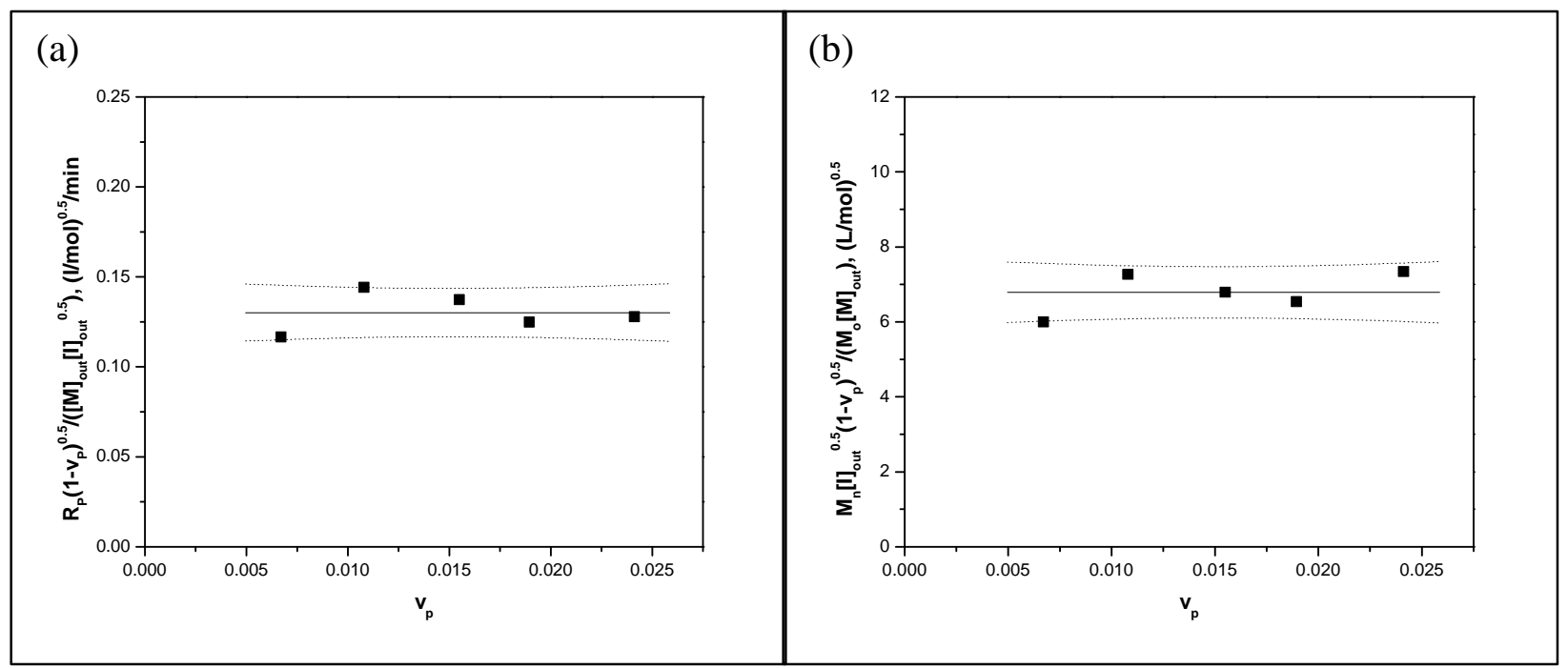

Figure 2: Test of the solution polymerization model for the continuous polymerization of low HFP-content poly(VF2-co-9.2mol\% HFP): (a) Rate of polymerization, (b) Molecular weight; $P=400$ bar, $T=40{ }^{\circ} \mathrm{C}$, varying inlet monomer concentration ${ }^{23}$; The line is the best linear fit for the data passing through the origin; The dotted points are the $95 \%$ confidence bands for the linear fit.

Finally, Figs. 3 (a) and (b) test the solution polymerization model against the high-HFPcontent poly(VF2-co-HFP). Three different copolymers are shown, with HFP contents of: 23.3, 26.3, and $30.3 \mathrm{~mol} \%$. The filled symbols in Fig. 3 are for polymerizations where the polymer precipitated during the course of the reaction. The open symbols are for homogenous 
polymerizations, where no precipitation occurred. Regardless of the mode of polymerization (i.e. precipitation or homogeneous), all the data obey the solution polymerization model fairly well. In Fig. 3, it is critical to recognize that the mode of polymerization (i.e. precipitation or homogeneous) has no effect on the trend of the experimental data. This confirms that the polymer phase does not make a significant contribution to the polymerization kinetics.

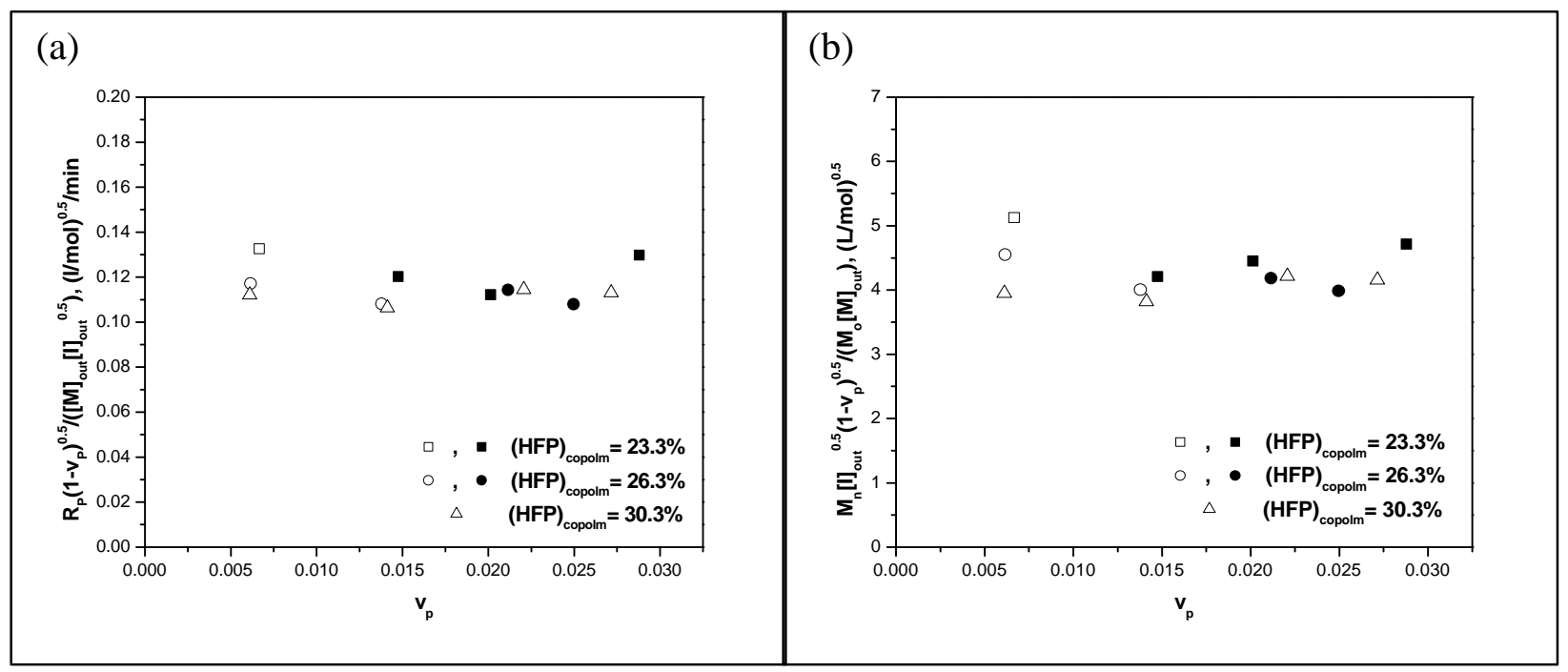

Figure 3: Test of the solution polymerization model for the continuous polymerization of high-HFP-content poly(VF2-co-HFP): (a) Rate of polymerization, (b) Molecular weight; $P=400$ bar, $T=40{ }^{\circ} \mathrm{C}$, varying inlet monomer concentration $^{24}$. Filled symbols: precipitation polymerization; Open symbols: homogeneous polymerization

6.3.2 Surface polymerization model. This model is based on two main assumptions. First, most polymer chains are assumed to precipitate or transport to the polymer phase at very low chain lengths, so that the rate of polymerization in the continuous phase is negligible compared to that in the polymer phase. This assumption implies that the characteristic time of termination is very slow compared to that of the transfer of radicals. Second, polymer particles are assumed to be so dense that diffusion of monomer(s) into the polymer particles is slow and 
polymerization takes place primarily in a thin layer on the particle surface. Chain initiation is assumed to take place in the solution phase, but chain propagation and chain termination take place exclusively on the polymer particle surface. Initiation in the polymer phase is ignored. This assumption can be rationalized by the expected very low decomposition efficiency of the initiator in the polymer particles since the efficiency is usually diffusion-controlled ${ }^{35}$. In addition, the surface polymerization model ignores any polymerization in the continuous phase. Consequently, it cannot account for the formation of new polymer particles, and it cannot be applied for very low conversions. With these assumptions, the overall rate of polymerization and the number-average molecular weight are described by Eqs. 7 and 8 for polymerization in an ideal $\operatorname{CSTR}^{17}$. These equations show that if surface polymerization model is obeyed, plots of $R_{P} /\left(\left[M_{T}\right]_{\text {out }}\left[I_{\text {out }}{ }^{0.5}\right)\right.$ and $M_{n}\left[I_{\text {out }}{ }^{0.5} /\left[M_{T}\right]_{\text {out }}\right.$ versus the cubic root of the polymer fraction in the reactor must form a straight line passing through the origin for constant temperature, pressure, and number of polymer particles per unit volume of the reactor $(N)$. Usually $N$ depends on the rate of initiation, which is a function of the average residence time in the CSTR. However, the dependence of Eqs. 7 and 8 on $N$ is weak since it is raised to the $1 / 6$ power. Thus, the right-hand side of Eqs. 7 and 8 should depend only on the temperature and pressure.

$$
\begin{gathered}
\frac{R_{P}}{\left[M_{T}\right]_{\text {out }}[I]_{\text {out }}^{0.5}}=(36 \pi N)^{1 / 6} \alpha \delta^{0.5} k_{p}\left(\frac{2 f k_{d}}{\left(2 k_{t}\right)}\right)^{0.5} v_{p}^{1 / 3} \\
\frac{M_{n}[I]_{\text {out }}^{0.5}}{M_{o}\left[M_{T}\right]_{\text {out }}}=\frac{\psi(36 \pi N)^{1 / 6} \alpha \delta^{0.5} k_{p}}{\left(2 f k_{d}\left(2 k_{t}\right)\right)^{0.5}} v_{p}^{1 / 3}
\end{gathered}
$$

where: $N$ is the number of polymer particles per unit volume and $\delta$ is the average thickness of the reaction zone on the polymer particle surface. 
The test of PVDF precipitation polymerization is shown in Figs. 4 (a) and (b) for the $R_{P}$ and $M_{n}$ experimental data respectively. All the experimental data for PVDF were used in the test of the surface polymerization model. However, for the sake of accuracy, the experimental data in Figs. 4 (a) and (b) generated by varying the average residence time are distinguished from those generated by varying the inlet monomer concentration. For both cases, the experimental data in Figs. 4 are far from being fitted by straight line passing through the origin, as the surface polymerization model requires.

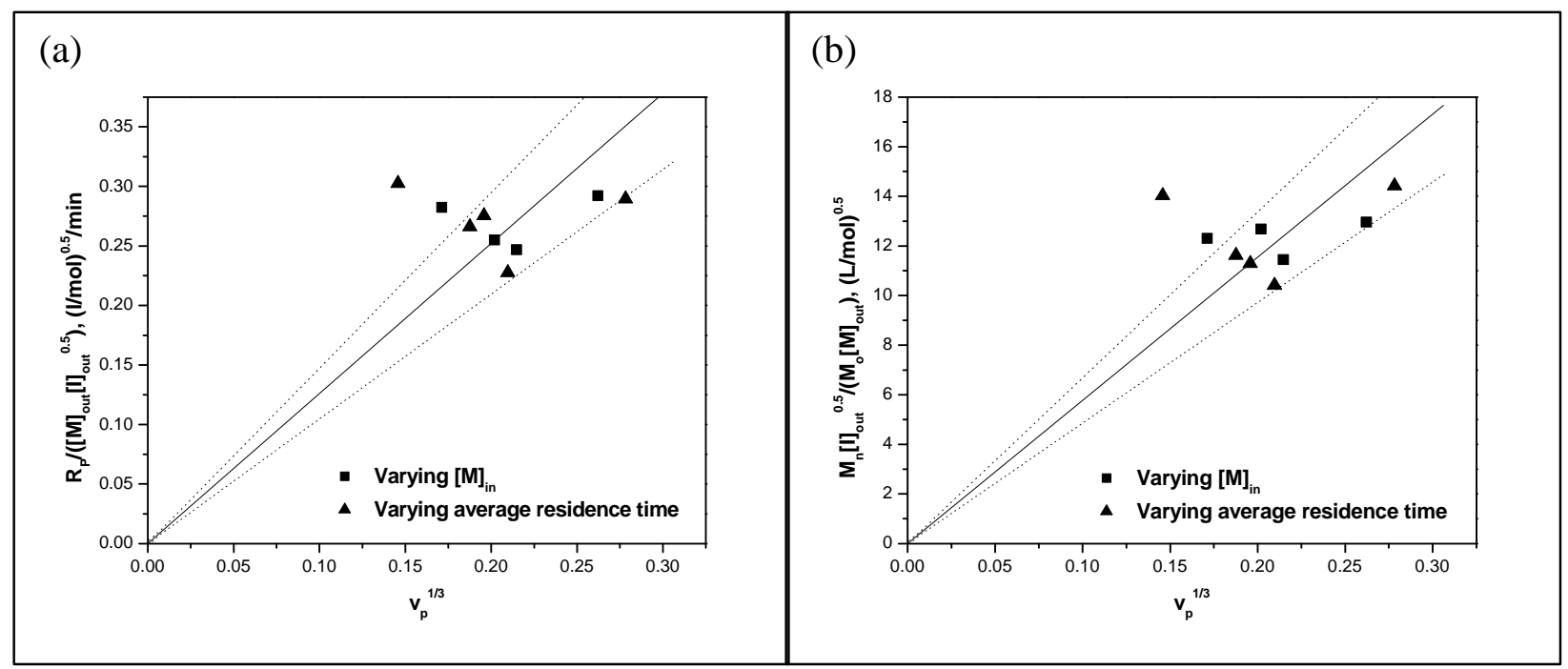

Figure 4: Test of the surface polymerization model for the continuous polymerization of PVDF: (a) Rate of polymerization, (b) Molecular weight; $P=276$ bar, $T=75{ }^{\circ} \mathrm{C}$, varying inlet monomer concentration and average residence time ${ }^{32}$; The line is the best linear fit for the data passing through the origin; The dotted points are the $95 \%$ confidence bands for the linear fit.

The data for the polymerization of low-HFP-content poly(VF2-co-HFP) is tested against the surface polymerization model in Figs. 5 (a) and (b). The dashed lines represent the best linear fit passing through the origin. Again, the results cannot be best fitted with a straight line passing 
through the origin. The surface polymerization model cannot account for the results of the continuous precipitation polymerization of low HFP-content poly(VF2-co-HFP).

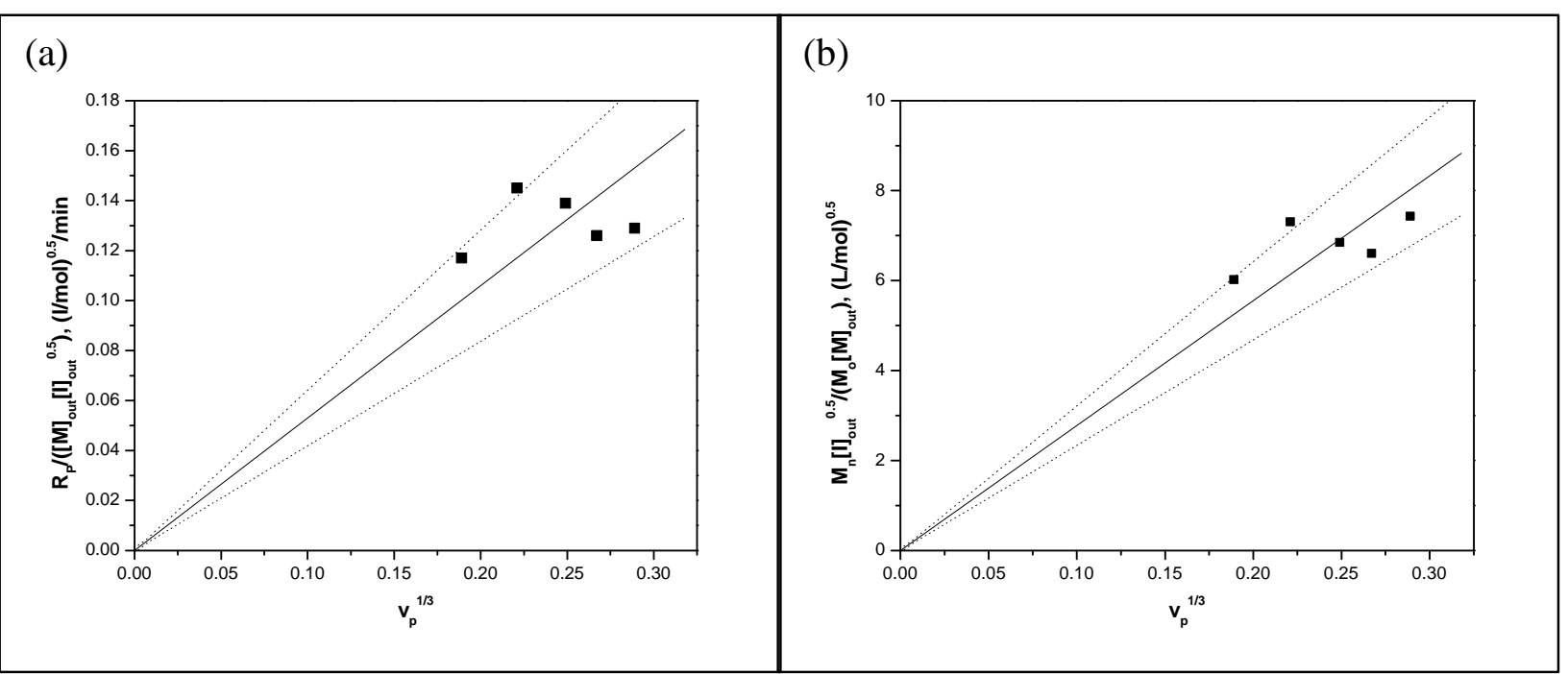

Figure 5: Test of the surface polymerization model for the continuous polymerization of low-HFP-content poly(VF2-co-9.2mol\% HFP): (a) Rate of polymerization, (b) Molecular weight; $P=400$ bar, $T=40{ }^{\circ} \mathrm{C}$, varying inlet monomer concentration ${ }^{23}$; The line is the best linear fit for the data passing through the origin; The dotted points are the $95 \%$ confidence bands for the linear fit.

Finally, Figs. 6 (a) and (b) are the test of the surface polymerization model for the highHFP-content polymerization. The data points where the polymerization was homogeneous are included to help in the comparison. The surface polymerization model fails completely; all the data are essentially independent of $v_{p}^{1 / 3}$. 


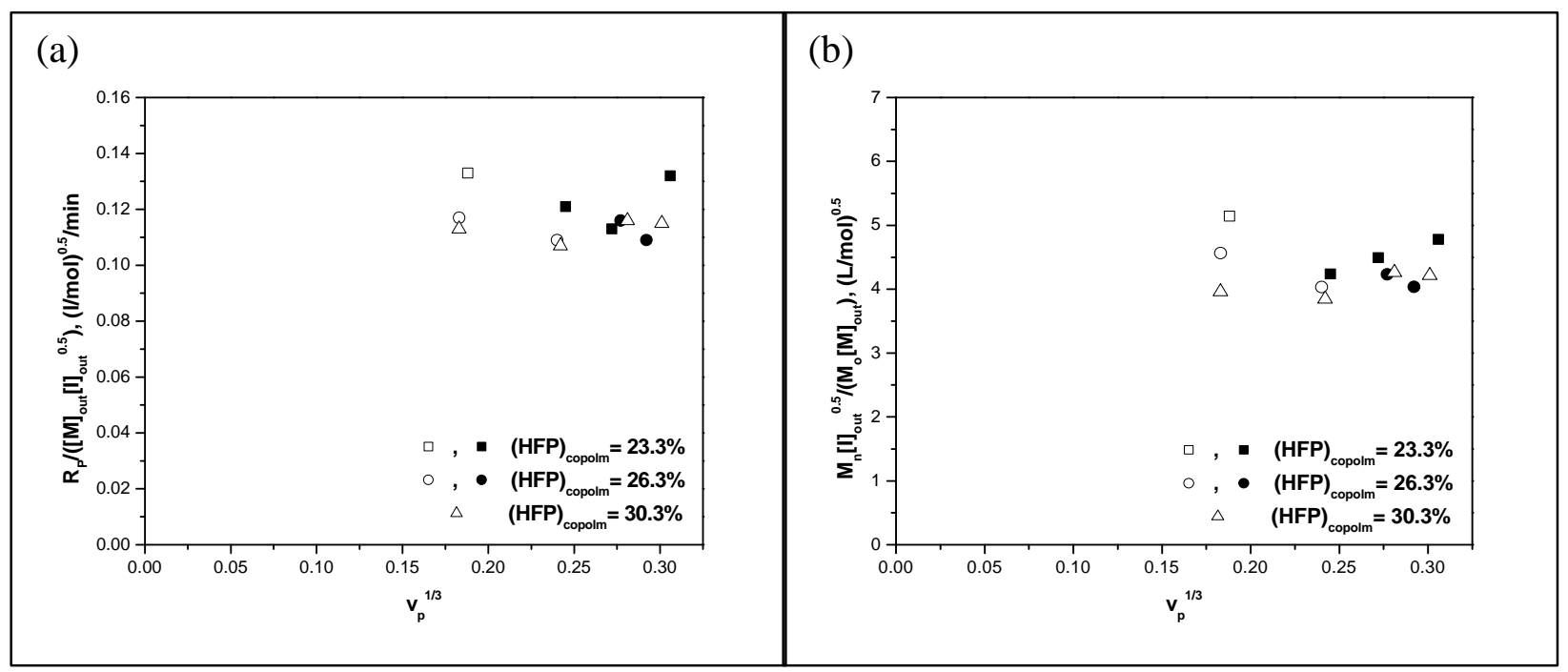

Figure 6: Test of the surface polymerization model for the continuous polymerization of high-HFP-content poly(VF2-co-HFP): (a) Rate of polymerization, (b) Molecular weight; $P=400$ bar, $T=40{ }^{\circ} \mathrm{C}$, varying inlet monomer concentration $^{24}$. Filled symbols: precipitation polymerization; Open symbols: homogeneous polymerization

6.3.3 Interior polymerization model. The interior polymerization model shares several important features with the surface polymerization model. First, the rate of polymerization in the continuous phase is negligible compared to that in the polymer phase. In addition, initiation takes place exclusively in the fluid phase. The two models differ in the way in which the monomer distributes throughout the polymer particles. In the interior polymerization model, the polymerization is assumed to occur homogenously through the whole volume of the polymer particles, and is not restricted to a small thin layer on the particles surface as in the surface model. With these assumptions, $R_{p}$ and $M_{n}$ for the copolymerization are described by Eqs. 9 and 10 for polymerization in an ideal CSTR ${ }^{17}$.

$$
\frac{R_{P}}{\left[M_{T}\right]_{\text {out }}[I]_{\text {out }}^{0.5}}=\alpha k_{p}\left(\frac{2 f k_{d}}{\left(2 k_{t}\right)}\right)^{0.5} v_{p}^{1 / 2}
$$




$$
\frac{M_{n}[I]_{\text {out }}^{0.5}}{M_{o}\left[M_{T}\right]_{\text {out }}}=\frac{\psi \alpha k_{p}}{\left(2 f k_{d}\left(2 k_{t}\right)\right)^{0.5}} v_{p}^{1 / 2}
$$

Tests of the interior polymerization model for PVDF, low-HFP-content poly(VF2-coHFP) and high-HFP-content poly(VF2-co-HFP) are shown in Figs. 7, 8, and 9, respectively. For the interior polymerization model to be obeyed, data obtained at constant temperature and pressure should lie on a straight line passing through the origin when potted against the square root of $v_{p}$. The data In Figs. 7, 8, and 9 do not fulfill this criterion. Clearly, the precipitation polymerization of PVDF and poly(VF2-co-HFP) cannot be described by the interior polymerization model.

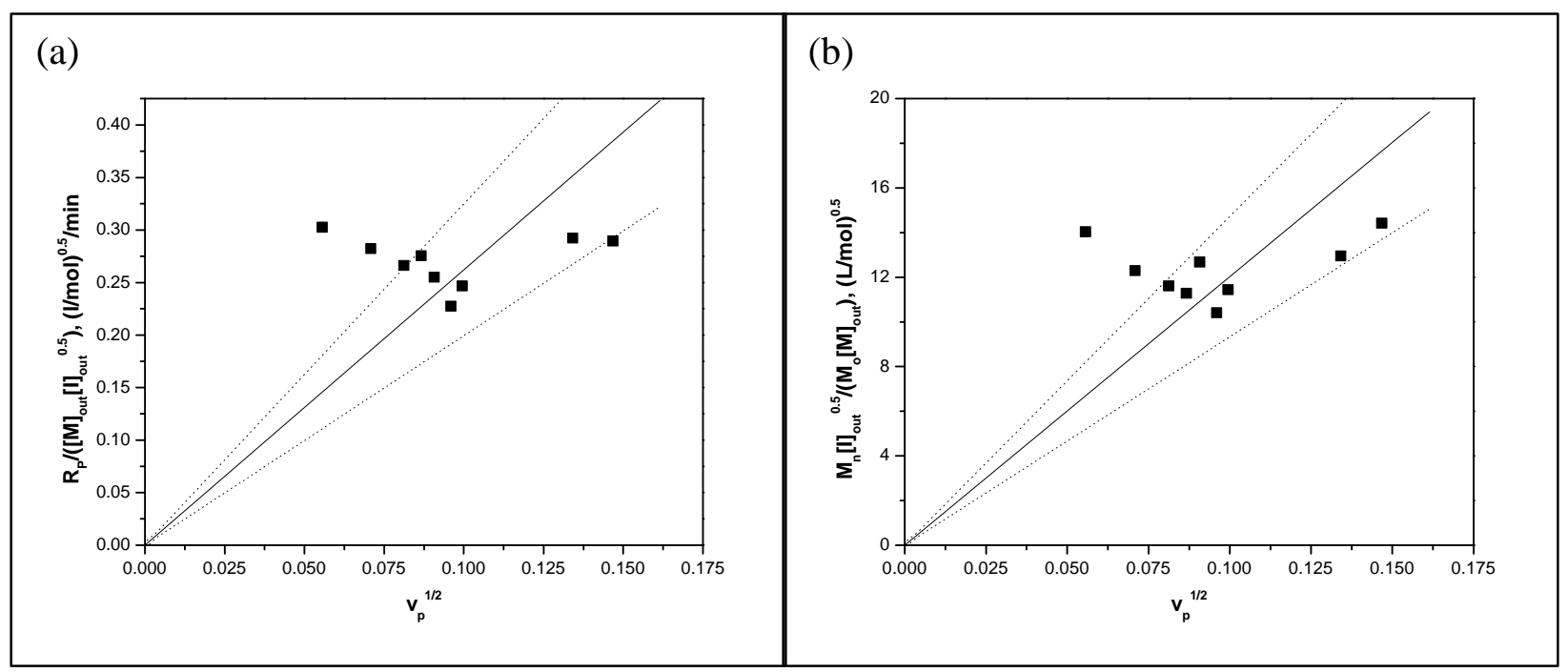

Figure 7: Test of the interior polymerization model for the continuous polymerization of PVDF: (a) Rate of polymerization, (b) Molecular weight; $P=276$ bar, $T=75{ }^{\circ} \mathrm{C}$, varying inlet monomer concentration and average residence time ${ }^{32}$; The line is the best linear fit for the data passing through the origin; The dotted points are the 95\% confidence bands for the linear fit. 


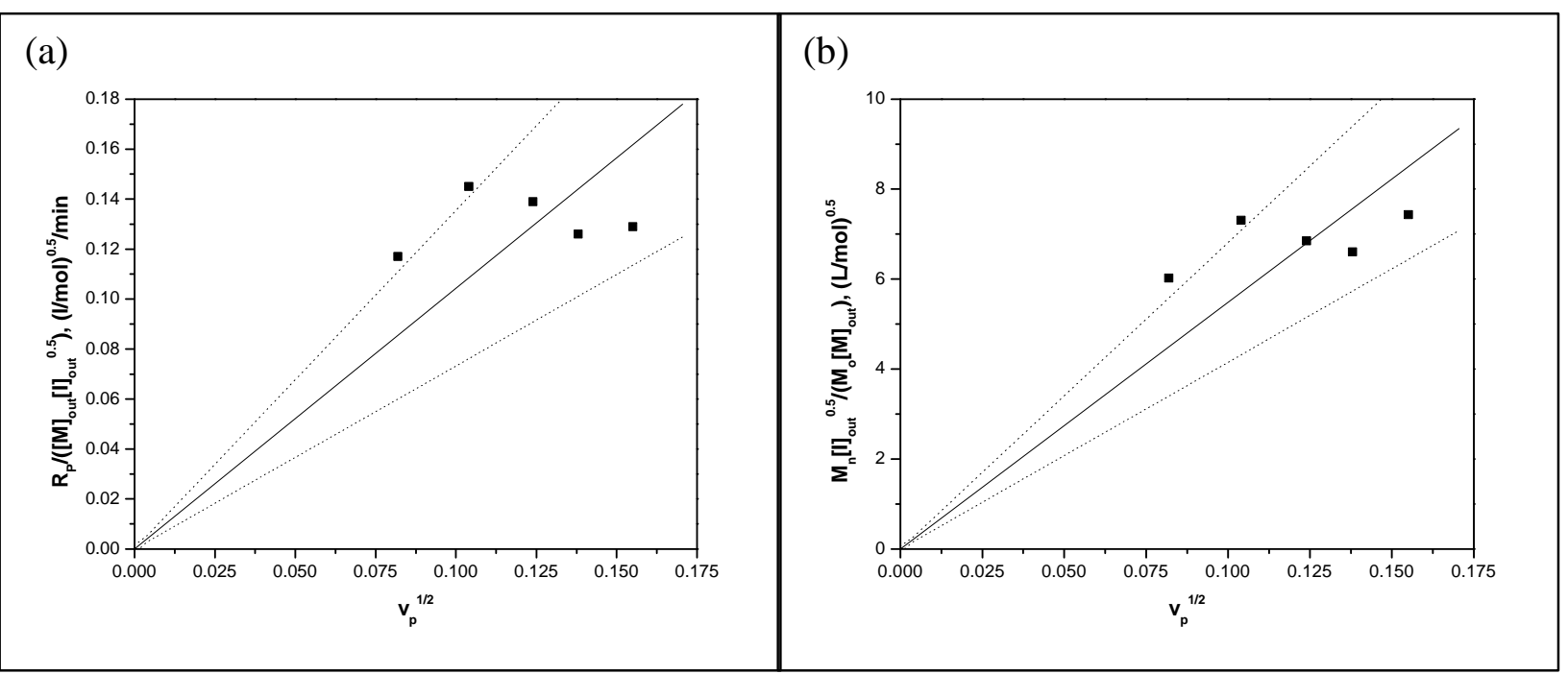

Figure 8: Test of the interior polymerization model for the continuous polymerization of low HFP-content poly(VF2-co-9.2mol\% HFP): (a) Rate of polymerization, (b) Molecular weight; $P=400$ bar, $T=40{ }^{\circ} \mathrm{C}$, varying inlet monomer concentration ${ }^{23}$; The line is the best linear fit for the data passing through the origin; The dotted points are the $95 \%$ confidence bands for the linear fit.
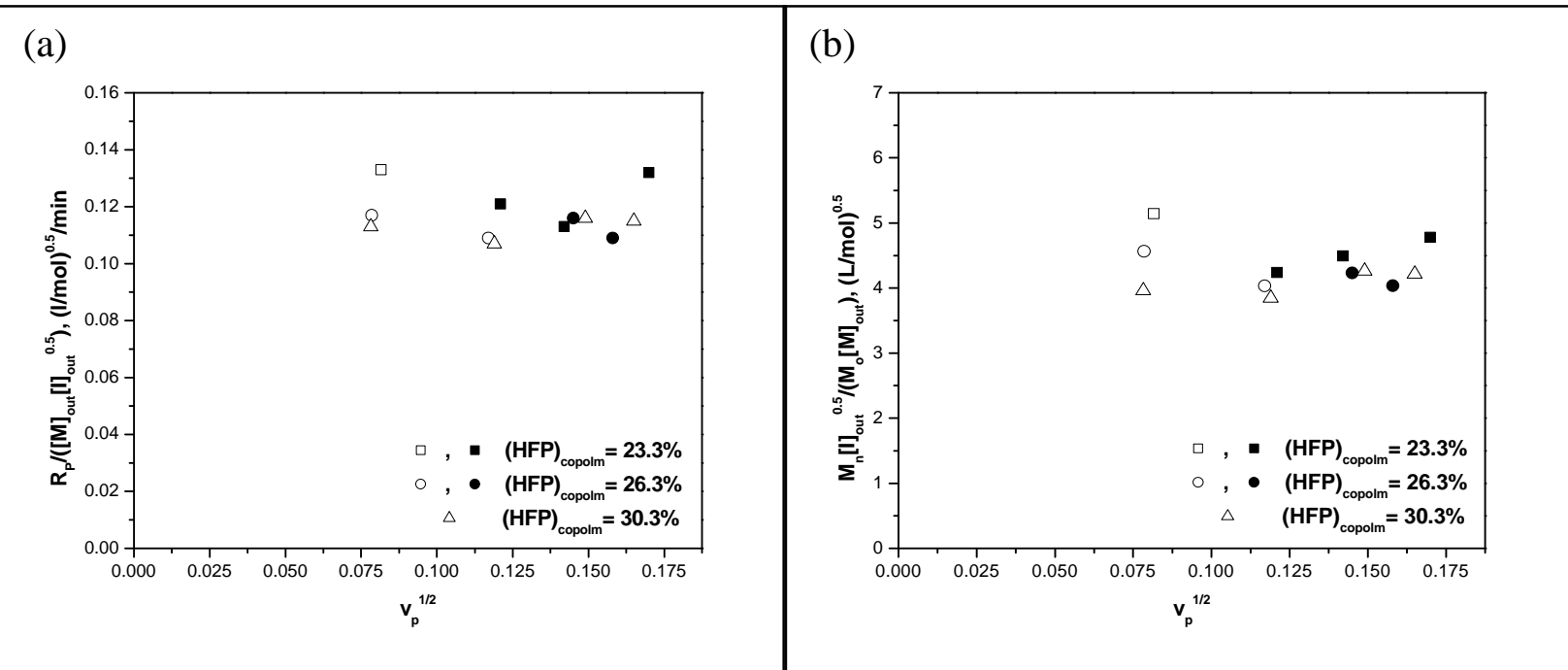

Figure 9: Test of the interior polymerization model for the continuous polymerization of high HFP-content poly(VF2-co-HFP):(a) Rate of polymerization, (b) Molecular weight; $P=400$ bar, $T=40{ }^{\circ} \mathrm{C}$, varying inlet monomer concentration $^{24}$. Filled symbols: precipitation polymerization; Open symbols: homogeneous polymerization 
The preceding analysis suggests that the precipitation polymerizations of VF2 homo- and co- polymers with $\mathrm{HFP}$ in $\mathrm{scCO}_{2}$ occur in the continuous $\mathrm{CO}_{2}$-rich phase. As discussed earlier, this may mean that the termination is much faster than precipitation and/or transport of macroradicals to the polymer phase. Another possibility is that the solubility of VF2 in the polymer is very low. The only study of the partitioning of VF2 between PVDF and $\mathrm{scCO}_{2}$ was reported by our research group ${ }^{15,}{ }^{39}$. This study showed that the partition coefficient of VF2 between PVDF and $\mathrm{scCO}_{2}$ is near zero at $75^{\circ} \mathrm{C}$ and 276 bar. Consequently, even if the polymeric chains precipitate without termination, the contribution to the rate of the polymerization in the polymer phase may be small. Considering the continuous phase as the main locus of polymerization can help in understanding some features of VF2 polymerization. For example, during one of the experiments on the precipitation polymerization of PVDF in our lab, a tough, essentially insoluble, one-piece polymer that filled the whole reactor was produced ${ }^{32,40}$. It has been suggested that chain transfer to polymer occurs for VF2 polymers ${ }^{38}$. Moreover, termination is by combination ${ }^{32}$. This mechanism of cross-linking can produce the tough polymer that filled the whole reactor, provided that polymerization took place in the fluid phase. If the polymerization occurred mainly in the polymer phase, only crosslinked separate polymer particles would have been produced, similar to the case of PAA ${ }^{18}$. Additional experimental observations during the copolymerization of VF2 and HFP that can be accounted for only by considering the continuous phase as the main locus of polymerization were discussed in our recent contributions ${ }^{23,24}$.

Finally, it is must be emphasized that the models developed by Liu et al. depend on the assumptions used during their derivations ${ }^{17}$. These models do not contain many complexities of 
the polymerization chemistry: phase behavior, interphase mass-transfer, etc. Nevertheless, these models do capture the difference in kinetic behavior between the two major loci of polymerization, the fluid phase and the polymer particles. Therefore, as demonstrated here, these models are very useful tools for the analysis of experimental data obtained in a CSTR to distinguish between the possible loci of polymerization. It is interesting to note the different behavior between the " $\mathrm{CO}_{2}$-phobic" PAA polymerization ${ }^{17}$ and the " $\mathrm{CO}_{2}$-philic" VF2 homo- and co- polymerization with HFP .

\subsection{Conclusions}

The experimental data for the polymerization of VF2 homo- and co- polymers with HFP in $\mathrm{scCO}_{2}$ has been tested against three different models that assume different loci of polymerization. In the solution polymerization model, the polymerization reactions are assumed to occur only in the fluid phase, with no reactions in the polymer phase. For the surface and interior polymerization models, chain initiation takes place in the fluid phase, but chain propagation and termination occur in a thin layer on the polymer surface for the surface polymerization model or homogeneously throughout the polymer particle for the case of the interior polymerization model. Monomer and initiator are assumed in equilibrium between the polymer and the continuous phases in the three models.

Comparison of the experimental data with the models suggests that the precipitation polymerizations of VF2 homo- and co- polymers with HFP in $\mathrm{scCO}_{2}$ occur mainly in the continuous, $\mathrm{CO}_{2}$-rich phase. The solution polymerization model accounts for the experimental data for PVDF and poly(VF2-co-HFP) quite well. On the other hand, the two models based on 
polymerization in the polymer phase are unable to fit the experimental data. Based on this study, it appears that the continuous $\mathrm{CO}_{2}$ phase is the main locus of polymerization for the precipitation polymerization of VF2 homo- and co- polymers with $\mathrm{HFP}$ in $\mathrm{scCO}_{2}$.

\subsection{Acknowledgement}

This material is based upon work supported by the STC Program of the National Science Foundation under Agreement No. CHE-9876674.

\subsection{References}

1. DeSimone, J. M.; Tumas, W., Green Chemistry Using Liquid and Supercritical Carbon Dioxide. Oxford University Press, Inc: New York, NY, 2003.

2. DeSimone, J. M. Science 2002, 297, (5582), 799-803.

3. Scheirs, J., Modern Fluoropolymers: High Performance Polymers for Diverse Applications. John Wiley \& Sons, Ltd.: 1997.

4. Preliminary Risk Assessment: Perfluorooctanic Acid (PFOA) and Fluorinated Telomers; US Environmental Protection Agency: April, 2003.

5. 2010/15 PFOA Stewardship Program; U.S. Environmental Protection Agency: January, 2006.

6. Wood, C. D.; Cooper, A. I.; DeSimone, J. M. Current Opinion in Solid State and Materials Science 2004, 8, (5), 325-331

7. Cooper, A. I. Journal of Materials Chemistry 2000, 10, (2), 207-234.

8. Canelas, D. A.; DeSimone, J. M. Advances in Polymer Science 1997, 133, 103-140. 
9. Kendall, J. L.; Canelas, D. A.; Young, J. L.; DeSimone, J. M. Chemical Reviews 1999, 99, (2), 543-563.

10. Ajzenberg, N.; Trabelsi, F.; Recasens, F. Chemical Engineering \& Technology 2000, 23, (10), 829-839.

11. Beckman, E. J. Journal of Supercritical Fluids 2004, 28, (2-3), 121-191.

12. Kennedy, K. A.; Roberts, G. W.; DeSimone, J. M. Advances in Polymer Science 2005, $175,329-346$.

13. Kemmere, M. F.; Meyer, T., Supercritical Carbon Dioxide in Polymer Reaction Engineering. Wiley-VCH: Weinheim, 2005.

14. Liu, T.; Garner, P.; DeSimone, J. M.; Roberts, G. W.; Bothun, G. D. Macromolecules 2006, 39, (19), 6489-6494.

15. Saraf, M. K.; Wojcinski, L. M., II; Kennedy, K. A.; Gerard, S.; Charpentier, P. A.; DeSimone, J. M.; Roberts, G. W. Macromolecular Symposia 2002, 182, 119-129.

16. DeSimone, J. M.; Maury, E. E.; Menceloglu, Y. Z.; McClain, J. B.; Romack, T. J.; Combes, J. R. Science 1994, 265, (5170), 356-359.

17. Liu, T.; DeSimone, J. M.; Roberts, G. W. Chemical Engineering Science 2006, 61, (10), 3129-3139.

18. Liu, T.; DeSimone, J. M.; Roberts, G. W. Polymer 2006, 47, (12), 4276-4281.

19. Mueller, P. A.; Storti, G.; Morbidelli, M. Chemical Engineering Science 2004, 60, (2), 377-397.

20. Mueller, P. A.; Storti, G.; Morbidelli, M. Chemical Engineering Science 2005, 60, (7), 1911-1925. 
21. Mueller, P. A.; Storti, G.; Apostolo, M.; Martin, R.; Morbidelli, M. Macromolecules 2005, 38, (16), 7150-7163.

22. Dohany, J. E., Poly(Vinylidene Fluoride). In Kirk-Othmer Encyclopedia of Chemical Technology, 4th ed.; Kirk-Othmer, Ed. John Wiley \& Sons: 1998.

23. Ahmed, T. S.; DeSimone, J. M.; Roberts, G. W. Continuous Copolymerization of Vinylidene Fluoride with Hexafluoropropylene in Supercritical Carbon Dioxide: Low Hexafluoropropylene-Content Copolymers, Accepted for publication in Macromolecules 2007.

24. Ahmed, T. S.; DeSimone, J. M.; Roberts, G. W. Continuous Copolymerization of Vinylidene Fluoride with Hexafluoropropylene in Supercritical Carbon Dioxide: High Hexafluoropropylene-Content Amorphous Copolymers, Submitted to Macromolecules 2007.

25. Ameduri, B.; Boutevin, B. Journal of Fluorine Chemistry 2000, 104, (1), 53-62.

26. Ameduri, B.; Boutevin, B.; Kostov, G. Progress in Polymer Science 2001, 26, (1), 105187.

27. $\quad$ Combes, J. R.; Guan, Z.; DeSimone, J. M. Macromolecules 1994, 27, (3), 865 - 867.

28. DiNoia, T. P.; Conway, S. E.; Lim, J. S.; McHugh, M. A. Journal of Polymer Science Part B-Polymer Physics 2000, 38, (21), 2832-2840.

29. Ahmed, T. S.; DeSimone, J. M.; Roberts, G. W. Macromolecules 2006, 39, (1), 15-18.

30. Charpentier, P. A.; DeSimone, J. M.; Roberts, G. W. Industrial \& Engineering Chemistry Research 2000, 39, (12), 4588-4596. 
31. Charpentier, P. A.; Kennedy, K. A.; DeSimone, J. M.; Roberts, G. W. Macromolecules Communications 1999, 32, (18), 5973-5975.

32. Saraf, M. K.; Gerard, S.; Wojcinski, L. M.; Charpentier, P. A.; DeSimone, J. M.; Roberts, G. W. Macromolecules 2002, 35, (21), 7976-7985.

33. Ahmed, T. S.; DeSimone, J. M.; Roberts, G. W. Chemical Engineering Science 2004, 59, (22-23), 5139-5144.

34. Charpentier, P. A.; DeSimone, J. M.; Roberts, G. W. Chemical Engineering Science 2000, 55, (22), 5341-5349.

35. Odian, G., Principles of Polymerization. 4th ed.; John Wiley \& Sons Inc: 2004.

36. Matyjaszewski, K.; Davis, T. P., Handbook of Radical Polymerization. WileyInterscience 2002.

37. Ito, K.; O'Driscoll, K. F. Journal of Polymer Science, Polymer Chemistry Edition 1979, 17, (12), 3913-3921.

38. Scanu, L. F.; DeSimone, J.; Roberts, G. W.; Khan, S. A. Abstracts of Papers, 229th ACS National Meeting, San Diego, CA, United States, March 13-17, 2005 2005, PMSE-376.

39. Kennedy, K. A. Characterization of Phase Equilibrium Associated with Heterogeneous Polymerizations in Supercritcal Carbon Dioxide. North Carolina State University, Raleigh, 2003.

40. Saraf, M. K. Polymerization of vinylidene fluoride in supercritical carbon dioxide: Molecular weight distribution. North Carolina State University, Raleigh, 2001. 


\title{
CHAPTER 7
}

Continuous Precipitation Polymerization of Vinylidene Fluoride in Supercritical Carbon Dioxide: Modeling the Molecular Weight

\author{
Distribution
}

Chapter 7 is a manuscript published in Chemical Engineering Science

Ahmed, T. S.; DeSimone, J. M.; Roberts, G. W. Chemical Engineering Science 2004, 59, (2223), 5139-5144 


\title{
Continuous Precipitation Polymerization of Vinylidene Fluoride in Supercritical Carbon Dioxide: Modeling the Molecular Weight Distribution
}

\author{
Tamer S. Ahmed ${ }^{a}$, Joseph M. DeSimone ${ }^{\mathrm{a}, \mathrm{b}}$, and George W. Roberts ${ }^{\mathrm{a}, *}$ \\ ${ }^{a}$ Department of Chemical Engineering, North Carolina State University, Box \#7905, Raleigh, North Carolina \\ 27695-7905, USA. \\ ${ }^{\mathrm{b}}$ Department of Chemistry, University of North Carolina-Chapel Hill, Venable and Kenan Laboratories, CB\#3290, \\ Chapel Hill, North Carolina 27599, USA.
}

\begin{abstract}
The molecular weight distribution (MWD) of poly(vinylidene fluoride) synthesized continuously in supercritical carbon dioxide is bimodal under some circumstances. A homogeneous model that can account for this bimodality is presented in this paper. The model takes into account the decrease in the mobility of polymeric radicals as they grow in size. This decrease in mobility impacts the rates of the termination reactions. The model, although simple, can describe many features of the experimental MWDs. For example as monomer concentration increases, the MWD changes from unimodal to bimodal, the second peak increases in size at the expense of the first one, and the peaks shift to higher molecular weights. In addition, the model can describe the effect of residence time on the MWD for both low and high monomer concentration. Finally, the effect of temperature on the MWD can be described fairly well using only one adjustable parameter.
\end{abstract}

\footnotetext{
${ }^{*}$ To whom correspondence should be addressed. Tel: +1-919-515-7328; Fax: +1-919-515-3465; E-mail addresses: desimone@unc.edu (J.M. DeSimone), groberts@eos.ncsu.edu (G.W. Roberts)
} 


\subsection{Introduction}

Since the early 1990s, considerable effort has been devoted to using supercritical carbon dioxide $\left(\mathrm{scCO}_{2}\right)$ for polymerization reactions. Carbon dioxide is an excellent reaction medium for a number of polymerizations (DeSimone et al., 1992, 1994; Romack et al., 1995; Lousenberg \& Shoichet, 2000; Baradie \& Shoichet, 2002; Michel et al., 2003). Using $\mathrm{scCO}_{2}$ as reaction medium has several advantages compared to conventional techniques. Carbon dioxide is nontoxic, non-flammable, inexpensive, environmentally benign, and there is no chain transfer to $\mathrm{CO}_{2}$. The polymer can be synthesized and easily isolated in a dry and pure form with no need for any additional steps to remove the solvent or water. The tunability of $\mathrm{scCO}_{2}$ can affect the solvency of the medium and therefore impact phase equilibria and partition coefficients in heterogeneous systems. Finally, free radical initiators have high efficiencies and acceptable decomposition kinetics in $\mathrm{scCO}_{2}$ (Charpentier et al., 2000a; Bunyard et al., 2001).

Poly(vinylidene fluoride) (PVDF) is a semicrystalline, thermoplastic polymer widely used for fabricating pipes, tubing in plastic heat exchangers, column packing, valves, and pumps. This polymer is produced commercially by a batch process, either emulsion or suspension polymerization in water.

As industrial interest in using $\mathrm{scCO}_{2}$ as a polymerization medium grew, Charpentier et al. (1999, 2000b) synthesized PVDF by precipitation polymerization using a continuous stirred tank reactor (CSTR) to circumvent the potential economic disadvantage of batch reactors. Their initiator was diethylperoxydicarbonate (DEPDC). Under certain conditions, the molecular weight distribution (MWD) of PVDF was bimodal (Fig. 1) (Saraf et al., 2002). Saraf et al. (2002) presented a homogeneous kinetic model that includes chain transfer to polymer in an attempt to 
describe the polymerization rate and polymer properties. This model predicted the high experimental polydispersity indices reasonably well and also predicted a region of inoperatibility for the CSTR that matched the experimental results. However, the MWDs predicted by this model were always unimodal. No quantitative study of the origin of this bimodality has been reported.

In this paper, we present a homogeneous model that can account for the observed bimodality and for its variation with reactor operating conditions. The model is based on the well-known reduction in termination rate of polymeric radicals as they grow in size. This phenomenon has been observed for some heterogeneous polymerizations when the polymer is not soluble in the solvent [e.g., methanol / polystyrene, hexane / poly(methyl methacrylate)] (Odian, 1991). In addition, diffusion-controlled termination is responsible for the well-known Trommsdorf effect in homogeneous polymerizations. In fact, this decrease in termination rate constant with radical chain length was reported to produce bimodal MWDs for the free-radical polymerization of methyl methacrylate in the presence of poly(methyl methacrylate) (Bogunjoko \& Brooks, 1983).

\subsection{Modeling}

7.2.1 Model description. The model presented here is based on the homogeneous kinetic scheme shown in Fig. 2. Polymerization is assumed to occur in solution. The mechanism consists of conventional initiator-decomposition, chain-initiation, and chain-propagation steps. Termination is by combination (Saraf et al., 2002). The termination reaction is kinetically controlled up to a critical chain length $\left(n_{c r}\right)$, beyond which the growing radicals experience diffusion limitations. Radicals containing up to $n_{c r}$ monomer units are referred to as unhindered, 
while hindered radicals are those containing more than $n_{c r}$ units. The reaction of any two radicals, both having a chain length shorter than the critical chain length, is kinetically controlled and is described by a rate constant $\left(k_{t}^{u u}\right)$. For radicals of chain length greater than the critical value, the reduction in the termination rate due to the diffusion limitations is approximated by two termination rate constants $\left(k_{t}^{u h}\right)$ and $\left(k_{t}^{h h}\right)$. The first describes termination by combination of an unhindered radical with a hindered radical, while the second is for the combination of two hindered radicals.

7.2.2 Model derivation. This model applies to an ideal CSTR operating at steady state. Let $R_{n}^{\bullet}$ be the concentration of unhindered radicals containing $n$ monomer units where $n \leq n_{c r}$. When $n>n_{c r}$, the concentration of hindered radicals containing $n$ monomer units is $R_{n}^{\circ h}$. Assuming that the quasi steady-state approximation holds, and neglecting the live polymer outflow from the CSTR, steady-state material balances on live polymers give:

$$
\begin{aligned}
& R_{1}^{\cdot}=\frac{2 f k_{d} I}{k_{p} M+2 k_{t}^{u u}\left(R_{n}^{\bullet}\right)_{T}+2 k_{t}^{u h}\left(R_{n}^{\circ h}\right)_{T}} \\
& R_{n}^{\bullet}=\frac{k_{p} M R_{n-1}^{\cdot}}{k_{p} M+2 k_{t}^{\text {uu }}\left(R_{n}^{\cdot}\right)_{T}+2 k_{t}^{\text {uh }}\left(R_{n}^{\circ h}\right)_{T}} \quad 1<n \leq n_{c r} \\
& R_{n}^{\circ h}=\frac{k_{p} M R_{n-1}^{\circ h}}{k_{p} M+2 k_{t}^{u h}\left(R_{n}^{\bullet}\right)_{T}+2 k_{t}^{\text {hh }}\left(R_{n}^{\circ h}\right)_{T}} \quad n>n_{c r} \\
& \text { where, } \quad\left(R_{n}^{*}\right)_{T}=\sum_{n=1}^{n_{c r}} R_{n}^{\cdot}
\end{aligned}
$$




$$
\left(R_{n}^{\bullet h}\right)_{T}=\sum_{n=n_{c r}+1}^{\infty} R_{n}^{\bullet h}
$$

Eq. (2) and Eq. (3) can be rewritten in terms of $R_{1}^{*}$ and $R_{n_{c r}}^{\bullet}$ respectively:

$$
\begin{gathered}
R_{n}^{\cdot}=\left(\frac{k_{p} M}{k_{p} M+2 k_{t}^{u u}\left(R_{n}^{\bullet}\right)_{T}+2 k_{t}^{u h}\left(R_{n}^{\circ h}\right)_{T}}\right)^{n-1} R_{1}^{\cdot} \quad n \leq n_{c r} \\
R_{n}^{\circ h}=\left(\frac{k_{p} M}{k_{p} M+2 k_{t}^{u h}\left(R_{n}^{\bullet}\right)_{T}+2 k_{t}^{\text {hh }}\left(R_{n}^{\circ h}\right)_{T}}\right)^{n-n_{c r}} R_{n_{c r}}^{\cdot} \quad n>n_{c r}
\end{gathered}
$$

By substituting Eq. (1) in Eq. (6):

$$
R_{n}^{\cdot}=\left(\frac{2 f k_{d} I}{k_{p} M}\right) \alpha^{n} \quad 1 \leq n \leq n_{c r}
$$

where,

$$
\alpha=\frac{k_{p} M}{k_{p} M+2 k_{t}^{\text {uu }}\left(R_{n}^{\bullet}\right)_{T}+2 k_{t}^{\text {uh }}\left(R_{n}^{\circ h}\right)_{T}}
$$

By substituting Eq. (8) for $n=n_{c r}$ in Eq. (7):

$$
R_{n}^{\circ h}=\left(\frac{2 f k_{d} I}{k_{p} M}\right)\left(\frac{\alpha}{\beta}\right)^{n_{c r}} \beta^{n} \quad n>n_{c r}
$$

where,

$$
\beta=\frac{k_{p} M}{k_{p} M+2 k_{t}^{u h}\left(R_{n}^{\bullet}\right)_{T}+2 k_{t}^{h h}\left(R_{n}^{\bullet h}\right)_{T}}
$$

Substituting Eq. (8) in Eq. (4) and Eq. (10) in Eq. (5):

$$
\begin{gathered}
\left(R_{n}^{\bullet}\right)_{T}=\left(\frac{2 f k_{d} I}{k_{p} M}\right) \sum_{n=1}^{n_{c r}} \alpha^{n} \\
\left(R_{n}^{\bullet h}\right)_{T}=\left(\frac{2 f k_{d} I}{k_{p} M}\right)\left(\frac{\alpha}{\beta}\right)^{n_{c r}} \sum_{n=n_{c+1}+1}^{\infty} \beta^{n}
\end{gathered}
$$


From the binomial series, since $\alpha$ and $\beta$ are $<1$,

$$
\begin{aligned}
& \left(R_{n}^{\bullet}\right)_{T}=\left(\frac{2 f k_{d} I}{k_{p} M}\right) \frac{\alpha}{1-\alpha}\left(1-\alpha^{n_{c r}}\right) \\
& \left(R_{n}^{\bullet h}\right)_{T}=\left(\frac{2 f k_{d} I}{k_{p} M}\right) \alpha^{n_{c r}}\left(\frac{\beta}{1-\beta}\right)
\end{aligned}
$$

A steady state material balance on the dead polymer for the CSTR gives:

$$
\begin{array}{cc}
P_{n}=\tau k_{t}^{u u} \sum_{m=1}^{n-1} R_{m}^{\bullet} R_{n-m}^{\bullet} & 1<n \leq n_{c r} \\
P_{n}=\tau\left(r_{p_{n}}^{a}+r_{p_{n}}^{b}+r_{p_{n}}^{c}\right) & n>n_{c r}
\end{array}
$$

where $\tau$ is the average residence time: $\tau=\frac{\text { Volume of CSTR }}{\text { Total volumetric flow rate }}$

$$
\begin{array}{cc}
r_{p_{n}}^{a}=k_{t}^{u u} \sum_{m=n-n_{c r}}^{n_{c r}} R_{m}^{\bullet} R_{n-m}^{\bullet} & n_{c r}<n \leq 2 n_{c r} \\
r_{p_{n}}^{b}=\left\{\begin{array}{ll}
2 k_{t}^{u h} \sum_{m=1}^{n-\left(n_{c r}+1\right)} R_{m}^{\bullet} R_{n-m}^{\bullet h} & n_{c r}<n \leq 2 n_{c r}+1 \\
2 k_{t}^{u h} \sum_{m=1}^{n_{c r}} R_{m}^{\bullet} R_{n-m}^{\bullet h} & n>2 n_{c r}+1
\end{array}\right\} \\
r_{p_{n}}^{c}=k_{t}^{h h} \sum_{m=n_{c r}+1}^{n-\left(n_{c r}+1\right)} R_{m}^{\bullet h} R_{n-m}^{\bullet h} & n \geq 2 n_{c r}+2
\end{array}
$$

By using Eq. (8) and Eq. (10),

- $\quad$ For $1<n \leq n_{c r}$,

$$
P_{n}=\tau k_{t}^{u u}\left(\frac{2 f k_{d} I}{k_{p} M}\right)^{2} \alpha^{n}(n-1)
$$


- $\quad$ For $n_{c r}+1 \leq n \leq 2 n_{c r}$,

$$
P_{n}=\tau\left(\frac{2 f k_{d} I}{k_{p} M}\right)^{2}\left[k_{t}^{u u} \alpha^{n}\left(2 n_{c r}+1-n\right)+2 k_{t}^{u h}\left(\frac{\alpha}{\beta}\right)^{n_{c r}} \beta^{n} \sum_{m=1}^{n-\left(n_{c r}+1\right)}\left(\frac{\alpha}{\beta}\right)^{m}\right]
$$

- $\quad$ For $n=2 n_{c r}+1$,

$$
P_{n}=2 k_{t}^{u h} \tau\left(\frac{2 f k_{d} I}{k_{p} M}\right)^{2}\left(\frac{\alpha}{\beta}\right)^{n_{c r}} \beta^{n} \sum_{m=1}^{n_{c r}}\left(\frac{\alpha}{\beta}\right)^{m}
$$

- $\quad$ For $n \geq 2 n_{c r}+2$,

$$
P_{n}=\tau \beta^{n}\left(\frac{\alpha}{\beta}\right)^{n_{c r}}\left(\frac{2 f k_{d} I}{k_{p} M}\right)^{2}\left\{2 k_{t}^{u h} \sum_{m=1}^{n_{c r}}\left(\frac{\alpha}{\beta}\right)^{m}+k_{t}^{h h}\left(\frac{\alpha}{\beta}\right)^{n_{c r}}\left[n-\left(2 n_{c r}+1\right)\right]\right\}
$$

Finally, steady-state material balances on monomer and initiator give:

$$
\begin{gathered}
M=\frac{M_{0}-2 \tau f k_{d} I}{1+\tau k_{p}\left[\left(R_{n}^{\bullet}\right)_{T}+\left(R_{n}^{\bullet h}\right)_{T}\right]} \\
I=\frac{I_{0}}{1+k_{d} \tau}
\end{gathered}
$$

where $M_{0}$ and $I_{0}$ are the feed concentrations of monomer and the initiator respectively.

The values of $P_{n}$ are used to construct plots of $n^{2} P_{n} / \sum_{n=0}^{\infty} n P_{n}$ which are proportional to the experimental GPC results of Saraf et al. (2002).

7.2.3 Model parameters. The model contains 6 parameters, $k_{d}, k_{t}^{u u}, k_{t}^{u h}, k_{t}^{h h}, k_{p}$, and $n_{c r}$. The only available experimental data for the polymerization of vinylidene fluoride in $\mathrm{scCO}_{2}$ 
using DEPDC initiator are the values of $k_{d}$ and $k_{p} /\left\langle k_{t}\right\rangle^{0.5}$ (Charpentier et al., 2000a, 2000b), where $\left\langle k_{t}\right\rangle$ is the average macroscopic termination rate constant.

The model proposed by Russell $(1994,1995)$ was used to evaluate the chain-dependence of the termination rate constant. This model is based on the long-term limit of the Smoluchowski equation, which is of proven accuracy as a description of diffusion-controlled reaction rate coefficients (Rise, 1985). Neglecting reaction diffusion, which is important only at very high conversions when the centre-of-mass diffusion is inhibited by the very high molecular weights of the polymer chains, the dependence of the termination rate constant $k_{t}(i, j)$ on chain length is given by:

$$
\begin{gathered}
k_{t}(i, j)=2 \pi p_{\text {spin }}\left(D_{i}+D_{j}\right) \sigma N_{A} \\
D_{i}=\left\{\begin{array}{ll}
D_{\text {mon }} / i^{a} & i \leq X_{c} \\
D_{\text {mon }}\left(X_{c}\right)^{b-a} / i^{b} & i>X_{c}
\end{array}\right\}
\end{gathered}
$$

Here $N_{A}$ is Avogadro's number; $\sigma$ is the capture radius of the reaction (a value of $\sim 0.3 \mathrm{~nm}$ (Benson \& North, 1959; Mahabadi \& O’Driscoll, 1977) seems reasonable for vinyl-vinyl combination and was used here); $p_{\text {spin }}$ is the spin probability (since $\mathrm{scCO}_{2}$ at the reaction conditions (27.5 $\mathrm{MPa}$ and $75{ }^{\circ} \mathrm{C}$ ) has a liquid-like density, a value of 0.25 was chosen (Russell, 1995)); $D_{i}$ is the centre-of-mass diffusion coefficient of the growing chains; $D_{\text {mon }}$ is the diffusion coefficient of the monomer (an estimated value for the diffusivity of vinylidene fluoride monomer in $\mathrm{scCO}_{2}$ using the method proposed by Riazi \& Whitson, 1993 is approximately $\left.1.4 \times 10^{-8} \mathrm{~m}^{2} / \mathrm{s}\right) ; X_{c}$ is the crossover chain length at which the scaling law is presumed to change 
from short- to long- chain diffusion, while $a$ and $b$ are the chain-length exponents (typical values lie approximately in the range 0.5 to 0.6 for dilute conditions (de Kock et al., 2001)).

The termination rate constants were estimated by using the functional form of the chain dependence given by Eqs. (27 and 28) but without a crossover chain length $X_{c}$ (Deady et al., 1993; Buback \& Kuchta, 1997). A single average chain-length exponent of 0.55 was used. Chain lengths of 265 and 1570 monomer units were assumed to represent the average unhindered and hindered radical respectively at $75{ }^{\circ} \mathrm{C}$. This evolved from a trial-and-error procedure on the average lengths for unhindered and hindered radicals.

The value of $k_{p}$ can be calculated from the reported values for $k_{p} /\left\langle k_{t}\right\rangle^{0.5}$ (Charpentier et al., 2000b) since $\left\langle k_{t}\right\rangle$ can be approximated from:

$$
\left\langle k_{t}\right\rangle=\frac{\sum_{i} \sum_{j} k_{t}(i, j) R_{i}^{\cdot} R_{j}^{\cdot}}{\left(\sum_{i} R_{i}^{\cdot}\right)^{2}} \approx \frac{k_{t}^{u u} \sum_{i=1}^{n_{c r}} \sum_{j=1}^{n_{c r}} R_{i}^{\cdot} R_{j}^{\cdot}+2 k_{t}^{u h} \sum_{i=1}^{n_{c r}} \sum_{j=n_{c r}+1}^{\infty} R_{i}^{\bullet} R_{j}^{\bullet h}+k_{t}^{h h} \sum_{i=n_{c r}+1}^{\infty} \sum_{j=n_{c r}+1}^{\infty} R_{i}^{\bullet h} R_{j}^{\bullet h}}{\left[\left(R_{n}^{\bullet}\right)_{T}+\left(R_{n}^{\bullet h}\right)_{T}\right]^{2}}
$$

This is done by a trial-and-error procedure. A value of $k_{p}$ is assumed, the model is solved, $\left\langle k_{t}\right\rangle$ is calculated from the concentration of the live polymers, and $k_{p}$ is calculated from the experimental values of $k_{p} /\left\langle k_{t}\right\rangle^{0.5}$. Finally, the calculated value of $k_{p}$ is compared with the one assumed.

The model predicts that the location of the minimum between the two peaks of a bimodal MWD occurs at a chain length of $2 n_{c r}+1$. Therefore, the value of $n_{c r}$ can be estimated from the experimental MWDs. Experimentally, the location of this minimum increases slightly as the 
monomer concentration increases (Fig. 1). However for the sake of simplicity, a constant average value of 540 was used for MWDs at $75^{\circ} \mathrm{C}$.

\subsection{Results and Discussion}

Fig. 3 summarizes calculations to explore the effect of varying the monomer feed concentration from 0.77 to $3.5 \mathrm{M}$ at otherwise identical conditions. As monomer concentration increases, the MWD changes from unimodal to bimodal, an effect that was observed experimentally (Fig. 1). In addition, the model captures the increase in the bimodality, the increase in the size of the second peak at the expense of the first one, and the shifting of both peaks to higher molecular weights with increasing monomer concentration.

Fig. 4 (a) \& (b) show the model predictions for the effect of residence time at low and high monomer feed concentration respectively. The model predicts successfully that the MWD is perfectly unimodal for any residence time provided that the monomer feed concentration is low $\left(\mathrm{M}_{0}=0.78 \mathrm{M}\right)$. This agrees with the experimental data (Figure 5(a) in Saraf et al, 2002). For high monomer feed concentrations, the model predicts the general experimental trend of increasing bimodality with increasing residence time. That was observed in experiments (Figure 5(b) in Saraf et al, 2002).

Finally, Fig. 5 shows the effect of temperature on the MWD. Experimentally, as temperature increased from 75 to $85^{\circ} \mathrm{C}$, the MWD changed from distinctly bimodal to unimodal with a small shoulder (Figure 4 in Saraf et al, 2002). At $85^{\circ} \mathrm{C}$, there was no distinct second mode from which a value for $n_{c r}$ can be obtained. Therefore, $n_{c r}$ was used as an adjustable parameter. Fig. 5 shows 
the MWD for $75{ }^{\circ} \mathrm{C}$ with $n_{c r}=540$ and for $85{ }^{\circ} \mathrm{C}$ with $n_{c r}=1000$. The MWDs predicted by the model is qualitatively similar to the experimental MWDs.

Although the model can describe satisfactorily most of the experimental trends, yet it has some drawbacks. For instance, the locations of the peaks predicted by the model do not match exactly the location of the experimental ones. More important, the relative peak heights predicted by the model do not agree quantitatively with the relative peak heights observed experimentally. This may be due to the simplicity of the model. First, three termination reactions and rate constants have been used to approximate a termination scheme that consists of an infinite number of reactions and constants. Second, the possible occurrence of chain transfer to polymer has been ignored. However, the uncertainty in the experimental MWDs for PVDF also may contribute to the differences between the model and the data (Saraf, 2001).

The sharp peak that appears at high monomer concentrations at $75{ }^{\circ} \mathrm{C}$ arises because the value of $n_{c r}$ (540) is lower than the value of chain length at which the low-molecular weight peak reaches a maximum. This is one of the costs for the simple approximation of the termination rate constants. This sharp change reflects the assumption of a large step change in mobility when the radicals reach a critical size. This feature disappears in Fig. 5 at $85{ }^{\circ} \mathrm{C}$ as a result of the higher value assigned for $n_{c r}$.

The ability of a homogeneous model to describe the behavior of a heterogeneous system such as the precipitation polymerization of vinylidene fluoride in $\mathrm{scCO}_{2}$ suggests that polymerization may be predominantly homogeneous, at least for this system. For example, the kinetics of chaingrowth and termination may be much faster than the kinetics of polymer precipitation. If so, most of the polymer chains will grow and terminate in the fluid phase before precipitation 
occurs. The model presented here, although simple, can give a reasonable description of the experimental MWDs. This semi-quantitative agreement suggests that diffusion-limited termination may be a possible cause of the bimodality observed for precipitation polymerization of PVDF in $\mathrm{scCO}_{2}$.

\subsection{Conclusions}

A homogeneous model is presented that can account for the bimodal MWDs of PVDF synthesized by precipitation polymerization in $\mathrm{scCO}_{2}$ using a CSTR. This model takes into account the variation of the termination rate constant with chain length due to the decrease in the mobility of polymeric chains as they grow in size. The model can capture successfully the effect of the operating parameters, such as the effect of monomer feed concentration, residence time for both low and high monomer concentration, and reaction temperature, on the MWD

\subsection{Acknowledgement}

This material is based upon work supported by the STC Program of the National Science Foundation under Agreement No. CHE-9876674.

\subsection{References}

- Baradie, B. \& Shoichet, M.S., (2002). Synthesis of Fluorocarbon-Vinyl Acetate Copolymers in Supercritical Carbon Dioxide: Insight into Bulk Properties. Macromolecules, 35, 35693575. 
- Benson, S.W., North A.M., (1959). A Simple Dilatometric Method of Determining the Rate Constants of Chain Reactions. II. The Effect of Viscosity on the Rate Constants of Polymerization Reactions. Journal of Americal Chemical Society, 81, 1339-1345.

- Bogunjoko, J.S.T., \& Brooks, B.W. (1983). Molecular weight distributions of poly(methyl methacrylate) produced at high viscosities. Die Makromolekulare Chemie, 184, 1623-1643.

- Buback, M. \& Kuchta, F.D., (1997). Termination kinetics of free-radical polymerization of styrene over an extended temperature and pressure range. Macromolecular Chemistry and Physics, 198, 1455-1480.

- Bunyard, W.C., Kadla, J.F., \& DeSimone, J.M., (2001). Viscosity Effects on the Thermal Decomposition of Bis(perfluoro-2-N-propoxypropionyl) Peroxide in Dense Carbon Dioxide and Fluorinated Solvents. Journal of the American Chemical Society, 123, 7199-7206.

- Charpentier, P.A., Kennedy, K.A., DeSimone, J.M., \& Roberts, G.W., (1999). Continuous Polymerizations in Supercritical Carbon Dioxide: Chain-Growth Precipitation Polymerizations. Macromolecules Communications, 32, 5973-5975.

- Charpentier, P.A., DeSimone, J.M, \& Roberts, G.W., (2000a). Decomposition of polymerisation initiators in supercritical $\mathrm{CO}_{2}$ : a novel approach to reaction kinetics using a CSTR. Chemical Engineering Science, 55, 5341-5349.

- Charpentier, P.A., DeSimone, J.M., \& Roberts, G.W., (2000b). Continuous Precipitation Polymerization of Vinylidene Fluoride in Supercritical Carbon Dioxide: Modeling the Rate of Polymerization. Industrial and Engineering Chemistry: Research, 39, 4588-4596. 
- Deady, M., Mau, A.W.H., \& Moad, G., (1993). Evaluation of the kinetic parameters for styrene polymerization and their chain length dependence by kinetic simulation and pulsed laser photolysis. Die Makromolekulare Chemie, 194, 1691.

- de Kock J.B.L., Van Herk A.M., German A.L., (2001). Bimolecular free-radical termination at low conversion. Journal of Macromolecular Science-Polymer Reviews, C41, 199-252.

- DeSimone, J.M., Guan, Z., Elsbernd, C.S., (1992). Synthesis of fluoropolymers in supercritical carbon dioxide. Science, 257, 945-947.

- DeSimone, J.M., Maury, E.E., Menceloglu, Y.Z., McClain, J.B., Romack, T.J., \& Combes, J. F., (1994). Dispersion polymerizations in supercritical carbon dioxide. Science, 265, 356359.

- Lousenberg, R.D. \& Shoichet, M.S., (2000). Synthesis of Linear Poly(tetrafluoroethylene-covinyl acetate) in Carbon Dioxide. Macromolecules, 33, 1682-1685.

- Mahabadi H.K. \& O’Driscoll, K.F., (1977). Termination rate constant in free-radical polymerization. Journal of Polymer Science: Polymer Chemistry, 15, 283-300.

- Michel, U., Resnick, P., Kipp, B., \& DeSimone, J.M., (2003). Copolymerization of Tetrafluoroethylene and 2,2-Bis(trifluoromethyl)-4,5-difluoro-1,3-dioxole in Supercritical Carbon Dioxide. Macromolecules, 36, 7107-7113.

- Odian, G. (1991). Principles of polymerization ( $3^{\text {rd }}$ ed.). New York: Wiley-Interscience, pp. 291.

- Riazi, M.R. \& Whitson, C.H., (1993). Estimating diffusion coefficients of dense fluids. Industrial and Engineering Chemistry: Research, 32, 3081-3088. 
- Rise, S.A., (1985). In Comprehensive Chemical Kinetics; Bamford, C.H., Tippeir, C.F.H., \& Compton, R.G. (Eds.); Elsevier: New York, vol. 25, 135.

- Romack, T.J., DeSimone, J.M., \& Treat, T.A., (1995). Synthesis of TetrafluoroethyleneBased, Nonaqueous Fluoropolymers in Supercritical Carbon Dioxide. Macromolecules, 28, 8429-8431.

- Russell, G.T., (1994). On exact and approximate methods of calculating an overall termination rate coefficient from chain length dependent termination rate coefficients. Macromolecular Theory and Simulations, 3, 439-468.

- Russell, G.T., (1995). The kinetics of free radical polymerizing systems at low conversion, 1. On the rate determining step of the bimolecular termination reaction. Macromolecular Theory and Simulations, 4, 497-517.

- Saraf, M. (2001) Polymerization of Vinylidene Fluoride in Supercritical Carbon Dioxide: Molecular Weight Distribution. M.S. Thesis, North Carolina State University, 2001.

- Saraf, M.S.,Gerard, S., Wojcinski, L.M., Charpentier, P.A., DeSimone, J.M., \& Roberts, G.W. (2002). Continuous Precipitation Polymerization of Vinylidene Fluoride in Supercritical Carbon Dioxide: Formation of Polymers with Bimodal Molecular Weight Distributions. Macromolecules, 35, 7976-7985. 


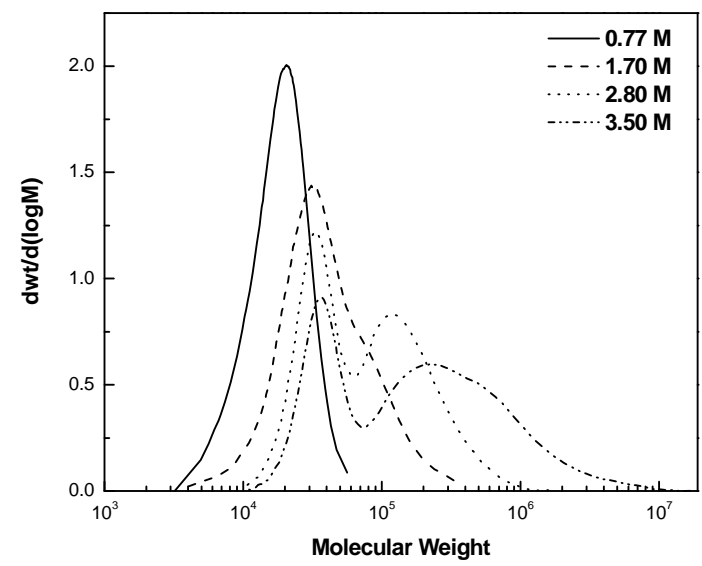

Figure 1: Experimental MWDs for PVDF. Varying monomer feed concentration at $75{ }^{\circ} \mathrm{C}$ and $27.5 \mathrm{MPa}$ total pressure $(P)$. Average initiator feed concentration $\left(I_{0}\right)$ equals $0.003 \mathrm{M}$ and average residence time $(\tau)$ equals 21 min (Saraf et $a l$, 2002). 
$I \stackrel{k_{d}}{\longrightarrow} 2 f R^{\bullet} \quad$ (Initiator decomposition)

$R^{\bullet}+M \stackrel{k_{m}}{\longrightarrow} R_{1}^{\bullet} \quad$ (Chain Initiation)

$R_{n}^{\bullet}+M \stackrel{k_{p}}{\longrightarrow} R_{n+1}^{\bullet} \quad$ (Propagation)

$R_{n}^{\bullet}+R_{m}^{\bullet} \stackrel{k_{t}^{u u}}{\longrightarrow} P_{n+m}$ (Termination, $n \& m \leq n_{c r}$ )

$R_{n}^{\bullet}+R_{m}^{\bullet h} \stackrel{k_{t}^{u h}}{\longrightarrow} P_{n+m}$ (Termination, $n \leq n_{c r} \& \mathrm{~m}>n_{c r}$ )

$R_{n}^{\bullet h}+R_{m}^{\bullet h} \stackrel{k_{t}^{h h}}{\longrightarrow} P_{n+m}$ (Termination, $n \& m>n_{c r}$ )

Figure 2: Kinetic scheme to model the bimodal MWD of PVDF synthesized continuously in $\mathrm{scCO}_{2} . I, M, R_{n}^{\bullet}$,

$R_{n}^{\bullet h} \& P_{n}$ are the concentrations of initiator, monomer, live unhindered radicals, live hindered radicals and dead polymer respectively. 


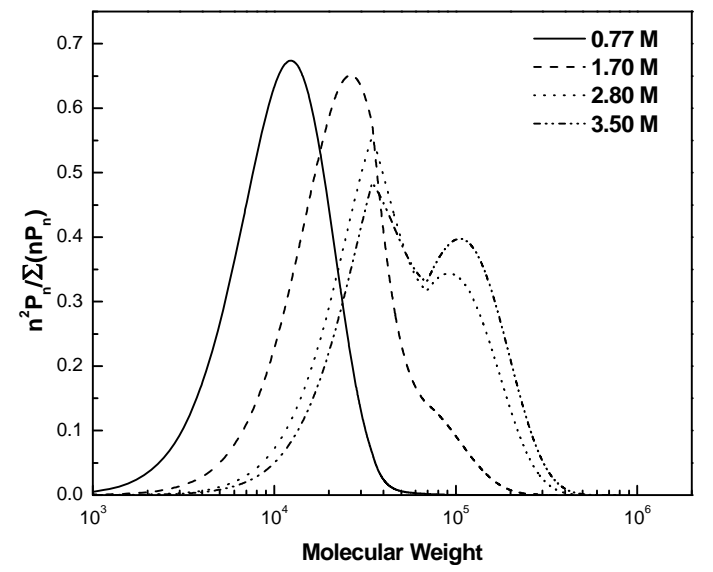

Figure 3: Effect of monomer feed concentration on MWD. $P=27.5 \mathrm{MPa}, T=75^{\circ} \mathrm{C}, k_{p} /\left\langle k_{t}\right\rangle^{0.5}=0.2, k_{p}=3250$ $\mathrm{dm}^{3} /$ mol.s, $k_{t}^{u u}=3.6 \times 10^{8} \mathrm{dm}^{3} /$ mol.s (taken less than $\mathrm{k}_{\mathrm{t}}(265,265)$ ), $2 k_{t}^{u h}=2.5 \times 10^{8} \mathrm{dm}^{3} / \mathrm{mol}^{\mathrm{u}} \mathrm{s}, k_{t}^{\text {hh }}=1.3 \times 10^{8}$ $\mathrm{dm}^{3} / \mathrm{mol} . \mathrm{s}, n_{c r}=540, k_{d}=0.00103 \mathrm{~s}^{-1}, I_{0}=0.003 \mathrm{M}, f=0.6, \& \tau=21 \mathrm{~min}$. The y-axis is proportional to the experimental one. 

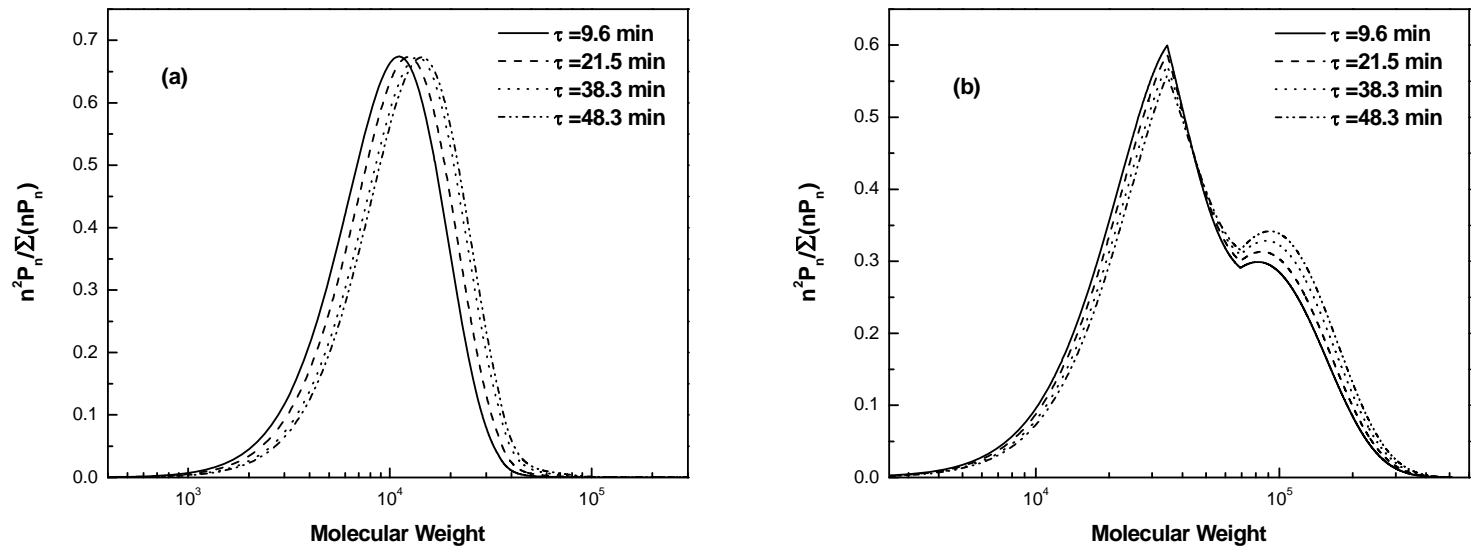

Figure 4: : Effect of residence time on the MWD: (a) $\mathrm{M}_{0}=0.78 \mathrm{M}$; (b) $\mathrm{M}_{0}=2.8 \mathrm{M} . P=27.5 \mathrm{MPa}, T=75^{\circ} \mathrm{C}$. 


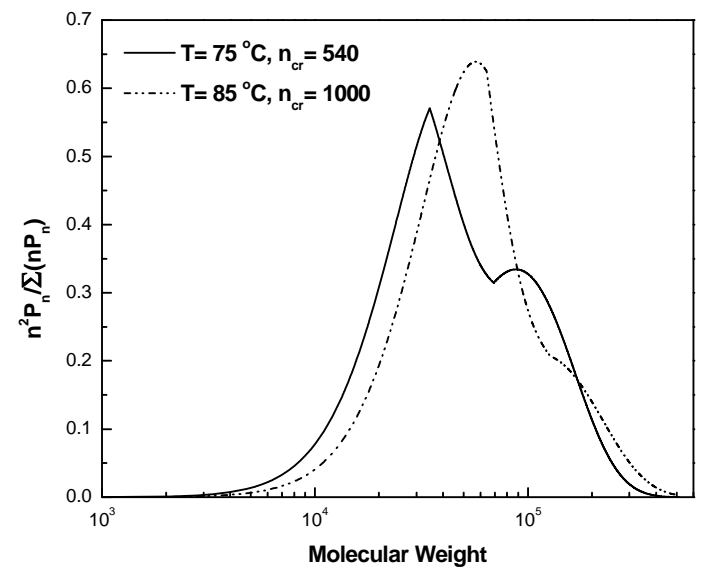

Figure 5: Effect of temperture on the MWD. $P=27.5 \mathrm{MPa}, M_{0}=2.69 \mathrm{M}, \tau=11 \mathrm{~min}, \& I_{0}=0.00268 \mathrm{M}$. For $75^{\circ} \mathrm{C}$, the parameters are those used in Fig.3. For $85{ }^{\circ} \mathrm{C}, k_{p} /\left\langle k_{t}\right\rangle^{0.5}=0.43, k_{d}=0.00351 \mathrm{M}$, average chain length used for hindered and hindered radicals are 460 and 2565 respectively; $k_{p}=7150 \mathrm{dm}^{3} / \mathrm{mol}_{\text {.s }}, k_{t}^{u u}=3.12 \times 10^{8} \mathrm{dm}^{3} / \mathrm{mol}_{\text {s }}$, $2 k_{t}^{u h}=2.23 \times 10^{8} \mathrm{dm}^{3} /$ mol.s, $\& k_{t}^{\text {hh }}=1.24 \times 10^{8} \mathrm{dm}^{3} /$ mol.s, \& $f=0.63$. The y-axis is proportional to the experimental one 


\section{CHAPTER 8}

Continuous Precipitation Polymerization of Vinylidene Fluoride in Supercritical Carbon Dioxide: Modeling the Molecular Weight Distribution - An Improved Model

Chapter 8 is a manuscript that will be submitted for publication in Industrial and Engineering Chemistry - Research 


\title{
Continuous Precipitation Polymerization of Vinylidene Fluoride in Supercritical Carbon Dioxide: Modeling the Molecular Weight Distribution - An Improved Model
}

\author{
Tamer S. Ahmed ${ }^{l}$, Joseph M. DeSimone ${ }^{1,2}$, and George W. Roberts ${ }^{1, *}$ \\ ${ }^{1}$ Department of Chemical and Biomolecular Engineering, North Carolina State University, Box \\ \# 7905, Raleigh, North Carolina 27695-7905 \\ ${ }^{2}$ Department of Chemistry, University of North Carolina at Chapel Hill, Box \# 3290, Chapel \\ Hill, North Carolina 27599-3290
}

\begin{abstract}
Poly(vinylidene fluoride) (PVDF) precipitation polymerization in supercritical carbon dioxide $\left(\mathrm{scCO}_{2}\right)$ were reported to show bimodal molecular weight distributions (MWDs) under specific reaction conditions. Different hypotheses and models claimed to account for this behavior are reviewed in this paper. In addition, an improved version of one of these models is presented to account for the bimodality of the MWDs and its variation with reaction conditions. This model is a homogenous model that takes into account the change of termination scheme of the polymeric radicals with chain length from chemically-controlled termination to diffusioncontrolled termination. The change of the termination scheme resulted in two populations that are responsible for the bimodality observed. In addition, the model includes chain transfer to polymer reaction, which is responsible for the broadness observed in the MWDs of the synthesized PVDF. The model was successful in accounting for the change of modality with reaction conditions such as monomer concentration, average residence time at low and high

\footnotetext{
${ }^{*}$ To whom correspondence should be addressed. Tel: +1-919-515-7328; Fax: +1-919-515-3465; E-mail address: groberts@eos.ncsu.edu
} 
monomer concentrations, and the reaction temperature. In addition, the model can capture the occurrence of gelation, which is responsible for an inoperability region that was confirmed in the polymerization experiments. The success of this homogeneous model in predicting the experimental observations support the $\mathrm{CO}_{2}$-rich phase as the main locus of polymerization for PVDF precipitation polymerization in $\mathrm{scCO}_{2}$, as reported previously.

\subsection{Introduction}

Poly(vinylidene fluoride) (PVDF) is a highly non-reactive thermoplastic fluoropolymer. It possesses unique properties such as excellent chemical, thermal and mechanical stability in addition to its pyroelectric and piezoelectric properties. Additionally, it has low surface energy, low water absorptivity, excellent weatherability and low flammability ${ }^{1,2}$. Consequently, PVDF is used generally in applications requiring the highest purity, strength, and resistance to solvents, acids, bases, and heat in addition to low smoke generation during a fire event. Some typical applications for PVDF include coatings and films, cables, pipes, tubing in plastic heat exchangers, column packing, valves, and pumps. In addition, PVDF is an acceptable material for biological systems ${ }^{3}$.

The homopolymerization of vinylidene fluoride (VF2) in supercritical carbon dioxide $\left(\mathrm{scCO}_{2}\right)$ was reported by both precipitation ${ }^{4-10}$ and dispersion ${ }^{11-15}$ polymerizations. Both continuous $^{4,5,8,9}$ and batch ${ }^{10-15}$ processes were reported. The molecular weight distributions (MWDs) of the synthesized PVDF in $\mathrm{scCO}_{2}$ exhibited some features that were not captured by the average molecular weights. In particular, the MWDs of PVDF showed bimodal distributions under certain reaction conditions in both the continuous ${ }^{8,9}$ and the batch ${ }^{7}$ processes. The main 
features associated with these bimodal $\mathrm{MWDs}^{8}$ were: 1) the MWD changed from being perfectly unimodal at low monomer concentrations to become bimodal with the increase of the monomer concentration at constant average residence time $(\tau) ; 2)$ the average residence time had no effect on the molecular weight and the MWD at low monomer concentration. At high monomer concentrations, the PDI was about 2.5 for $\tau$ between 11 and $20 \mathrm{~min}$, and it increased sharply to about 6.6 at about $\tau=25 \mathrm{~min} ; 3$ ) the molecular weights, PDI, and the extent of bimodality of the MWD decreased with increasing temperature.

Typically, broad and bimodal MWDs are obtained by polymer blending, i.e. mixing of high and low molecular weight fractions. Polymer blending usually requires a multi step process, where the low and high molecular weight fractions are synthesized independently and then mixed together. On the other hand, $\mathrm{CO}_{2}$-based polymerization technique is a single step process. In addition, the broad polydispersity indices (PDI) and the bimodality contribute in improving flow characteristics and processing behavior ${ }^{16,17}$. Therefore, the production of bimodal MWDs is of significant commercial interest. However, in order to synthesize polymer of desired properties, it is very important to understand the origin of the bimodal MWD, and to be able to control the relative amounts and molecular weights of the two fractions.

The bimodality of the MWD of PVDF was attributed in the literature to four different hypotheses. The first hypothesis is that the mixing was imperfect in the continuously stirred tank reactor (CSTR) used in the polymerization that resulted in two polymer populations leading to the bimodal MWDs ${ }^{8}$. This hypothesis was influenced by the work of Zhang and Ray ${ }^{18}$ in which it was showed that broad MWDs with shoulder can be generated by the imperfect mixing in a CSTR. However, Saraf et al. ${ }^{8}$ showed that the changing of the mixing speed or agitator type 
during the continuous precipitation polymerization of PVDF does not significantly affect the MWD.

The second hypothesis is that long chain branching, a result of chain transfer to polymer, caused a second population of highly branched polymer chains, which could be the cause of the second mode in the MWD. Saraf et al. ${ }^{8}$ proposed a homogeneous kinetic model that included a chain transfer to polymer step in order to explore this possibility. The model was successful in predicting the PDI variation with inlet monomer concentration and residence time reasonably well. In addition, the model predicted a region of inoperability for the CSTR. This region was confirmed experimentally since the CSTR could not reach steady state in this region. Although, chain transfer to polymer could account for the breadth of the MWD, however, the bimodality of the MWD could not be generated ${ }^{8}$.

The third hypothesis is that the bimodality is due to the transition of the termination reaction from a kinetically-controlled regime to a diffusion-controlled regime with increasing macroradical molecular weight ${ }^{19}$. Accordingly, the termination reaction in the diffusioncontrolled regime is chain length-dependent. Therefore, the second mode is a result of the hindered-terminated chains. The phenomenon of reduced termination due to diffusion limitations has been observed for some polymerizations when the polymer is not soluble in its own monomer. Examples of this type of behavior are acrylonitrile, vinyl chloride, trifluorochloroethylene, and vinylidene chloride $\mathrm{c}^{20-25}$. In addition, similar effects are observed in other polymerizations when the medium used for polymerization is nonsolvent for the polymer (e.g., methanol/polystyrene, hexane/poly(methyl methacrylate) $)^{26}$. In fact, this decrease in termination rate constant with radical chain length was reported to produce bimodal MWDs for 
the free-radical polymerization of methyl methacrylate in the presence of poly(methyl methacrylate $)^{27}$. Recently, we proposed a homogeneous kinetic model based on the hypothesis of hindered termination for long chains in order to explore this possibility ${ }^{19}$. In this model, three termination reactions and rate constants were used to approximate the termination scheme. The model could capture successfully the effect of the operating parameters, such as the effect of monomer feed concentration, residence time for both low and high monomer concentration, and reaction temperature, on the MWD. However, it had some drawbacks as a result of the oversimplification adopted by approximating a termination scheme that consists of an infinite number of reactions and constants with only three termination rate constants. Moreover, the model neglected chain transfer to polymer reaction. Consequently, the model underestimated the high PDI observed during the experiments.

The fourth and final hypothesis is that the bimodality is a result of a simultaneous polymerization in both the fluid and the polymer phases. Recently, Mueller et al. developed a mathematical model for the dispersion polymerization of poly(methyl methacrylate) in $\mathrm{scCO}_{2}$ taking into account the transport of polymeric radicals between the two phases ${ }^{28,29}$. They applied this model for the precipitation polymerization of $\mathrm{PVDF}$ in $\mathrm{scCO}_{2}{ }^{7}$. The main assumptions associated with this model are that: 1) the polymerization in both the polymer-rich and $\mathrm{CO}_{2}$-rich phases is considered; 2) low molecular weight species $\left(\mathrm{CO}_{2}\right.$, monomer, and initiator) are assumed to be in equilibrium between the two phases at all times; 3) polymeric live radicals are not in equilibrium between the two phases. The diffusion of these radicals between phases is governed by the finite mass transport of the radicals according to their chain lengths; 4) a constant number of polymeric particles are assumed throughout the polymerization since the 
process of nucleation or particle formation is neglected in this model. The model inevitably included a very large number of parameters. However, Mueller et al. made a considerable effort to estimate most of the parameters from independent sources. Nevertheless, three adjustable parameters were needed to model the polymerization with two of these parameters having very significant impact on the system behavior while the third adjustable parameter (chain transfer to polymer rate constant) only affecting the broadness of the MWDs ${ }^{7}$. Mueller et al. ${ }^{7}$ compared the model predictions to their own few batch polymerization data. Very reasonable agreement between the model predictions and experimental observations were observed.

For precipitation/dispersion polymerization, two factors determine the relative importance of polymerization in the polymer phase to that in the fluid phase. First, the time scale of termination compared to that of precipitation and/or diffusion. Second, the availability of monomer in the polymer phase as a result of monomer partitioning between phases. For the first factor, if the characteristic time for termination is much less than that of diffusion/precipitation, the polymer chains will terminate in the fluid phase rather than transfer to the polymer phase and vice versa. Mueller et al. ${ }^{7}$ handled this factor using what they called $\Omega$-parameter (ratio of the characteristic times of mass transport of radicals to that of termination), although they neglected the precipitation of radicals, which is a more important way of transfer of the radicals to the polymer phase. It is important to take into consideration here that their values for the $\Omega$ parameter depend on the specific interphase surface area of the polymer particles, which was one of the key adjustable parameters in their model and had a significant impact on the model output $^{7}$. In fact, they showed that small changes in the value of the total area of the particles is sufficient to completely change the output of the $\operatorname{model}^{7}$. In any case, they showed that values of 
the $\Omega$-parameter were less than 1.0 for the precipitation polymerization of PVDF. This demonstrated that the characteristic time of termination is shorter than that of mass transport. Nevertheless, it also showed that the polymer phase is a possible locus of polymerization along with the fluid phase.

For the second factor, Mueller et al. ${ }^{7}$ used the Sanchez-Lacombe equation of state with the mixing rules proposed by McHugh and Krukonis ${ }^{30}$ to model the partitioning of VF2 between the fluid and polymer phases. They used the experimental data from our lab ${ }^{31}$ to obtain the interaction coefficients of $\mathrm{VF} 2 / \mathrm{CO}_{2}$ and $\mathrm{CO}_{2} / \mathrm{PVDF}$. As for $\mathrm{VF} 2 / \mathrm{PVDF}$, they neglected the entropic interaction parameter and used the other binary interaction parameter as an adjustable parameter. This is the second adjustable parameter that had a very significant impact on the system behavior as they mentioned ${ }^{7}$.

The only study available in the literature about the partitioning of VF2 between PVDF and $\mathrm{scCO}_{2}$ was done in our lab ${ }^{9,}{ }^{31}$. Figure 1 shows the partition coefficient of VF2 between PVDF and $\mathrm{CO}_{2}$ as a function of pressure and tempertaure ${ }^{31}$. It showed that VF2 has a near zero partitioning between PVDF and $\mathrm{scCO}_{2}$ at pressure above 240 bar. In addition, the partition coefficient decreases with increasing pressure or decreasing temperature. Therefore, at the operating conditions of the continuous polymerization ${ }^{8}\left(75^{\circ} \mathrm{C}\right.$ and $\left.276 \mathrm{bar}\right)$, there is a negligible amount of VF2 in PVDF compared to that in the $\mathrm{CO}_{2}$-fluid phase, which diminishes the rate of polymerization in the polymer. In addition, the trend of increasing the VF2 partitioning coefficient with temperature contradicts that the bimodality is a result of a simultaneous polymerization in both the fluid and the polymer phases, since the bimodality was shown to decrease with temperture ${ }^{8}$. It is interesting to notice here that Mueller et al. ${ }^{7}$, although they used 
the experimental data from our lab ${ }^{31}$ to estimate the interaction coefficients of $\mathrm{VF} 2 / \mathrm{CO}_{2}$ and $\mathrm{CO}_{2} / \mathrm{PVDF}$, they neglected this study. In addition, they neglected that in the same study ${ }^{31}$, it was shown that Sanchez-Lacombe equation of state overestimated VF2 partitioning in PVDF especially at high pressures, although it predicted the same trend as the experimental data.

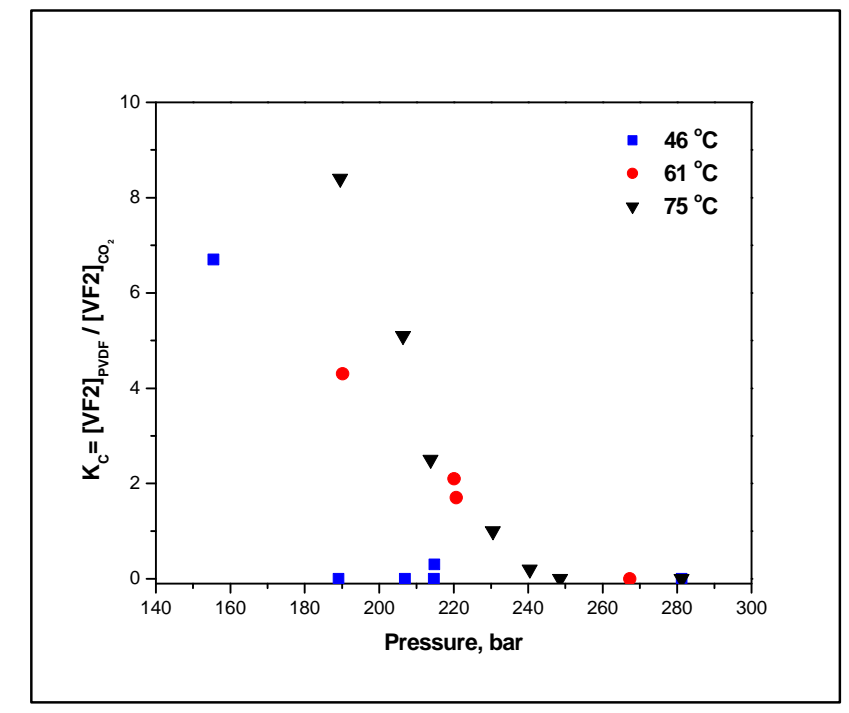

Figure 1: Partition coefficients of VF2 between PVDF (Solef $® 1010, \mathrm{M}_{\mathrm{w}}=180,000$ ) and $\mathrm{CO}_{2}$ phases as a function of temperature and pressure; $5 \mathrm{wt} \% \mathrm{PVDF}$ and $15 \mathrm{wt} \% \mathrm{VF} 2$ in $\mathrm{CO}_{2}{ }^{31}$.

There are some concerns about the Mueller et al. ${ }^{7}$ model and its suitability to account for the bimodal MWDs observed for PVDF. These concerns are summarized in the following points:

(1) Their model credibility depends mainly on its adjustable parameters. As was shown above, two of these parameters are related to the factors that determine if the polymer phase is an active locus of polymerization or not. Although, the model performance is very sensitive to these two parameters ${ }^{7}$, there is a lot of uncertainty in the values of these parameters. 
(2) Although the initiator efficiency in the polymer phase is expected to be very low, initiation cannot be totally neglected in the polymer phase. Consequently, it is inevitable to have a second mode if monomer is available in the polymer phase even if at a low $\Omega$ parameter, as in the case for low monomer concentrations. However, the experimental results showed that at low monomer concentration, the MWD is perfectly unimodel ${ }^{8}$. This inconsistancy is clear in their model predictions for low monomer concentration (run \#2, Figure 9 in Mueller et al. ${ }^{7}$ ).

(3) The assumption that the bimodality is a result of a simultaneous polymerization in both the fluid and the polymer phases cannot account for the decrease of bimodality with temperature as seen in the experiments ${ }^{8}$. As the temperature increases, the transport of the polymeric radicals from the fluid- $\mathrm{CO}_{2}$ phase to the polymer phase by finite mass transport will increase since the diffusion coefficients of the polymeric radicals increase with temperature. At the same time, the termination reaction is not expected to increase with the same rate because of very low activation energy associated with radical combination reactions ${ }^{32}$. Consequently, according to this model, a larger secondmolecular weight mode is expected with increasing temperature, which totally contradicts the experimental results.

(4) In our recent contribution on the precipitation copolymerization of vinylidene fluoride with hexafluoropropylene (HFP) ${ }^{33}$, a tail in the MWD was observed. This tail increased to become a second mode/shoulder with increasing monomer concentration and with increasing pressure. If the Mueller et al. ${ }^{7}$ hypothesis of simultaneous polymerization in both the fluid and the polymer phases is applied, their heterogeneous model is expected 
to predict a decrease of the tail with pressure since the diffusion coefficients are expected to decrease with increasing pressure. This is another contradiction between the hypothesis of simultaneous polymerization in both the fluid and the polymer phases and the observed experimental results. Additional experimental observations during the copolymerization of VF2 and HFP that can be accounted for only by considering the continuous phase as the locus of polymerization were discussed in our recent contributions $^{33,34}$.

The above concerns suggest that the heterogeneous polymerization model suggested by Mueller et al. ${ }^{7}$ may not be the final word on the issue of bimodal MWDs observed for PVDF in $\mathrm{scCO}_{2}$. In addition, in our recent contribution ${ }^{35}$, we have established that the precipitation homopolymerization of VF2 and the precipitation copolymerization of VF2 with hexafluoropropylene in $\mathrm{scCO}_{2}$ take place primarily in the continuous, $\mathrm{CO}_{2}$-rich fluid phase. Analysis of experimental data has shown that the data for the rate of polymerization $\left(R_{p}\right)$ and the number-average molecular weight $\left(M_{n}\right)$ are well described by a model based on the assumption that all of the polymerization reactions take place in the fluid phase. Conversely, two models based on the assumption that propagation and termination take place either on the surface of the polymer particles or throughout the polymer particles fail to describe the $R_{p}$ and $M_{n}$ data.

The objective of the current work is to demonstrate the ability of a homogenous model that adequately accounts for termination and chain transfer to polymer to capture all the features of the MWDs of PVDF. The experimental data of the continuous precipitation polymerization of PVDF in $\mathrm{scCO}_{2}$ at $75^{\circ} \mathrm{C}$ and 276 bar with diethylperoxydicarbonate (DEPDC) initiator reported by Saraf et al. ${ }^{8}$ is used to test the performance of the model predictions. 


\subsection{Model Development}

The model described here consists of classical initiator-decomposition, chain-initiation, and chain-propagation steps. Termination reaction is solely by combination ${ }^{8}$ and is assumed to be kinetically controlled up to a critical chain length $\left(n_{c r}\right)$, beyond which the growing radicals experience diffusion limitations. The termination of the diffusion-limited radicals is chain lengthdependent. Radicals containing up to $n_{c r}$ monomer units are referred to as unhindered, while hindered radicals are those containing more than $n_{c r}$ units. The reaction of any two radicals, both having a chain length shorter than the critical chain length, is described by the chemical termination rate constant $\left(k_{t}^{u u}\right)$. For radicals of chain length greater than the critical value, the reduction in the termination rate due to the diffusion limitations is approximated by two termination rate constants $\left(k_{t}^{u h}\right)$ and $\left(k_{t}^{\text {hh }}\right)$. The first describes termination by combination of an unhindered radical with a hindered radical, while the second is for the combination of two hindered radicals. The diffusion limitations on the rate constant for propagation $\left(k_{p}\right)$ are neglected in view of the low conversions involved in the experimental polymerizations ${ }^{8}$. As an addition to our previous model ${ }^{19}$, chain transfer to polymer (CTP) reaction was taken into account. No diffusion limitations is expected for CTP reactions since these reactions are very slow $^{26}$. Figure 2 shows the kinetic scheme of the model. 


$$
\begin{aligned}
& I \stackrel{k_{d}}{\longrightarrow} 2 f R^{\cdot} \quad \text { (Initiator decomposition) } \\
& R^{\cdot}+M \stackrel{k_{m}}{\longrightarrow} R_{1}^{\cdot} \quad \text { (Chain Initiation) } \\
& R_{n}^{\cdot}+M \stackrel{k_{p}}{\longrightarrow} R_{n+1}^{\cdot} \quad \text { (Propagation) } \\
& R_{n}^{\cdot}+R_{m}^{\cdot} \stackrel{k_{t}^{u n}}{\longrightarrow} P_{n+m} \quad \text { (Termination, } n \& m \leq n_{c r} \text { ) } \\
& \left.R_{n}^{\cdot}+R_{m}^{\cdot h} \stackrel{k_{t}^{u h} \longrightarrow}{\longrightarrow} P_{n+m} \text { (Termination, } n \leq n_{c r} \& m>n_{c r}\right) \\
& R_{n}^{\cdot h}+R_{m}^{\cdot h} \stackrel{k_{t}^{h h}}{\longrightarrow} P_{n+m} \text { (Termination, } n \& m>n_{c r} \text { ) } \\
& P_{n}+R_{m}^{\cdot} / R_{m}^{\cdot h} \stackrel{n k_{p}}{\longrightarrow} P_{n}^{\cdot}+P_{m} \quad \text { (Chain transfer to polymer) }
\end{aligned}
$$

Figure 2: Proposed kinetic scheme for PVDF polymerization in $\mathrm{scCO}_{2} . I, M, R_{n}^{\bullet}, R_{n}^{\bullet h} \& P_{n}$ are the concentrations of initiator, monomer, live unhindered radicals, live hindered radicals and dead polymer respectively.

The model is derived for polymerization in an ideal CSTR operating at steady state with the following main assumptions and characteristics:

(1) The continuous $\mathrm{CO}_{2}$ phase is considered as the only locus of polymerization (i.e. the rates of any reaction occurring in the polymer phase are negligible compared to the rates in the fluid phase).

(2) The quasi steady state approximation is valid. This assumption implies that the radical lifetime is very small compared to the residence time. Hence, the radical outflow from the CSTR is neglected.

(3) Since the hydrogen in the CTP step can be extracted from any one of the repeat units of the dead polymer, the rate constant is proportional to its chain length. Shielding of the inner portion of the molecules, which is possible in the case of very large molecules is neglected. 
8.2.1 Model equations. Let $R_{n}^{\bullet}$ and $R_{n}^{* h}$ be the concentration of the unhindered $\left(n \leq n_{c r}\right)$ and hindered $\left(n>n_{c r}\right)$ radicals containing $n$ monomer units respectively. The steady-state material balances on live polymers give:

$$
\begin{gathered}
R_{1}^{\bullet}=\frac{2 f k_{d} I}{k_{p} M} \Delta \\
R_{n}^{\bullet}=\Delta\left[R_{n-1}^{\bullet}+n P_{n} \Phi\right] \quad 1<n \leq n_{c r} \\
R_{n}^{\bullet h}=\Psi\left[R_{n-1}^{\bullet h}+n P_{n} \Phi\right] \quad n>n_{c r}
\end{gathered}
$$

where,

$$
\begin{gathered}
\left(R_{n}^{\bullet}\right)_{T}=\sum_{n=1}^{n_{c r}} R_{n}^{\bullet} \\
\left(R_{n}^{\bullet h}\right)_{T}=\sum_{n=n_{c r+1}}^{\infty} R_{n}^{\bullet h} \\
\Phi=\frac{k_{t p}\left(\left(R_{n}^{\bullet}\right)_{T}+\left(R_{n}^{\bullet h}\right)_{T}\right)}{k_{p} M} \\
\Psi=\frac{k_{p} M}{k_{p} M+2 k_{t}^{u u}\left(R_{n}^{\bullet}\right)_{T}+2 k_{t}^{u h}\left(R_{n}^{\bullet h}\right)_{T}+k_{t p} \sum_{n=2}^{\infty} n P_{n}} \\
k_{p} M+2 k_{t}^{u h}\left(R_{n}^{\bullet}\right)_{T}+2 k_{t}^{\text {hh }}\left(R_{n}^{\bullet h}\right)_{T}+k_{t p} \sum_{n=2}^{\infty} n P_{n}
\end{gathered}
$$

Equation 2 can be rewritten in terms of $R_{1}^{\bullet}$ then by substituting for $R_{1}^{\bullet}$ from Eq. 1:

$$
R_{n}^{\cdot}=\left(\frac{2 f k_{d} I}{k_{p} M}\right) \Delta^{n}+\Phi \sum_{m=1}^{n-1}\left(\Delta^{n-m}(m+1) P_{m+1}\right) \quad 1<n \leq n_{c r}
$$

Similarly, Eq. 3 can be rewritten in terms of $R_{n_{c r}}^{\bullet}$ : 


$$
R_{n}^{\bullet h}=\Psi^{n-n_{c r}} R_{n_{c r}}^{\bullet}+\Phi \sum_{m=n_{c r}}^{n-1}\left(\Psi^{n-m}(m+1) P_{m+1}\right) \quad n>n_{c r}
$$

where $R_{n_{c r}}^{\bullet}$ is obtained from Eq. 9 after setting $n=n_{c r}$ :

$$
R_{n_{c r}}^{\bullet}=\left(\frac{2 f k_{d} I}{k_{p} M}\right) \Delta^{n_{c r}}+\Phi \sum_{m=1}^{n_{c r}-1}\left(\Psi^{n_{c r}-m}(m+1) P_{m+1}\right)
$$

Substituting Eq. 9 in Eq. 4 and Eqs. 10 and 11 in Eq. 5:

$$
\begin{aligned}
& \left(R_{n}^{\bullet}\right)_{T}=\left(\frac{2 f k_{d} I}{k_{p} M}\right)_{n=1}^{n_{c r}} \Delta^{n}+\Phi \sum_{n=2}^{n_{c r}} \sum_{m=1}^{n-1}\left(\Delta^{n-m}(m+1) P_{m+1}\right) \\
\left(R_{n}^{\bullet h}\right)_{T}= & \left(\frac{2 f k_{d} I}{k_{p} M}\right)\left(\frac{\Delta}{\Psi}\right)^{n_{c r}} \sum_{n=n_{c r}+1}^{\infty} \Psi^{n} \\
+ & \Phi \sum_{n=n_{c r}+1}^{\infty}\left\{\Psi^{n-n_{c r}} \sum_{m=1}^{n_{c r}-1}\left(\Psi^{n_{c r}-m}(m+1) P_{m+1}\right)+\sum_{m=n_{c r}}^{n-1}\left(\Psi^{n-m}(m+1) P_{m+1}\right)\right\}
\end{aligned}
$$

Finally, from the binomial series, since $\Delta<1$ and $\Psi<1$, Eqs. 12 and 13 reduce to:

$$
\begin{aligned}
\left(R_{n}^{\bullet}\right)_{T}=\left(\frac{2 f k_{d} I}{k_{p} M}\right) \frac{\Delta}{1-\Delta}\left(1-\Delta^{n_{c r}}\right)+\Phi \sum_{n=2}^{n_{c r}} \sum_{m=1}^{n-1}\left(\Delta^{n-m}(m+1) P_{m+1}\right) \\
\left(R_{n}^{\bullet h}\right)_{T}=\left(\frac{2 f k_{d} I}{k_{p} M}\right) \Delta^{n_{c r}}\left(\frac{\Psi}{1-\Psi}\right) \\
+\Phi \sum_{n=n_{c r}+1}^{\infty}\left\{\Psi^{n-n_{c r}} \sum_{m=1}^{n_{c r}-1}\left(\Psi^{n_{c r}-m}(m+1) P_{m+1}\right)+\sum_{m=n_{c r}}^{n-1}\left(\Psi^{n-m}(m+1) P_{m+1}\right)\right\}
\end{aligned}
$$

A steady state material balance on the dead polymer for the CSTR gives:

$$
\begin{gathered}
P_{n}=\tau\left\{k_{t}^{u n} \sum_{m=1}^{n-1}\left(R_{m}^{\bullet} R_{n-m}^{\bullet}\right)+k_{t p}\left[R_{n}^{\bullet} \sum_{m=2}^{\infty}\left(m P_{m}\right)-n P_{n}\left(\left(R_{n}^{\bullet}\right)_{T}+\left(R_{n}^{\bullet h}\right)_{T}\right)\right]\right\} \quad 1<n \leq n_{c r}(16) \quad n>n_{c r} \\
P_{n}=\tau\left(r_{p_{n}}^{a}+r_{p_{n}}^{b}+r_{p_{n}}^{c}+r_{p_{n}}^{d}\right)
\end{gathered}
$$


where $\tau$ is the average residence time: $\tau=\frac{\text { Volume of CSTR }}{\text { Total volumetric flow rate }}$

$$
\begin{array}{cc}
r_{p_{n}}^{a}=k_{t}^{u u} \sum_{m=n-n_{c r}}^{n_{c r}}\left(R_{m}^{\bullet} R_{n-m}^{\bullet}\right) & n_{c r}<n \leq 2 n_{c r} \\
r_{p_{n}}^{b}=\left\{\begin{array}{lc}
2 k_{t}^{u h} \sum_{m=1}^{n-\left(n_{c r}+1\right)}\left(R_{m}^{\bullet} R_{n-m}^{\bullet h}\right) & n_{c r}+1<n \leq 2 n_{c r}+1 \\
2 k_{t}^{u h} \sum_{m=1}^{n_{c r}}\left(R_{m}^{\bullet} R_{n-m}^{\bullet h}\right) & n>2 n_{c r}+1
\end{array}\right\} \\
r_{p_{n}}^{c}=k_{t}^{h h} \sum_{m=n_{c r}+1}^{n-\left(n_{c r}+1\right)}\left(R_{m}^{\bullet h} R_{n-m}^{\bullet h}\right) & n \geq 2 n_{c r}+2 \\
r_{p_{n}}^{d}= & k_{t p}\left[R_{n}^{\bullet h} \sum_{2}^{\infty}\left(m P_{m}\right)-n P_{n}\left(\left(R_{n}^{\bullet}\right)_{T}+\left(R_{n}^{\bullet h}\right)_{T}\right)\right] \\
\end{array}
$$

Finally, steady-state material balances on monomer and initiator give:

$$
\begin{gathered}
M=\frac{M_{i n}-2 f k_{d} I \tau}{1+\tau k_{p}\left(\left(R_{n}^{\bullet}\right)_{T}+\left(R_{n}^{\bullet h}\right)_{T}\right)} \\
I=\frac{I_{i n}}{1+k_{d} \tau}
\end{gathered}
$$

where $M_{\text {in }}$ and $I_{\text {in }}$ are the feed concentrations of monomer and the initiator respectively and $f$ and $k_{d}$ are DEPDC initiator decomposition efficiency and decomposition rate constant respectively.

8.2.2 Parameter evaluation. The decomposition kinetics of DEPDC initiator in $\mathrm{scCO}_{2}$ was obtained from Charpentier et al. ${ }^{36}$ (At $75^{\circ} \mathrm{C}, f=0.6$ and $k_{d}=9.9 \times 10^{-4} \mathrm{~s}^{-1}$ ). All the other parameters were determined for a single experimental data point $\left(M_{\text {in }}=3.5 \mathrm{M}, I_{\text {in }}=0.003 \mathrm{M}, \tau=\right.$ 
$21 \mathrm{~min}, 75{ }^{\circ} \mathrm{C}, 276 \mathrm{bar}$ ) and were used to evaluate the ability of the model to predict the experimental results at other experimental conditions for the same temperature and pressure.

8.2.2.1 Termination rate constants. Similar to our previous mode ${ }^{19}$, the Russell model ${ }^{37}$, 38 was used to evaluate the chain-dependence of the termination rate constant. Neglecting reaction diffusion, which is important only at very high conversions, the dependence of the termination rate constant $k_{t}(i, j)$ on chain length is given by:

$$
\begin{gathered}
k_{t}(i, j)=2 \pi p_{\text {spin }}\left(D_{i}+D_{j}\right) \sigma N_{A} \\
D_{i}=\left\{\begin{array}{ll}
D_{\text {mon }} / i^{a} & i \leq X_{c} \\
D_{\text {mon }}\left(X_{c}\right)^{b-a} / i^{b} & i>X_{c}
\end{array}\right\}
\end{gathered}
$$

Here $N_{A}$ is Avogadro's number; $\sigma$ is the capture radius of the reaction (a value of $\sim 0.3$ $\mathrm{nm}^{39,40}$ seems reasonable for vinyl-vinyl combination and was used here); $p_{\text {spin }}$ is the spin probability (since $\mathrm{scCO}_{2}$ at the reaction conditions $\left(276\right.$ bar and $75^{\circ} \mathrm{C}$ ) has a liquid-like density, a value of 0.25 was chosen $\left.^{38}\right) ; D_{i}$ is the diffusion coefficient of the growing chains; $D_{m o n}$ is the diffusion coefficient of the monomer (an estimated value for the diffusivity of vinylidene fluoride monomer in $\mathrm{scCO}_{2}$ using the method proposed by Riazi \& Whitson ${ }^{41}$ is approximately $1.4 \times 10^{-8} \mathrm{~m}^{2} / \mathrm{s}$ at $75{ }^{\circ} \mathrm{C}$ and $\left.276 \mathrm{bar}\right) ; X_{c}$ is the crossover chain length at which the scaling law is presumed to change from short- to long- chain diffusion, while $a$ and $b$ are the chain-length exponents (typical values lie approximately in the range 0.5 to 0.6 for dilute conditions ${ }^{42}$ ).

The termination rate constants were estimated by using the functional form of the chain dependence given by Eqs. 24 and 25, but without a crossover chain length $X_{c}^{43,44}$. A single average chain-length exponent of 0.55 was used. Weighted-average chain lengths of 285 and 
39,000 monomer units were used to represent the average unhindered and hindered radical respectively at $75{ }^{\circ} \mathrm{C}$. This evolved from a trial-and-error procedure by running the model and obtaining the complete radical distribution. From the radical distribution, the weighted-average chain lengths were calculated which is then compared to the assumed ones.

8.2.2.2 Propagation rate constant. The value of $k_{p}$ was calculated from the reported values for $k_{p} /\left\langle k_{t}\right\rangle^{0.5}$ for the precipitation polymerization of $\mathrm{PVDF}$ in $\mathrm{scCO}_{2}$ at $75{ }^{\circ} \mathrm{C}$ and $276 \mathrm{bar}^{4}$, where $\left\langle k_{t}\right\rangle$ (the average macroscopic termination rate constant) was approximated from Eq. 26. A value of $k_{p}=2775 \mathrm{~L} / \mathrm{mol} . \mathrm{s}$ was obtained

$$
\left\langle k_{t}\right\rangle=\frac{\sum_{i} \sum_{j} k_{t}(i, j) R_{i}^{\bullet} R_{j}^{\cdot}}{\left(\sum_{i} R_{i}^{\cdot}\right)^{2}} \approx \frac{k_{t}^{u u} \sum_{i=1}^{n_{c r}} \sum_{j=1}^{n_{c r}} R_{i}^{\bullet} R_{j}^{\cdot}+2 k_{t}^{u h} \sum_{i=1}^{n_{c r}} \sum_{j=n_{c r t}+1}^{\infty} R_{i}^{\bullet} R_{j}^{\bullet h}+k_{t}^{h h} \sum_{i=n_{c r}+1}^{\infty} \sum_{j=n_{c r}+1}^{\infty} R_{i}^{\bullet h} R_{j}^{\bullet h}}{\left[\left(R_{n}^{\bullet}\right)_{T}+\left(R_{n}^{\bullet h}\right)_{T}\right]^{2}}
$$

8.2.2.3 Chain transfer to polymer rate constant. The rate constant for the CTP reaction was estimated by fitting the experimental PDI at $M_{i n}=3.5 \mathrm{M}$. A value of $k_{t p} / k_{p}=1.5 \times 10^{-3}$ was obtained.

8.2.2.4 Critical chain length. The model predicts that the location of the minimum between the two peaks of a bimodal MWD occurs at a chain length of $2 n_{c r}+1$. Therefore, the value of $n_{c r}$ can be estimated from the experimental MWDs. For the sake of simplicity, a constant average value of 540 was used for MWDs at $75{ }^{\circ} \mathrm{C}$, although the location of this minimum was shown experimentally to increase slightly as the monomer concentration increased $^{8}$. 


\subsection{Results and Discussion}

Figure 3 shows the experimental MWDs ${ }^{8}$ along with the model predictions for varying the monomer feed concentration from $0.77 \mathrm{M}$ to $3.5 \mathrm{M}$ at otherwise constant conditions. The model predicted the change from unimodality to bimodality in a very good way with monomer concentration. For the low monomer concentration, the model predicts perfectly unimodal MWD. As monomer concentration increases, the model predicts the transition from unimodal to bimodal MWD by the appearance of the inflection in the MWD (1.7 M curve). Finally, for high monomer concentrations, the model predicted the bimodal MWD as the experimental results. In addition, the model captures the increase in the bimodality, the increase in the size of the second peak at the expense of the first one, the shifting of peaks to higher molecular weights with increasing monomer concentration, and the appearance of long tail for the highest monomer concentration ( $3.5 \mathrm{M}$ curve).

As for PDI, Fig. 4 shows the model prediction for the PDI and its change with monomer concentration compared to the experimental $\mathrm{PDI}^{8}$. The introduction of the CTP reaction allowed the model to predict the experimental PDI trend reasonably well especially the abrupt increase seen in the experimental PDI. 

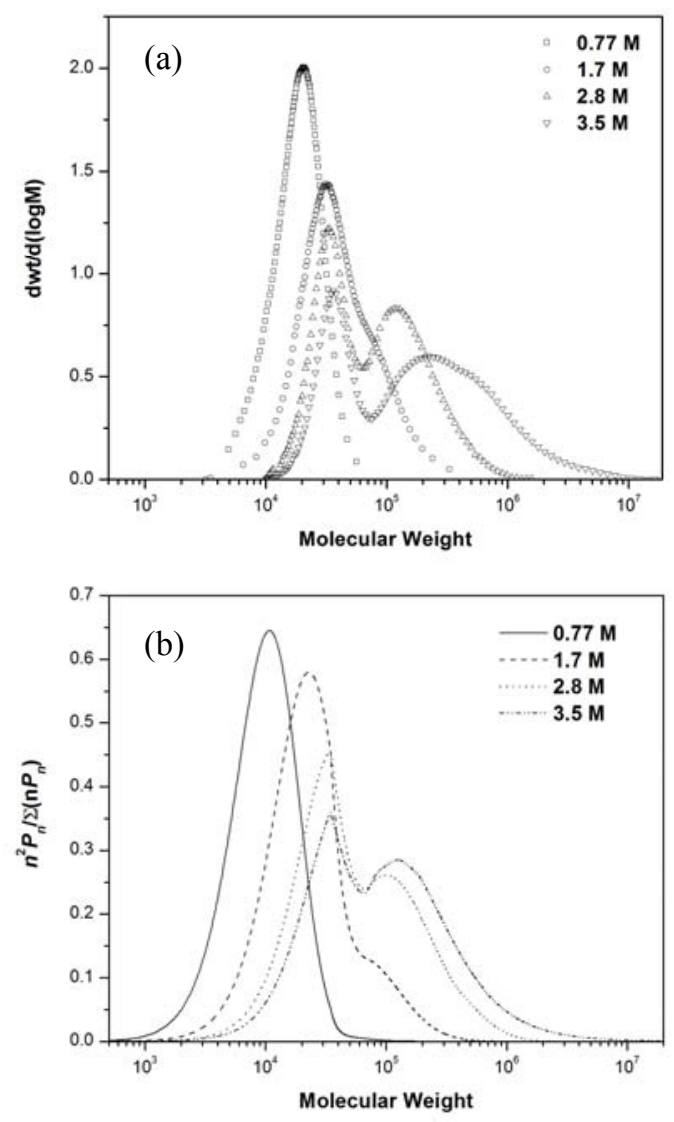

Figure 3: Effect of monomer feed concentration on MWD: (a) Experimental ${ }^{8}$; (b) Model: The y-axis is proportional to the experimental one. $75{ }^{\circ} \mathrm{C}, 276 \mathrm{bar}$, and 21 min average residence time. 


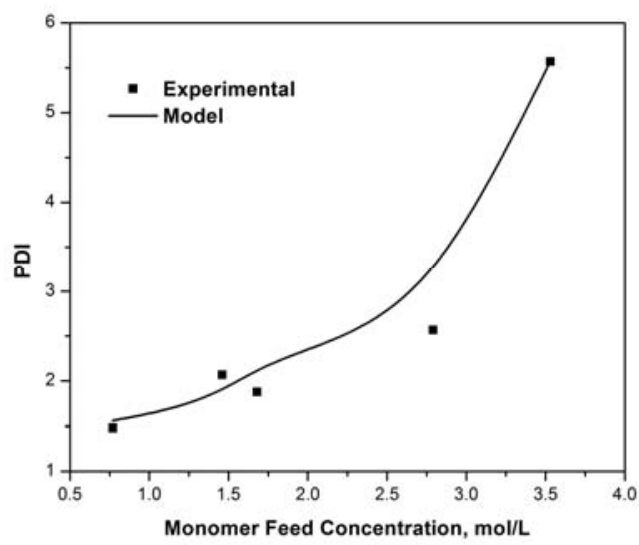

Figure 4: Effect of monomer feed concentration on PDI. $75^{\circ} \mathrm{C}, 276$ bar, and 21 min average residence time.

Figures 5 and 6 show the model prediction for the effect of $\tau$ on the MWDs for low and high monomer feed concentrations respectively along with their experimental MWDs ${ }^{8}$. Similar to the original model without CTP reaction ${ }^{19}$, essentially identical unimodal MWDs similar to the experimental MWDs are predicted with increasing $\tau$ for low monomer concentration. As for the high monomer concentration, the current model shows much better prediction for the experimental MWDs compared to the original model without $\mathrm{CTP}^{19}$. In addition, it is interesting to notice the ability of the model to capture the very long tail that appeared for the $25.5 \mathrm{~min}$ residence time.

The model predictions for the effect of $\tau$ on the PDI for low and high monomer concentrations are shown in Fig. 7. For low monomer concentration, the essentially constant 1.5 PDI is predicted in an excellent way by the model. As for the effect at high monomer concentration, the model overestimates slightly the PDI. Nevertheless, the model captures the 
trend of the PDI and the abrupt increase seen in the experimental PDI at high residence times nicely.
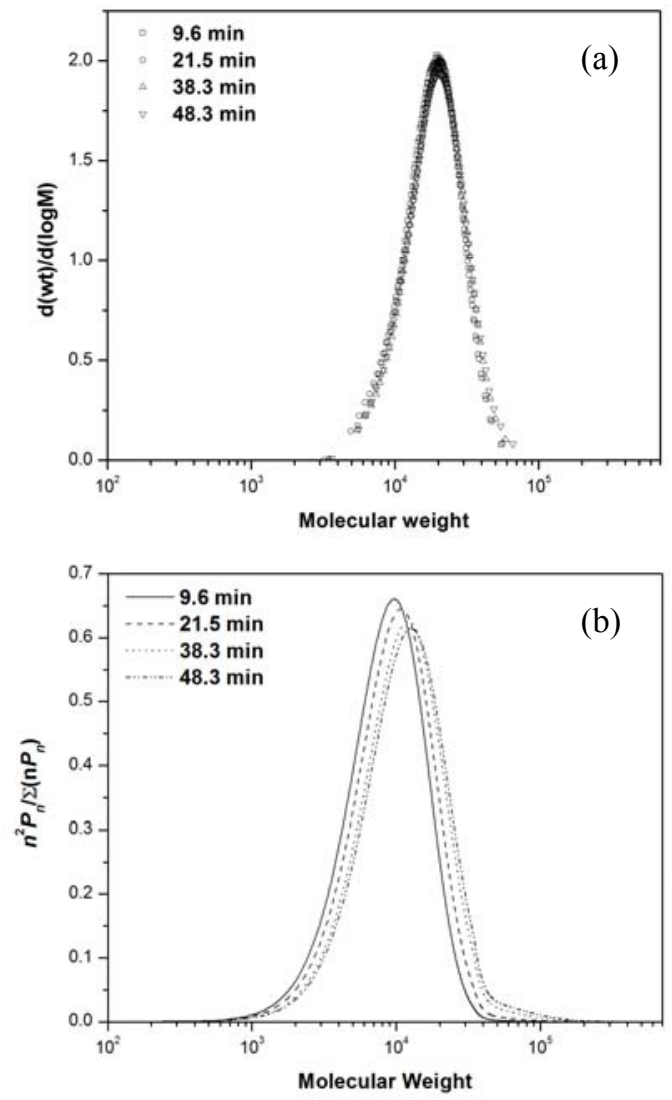

Figure 5: Effect of average residence time on the MWD for low monomer feed concentration with $M_{i n}=0.78 \mathrm{M}$ : (a) Experimental ${ }^{8}$; (b) Model: The y-axis is proportional to the experimental one. $75^{\circ} \mathrm{C}$ and 276 bar. 

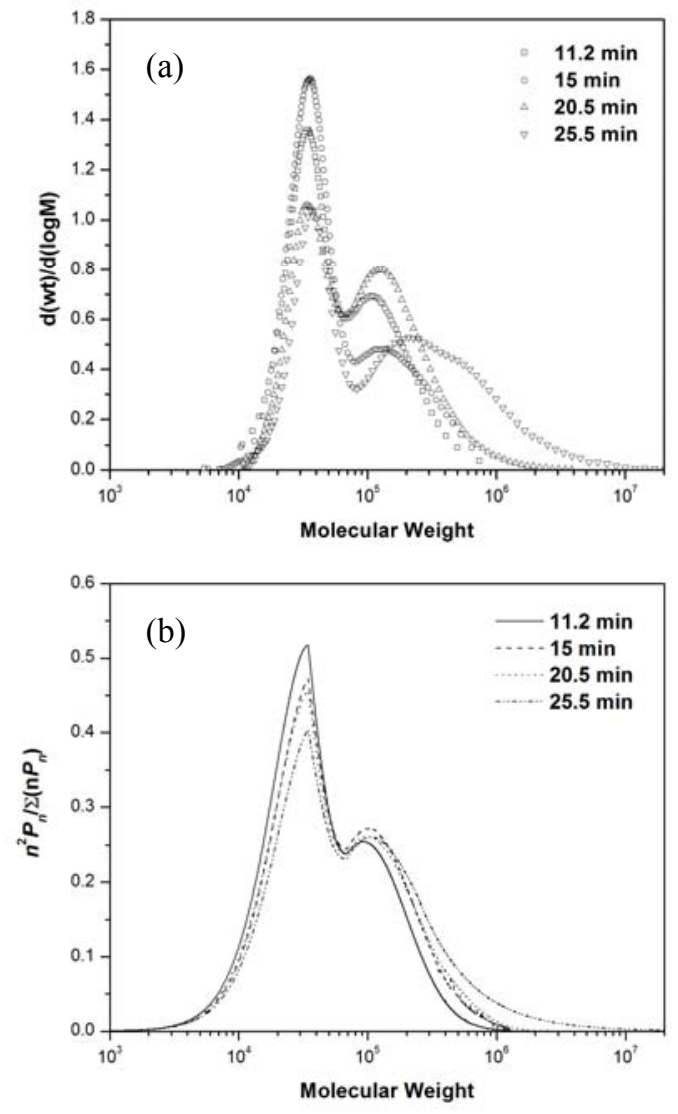

Figure 6: Effect of average residence time on the MWD for high monomer feed concentration with $M_{i n}=2.8 \mathrm{M}$ : (a) Experimental ${ }^{8}$; (b) Model: The y-axis is proportional to the experimental one. $75^{\circ} \mathrm{C}$ and 276 bar.

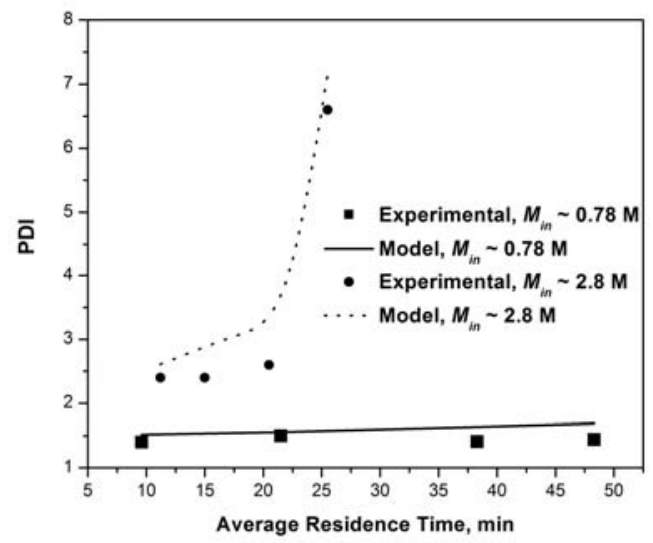

Figure 7: Effect of average residence time on PDI. $75^{\circ} \mathrm{C}$ and 276 bar. 
The ability of the current model to capture the steep increase in the PDI for either cases of high monomer concentrations (Fig. 4) or high residence times (Fig. 7) shows its ability to capture the inoperability region observed during the continuous polymerization experiments ${ }^{8}$. This inoperability region was attributed to gelation ${ }^{8}$ where the polymer chains form an infinite network as a result of crosslinking to form a macroscopic molecule ${ }^{26,45,46}$. The crosslinking mechanism here for the PVDF polymerization is the CTP reaction and termination by combination. Therefore, the current model by its capturing of this steep increase in the PDI can account for the production of a tough, essentially insoluble in any solvent, one-piece polymer that filled the whole reactor during the precipitation polymerization of $\mathrm{PVDF}$ in $\mathrm{scCO}_{2}$ at monomer feed concentration $\sim 6 \mathrm{M}$ and residence time $\sim 20 \min ^{8,47}$. From Fig. 4 , at these conditions, the PDI approaches infinity indicating the occurrence of the gelation. This result provides a rather strong confirmation of the ability of the current simple homogeneous kinetic model to describe the precipitation polymerization of $\mathrm{PVDF}$ in $\mathrm{scCO}_{2}$.

On the other hand, the inoperability region observed experimentally is not expected to be captured by the two loci of polymerization model of Mueller et al. ${ }^{15}$. According to their model, the increase of polymeric chains molecular weight will result in the increase of the transport of these chains to the polymer-rich phase. According, If the above mentioned crosslinking mechanism occurred in the polymer phase, only crosslinked separate polymer particles would have been produced similar to the case of the precipitation polymerization of poly(acrylic acid $)^{48}$ where the polymer-rich phase was believed to be the main locus of polymerization ${ }^{49}$. In addition, the occurrence of the above mentioned mechanism of crosslinking the in Mueller et al. ${ }^{15}$ model is even uncertain in view of the very low value of CTP rate constant they used in their model by 
fitting one of their experimental results $\left(k_{t p} / k_{p}=1 \times 10^{-6}\right.$ with $k_{p}=3870 \mathrm{~L} / \mathrm{mol}^{7} \mathrm{~s}^{7}$ compared to $k_{t p} / k_{p}=1.5 \times 10^{-3}$ with $k_{p}=2775 \mathrm{~L} / \mathrm{mol} . \mathrm{s}$ in the current work and $k_{t p} / k_{p}=2.6 \times 10^{-3}$ in Saraf et al. model $\left.{ }^{8}\right)$. Such a low value was obtained since the presence of two polymerization loci contributes to increase the $\mathrm{PDI}^{7}$. Moreover, the termination reaction is expected to be highly hindered as a result of high viscosity in the polymer phase. Therefore, their low values for CTP and termination rate constants will likely prevent the occurrence of the crosslinking mechanism or at least allow only its occurrence at very impractical monomer concentrations which totally contradicts the experimental observations.

Finally, the current model can account for the decrease of the bimodality of the MWD with increasing temperature as observed expeimentally ${ }^{8}$. As mentioned before, the increase of temperature has a little effect on the chemical termination rate constant because of the very low activation energy associated with radical combination reactions ${ }^{32}$. On the other hand, the diffusion coefficients of the radicals are expected to increase strongly with temperature. This will cause chemical termination to be limiting for a higher chain length (i.e. $n_{c r}$ will shifts to a higher value). Consequently, the population of the unhindered radicals will increase at the expense of the hindered radicals, which will result in the decrease of the bimodality. It is worth stressing again that the two loci of polymerization model of Mueller et al. ${ }^{15}$ cannot capture the effect of temperature. In fact, it contradicts the experimental observations.

The current model including CTP reaction is a big improvement over the original model ${ }^{19}$ especially for predicting the inoperability region and the PDI fairly well. Nevertheless, the model still has some drawbacks. These drawbacks can be classified into two categories. The first category is associated with drawbacks generated from some of the model assumptions. The most 
prominent example is that the low-molecular weight peak is sometimes represented by a sharp peak when the low-molecular weight peak maximum is located after $n_{c r}$ (540 monomer units). This sharp change reflects the assumption of the large step change in termination when the radicals reach the critical size, and represents one of the costs for the simple approximation of the decrease in the termination rate constant. The second category of drawbacks is a result of the unsatisfactory prediction of some of the experimental observations. This category involves the underestimating of the molecular weights of the two peaks, which is represented in the slight underestimating of the peaks location. In addition, the model underestimates the size of the broad high-molecular weight peak for high monomer concentration and high residence times. This may be due to the simplicity of the model, where only two termination reactions and rate constants have been used to approximate the hindered termination scheme that consists of an infinite number of reactions and constants. However, the uncertainty in the experimental molecular weights for PVDF also may contribute to the differences between the model and the data. For example, the polymerization procedure for $\mathrm{PVDF}$ polymerization in $\mathrm{scCO}_{2}$ involved the extraction of the monomer and initiator from the synthesized polymer using $\mathrm{scCO}_{2}$ after the polymer collection ${ }^{8}$. This might have leached some of the low molecular weight chains. Accordingly, the polymer that was analyzed with gel permeation chromatography (GPC) would show higher molecular weights peak locations than the original synthesized polymer. Another factor is that the molecular weights obtained from GPC were not absolute but against poly(methyl methacrylate) standards and these measurements were somewhat difficult since some PVDF samples included gelled fractions ${ }^{47}$. Saraf et al. ${ }^{8}$ homogeneous model that contained only CTP reaction similarly underestimated the molecular weights of the PVDF. They attributed 
this to one of two possibilities. First, the uncertainty in the value of the DEPDC initiator efficiency ${ }^{8}$ reported by Chapentier et al. ${ }^{36}$ since this value was calculated for the reaction between ethoxy radicals and galvinoxyl radicals in the presence of $\mathrm{CO}_{2}$ only. The efficiency of the reaction between the ethoxy radicals and VF2 monomer in the presence of $\mathrm{CO}_{2}$ and PVDF might not be the same. The second possibility is that there was a systematic error in the experimental values of the molecular weights obtained from the GPC. In fact, they showed that the number-average molecular weights obtained form nuclear magnetic resonance spectroscopy end-group analysis were significantly lower than those measured using GPC and appear to agree with their model predictions reasonably well ${ }^{47}$.

The model presented here, although simple, can give a good description of the experimental observation of PVDF polymerization in $\mathrm{scCO}_{2}$. In addition, it helps in understanding the origin of the bimodal MWDs observed, in predicting the polymerization behavior and the relative amount of the two MWD modes, and in establishing safe control and operation for PVDF polymerizations in $\mathrm{scCO}_{2}$.

\subsection{Conclusions}

Different hypotheses and models claimed to account for the bimodal MWDs of PVDF synthesized in $\mathrm{scCO}_{2}$ observed at certain conditions are reviewed in this paper. In addition, an improvement of one of these models is presented. This model is a homogeneous model that takes into account the diffusion limitation on the termination of the polymeric chains as well as CTP reaction. It accounts for the bimodal MWD with two populations of polymeric chains differing in the termination scheme: chemical-controlled termination and diffusion-controlled termination. 
The diffusion-controlled termination is approximated by two reaction constants: one for the termination of unhindered and hindered radicals, and the other for termination of hindered radicals with each other.

The model can capture successfully the effect of the operating parameters, such as the effect of monomer feed concentration, residence time for both low and high monomer concentration, and reaction temperature on the MWD. In addition, it can capture the steep increase of PDI of the synthesized polymers for high monomer concentrations and for high residence times fairly well. Moreover, the model can account for the inoperability region observed experimentally during the continuous polymerization of PVDF. Finally, the merits and the drawbacks of the model are discussed.

\subsection{Acknowledgement}

This material is based upon work supported by the STC Program of the National Science Foundation under Agreement No. CHE-9876674.

\subsection{References}

1. Lovinger, A. J., Poly(vinylidene fluoride). In Developments in crystalline polymers, Basset, D. C., Ed. Applied Science Publishers: London, 1982; Vol. 1, pp 195-273.

2. Scheirs, J., Modern Fluoropolymers: High Performance Polymers for Diverse Applications. John Wiley \& Sons, Ltd.: 1997.

3. Klinge, U.; Klosterhalfen, B.; Öttinger, A. P.; Junge, K.; Schumpelick, V. Biomaterials 2002, 23, (16), 3487-3493. 
4. Charpentier, P. A.; DeSimone, J. M.; Roberts, G. W. Industrial \& Engineering Chemistry Research 2000, 39, (12), 4588-4596.

5. Charpentier, P. A.; Kennedy, K. A.; DeSimone, J. M.; Roberts, G. W. Macromolecules Communications 1999, 32, (18), 5973-5975.

6. Liu, J.; Tai, H.; Howdle, S. M. Polymer 2005, 46, (5), 1467-1472.

7. Mueller, P. A.; Storti, G.; Apostolo, M.; Martin, R.; Morbidelli, M. Macromolecules 2005, 38, (16), 7150-7163.

8. Saraf, M. K.; Gerard, S.; Wojcinski, L. M.; Charpentier, P. A.; DeSimone, J. M.; Roberts, G. W. Macromolecules 2002, 35, (21), 7976-7985.

9. $\quad$ Saraf, M. K.; Wojcinski, L. M., II; Kennedy, K. A.; Gerard, S.; Charpentier, P. A.; DeSimone, J. M.; Roberts, G. W. Macromolecular Symposia 2002, 182, 119-129.

10. Galia, A.; Caputo, G.; Spadaro, G.; Filardo, G. Industrial \& Engineering Chemistry Research 2002, 41, (24), 5934-5940.

11. Galia, A.; Giaconia, A.; Scialdone, O.; Apostolo, M.; Filardo, G. Journal of Polymer Science, Part A: Polymer Chemistry 2006, 44, (8), 2406-2418.

12. Tai, H.; Liu, J.; Howdle, S. M. European Polymer Journal 2005, 41, (11), 2544-2551.

13. Tai, H.; Wang, W.; Howdle, S. M. Macromolecules 2005, 38, (5), 1542-1545.

14. Tai, H.; Wang, W.; Martin, R.; Liu, J.; Lester, E.; Licence, P.; Woods, H. M.; Howdle, S. M. Macromolecules 2005, 38, (2), 355-363.

15. Mueller, P. A.; Storti, G.; Morbidelli, M.; Costa, I.; Galia, A.; Scialdone, O.; Filardo, G. Macromolecules 2006, 39, (19), 6483-6488.

16. Tervoort, T.; Visjager, J.; Graf, B.; Smith, P. Macromolecules 2000, 33, (17), 6460-6465. 
17. Maccone, J.; Apostolo, M.; Ajroldi, G. Macromolecules 2000, 33, (5), 1656-1663.

18. Zhang, S. X.; Ray, W. H. AIChE Journal 1997, 43, (5), 1265-1277

19. Ahmed, T. S.; DeSimone, J. M.; Roberts, G. W. Chemical Engineering Science 2004, 59, (22-23), 5139-5144.

20. Billingham, N. C.; Jenkins, A. D., Free Radical Polymerization in Heterogeneous Systems. In Comprehensive Chemical Kinetics (Chap 6), Bamford, C. H.; Tipper, C. F. H., Eds. Elsevier: New York, 1976; Vol. 14A.

21. Gromov, V. F.; Galperina, N. I.; Osmanov, T. O.; Khomikovskii, P. M.; Abkin, A. D. European Polymer Journal 1980, 16, (6), 529-35.

22. Gromov, V. F.; Osmanov, T. O.; Khomikovskii, P. M.; Abkin, A. D. European Polymer Journal 1980, 16, (9), 803-8.

23. Guyot, A. Makromolekulare Chemie, Macromolecular Symposia 1987, 10-11, 461-481.

24. Jenkins, A. D., Occlusion Phenomenon in the Polymerization of Acrylonitrile and Other Monomers. In Vinyl Polymerization (Chap 6), Ham, G. E., Ed. Marcel Dekker: New York, 1967; Vol. 1, Part I.

25. Talamini, G.; Peggion, E., Polymerization of Vinyl Chloride and Vinylidene Chloride. In Vinyl Polymerization (Chap 5), Ham, G. E., Ed. Marcel Dekker: New York, 1967; Vol. 1, Part I.

26. Odian, G., Principles of Polymerization. 4th ed.; John Wiley \& Sons Inc: 2004.

27. Bogunjoko, J. S. T.; Brooks, B. W. Makromolekulare Chemie-Macromolecular Chemistry and Physics 1983, 184, (8), 1623-1643. 
28. Mueller, P. A.; Storti, G.; Morbidelli, M. Chemical Engineering Science 2004, 60, (2), $377-397$.

29. Mueller, P. A.; Storti, G.; Morbidelli, M. Chemical Engineering Science 2005, 60, (7), 1911-1925.

30. McHugh, M. A.; Krukonis, V. J., Supercritical Fluid Extraction: Principles and Practice. 2nd ed.; Butterworth-Heinemann: Boston, 1994.

31. Kennedy, K. A. Characterization of Phase Equilibrium Associated with Heterogeneous Polymerizations in Supercritcal Carbon Dioxide. North Carolina State University, Raleigh, 2003.

32. Matyjaszewski, K.; Davis, T. P., Handbook of Radical Polymerization. WileyInterscience 2002.

33. Ahmed, T. S.; DeSimone, J. M.; Roberts, G. W. Continuous Copolymerization of Vinylidene Fluoride with Hexafluoropropylene in Supercritical Carbon Dioxide: Low Hexafluoropropylene-Content Copolymers, Accepted for publication in Macromolecules 2007.

34. Ahmed, T. S.; DeSimone, J. M.; Roberts, G. W. Continuous Copolymerization of Vinylidene Fluoride with Hexafluoropropylene in Supercritical Carbon Dioxide: High Hexafluoropropylene-Content Amorphous Copolymers, Submitted to Macromolecules 2007.

35. Ahmed, T. S.; DeSimone, J. M.; Roberts, G. W. Kinetics of the Homopolymerization of Vinylidene Fluoride and its Copolymerization with Hexafluoropropylene in Supercritical Carbon Dioxide: The Locus of Polymerization, Submitted to Macromolecules 2007. 
36. Charpentier, P. A.; DeSimone, J. M.; Roberts, G. W. Chemical Engineering Science 2000, 55, (22), 5341-5349.

37. Russell, G. T. Macromolecular Theory and Simulations 1994, 3, (2), 439-68.

38. Russell, G. T. Macromolecular Theory and Simulations 1995, 4, (3), 497-517.

39. Benson, S. W.; North, A. M. Journal of the American Chemical Society 1959, 81, (6), $1339-1345$.

40. Mahabadi, H. K.; O'Driscoll, K. F. Journal of Polymer Science, Polymer Chemistry Edition 1977, 15, (2), 283-300.

41. Riazi, M. R.; Whitson, C. H. Industrial \& Engineering Chemistry Research 1993, 32, (12), 3081-8.

42. de Kock, J. B. L.; Van Herk, A. M.; German, A. L. Journal of Macromolecular Science, Polymer Reviews 2001, C41, (3), 199-252.

43. Buback, M.; Kuchta, F. D. Macromolecular Chemistry and Physics 1997, 198, (5), $1455-$ 1480.

44. Deady, M.; Mau, A. W. H.; Moad, G.; Spurling, T. H. Makromolekulare Chemie 1993, 194, (6), 1691-705.

45. Dotson, N. A.; Galvan, R.; Laurence, R. L.; Tirrell, M., Polymerization Process Modeling Wiley-VCH 1996.

46. Tobita, H. Journal of Polymer Science, Part B: Polymer Physics 1993, 31, (10), $1363-$ 1371

47. Saraf, M. K. Polymerization of vinylidene fluoride in supercritical carbon dioxide: Molecular weight distribution. North Carolina State University, Raleigh, 2001. 
48. Liu, T.; DeSimone, J. M.; Roberts, G. W. Polymer 2006, 47, (12), 4276-4281.

49. Liu, T.; DeSimone, J. M.; Roberts, G. W. Chemical Engineering Science 2006, 61, (10), 3129-3139. 


\section{CHAPTER 9}

\section{CONCULSIONS AND RECOMMENDATIONS FOR FUTURE}

\section{WORK}

\subsection{Conclusions}

\subsubsection{Copolymerization of vinylidene fluoride with hexafluoropropylene in supercritical carbon dioxide}

The precipitation and solution copolymerization of vinylidene fluoride (VF2) with hexafluoropropylene (HFP) in supercritical carbon dioxide $\left(\mathrm{scCO}_{2}\right)$ was studied in a continuous stirred-tank reactor (CSTR) using perfluorobutyryl peroxide as the free radical initiator. The experiments were done at $40{ }^{\circ} \mathrm{C}$ with pressure in the range of $207-400$ bar. Four different HFP/VF2 feed ratios were studied: 26.3/73.7, 59/41, 66/34, and 73/27, giving rise to about 10, 23, 26, and 31 mole \% HFP copolymers respectively. The copolymer of the 26.3/73.7 feed ratio was collected as a dry free-flowing semicrystalline powder while the other compositions were amorphous elastomeric materials collected continuously using acetone.

The effect of inlet total monomer concentration $\left(\left[M_{T}\right]_{i n}\right)$ and the reaction pressure were both explored at otherwise constant conditions. All the experiments done with the 73/27 feed ratio were completely homogeneous at 400 and 310 bar. Conversely, all the experiments with 26.3/73.7 feed ratio precipitated from the reaction medium during the course of the reaction. For the other feed ratios, some reactions were homogeneous and some were heterogeneous, depending on the copolymer composition, reaction pressure and molecular weight of the synthesized copolymers. 
The rate of polymerization $\left(R_{p}\right)$ and the number-average molecular weight $\left(M_{n}\right)$ were not affected by the mode of polymerization and increased linearly with $\left[M_{T}\right]_{i n}$ for the four compositions, similar to a conventional solution copolymerization. The reaction pressure influenced strongly both the $R_{p}$ and the $M_{n}$ for the 26.3/73.7 feed ratio copolymers. An increase in the reaction pressure from 207 to 400 bar resulted in about $80 \%$ increase in both $R_{p}$ and $M_{n}$. The effect of pressure was less prominent for the other compositions. For the same range of pressure, both the $R_{p}$ and $M_{n}$ increased only by $20-30 \%$.

The molecular weight distributions (MWDs) of the copolymers with 26.3/73.7 feed ratio showed a long tail that increased to become a broad shoulder with increasing $\left[M_{T}\right]_{i n}$. This tail increased with increasing reaction pressure. In case of the copolymers with 59/41 feed-ratio, the tail appeared only for the highest $\left[M_{T}\right]_{i n}$. For the other compositions, the tail did not appear for all $\left[M_{T}\right]_{\text {in }}$ up to $6.5 \mathrm{M}$.

The experimental results suggest that the $\mathrm{CO}_{2}$-rich fluid phase is the primary locus of polymerization. Homogenous polymerization in the $\mathrm{CO}_{2}$-rich fluid phase can account for the first-order dependence of $R_{p}$ and $M_{n}$ on the total monomer concentration, the increase of $R_{p}$ and $M_{n}$ with pressure, and the increase of the MWD tail with pressure.

Further analysis of the locus of polymerization for VF2 precipitation homopolymerization and VF2/HFP precipitation copolymerization in $\mathrm{scCO}_{2}$ was done. The experimental results were tested against three different models that assume different loci of polymerization. In the first model: solution polymerization model, the polymerization reactions were assumed to occur only in the fluid phase, with no reactions in the polymer phase. For the other two models: surface and interior polymerization models, chain initiation took place in the 
fluid phase, but chain propagation and termination occurred in a thin layer on the polymer surface for the surface polymerization model or throughout the polymer particle for the case of the interior polymerization model. Monomer and initiator were assumed in equilibrium between the polymer and the continuous phases in the three models.

Comparison of the experimental data with the models suggested that the precipitation polymerizations of VF2 homo- and co- polymers with HFP in $\mathrm{scCO}_{2}$ occur mainly in the continuous, $\mathrm{CO}_{2}$-rich phase. The solution polymerization model could account for the experimental data for PVDF and poly(VF2-co-HFP) quite well. On the other hand, the two models based on polymerization in the polymer phase were unable to fit the experimental data.

\subsubsection{Modeling the molecular weight distribution of poly(vinylidene fluoride) synthesized in $\mathrm{scCO}_{2}$ by precipitation polymerization}

Polymerization of poly(vinylidene fluoride) (PVDF) in $\mathrm{scCO}_{2}$ was established to occur mainly in the $\mathrm{CO}_{2}$-rich fluid phase. A homogeneous model was presented to account for the bimodal MWDs observed during the precipitation polymerization of PVDF in $\mathrm{scCO}_{2}$. The model accounted for the bimodal MWD by two populations of polymeric chains differing in the termination scheme: chemical-controlled termination and diffusion-controlled termination. The diffusion-controlled termination was approximated by two reaction constants: one for the termination of unhindered and hindered radicals, and the other for termination of hindered radicals with each other. In addition, chain transfer to polymer reaction was included in the kinetic scheme to account for the broadness observed in the MWDs. The model could capture successfully the effect of the operating parameters, such as the effect of monomer feed 
concentration, residence time for both low and high monomer concentration, and reaction temperature on the MWDs. In addition, it could capture the steep increase of PDI of the synthesized polymers for high monomer concentrations and for high residence times fairly well. Finally, the model could account for the inoperability region observed experimentally during the continuous polymerization of PVDF.

\subsection{Recommendations for future work}

Copolymerization of VF2 with HFP in $\mathrm{scCO}_{2}$ and modeling the MWDs of PVDF polymerization in $\mathrm{scCO}_{2}$ done in this thesis were successful in shedding light on the fundamentals of VF2 fluoropolymers polymerization in $\mathrm{scCO}_{2}$. However, to have more understanding and to confirm some of the hypotheses assumed during the analysis of the experimental results, more investigation is needed in some specific areas. In particular, 1) More investigation is needed on the effect of residence time, initiator concentration and temperature on the polymerization kinetics of VF2/HFP copolymerization; 2) Partitioning studies for the monomers/initiator/ $\mathrm{CO}_{2} /$ copolymer system is needed; 3) Study of perfluorobutyryl peroxide decomposition kinetics in $\mathrm{scCO}_{2}$. 
Appendices 


\section{Appendix A \\ Perfluoro Butyryl Peroxide (PBP)}

\section{A.1 Reaction Scheme}

$\mathrm{C}_{3} \mathrm{~F}_{7} \mathrm{COCl}+\mathrm{KOH}+\frac{1}{2} \mathrm{H}_{2} \mathrm{O}_{2} \underset{\text { Freon } 113}{\stackrel{-5}{1} \mathrm{C}-7^{\circ}}\left(\mathrm{C}_{3} \mathrm{~F}_{7} \mathrm{COO}\right)_{2}$

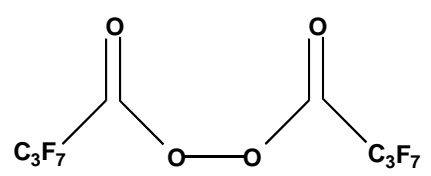

\section{A.2 Raw Materials}

- Heptafluorobutyryl chloride (CAS \#: 375-16-6)

- Potassium hydroxide solution (5 N)

- Hydrogen Peroxide (35\%)

\section{A.3 Procedure}

- Purge the reaction system with Argon and cool it in $\mathrm{NaCl} /$ ice/water $\left(-5\right.$ to $\left.-7^{\circ} \mathrm{C}\right)$

- Charge the flask with Freon and begin stirring using a magnetic agitator (5g Heptafluorobutyryl chloride and $35 \mathrm{ml}$ Freon will yield roughly $0.09 \mathrm{M}$ solution)

- Add $\mathrm{H}_{2} \mathrm{O}_{2}$ to the Freon all at once and leave the system until being cooled down.

- Add $\mathrm{KOH}$ drop by drop so that the temperature never exceeds $-5{ }^{\circ} \mathrm{C}$

- Add Heptafluorobutyryl chloride drop by drop. Never allow the temperature to exceeds $-5{ }^{\circ} \mathrm{C}$

- After the addition is complete, allow the reaction mixture to stir for another $15 \mathrm{~min}$.

- Pour the reaction mixture into a separation funnel. Add $30 \mathrm{ml}$ of pre-cooled saturated solution of $\mathrm{NaHCO}_{3}$. Shake the funnel and then collect the Freon layer (lower layer).

- Repeat the above step but with pre-cooled deionized water.

- Put some molecular sieves beads into the solution to dry it.

\section{A.4 Storage}

Dry ice $\left(-78^{\circ} \mathrm{C}\right)$ 


\section{A.5 Iodometric Titration}

- Prepare a $30 \%$ solution of KI in deionized water and $0.5 \mathrm{~g}$ of thyodene indicator (starch indicator, CAS\# 9005-84-9, Fisher Scientific catalog \#: T138-100) in $10 \mathrm{~mL}$ of dionized water. Bubble argon into the Thyodene solution for 5 min before using or put a piece of dry ice in the solution.

- Put the following in order in a flask covered with an aluminum foil: about $1 \mathrm{~g}$ sodium bicarbonate then add, $2.5 \mathrm{ml}$ of KI solution, and12.5 mL of glacial acetic acid. Stir while the flask is closed for 2 min then add 1 drop of $0.1 \mathrm{~N}$ sodium thiosulfate to the flask.

- Add $2 \mathrm{ml}$ of the initiator solution to the flask quickly. The color of the solution changes to red brownish. Stir for 30 min while the flask is closed.

- Titrate with $0.1 \mathrm{~N}$ sodium thiosulfate solution until the color becomes pale yellowish.

- Add the thyodene solution to the flask. The color changes to violet. Continue titration until the solution becomes colorless

- $(\mathrm{NV})_{\text {thiosulfate }} / 2=(\mathrm{NV})_{\text {initiator }}$ 
CONFIDENTIAL

\section{Appendix B}

\section{Reduction of Fouling during Polymerization of Fluoromonomers}

Appendix B is a an invention disclosure accepted by the Office of Technology

Transfer, NC State University, August 2007 
CONFIDENTIAL

\title{
Invention Disclosure
}

\section{Reduction of Fouling during Polymerization of Fluoromonomers}

\author{
Tamer S. Ahmed ${ }^{1}$, Joseph M. DeSimone, ${ }^{1,2}$, and George W. Roberts ${ }^{1, *}$ \\ ${ }^{1}$ Department of Chemical and Biomolecular Engineering, North Carolina State University, Box \\ \#7905, Raleigh, North Carolina 27695-7905 \\ ${ }^{2}$ Department of Chemistry, University of North Carolina-Chapel Hill, Box \# 3290, Chapel Hill, \\ North Carolina 27599-3290

\section{B.1 Polymerization Apparatus and Procedure} \\ Figure 1 shows a schematic of the continuous polymerization system. The reactor $(\mathrm{C})$ is a \\ $100 \mathrm{~mL}$ high-pressure autoclave (Autoclave Engineers) with a magnetically-driven agitator \\ (Autoclave Engineers). Three downward-pumping impellers were mounted on the shaft of the \\ agitator.
}

\footnotetext{
* To whom correspondence should be addressed. Tel: +1-919-515-7328; Fax: +1-919-515-3465; E-mail address: groberts@eos.ncsu.edu
} 


\section{CONFIDENTIAL}

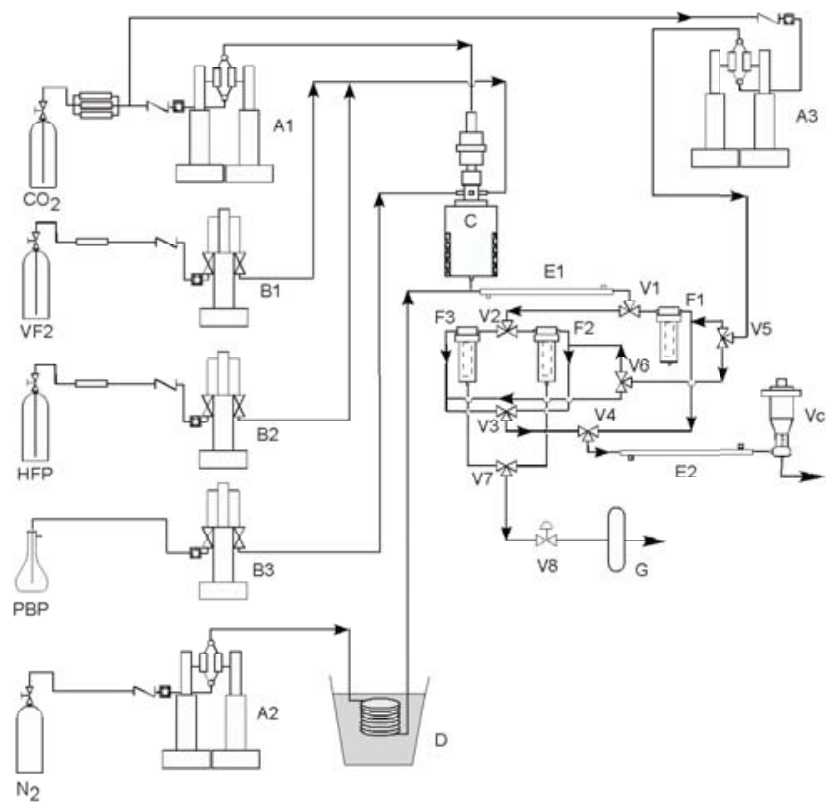

Figure 1: CSTR polymerization system: A1,A2,A3- Continuous syringe pumps; B1,B2,B3- Syringe pumps; CAutoclave with stirrer; D- Dry ice/Acetone bath; E1,E2- Heat exchangers; F1- Steady state filter; F2,F3- Non steady state filters; G- Bag filter; V1,V2,V3,V4,V5,V6,V7- 3-Way valves; V8- 2-Way valve; Vc- Control valve

\section{B.2 Attainment of Steady State}

A previous investigation showed that the steady state condition was reached after about five residence times from the startup. This was true for both poly(vinylidne fluoride) (PVDF) ${ }^{1}$ and poly(acrylic acid) (PAA) ${ }^{2}$. However, in case of the copolymers of vinylidene fluoride (VF2) with hexafluoropropylene(HFP) with low HFP content (ca. 10 mole\% HFP), the steady state condition was not reached until the $10^{\text {th }}$ residence time. This was attributed to fouling caused by these copolymers. The copolymer tended to foul the reactor interior and to accumulate inside the reactor, which was not observed for PVDF or PAA homopolymers. 
CONFIDENTIAL

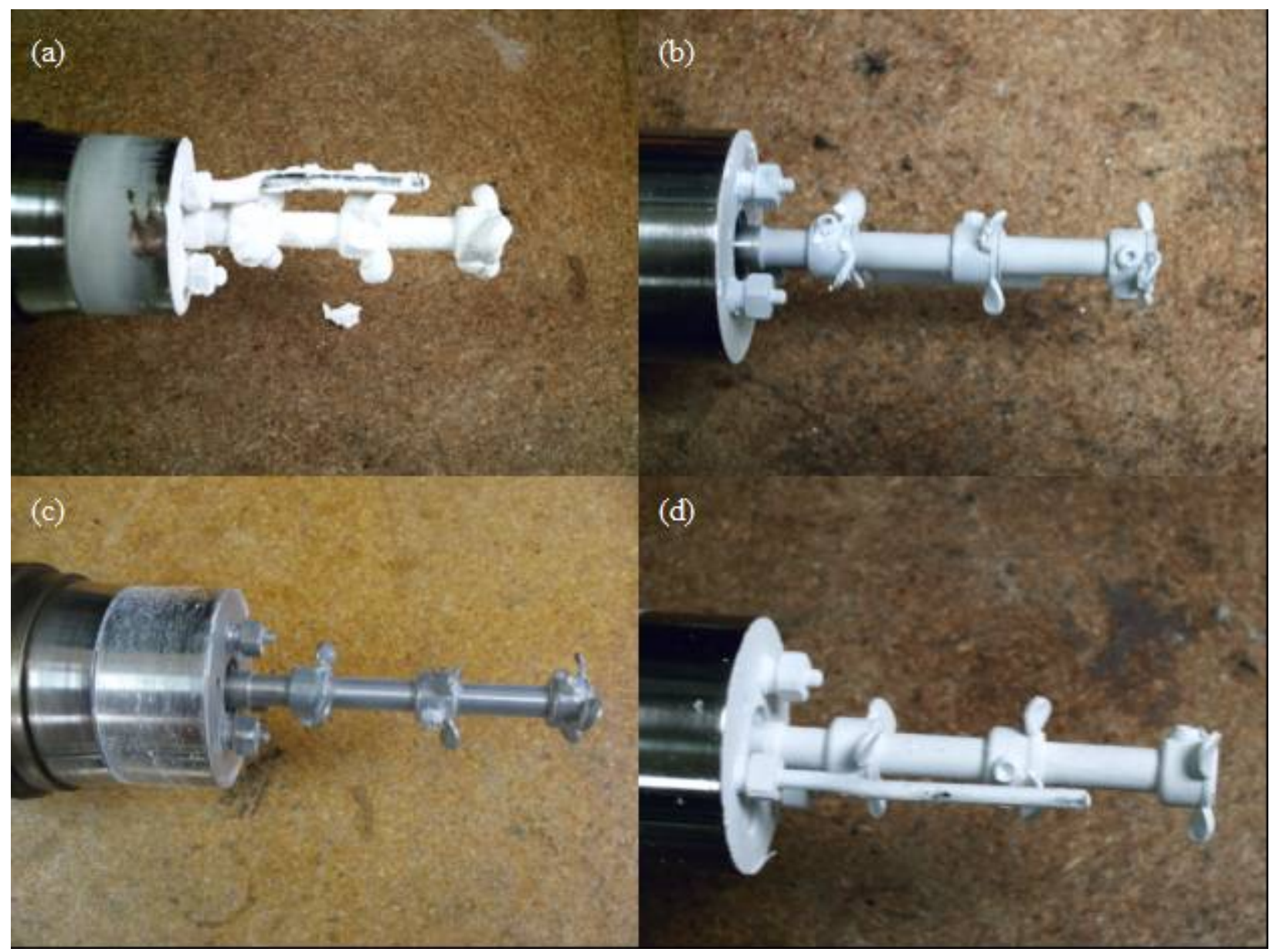

Figure 2: Snapshots of the reactor agitator shaft. (a) 10\% mole HFP poly(VF2-co-HFP); (b) PVDF; (c) Baked PVDF; (d) 10\% mole HFP poly(VF2-co-HFP) polymerized after baking PVDF onto interior surfaces. Polymerization reaction conditions: Pressure $=310$ bars; Temperature $=40{ }^{\circ} \mathrm{C}$; Average residence time $=20 \mathrm{~min}$; Inlet initiator concentration $=0.003 \mathrm{M}$ of $0.03 \mathrm{M}$ solution in Freon 113; Inlet total monomer concentration $=1.5 \mathrm{M}$ (PVDF, b) \& $3.8 \mathrm{M}$ (10\% mole HFP poly(VF2-co-HFP), a \& d). Baking conditions for (c): $100{ }^{\circ} \mathrm{C}$ for $30 \mathrm{~min}$

Figure 2 shows a photograph for the agitator shaft after the reaction for the 10 mole\% HFP poly(VF2-co-HFP) (Figure 3a) compared to PVDF (Figure 3b). The problem of fouling was essentially eliminated through precoating the reactor interior surface with a thin film of PVDF. The coating was done by polymerizing VF2 in the reactor and then baking the PVDF coating in $\mathrm{scCO}_{2}$ at $100{ }^{\circ} \mathrm{C}$ for 30 min before finally starting the normal copolymerization of VF2 with HFP. Figure 3c shows the baked PVDF coating on the agitator shaft and Figure 3d shows the 


\section{CONFIDENTIAL}

shaft after finishing the copolymerization of VF2 and HFP after first coating the reactor interior with PVDF. The PVDF helped in minimizing the sticking of the poly(VF2-co-HFP) on the reactor walls and agitator shaft.

Figure 3 shows the total conversion $\left(\mathrm{X}_{\mathrm{T}}\right)$ for copolymer collected without prior PVDF coating (run A) and after PVDF coating (run B) for $6^{\text {th }}, 8^{\text {th }}$, and $10^{\text {th }}$ residence times. In situ polymerization of VF2 in the reactor followed by baking the PVDF coat helped prevent the fouling caused by the low-HFP poly(VF2-co-HFP). As a result, the reactor reached steady state after the $5^{\text {th }}$ residence time, similar to the behavior of PVDF and PAA.

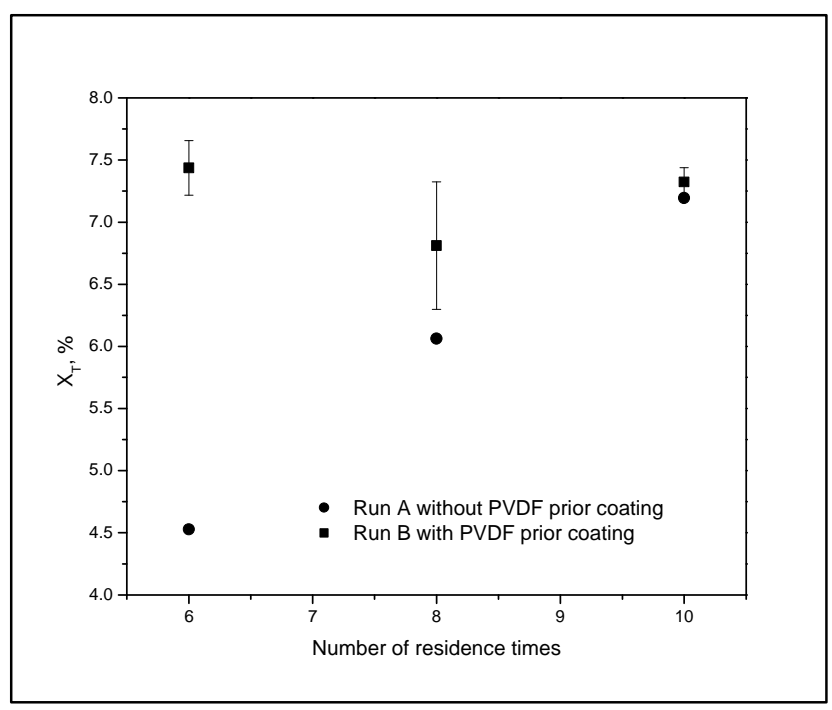

Figure 3: Total monomers conversion at different residence times. Run A: Copolymerization without coating the reactor interior with PVDF. Run B: Copolymerization after coating the reactor with PVDF.

Reaction conditions: Pressure $=310$ bars; Tempertaure $=40{ }^{\circ} \mathrm{C}$; Average Residence time $=20 \mathrm{~min}$; Inlet initiator concentration $=0.003 \mathrm{M}$ of $0.03 \mathrm{M}$ solution in Freon 113; Inlet total monomer concentration $=3.8 \mathrm{M}$; Copolymer composition $=10$ mole\% HFP; Baking conditions for PVDF coating: $100{ }^{\circ} \mathrm{C}$ for $30 \mathrm{~min}$.

\section{B.3 References}

1. Charpentier, P. A.; DeSimone, J. M.; Roberts, G. W. Industrial \& Engineering Chemistry

Research 2000, 39, (12), 4588-4596. 


\section{CONFIDENTIAL}

2. Liu, T.; Desimone, J. M.; Roberts, G. W. Journal of Polymer Science, Part A: Polymer Chemistry 2005, 43, (12), 2546-2555. 


\section{Appendix C}

\section{Matlab Code for the Model in Chapter 8}

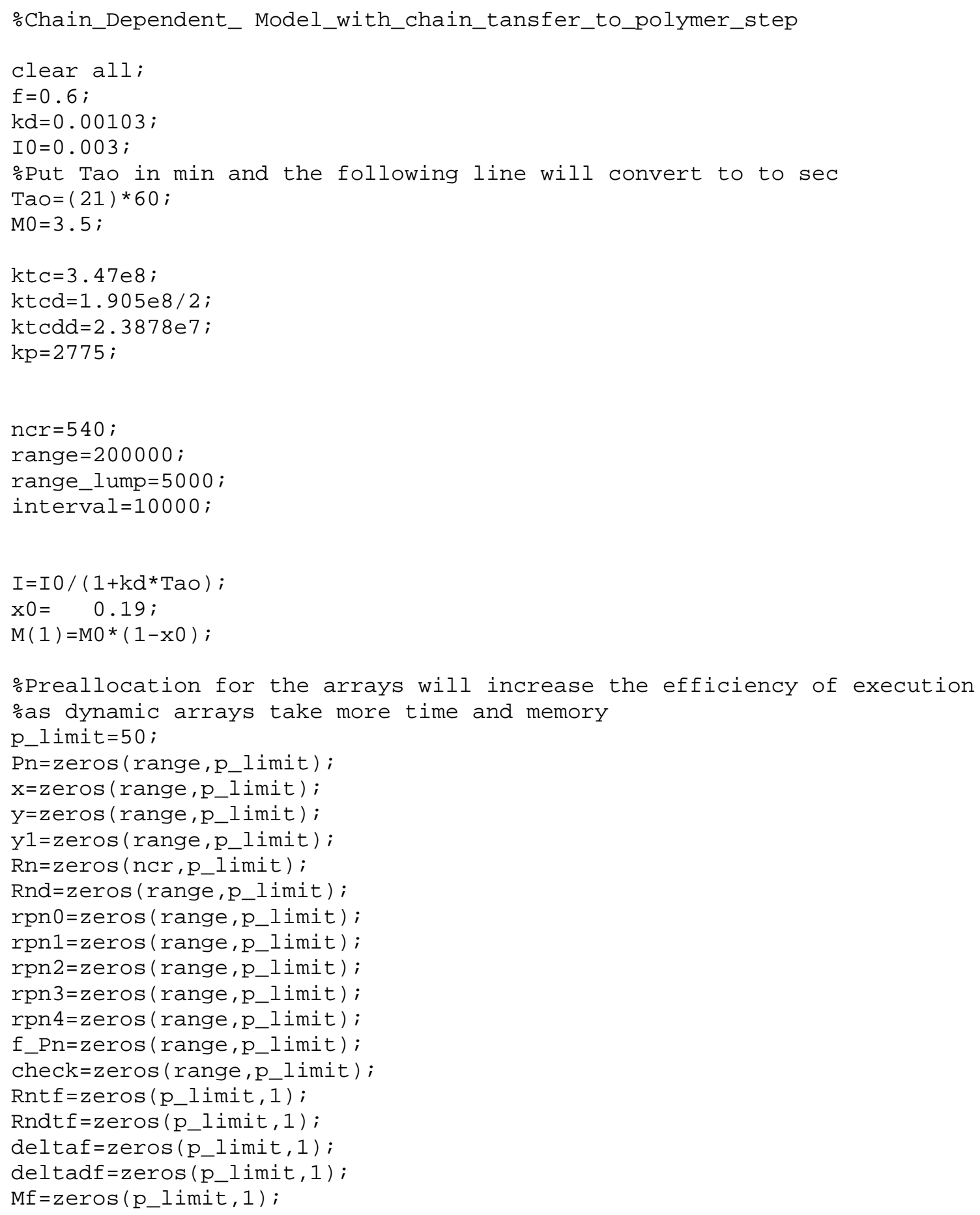




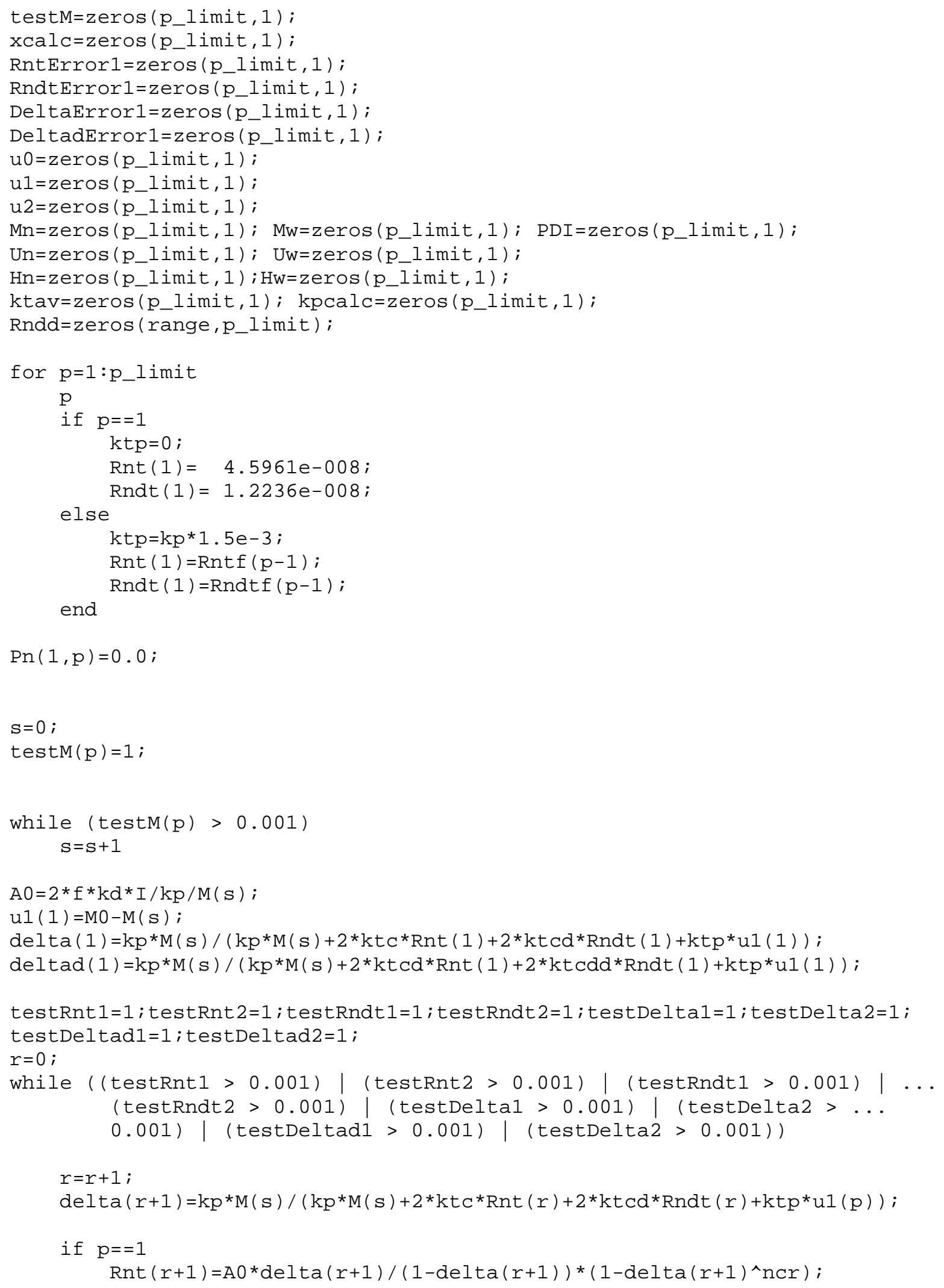




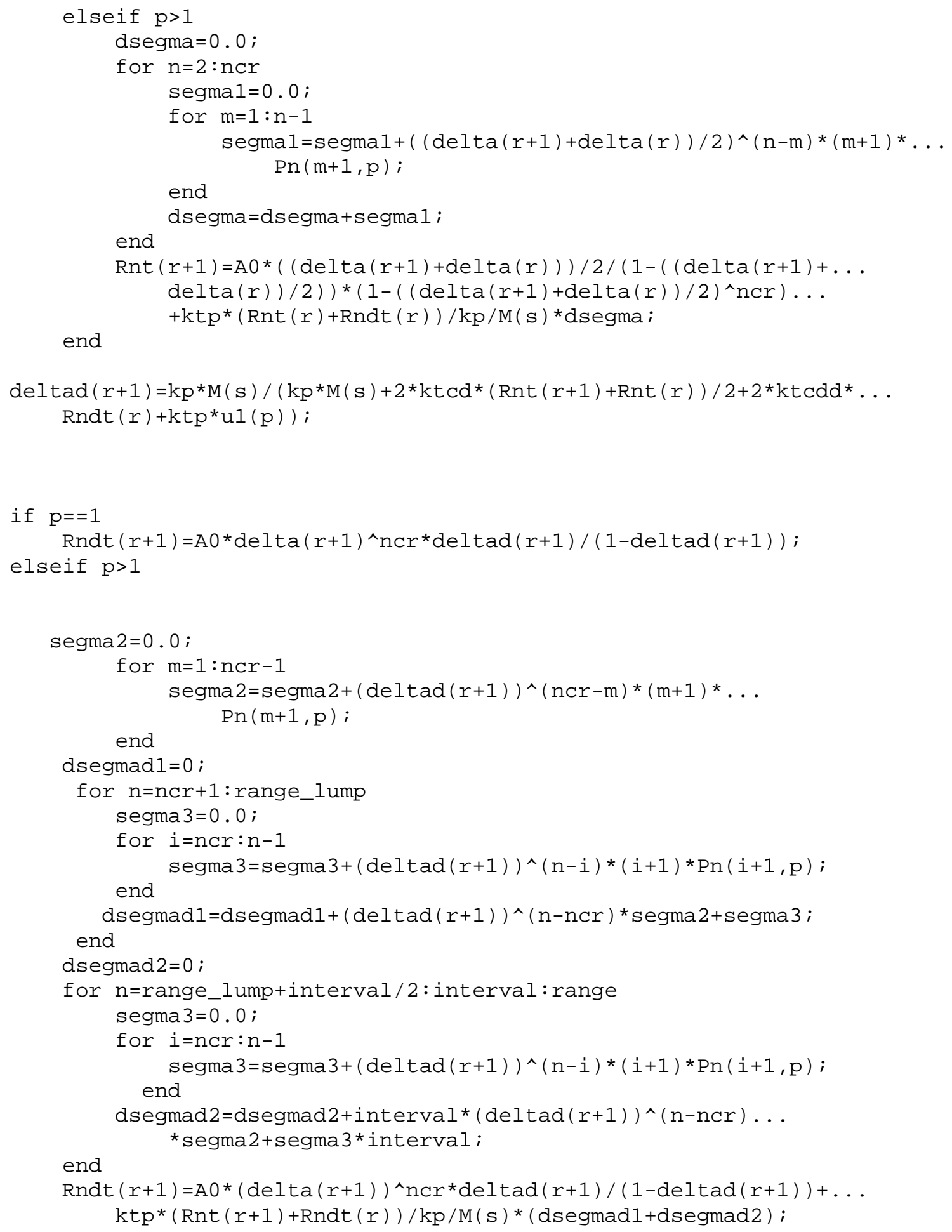

end 


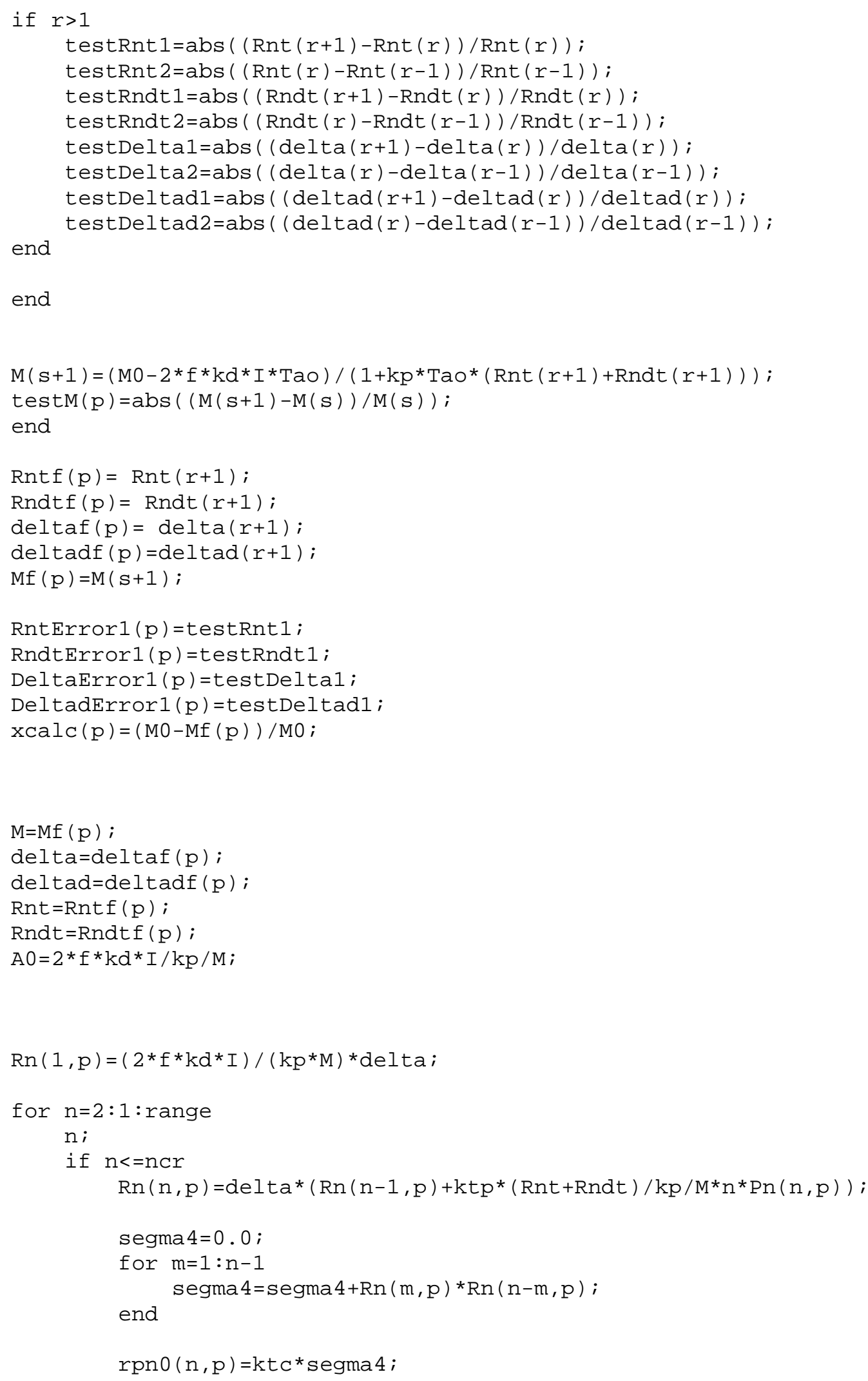




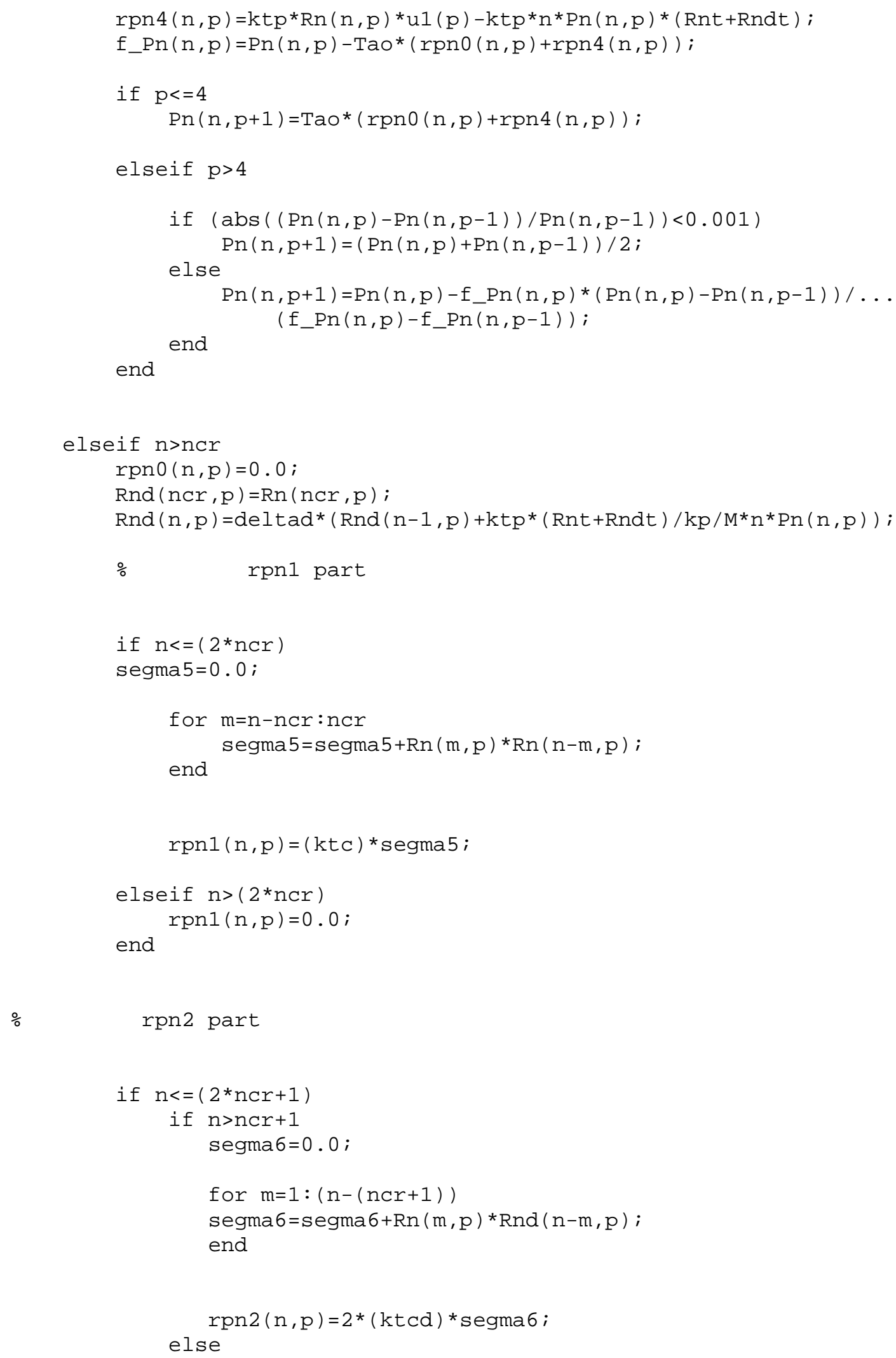




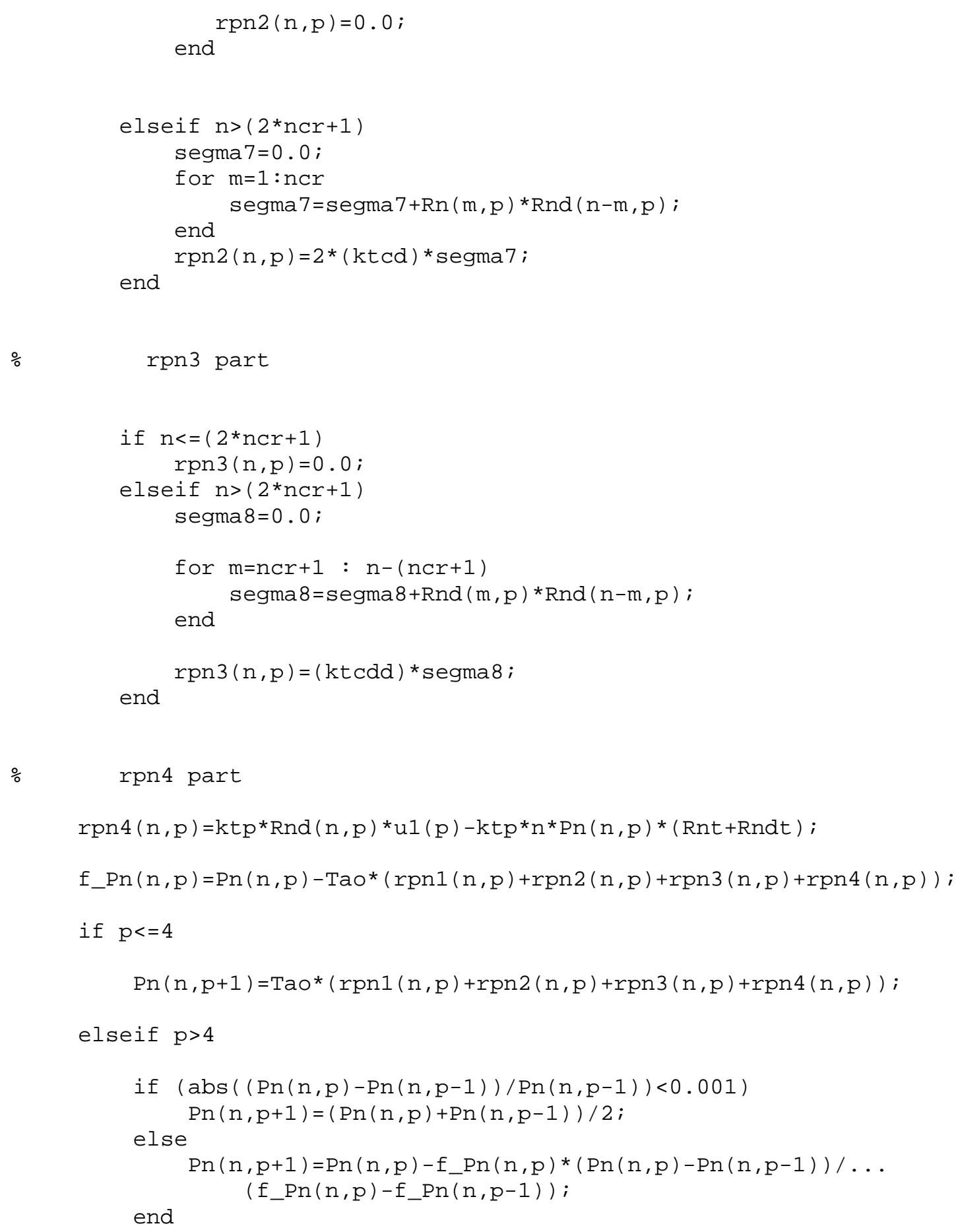




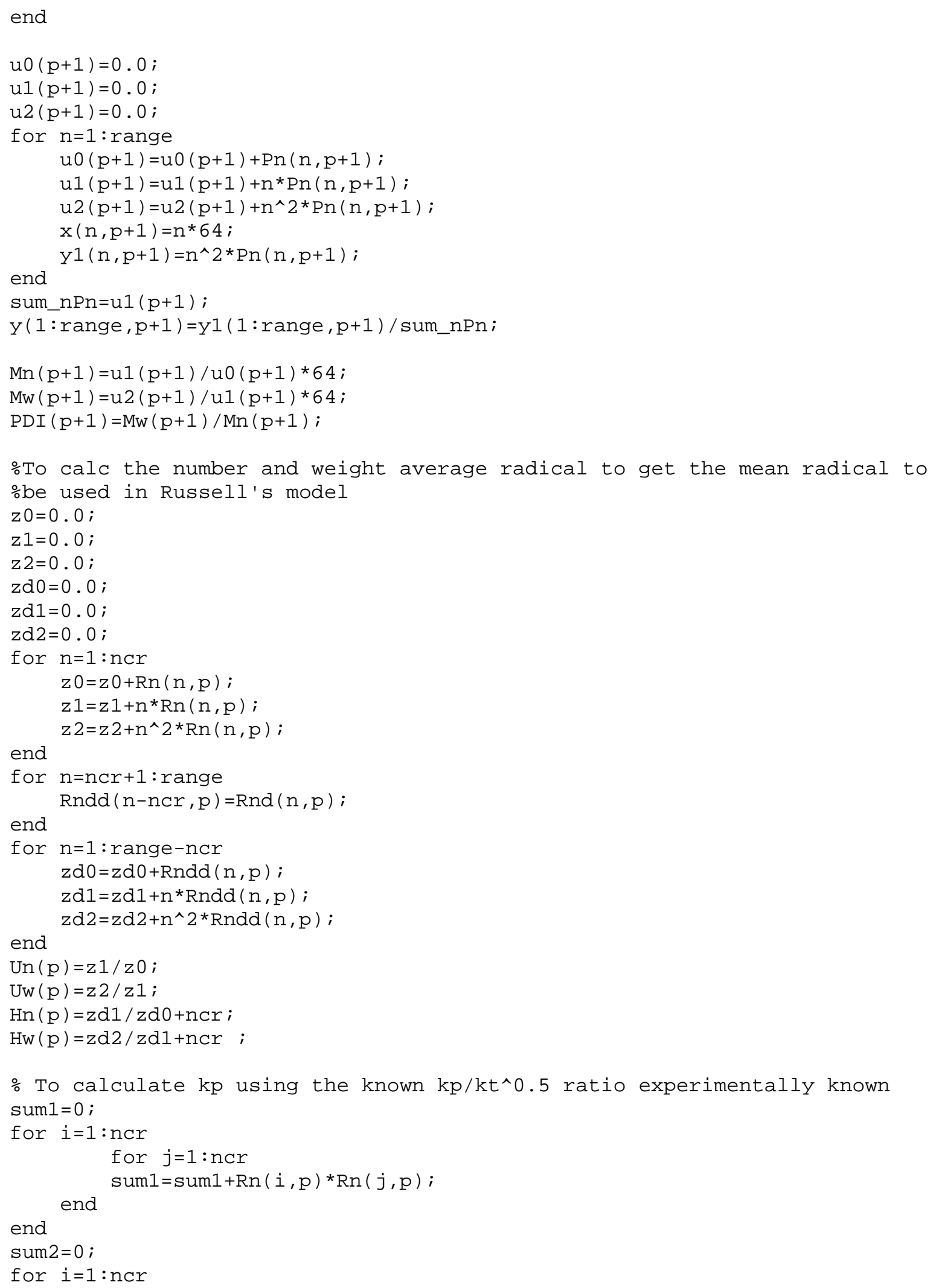




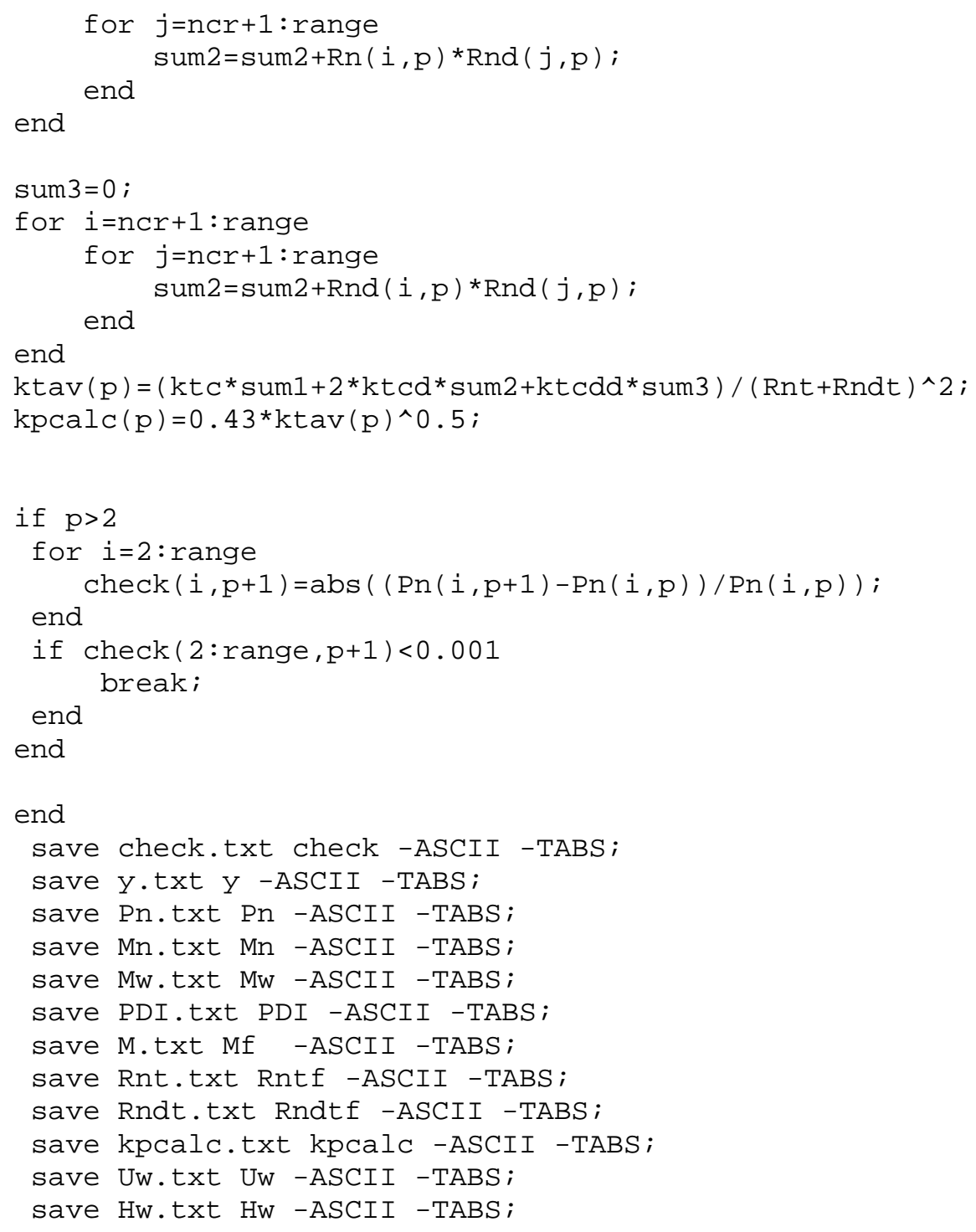

